\title{
Spezifität der Wechselwirkung von Collybistin 2 mit Phosphatidylinositolphosphaten: Einfluss der verschiedenen Proteindomänen
}

\author{
Dissertation \\ zur Erlangung des mathematisch-naturwissenschaftlichen Doktorgrades \\ „Doctor rerum naturalium“ \\ der Georg-August-Universität Göttingen \\ im Promotionsprogramm Chemie \\ der Georg-August University School of Science (GAUSS) \\ vorgelegt von \\ Michaela Ludolphs \\ aus Uelzen
}

Göttingen, 2015 



\section{$\underline{\text { Betreuungsausschuss }}$}

Prof. Dr. Claudia Steinem, Institut für Organische und Biomolekulare Chemie

Prof. Dr. Sarah Köster, Institut für Röntgenphysik

\section{Mitglieder der Prüfungskommission}

Referentin:

Prof. Dr. Claudia Steinem, Institut für Organische und Biomolekulare Chemie

Korreferentin:

Prof. Dr. Sarah Köster, Institut für Röntgenphysik

Weitere Mitglieder der Prüfungskommission:

Prof. Dr. Michael Meinecke, Zentrum für Biochemie und Molekulare Zellbiologie

Prof. Dr. Bert de Groot, Max Planck Institut für Biophysikalische Chemie

Prof. Dr. Claudia Höbartner, Institut für Organische und Biomolekulare Chemie

Prof. Dr. Nils Brose, Max Planck Institut für Experimentelle Medizin

Tag der mündlichen Prüfung: 27.04.2015 

- Meinen Schwestern -

„Zwei Dinge sind zu unserer Arbeit nötig:

Unermüdliche Ausdauer und die Bereitschaft, etwas, in das man viel Zeit und Arbeit gesteckt hat, wieder wegzuwerfen."

Albert Einstein 



\begin{abstract}
Collybistin, a brain-specific GEF, is required for gephyrin clustering at the postsynaptic membrane. This is important for the correct arrangement of $\mathrm{GABA}_{\mathrm{A}}$ and glycine receptors. Binding of collybistin to a membrane is initiated by a C-terminal PH-domain. In general, this domain is known to specifically bind to phosphoinositides (PIPs) in the membrane.
\end{abstract}

The aim of this study was to design an in vitro assay that enables detailed studies of binding of collybistin binding to phosphoinositides. With this assay we analyzed the impact of different collybistin 2 domains on binding to a membrane. Solidsupported lipid bilayers (SLB) with different phosphoinositides mimicking the cellular postsynaptic membrane. This approach allowed to investigate specific binding of the protein isoforms using reflective interference spectroscopy (RIfS). We found out that the $\mathrm{PH}$ domain $(\mathrm{CB} 2 \mathrm{PH})$ from collybistin prefers binding to monophosphorylated PIPs with moderate binding affinity. The PH/DH-tandem domain $\left(\mathrm{CB} 2_{\mathrm{SH} 3}\right)$ reveals a weaker binding affinity to different PIPs except for $\mathrm{PI}(3,5) \mathrm{P}_{2}$. In addition the collybistin isoform containing an additional SH3 domain $\left(\mathrm{CB} 2_{\mathrm{SH} 3+}\right)$ showed no significant binding to PIPs. This suggested a closed/inactive protein conformation. Activation of $\mathrm{CB}_{\mathrm{SH} 3+}$ is initiated in vivo by the postsynaptic cell adhesion protein Neuroligin-2. For our in vitro studies this was successfully mimicked by two point mutations in the protein isoform $\mathrm{CB} 2_{\mathrm{SH} 3+} / \mathrm{W} 24 \mathrm{~A}-\mathrm{E} 262 \mathrm{~A}$. In contrast to $\mathrm{CB} 2{ }_{\mathrm{SH} 3+}$, the partly-activated mutant $\mathrm{CB} 2 \mathrm{SH}_{3+} / \mathrm{W} 24 \mathrm{~A}-\mathrm{E} 262 \mathrm{~A}$ binds to phosphoinositides in SLBs with decreasing binding affinity to $\mathrm{PI}(3) \mathrm{P}, \mathrm{PI}(4) \mathrm{P}$ and $\mathrm{PI}(3,5) \mathrm{P}_{2}$.

This study provides new insights into the binding of collybistin to phosphoinositides in membranes. In order to draw a comprehensive picture of this protein to membrane binding process, the impact of each protein domain was investigated. 



\section{Inhaltverzeichnis}

1 Einleitung _ 1

$1.1 \quad$ Inhibitorische Synapsen _ 1

1.2 Collybistin 2

1.3 Phosphatidylinositolphosphate in Membranen _ 7

2 Zielsetzung_ـ 11

3 Materialien und Methoden _ 12

3.1 Proteinbiochemische Methoden 12

3.1.1 Herstellung chemisch kompetenter Zellen __ 13

3.1.2 Transformation _ 14

3.1.3 Plasmidisolierung und Reinigung ___ 15

3.1.4 Agarose-Gelelektrophorese___ 17

3.1.5 Heterologe Proteinexpression und Zelllyse __ 19

3.1.6 Affinitätschromatographische Aufreinigung der Intein-fusionierten Proteine20

3.1.7 Anionenchromatographische Proteinaufreinigung über das ÄKTA ${ }^{\circledR}$-System 23

3.1.8 SDS-PAGE nach Laemmli / Schägger __ 26

3.1.9 Western-Blot 229

3.1.10 Lipid-overlay Assay___ 31

3.1.11 Bestimmung der Proteinkonzentration ___ 32

$3.2 \quad$ Präparative Methoden

3.2.1 Herstellung von Lipidfilmen ___ 34

3.2.2 Vesikelpräparation _ 36

3.2.3 Hydrophilisierung von Si-Wafern __ 36 
3.3 Biophysikalische Methoden 38

3.3.1 Reflektometrische Interferenzspektroskopie__ 38

3.3 .2 CD-Spektroskopie __ 46

3.3.3 Thermofluor-Experimente mittels real-time PCR _ 50

\section{Aufreinigung und Charakterisierung der Collybistin-Isoformen}

$\mathrm{CB} 2_{\mathrm{PH}}, \mathrm{CB} 2_{\mathrm{SH} 3-}, \mathrm{CB} 2_{\mathrm{SH} 3+}$ und $\mathrm{CB} 2_{\mathrm{SH} 3+} / \mathrm{W} 24 \mathrm{~A}-\mathrm{E} 262 \mathrm{~A}$

4.1 Plasmidisolierung aller Isoformen 53

4.2 Expression und Aufreinigung von CB2 $\mathrm{PH}$ 54

4.3 Expression und Aufreinigung von $\mathrm{CB}_{\mathrm{SH} 3-}$ 56

4.4 Expression und Aufreinigung von $\mathrm{CB} 2{ }_{\mathrm{SH} 3+}$ 60

4.5 Expression und Aufreinigung von CB2 ${ }_{\mathrm{SH} 3+} / \mathrm{W} 24 \mathrm{~A}-\mathrm{E} 262 \mathrm{~A}$ 62

4.6 Untersuchung der Stabilität der aufgereinigten CB-Isoformen in verschiedenen Puffern

4.7 Bestimmung der Sekundärstrukturelemente der aufgereinigten Proteine 68

4.8 Änderung der Sekundärstruktur durch Phosphatidylinositolbindung 72

4.9 Diskussion 73

$5 \quad$ Festkörperunterstützte Membranen 80

5.1 Herstellung von festkörperunterstützten PIP-haltigen Membranen 80

5.2 Diskussion 85 
6 Untersuchung der Wechselwirkung von CB2 $2_{P H}$ mit PIP-haltigen

Membranen

6.1 Etablierung des Messsystems für die Adsorption von CB2 ${ }_{\mathrm{PH}}$ an

Membranen 89

6.1.1 Etablierung des Messsystems im Phosphat-Puffer 89

6.1.2 Etablierung des Messsystems im TRIS-Puffer 91

6.1.3 Etablierung des Messsystems in HEPES-Puffer 92

6.2 Theoretische Grundlagen der Proteinadsorption an Grenzflächen _ 94

6.2.1 Langmuir-Adsorptionsisotherme 94

6.3 Quantifizierung der Wechselwirkung zwischen Phosphatidylinositolphosphaten und $\mathrm{CB} 2 \mathrm{PH}$ 98

6.4 Diskussion 102

7 Quantifizierung der Wechselwirkung zwischen CollybistinIsoformen und Phosphatidylinositol-phosphaten 107

7.1 Wechselwirkung von CB2 ${ }_{\text {SH3- }}$ mit Phosphatidyl-inositolphosphaten107

7.1.1 Wechselwirkung von CB2 $2_{\mathrm{SH} 3}$ mit PIP-haltigen Membranen 107

7.1.2 Erkennungsmotiv in den Membranen 113

7.1.3 Lipid-overlay Assay 115

7.2 Wechselwirkung von $\mathrm{CB}_{\mathrm{SH} 3+}$ mit PIP-haltigen Membranen 118

7.3 Wechselwirkung von CB2 ${ }_{\mathrm{SH} 3+} / \mathrm{W} 24 \mathrm{~A}-\mathrm{E} 262 \mathrm{~A}$ mit PIP-haltigen Membranen 121

8 Diskussion der Wechselwirkung von Collybistin-Isoformen mit Phosphatidylinositolphosphaten 
11.1 Aminosäuresequenzen der Proteine

11.2 Chemikalien 153

11.3 Materialien 155

11.4 Geräte 156

11.5 Abkürzungsverzeichnis 158

11.6 Symbolverzeichnis 160 




\section{Einleitung}

\subsection{Inhibitorische Synapsen}

Synapsen bilden die Kontaktstelle zwischen zwei Neuronen und dienen der Reizübertragung. In chemischen Synapsen werden an der präsynaptischen Membran Neurotransmitter über die Fusion von Vesikeln in den synaptischen Spalt freigesetzt. Sie diffundieren durch den synaptischen Spalt und binden an passende Rezeptoren in der postsynaptischen Membran. In inhibitorischen Synapsen docken die inhibitorischen Neurotransmitter GABA ( $\gamma$-Aminobuttersäure) oder Glycin in der postsynaptischen Membran an den entsprechenden GABA- bzw. Glycinrezeptoren an. Die Aktivierung der Rezeptoren führt zur Öffnung der ligandgesteuerten Chlorid-Kanäle, die eine Hyperpolarisation an der postsynaptischen Membran auslösen. Die Reizweiterleitung wird unterdrückt. Im Gegensatz dazu wird durch andere Neurotransmitter wie z.B. Adrenalin an exzitatorischen Synapsen eine Depolarisation der Membran erreicht, wodurch es zur Ausbildung von Aktionspotenzialen kommt. Die inhibitorischen Synapsen werden aufgrund der spezifischen Neurotransmitter auch als glycinerge bzw. GABAerge Synapsen bezeichnet. In Mausstudien konnte gezeigt werden, dass Störungen an inhibitorischen Synapsen schwerwiegende Fehler in der Funktion des Nervensystems auslösen können. ${ }^{[1]}$ Dies kann zu einer erhöhten Ängstlichkeit, veränderter Motorik und epileptischen Anfällen führen.

An der postsynaptischen Membran inhibitorischer Synapsen wurde gezeigt, dass das Gerüstprotein Gephyrin essentiell für die korrekte Lokalisation der Glycin- 
Rezeptoren (GlyR) und der GABA $A_{A}$-Rezeptoren $\left(\mathrm{GABA}_{\mathrm{A}} \mathrm{R}\right)$ ist. ${ }^{[2],[3]}$ Gephyrin bildet unterhalb der postsynaptischen Plasmamembran ein hexagonales Gitter aus, an dem die inhibitorischen Rezeptoren verankert werden. ${ }^{[4]}$ Die Bindung des Gephyringerüsts an die Plasmamembran wird dabei über die Wechselwirkung mit dem Protein Collybistin und dem Adhäsionsprotein Neuroligin-2 realisiert. ${ }^{[5],[6]}$ Neuroligin-2 durchspannt die postsynaptische Membran und stellt zusammen mit den präsynaptischen $\beta$-Neurexinen die Verbindung von prä- und postsynaptischer Membran her.

\subsection{Collybistin}

Das hirnspezifische Protein Collybistin (CB) wurde in einem Hefe-Zwei-HybridSystem (yeast two-hybrid screen) des Proteins Gephyrin identifiziert. Collybistin ist ein zur Familie der Dbl-Proteine (diffuse B-cell lymphoma) gehörender GuaninNukleotid-Austauschfaktor (GEF, guanine nucleotid exchange factor). Bisher wurden in tierischen Zellen drei Isoformen des Proteins (CB1 - CB3) gefunden, die sich lediglich am C-Terminus unterscheiden. Die Isoformen bestehen strukturell aus einer N-terminalen SH3-Domäne und einer DH-/PH-Tandemdomäne, die typisch für GEF-Proteine ist. Die vierte Isoform CB2 ${ }_{\mathrm{SH} 3}$ weist den C-Terminus des CB2 auf, allerdings fehlt die N-terminale SH3-Domäne. In Abbildung 1 ist die Struktur der natürlich vorkommenden Isoformen schematisch dargestellt. 


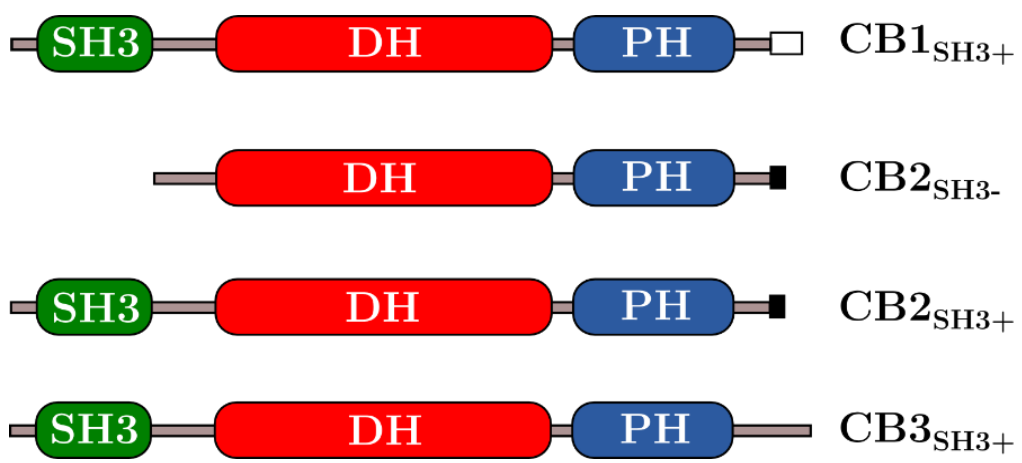

Abbildung 1: Schematische Darstellung der in der Zelle vorkommenden Collybistin Isoformen.

Die Pleckstrin-Homologie-Domäne $\quad(\mathrm{PH})$ von Collybistin umfasst 164 Aminosäuren. Allgemein kommen PH-Domänen in vielen an der Signaltransduktion beteiligten Proteinen vor und stellen ein gemeinsames Strukturmerkmal von Regulatoren GTP-bindender Proteine dar. Reddy-Alla et al. haben gezeigt, dass die PH-Domäne in Collybistin für die Bindung des Proteins an Phosphatidylinositolphosphate (PIPs) in Membranen zuständig ist. ${ }^{[7]}$ Durch die Bindung an verschiedene PIPs kann das Protein je nach Lokalisation des Phosphatidylinositolphosphats spezifisch in verschiedenen Zellkompartimenten vorkommen. ${ }^{[8]}$ Kalscheuer et al. zeigten, dass die PH-Domäne von Collybistin spezifisch mit PI(3)P wechselwirkt. ${ }^{[9]}$ Die Bindungsstelle für die Membranbindung wird durch die Aminosäuren R294 und R295 im CB2 $2_{\mathrm{SH} 3-}$ gebildet. Diese liegen in der Schleife zwischen dem $\beta 3$ - und $\beta 4$-Faltblatt der aus sieben antiparallel angeordneten $\beta$-Faltblättern bestehenden Struktur. ${ }^{[7],[10],[11]}$ In PH-Domänen sind keine apolaren Seitenketten verfügbar, die eine Insertion des Proteins in die Membran ermöglichen würden, sodass eine Lipidbindung ausschließlich an Lipidkopfgruppen erfolgen kann. ${ }^{[12]}$

Die 194 Aminosäuren umfassende Dbl-Homologie-Domäne (DH) ist am CTerminus über eine kurze, flexible $\alpha$-Helix mit der PH-Domäne verbunden. ${ }^{[13]}$ Die DH-Domäne wird strukturell aus einem dicht gepackten Bündel aus 12 
unterschiedlichen langen $\alpha$-Helices gebildet. DH-Domänen steuern die Aktivität des GDP/GTP-Austauschs von bdl-ähnlichen Onkoproteinen. ${ }^{[14]}$ Collybistin aktiviert in der Zelle spezifisch die GTPase Cdc42. ${ }^{[15],[16]}$ Dabei wird ein Komplex aus Collybistin und Cdc42 gebildet, was die Dissoziation des gebundenen GDP von der GTPase stimuliert. Dies führt zu einer Verstärkung von Signalen.

Die N-terminale src-Homologie 3-Domäne (SH3) wird aus fünf über lange Schleifen verbundenen, antiparallel angeordneten $\beta$-Faltblättern gebildet. ${ }^{[13]}$ Mit insgesamt 58 Aminosäuren stellt sie die kleinste im Collybistin vorkommende Domäne dar. SH3-Domänen vermitteln spezifische Proteininteraktionen und erkennen dabei insbesondere prolinreiche Aminosäuresequenzen. Die CollybistinIsoformen mit SH3-Domäne liegen in Lösung in einer geschlossenen, dreieckähnlichen Konformation vor, die durch eine Wechselwirkung zwischen den Aminosäuren W24, R249 und E262 ausgelöst wird.[17],[18],[13] Die für $\mathrm{CB} 2_{\mathrm{SH} 3-}$ beobachtete Aktivität des Proteins in der Zelle ist stark reduziert. Dies verdeutlicht, dass die SH3-Domäne autoinhibitorisch wirkt. ${ }^{[19]}$

In Abbildung 2 ist die Kristallstruktur von $\mathrm{CB}_{\mathrm{SH} 3+}$ in der geschlossenen Konformation gezeigt. ${ }^{[13]}$ Die PH-Domäne ist in rot/gelb, die DH-Domäne in grün und die SH3-Domäne in blau eingefärbt. 


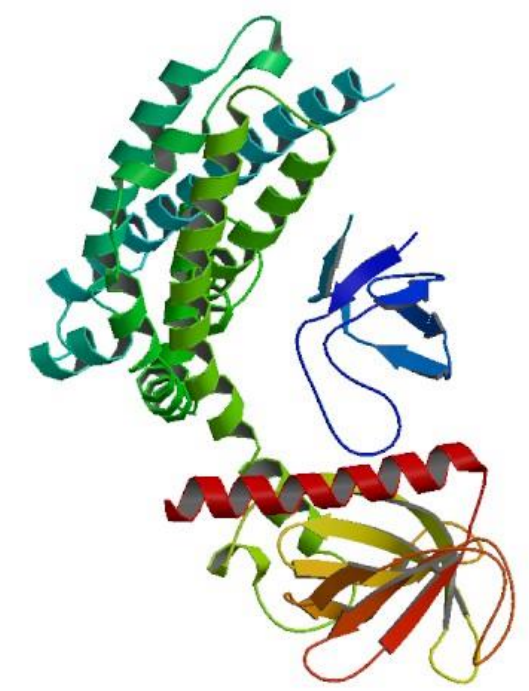

Abbildung 2: Kristallstruktur der geschlossenen Konformation von $\mathrm{CB}_{\mathrm{SH} 3+}$ (pdb Code: 4MT6).[13]

In Zellexperimenten wurde gezeigt, dass die Koexpression von $\mathrm{CB}_{\mathrm{SH} 3+}$ mit Gephyrin zu großen cytoplasmatischen Aggregaten führt. Im Gegensatz dazu wurde mit koexprimiertem CB2 ${ }_{\mathrm{SH} 3}$ eine Neuverteilung von Gephyrin in kleine Mikrocluster unter der Plasmamembran beobachtet. ${ }^{[20]}$ Diese Mikrocluster gleichen den GlyRClustern, die im initialen Schritt der Differenzierung der postsynaptischen Membran detektiert wurden. ${ }^{[5]}$ Dies deutet darauf hin, dass $\mathrm{CB} 2{ }_{\mathrm{SH} 3+}$ durch das Vorhandensein der autoinhibitorischen SH3-Domäne nicht ohne zusätzliche Aktivierung an die postsynaptische Membran binden kann.

Im cytoplasmatischen Bereich von Neuroligin-2 befindet sich neben einer Gephyrin-Bindungsstelle auch eine prolinreiche Aminosäuresequenz. Diese wechselwirkt mit der SH3-Domäne von Collybistin und führt durch die Bindung zu einer spezifische Aktivierung des Proteins. ${ }^{[6]}$ Dies führt zu einer Öffnung der Proteinstruktur, sodass die PH-Domäne für die Bindung von membranständigen Phosphatidylinositolphosphaten zugänglich wird (Abbildung 3). 
Die Aktivierung des Proteins $\mathrm{CB} 2_{\mathrm{SH} 3+}$ kann im in vitro Experiment durch zwei Punktmutationen an den Position W24 und E262 nachgebildet werden. Diese Proteinmutante verhindert die intramolekulare Wechselwirkung der SH3-Domäne mit der PH-/DH-Tandemdomäne, sodass das Protein in einer eher aktivierten/geöffneten Konformation vorliegt. ${ }^{[13]}$
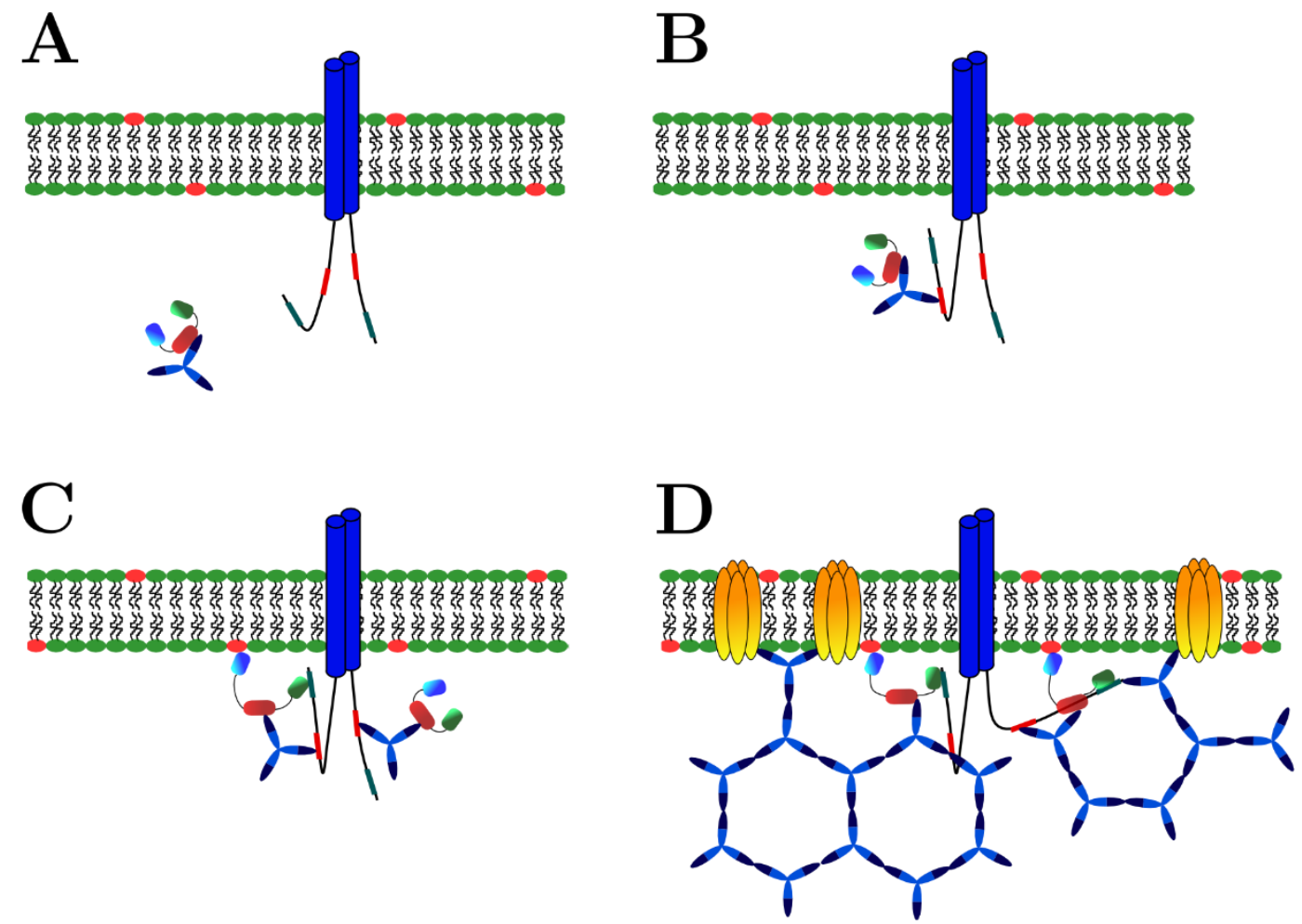

\begin{tabular}{|c|c|c|}
\hline Collybistin & Neuroligin 2 & GABA A Rezeptor \\
\hline Gephyrin-Trimer & Gephyrin-Bindungsstelle & I poly-Pro Sequenz \\
\hline
\end{tabular}

Abbildung 3: Modell der Neuroligin-2 induzierten Aktivierung von Collybistin an inhibitorischen Synapsen. (A) Gephyrin-Trimere binden an die DH-Domäne von Collybistin. Collybistin liegt in einer geschlossenen Konformation vor. (B) Der gebildete Gephyrin-Collybistin-Komplex wird an der Gephyrin-Bindungsstelle von Neuroligin-2 gebunden. (C) Durch die räumliche Nähe zwischen der Polyprolin-Sequenz von Neuroligin-2 und dem Gephyrin-Collybistin-Komplex kommt es zur Bindung der SH3Domäne von Collybistin an Neuroligin-2. (C) Die Bindung der SH3-Domäne an Neuroligin-2 führt zu einer Öffnung der Proteinkonformation von Collybistin. Die PHDomäne wird für die Bindung an Phosphatidylinositolphosphate in der Plasmamembran 
(rote Kreise) zugänglich. (D) Durch die Membranbindung von Collybistin wird Gephyrin an der Plasmamembran verankert. Mit weiteren Gephyrin-Trimeren wird ein hexagonales Gephyrin-Gitter unterhalb der postsynaptischen Membran ausgebildet. Dies führt zur Lokalisation von $\mathrm{GABA}_{\mathrm{A}}$-Rezeptoren in der postsynaptischen Membran, sodass die inhibitorische Synapse korrekt funktionieren kann.

\subsection{Phosphatidylinositolphosphate in Membranen}

Phosphatidylinositol (PI, Abbildung 4) gehört zur Gruppe der Glycerophospholipide und ist ein Bestandteil der cytosolischen Seite der eukaryotischen Zellmembran. Bei physiologischem pH-Wert der Umgebung ist das Lipid durch die Hydroxylgruppe am Phosphatester einfach negativ geladen. Die Fettsäureketten von Phosphatidylinositol werden am häufigsten durch Stearinsäure und Arachidonsäure gebildet.

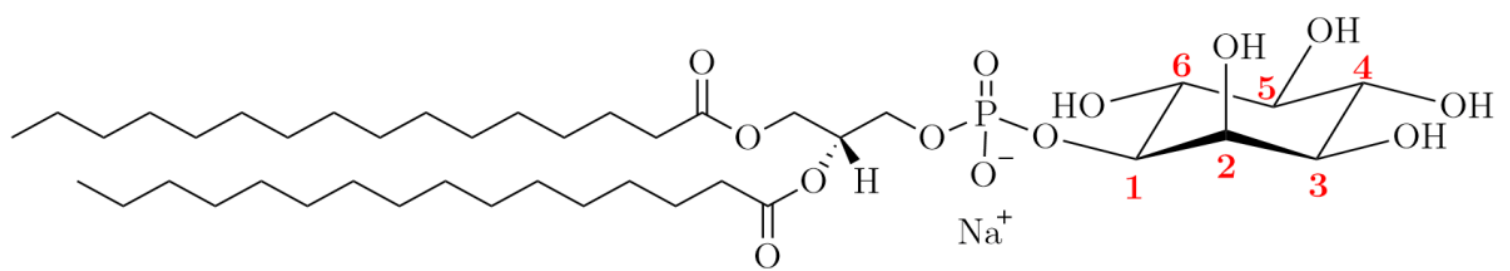

Abbildung 4: Chemische Struktur von Phosphatidylinositol (PI) mit zwei gesättigten C16 Fettsäureketten und der Inositolkopfgruppe.

Phosphatidylinositol kann durch eine Vielzahl spezifischer Kinasen an der $3^{6}-$, 4'und 5'-Hydroxylgruppe des Inositolrings phosphoryliert werden. Dadurch können mono-, di- und tri-phosphorylierte Phosphatidylinositole entstehen. Die 26- und 66Hydroxylgruppe im Inositolring kann aufgrund von sterischer Hinderung nicht phosphoryliert werden. Alle entstehenden Phosphatidylinositolphosphate haben eine für die Zelle wichtige und definierte Funktion. ${ }^{[21]}$

Phosphatidylinositol-3-phosphat $(\mathrm{PI}(3) \mathrm{P})$ wird durch die Phosphatidylinositol-3Kinase aus PI erzeugt und stellt einen Bestandteil der frühen Endosomen dar. Es 
spielt in der Dynamik der Endosomen eine entscheidende Rolle. Verschiedene Proteindomänen wie z.B. PH- und FYVE-Domänen zeigen Bindung an PI(3)P.22] Die Bindung von FYVE-Domänen ist hochspezifisch für $\mathrm{PI}(3) \mathrm{P}$ und weist Dissoziationskonstanten von etwa $50 \mathrm{nM}$ auf. ${ }^{[22]}$ Im Gegensatz dazu können PHDomänen mit Dissoziationskonstanten im Bereich von 10-250 nM an verschiedene Phosphatidylinositolphosphate in Membranen binden. Die Bindung des Proteins PDPK 1 (phosphoinositide-dependent protein kinase 1) an $\mathrm{PI}(3) \mathrm{P}$ weist eine Dissoziationskonstante von $K_{\mathrm{D}}=84 \mathrm{nM}$ auf. Die Bindung des Proteins an andere Phosphatidylinositolphosphate ist allerdings stärker. Die bevorzugte Bindung von Collybistin an $\mathrm{PI}(3) \mathrm{P}$ wurde lediglich qualitativ über lipid-overlay Assays beschrieben. ${ }^{[8]}$

Phosphatidylinositol-4-phosphat (PI(4)P) kommt vorwiegend an der Membran des Golgi-Apparats vor. Dort bildet es mit einem Effektorprotein und dem Protein ARF einen Komplex, der für den Transport von Proteinen zur Zellmembran dient. ${ }^{[23],[24]}$ Zudem wird PI(4)P zur Aufrechterhaltung der Struktur und der Funktion des Golgi-Apparates benötigt.

Die Funktion von Phosphatidylinositol-5-phosphat (PI(5)P) ist bisher nur schlecht verstanden. Die Konzentration von PI(5)P in der Zelle ist stark von der Umgebung abhängig. Bei einer hohen Konzentration von Insulin oder Thrombin in der Zelle, steigt die PI(5)P-Konzentration. ${ }^{[25],[26]}$ Bei der Histaminaufnahme oder einem hypoosmotischen Schock sinkt die PI(5)P-Konzentration ab. ${ }^{[27]}$ Bisher konnte PI(5)P nur im Zellkern nachgewiesen werden. ${ }^{[28]}$

Phosphatidylinositol-(3,4)-bisphosphat $\quad\left(\mathrm{PI}(3,4) \mathrm{P}_{2}\right) \quad$ ist Bestandteil der Plasmamembran und aktiviert dort für die Zelle wichtige Signalwege. Die Entstehung des Lipids an der Plasmamembran wird durch Kinasen ausgelöst und 
führt zur Translokation von $\mathrm{PI}(3,4) \mathrm{P}_{2}$-bindenden Proteinen an die Plasmamembran. ${ }^{[29]} \mathrm{PI}(3,4) \mathrm{P}_{2}$ wird von der $\mathrm{PH}$-Domäne verschiedener Proteine wie dem PDPK1 gebunden. PDPK1 bindet spezifischer an $\mathrm{PI}(3,4) \mathrm{P}_{2}\left(K_{\mathrm{D}}=5.2 \mathrm{nM}\right)$ als an $\mathrm{PI}(3) \mathrm{P} \cdot{ }^{[30]}$

Phosphatidylinositol-(3,5)-bisphosphat $\quad\left(\mathrm{PI}(3,5) \mathrm{P}_{2}\right)$ ist das Phosphatidylinositolphosphat mit der geringsten Konzentration in tierischen Zellen. $\mathrm{PI}(3,5) \mathrm{P}_{2}$ wird kurz nach der Synthese in der Zelle direkt die spezifische Phosphatase Sac3 in PI(3)P umgewandelt. ${ }^{[31]}$ In der Zelle hat es einen Einfluss auf die Vesikelentstehung bei der Bildung von Endosomen. ${ }^{[12]}$

Das wichtigste und am besten erforschte Phosphatidylinositolphosphat ist Phosphatidylinositol-(4,5)-bisphosphat $\left(\mathrm{PI}(4,5) \mathrm{P}_{2}\right)$. Es hat einen Anteil von bis zu $0.5 \%$ an den Gesamtlipiden in der Plasmamembran und tritt nahezu ausschließlich an der cytoplasmatischen Seite der Plasmamembran auf. Neben der Kontrolle der Endo- und Exocytose spielt $\mathrm{PI}(4,5) \mathrm{P}_{2}$ eine wichtige Rolle in der Weiterleitung extrazellulärer Signale in die Zelle. ${ }^{[32]}$ Zudem ist es eine Quelle für die Bildung anderer aktiver Metabolite wie z.B. PI(3,4,5) $\mathrm{P}_{3}$. Die PH-Domäne der Phospholipase C- $\delta 1($ PLC- $\delta 1)$ bindet mit einer Dissoziationskonstanten von $K_{\mathrm{D}}=2 \mu \mathrm{M}$ spezifisch an $\mathrm{PI}(4,5) \mathrm{P}_{2}$ und führt zur Hydrolyse von $\mathrm{PI}(4,5) \mathrm{P}_{2}$ in Inositoltriphosphat und Diacylglycerol. Im Gegensatz dazu weist die Bindung der PH-Domäne von Pleckstrin an $\mathrm{PI}(4,5) \mathrm{P}_{2}$ eine viel geringere Dissoziationskonstante von $K_{\mathrm{D}}=30 \mu \mathrm{M}$ auf. ${ }^{[33]}$

Phosphatidylinositol-(3,4,5)-trisphosphat $\left(\mathrm{PI}(3,4,5) \mathrm{P}_{3}\right)$ ist das einzige dreifach phosphorylierte Phosphatidylinositol. Es wird mit Hilfe von Kinasen aus $\mathrm{PI}(4,5) \mathrm{P}_{2}$ generiert. ${ }^{[34]}$ Durch die Bindung der PH-Domäne der Proteinkinase B (PKB) an 
$\mathrm{PI}(3,4,5) \mathrm{P}_{3}$ kommt es zur Aktivierung von PKB. Dies führt zu einer Aktivierung von für das Zellwachstum und die Zellvermehrung wichtigen anabolischen Signalwegen.[35]

In Abbildung 5 ist die Verteilung der Phosphatidylinositolphosphate in eukaryotischen Zellen dargestellt. Die Konzentration der PIPs ist sehr unterschiedlich. $\mathrm{PI}(4,5) \mathrm{P}_{2}$ hat einen Anteil von $0.5 \%$ an den Gesamtlipiden der Plasmamembran und besitzt die gleiche Konzentration wie PI(4)P in der Zelle. ${ }^{[36]}$ $\mathrm{PI}(3,4) \mathrm{P}_{2}$ und $\mathrm{PI}(3,4,5) \mathrm{P}_{3}$ sind in Zellen im Normalzustand nicht nachweisbar. ${ }^{[37]} \mathrm{Im}$ angeregten Zustand beträgt ihre Konzentration $3 \%$ der Konzentration von $\mathrm{PI}(4,5) \mathrm{P}_{2}$ und PI(4)P. Die Konzentration von PI(3)P ist um den Faktor 20 kleiner als $c\left(\mathrm{PI}(4,5) \mathrm{P}_{2}\right)$. In eukaryotischen Zellen wurden zudem $\mathrm{PI}(3,5) \mathrm{P}_{2}$ und $\mathrm{PI}(5) \mathrm{P}$ nachgewiesen. ${ }^{[36]}$

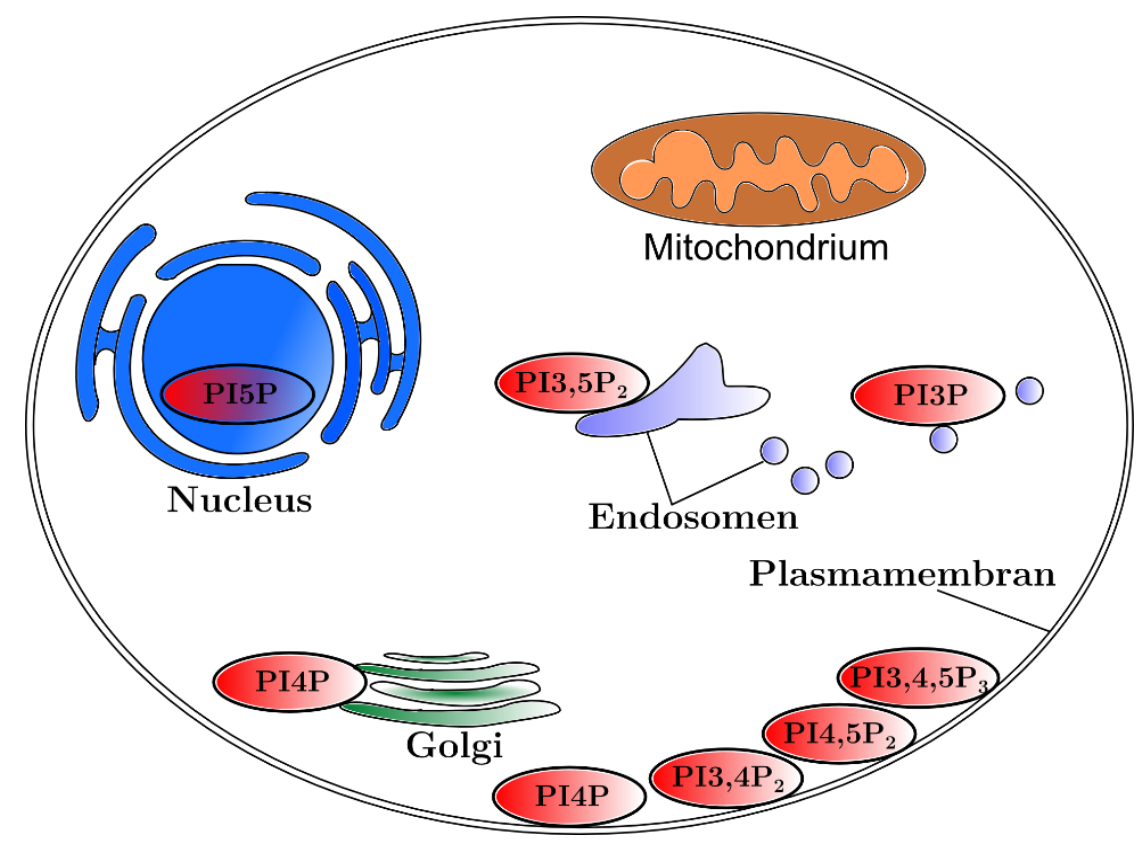

Abbildung 5: Verteilung von Phosphatidylinositolphosphaten in eukaryotischen Zellen. 


\section{Zielsetzung}

Der gehirnspezifische Guanin-Nukleotid-Austauschfaktor Collybistin besteht aus drei Domänen und dient in Nervenzellen der Verknüpfung des hexagonalen Gephyringitters mit der Plasmamembran. Dieses ist für die korrekte Anordnung der $\mathrm{GABA}_{\mathrm{A}^{-}}$und Glycin-Rezeptoren an der postsynaptischen Membran essentiell. Das Protein Collybistin soll dazu über die C-terminale PH-Domäne an Phosphatidylinositolphosphate in der Plasmamembran gebunden werden. Bisher konnte in vitro lediglich qualitativ die bevorzugte Bindung an monophosphorylierte Phosphatidylinositole nachgewiesen werden. Diese sind allerdings nicht in hohen Konzentrationen an der Plasmamembran, sondern am Golgi-Apparat (PI(4)P) sowie an den Endosomen $(\mathrm{PI}(3) \mathrm{P})$ von Nervenzellen präsent.

Ziel der vorliegenden Arbeit ist die Realisierung eines Modellsystems auf Basis von festkörperunterstützten Membranen, anhand dessen die Bindung von Collybistin an die verschiedenen Phosphatidylinositolphosphate untersucht werden kann. Hierbei sollen insbesondere die Einflüsse der einzelnen Proteindomänen auf die Bindung an Phosphatidylinositolphosphate individuell adressiert werden. Neben den in tierischen Zellen vorkommenden Proteinisoformen $\mathrm{CB} 2_{\mathrm{SH} 3+}$ und $\mathrm{CB} 2_{\mathrm{SH} 3-}$ dienen die Isoformen $\mathrm{CB}_{\mathrm{PH}}$ und $\mathrm{CB}_{\mathrm{SH} 3+} / \mathrm{W} 24 \mathrm{~A}-\mathrm{E} 262 \mathrm{~A}$ - die reine $\mathrm{PH}-$ Domäne sowie eine teilaktivierte Form des Proteins - der Untersuchung des Einflusses der Proteindomänen auf die Proteinstruktur und die daraus resultierende Membranbindung. Die Interaktionsstudien an Oberflächen sollen durch Untersuchungen der Proteinstruktur in Lösung ergänzt werden. 


\section{Materialien und Methoden}

\subsection{Proteinbiochemische Methoden}

In diesem Kapitel werden die angewandten biochemischen Methoden beschrieben. Bei allen biochemischen Arbeiten mit lebenden Zellen wurden RNase- und endotoxinfreie Pipettenspitzen (Eppendorf, Hamburg, Deutschland), sterile Gefäße, Nährmedien und Lösungen verwendet. Alle Arbeiten wurden in einer mikrobiologischen Sicherheitswerkbank durchgeführt.

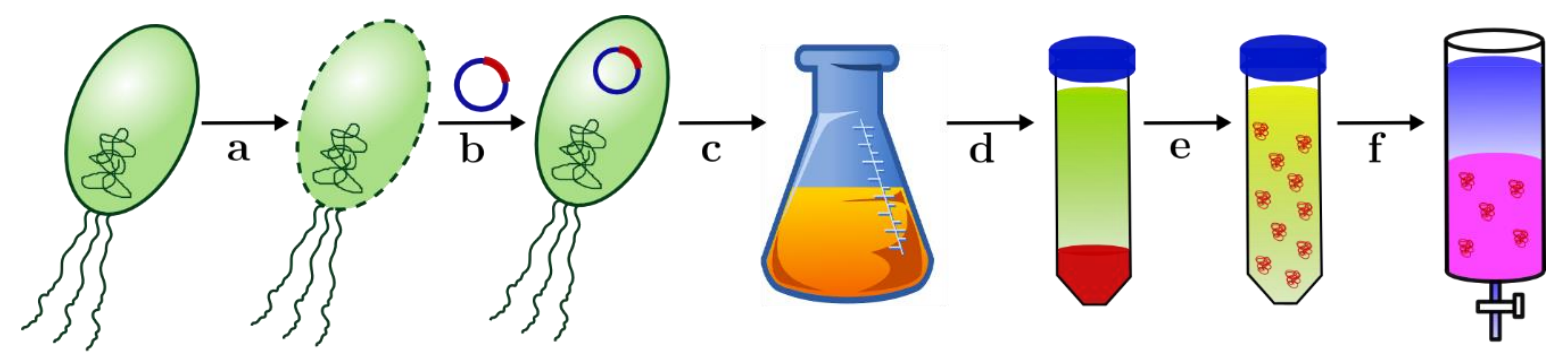

Abbildung 6: Schematische Darstellung der Arbeitsschritte zur Proteinisolierung. a:

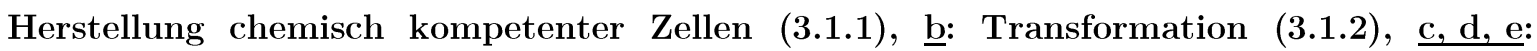
Heterologe Proteinexpression und Zelllyse (3.1.5), f: Säulenchromatographische Aufreinigung der Proteine (3.1.6, 0)

Folgendes Nährmedium wurde für alle Expressionsschritte verwendet: ${ }^{[38]}$

LB-Medium (nach Miller): $1 \% \mathrm{NaCl}, 0.5 \%$ Hefeextrakt, $1 \%$ Trypton, pH 7.0 Für die Herstellung von Kulturplatten wurde dem Medium 1.5\% (w/v) Agar zugesetzt. 


\subsubsection{Herstellung chemisch kompetenter Zellen}

Bakterienzellen sind unter natürlichen Bedingungen nur schlecht in der Lage genetisches Material aufzunehmen. Um die Effizienz der Plasmidaufnahme von E. coli zu steigern, wird die Permeabilität der Zellmembranen durch einen Überschuss an Calciumionen kurzzeitig erhöht.

Tabelle 1: Verwendete E. coli-Stämme und dazugehörige Genotypen

Stamm Genotyp

DH5a fhuA2 lac(del)U169 phoA glnV44 $\$ 80$ ' lacZ(del)M15 gyrA96 recA1 relA1 endA1 thi-1 hsdR17

BL21(DE3) F- ompT hsdSB (rBmB-) gal dem (DE3)

Zur Herstellung kompetenter Zellen wurde ein Glycerolstock des jeweiligen Bakterienstamms (DH5 $\alpha$ oder BL21(DE3)) auf Eis aufgetaut. $50 \mu \mathrm{L}$ der Zellsuspension wurden auf eine Agarplatte aus LB-Medium gegeben und mit Hilfe steriler Glaskugeln verteilt. Die Platte wurde upside-down bei $37^{\circ} \mathrm{C}$ über Nacht inkubiert. Eine einzelne Kolonie wurde mit Hilfe einer Pipettenspitze in $5 \mathrm{~mL}$ LBMedium überführt. Die Kultur wurde bei $37^{\circ} \mathrm{C}$ und $250 \mathrm{rpm}$ über Nacht geschüttelt (Vorkultur). $100 \mathrm{~mL}$ LB-Medium wurden mit $1 \mathrm{~mL}$ der gewachsenen Vorkultur inokuliert und bis zu einer optischen Dichte $O D_{600}=0.4$ bei $37^{\circ} \mathrm{C}$ und $250 \mathrm{rpm}$ wachsen gelassen (Hauptkultur). Die Kultur wurde für 10 min auf Eis gekühlt, um das Zellwachstum stark zu verlangsamen. Alle nun folgenden Schritte wurden mit vorgekühlten Gefäßen, Pipettenspitzen und Geräten durchgeführt. Die Hauptkultur wurde zentrifugiert $\left(2700 \mathrm{xg}, 10 \mathrm{~min}, \quad 4^{\circ} \mathrm{C}\right)$ und das überstehende Medium 
verworfen. Das Pellet wurde durch vorsichtiges Schwenken in $1.6 \mathrm{~mL}$ eiskalter $\mathrm{CaCl}_{2}$-Lösung (100 mM) gelöst und die Suspension für 30 min auf Eis inkubiert. Die Zentrifugation und das Lösen des Pellets wurde unter gleichen Bedingungen noch einmal durchgeführt und die resultierende Suspension für 20 min auf Eis gelagert. Zu der Suspension wurden $500 \mu \mathrm{L}$ eiskalte Glycerollösung (80\%) gegeben. Die Suspension wurde zu $100 \mu \mathrm{L}$ aliquotiert. Die Aliquots wurden sofort in flüssigem Stickstoff schockgefroren und bis zu 4 Monate bei $-80^{\circ} \mathrm{C}$ gelagert. Eine längere Lagerung führt zu einer abnehmenden Transformationseffizienz der Zellen. Für den Stamm BL21(DE3) wurde dem Medium zusätzlich $100 \mu \mathrm{gg} / \mathrm{mL}$ Ampicillin als Resistenzantibiotikum zugegeben.

\subsubsection{Transformation}

SOC-Medium: $\quad 0.5 \%$ Hefeextrakt, $2 \%$ Trypton, $10 \mathrm{~mm} \mathrm{NaCl}, 2.5 \mathrm{~mm} \mathrm{KCl}$, $20 \mathrm{mM} \mathrm{MgCl}_{2}, 20 \mathrm{mM}$ Glucose, $\mathrm{pH} 7.0$

Folgende Plasmide wurden in dieser Arbeit verwendet:

Tabelle 2: Übersicht über die verwendeten Plasmide mit Resistenzgen.

\begin{tabular}{cccc}
\hline cDNA & Herkunftsorganismus & Vektor & Resistenz \\
\hline $\mathrm{CB} 2{ }_{\mathrm{PH}}$ & Ratte & pTYB12 & Ampicillin \\
\hline $\mathrm{CB} 2_{\mathrm{SH} 3-}$ & Ratte & pTYB12 & Ampicillin \\
\hline $\mathrm{CB} 2_{\mathrm{SH} 3+}$ & Ratte & pTXB1 & Ampicillin \\
\hline $\mathrm{CB} 2_{\mathrm{SH} 3+} / \mathrm{W} 24 \mathrm{~A}-\mathrm{E} 262 \mathrm{~A}$ & Ratte & pTXB1 & Ampicillin \\
\hline
\end{tabular}

Die verwendeten Plasmide wurden in einer Kooperation mit D. Schneeberger am Rudolf-Virchow-Zentrum für experimentelle Biomedizin in Würzburg hergestellt. 
Der Prozess der Transformation beschreibt die Aufnahme von rekombinanter DNA in kompetente Bakterien während der exponentiellen Wachstumsphase. Die zugegebene Plasmid-DNA wird dabei in E. coli- Zellen durch einen Secretin-Kanal in der äußeren, sowie einen DNA-Transporter in der inneren Bakterienmembran in das Cytoplasma des Bakteriums transportiert und kann dort kloniert werden.

Ein Aliquot der kompetenten Zellen wurden zusammen mit dem Plasmid auf Eis aufgetaut. Anschließend wurden $2 \mu \mathrm{L}$ des Plasmids zur Zellsuspension gegeben. Die Suspension wurde vorsichtig geschwenkt, für $30 \mathrm{~min}$ auf Eis inkubiert und anschließend für $30-60 \mathrm{~s}$ bei $42^{\circ} \mathrm{C}$ einem Hitzeschock unterzogen. Der letzte Schritt erleichtert das Eindringen des Plasmids in das Bakterium. Anschließend wurden die Zellen für 5 min auf Eis inkubiert. Es wurden $900 \mu \mathrm{L}$ SOC-Medium zugegeben und die Zellsuspension für $1 \mathrm{~h}$ bei $37^{\circ} \mathrm{C}$ und $250 \mathrm{rpm}$ inkubiert. Nach der Klonierung wurden die Zellen zentrifugiert (5000 rpm, $45 \mathrm{~s})$ und $600 \mu \mathrm{L}$ des Überstands entfernt. Das Zellpellet wurde durch vorsichtiges Schwenken resuspendiert. $100 \mu \mathrm{L}$ der Lösung wurden auf einer Agarplatte mit Hilfe von Glaskugeln ausgestrichen und die Platten bei $37^{\circ} \mathrm{C}$ über Nacht inkubiert. Nur erfolgreich transfizierte E. coli Stämme wachsen durch die Ampicillin-Resistenz.

\subsubsection{Plasmidisolierung und Reinigung}

Die für die vorliegende Arbeit verwendeten Plasmide wurden aus E. coli Zellen des Stamms DH5a isoliert. Dieser Stamm eignet sich besonders gut für die Plasmidvermehrung und -isolierung, da er neben einem schnellen Zellwachstum eine Mutation im endA1-Gen besitzt. Dadurch ist eine intrazelluläre Endonuclease inaktiviert, was die Zersetzung der Plasmid-DNA verhindert. Die Plasmidisolierung 
erfolgte durch alkalische Lyse der Zellen. Es wurde ein Kit zur Isolierung (NucleoBond ${ }^{\circledast}$ Xtra Midi EF, Macherey-Nagel, Düren, Deutschland) verwendet. Dies hat den Vorteil, dass alle verwendeten Lösungen sowohl steril, als auch endotoxinfrei vorliegen.

Für die Amplifizierung des Plasmids wurde eine Vorkultur aus $5 \mathrm{~mL}$ LB-Medium mit einer Einzelkolonie von der Agarplatte angeimpft und über Nacht bei $37^{\circ} \mathrm{C}$ und 200 rpm geschüttelt. Für spätere Plasmidisolierungen wurden aus der Vorkultur Glycerolstocks (50\% Glycerin/50 \% Vorkultur) angelegt, in flüssigem Stickstoff schockgefroren und bei $-80^{\circ} \mathrm{C}$ gelagert. Für zwei Hauptkulturen wurden jeweils $100 \mathrm{~mL}$ LB-Medium mit der Vorkultur inokuliert (1/1000). Die Kulturen wurden für 12-16 h angezogen $\left(200 \mathrm{rpm}, 37^{\circ} \mathrm{C}\right)$. Die optische Dichte $O D_{600}$ der Kulturen wurde gemessen und nach Gleichung (1) das benötigte Volumen $V$ des Resuspensionspuffers bestimmt. Die $O D_{600}$ sollte nicht größer als 1.5 sein.

$$
\frac{V}{\mathrm{~mL}}=\frac{800}{O D_{600}}
$$

Die Zellen der Übernachtkultur wurde durch zentrifugieren $(4500 \mathrm{x} g, 10 \mathrm{~min}$, $4{ }^{\circ} \mathrm{C}$ ) geerntet und in der berechneten Menge Resuspensionspuffer (RES-EF) resuspendiert. Es wurde das gleiche Volumen Lysepuffer (LYS-EF) zugegeben und die Suspension durch vorsichtiges Schwenken gemischt. Durch den stark alkalischen pH-Wert des Lysepuffers lösen sich die Wasserstoff-Brückenbindungen zwischen den komplementären DNA-Strängen. Nach 5 min Inkubation bei Raumtemperatur wurde die Lösung neutralisiert (NEU-EF) und für 5 min auf Eis gelagert. Dies führt zu einer Renaturierung der Plasmid-DNA, Proteine und chromosomale DNA können nicht renaturiert werden. Die ausgefallenen Bestandteile wurden über einen Säulenfilter entfernt und die an das Säulenmaterial gebundene Plasmid-DNA gewaschen (ENDO-EF/WASH-EF-Puffer). Das Plasmid wurde mit Hilfe des 
Elutionspuffers von der Säule eluiert. Anschließend wurde die Plasmid-DNA mit Isopropanol ausgefällt, mit $70 \%$ Ethanol gewaschen und anschließend in endotoxinfreiem Wasser aufgenommen. Die Konzentration und die Reinheit des Plasmids wurden über UV-Absorption bestimmt. Bei reiner Plasmid-DNA ist das Verhältnis der Absorption $A_{260} / A_{280}=1.8$ - 1.9. Eine qualitative Überprüfung des gewonnenen Plasmids wurde durch eine Agarose-Gelelektrophorese vorgenommen.

\subsubsection{Agarose-Gelelektrophorese}

Mit Hilfe der Agarose-Gelelektrophorese kann die Reinheit von NukleinsäureSträngen nachgewiesen werden. Unter elektrophoretischen Bedingungen sind die Phosphatgruppen im Nukleinsäurerückgrat ionisiert, sodass die Nukleinsäure-Stränge als Polyanionen vorliegen. Sie bewegen sich im elektrischen Feld in Richtung der Anode und werden dabei nach ihrer Kettenlänge und ihrer Topologie getrennt. Die isolierte Plasmid-DNA liegt in einer superhelikalen Form vor, sodass verschiedene Plasmide nur im Verhältnis zueinander unterschieden werden können.

Für eine native Agarose-Gelelektrophorese wurde ein $1 \%(w / v)$ Agarose-Gel mit einer resultierenden Porengröße von $150 \mathrm{~nm}$ hergestellt. Dazu wurden $300 \mathrm{mg}$ Agarose in $30 \mathrm{~mL}$ TAE-Puffer (1x) gegeben und die Suspension in der Mikrowelle bis zum Sieden erhitzt. Es wurden $3 \mu \mathrm{L}$ GelRed-Farbstoff (10.000 x) hinzugegeben und die Lösung in die Gelkammer gegossen. Der UV-aktive Farbstoff interkaliert in die zu untersuchende DNA, sodass die aufgetrennten Plasmide nach der Elektrophorese mittels UV-Licht sichtbar gemacht werden können. Um Probentaschen zu generieren, wurde ein Kamm in die noch warme Agarose-Lösung eingesetzt. Während des Abkühlens bilden sich Doppelhelices aus der Agarose, die 
sich in Gruppen parallel zu Fäden zusammenlagern und aushärten. Das ausgehärtete Gel wurde in die Elektrophoresekammer eingesetzt und mit $300 \mathrm{~mL}$ TAE-Puffer (1x) überschichtet. Die Plasmidproben wurden verdünnt $(1 \mu \mathrm{L}$ Plasmid $+9 \mu \mathrm{L}$ Reinstwasser). Von der Verdünnung wurden $1.25 \mu \mathrm{L}$ mit $2 \mu \mathrm{L}$ Probenpuffer $(6 \mathrm{x})$ und $8.75 \mu \mathrm{L}$ Reinstwasser versetzt. Der Probenpuffer führt durch das enthaltene Glycerin zu einem besseren Einsinken in die Probentaschen. Außerdem zeigt er aufgrund der zugesetzten Farbstoffe während der Auftrennung die Lauffront der Proben an, sodass ein Überlaufen der Proben verhindert werden kann. Zusätzlich wurden $1 \mu \mathrm{L}$ eines DNA-Größenstandards (GeneRuler ${ }^{\mathrm{TM}}$ 1kb DNA Ladder, Thermo Scientific, Schwerte, Deutschland) mit $9 \mu \mathrm{L}$ Reinstwasser und $2 \mu \mathrm{L}$ Probenpuffer (6x) gemischt. Dieser dient zur Größenbestimmung und zur Zuordnung von Nukleinsäurefragmenten. Es wurden jeweils $6 \mu \mathrm{L}$ Größenstandard bzw. Probe auf das Gel aufgetragen und eine Spannung von $100 \mathrm{~V}$ für $60 \mathrm{~min}$ angelegt. Anschließend wurde das Gel mittels UV-Licht analysiert.

Probenpuffer $(6 \mathrm{x}): 10 \mathrm{~mm}$ TRIS/HCl, pH 7.6

$60 \mathrm{mM}$ EDTA

$60 \%$ Glycerol

$0.03 \%$ Bromphenolblau

$0.03 \%$ Xylencyanol FF

TAE-Puffer $(\mathbf{1 0} \mathbf{x}): \quad 0.4 \mathrm{M}$ TRIS/HCl, $\mathrm{pH} 8.3$

$0.2 \mathrm{M}$ Acetat

$10 \mathrm{~mm}$ EDTA 


\subsubsection{Heterologe Proteinexpression und Zelllyse}

Für die Proteinexpression wurden die jeweiligen Plasmide in kompetente E. coli Zellen des Stamms BL21(DE3) transformiert. Diese Zellen besitzen das DE3Lysogen, welches die Gene für die T7 RNA-Polymerase trägt. Die Expression der T7 RNA-Polymerase wird durch Zugabe von Isopropyl- $\beta$-D-thiogalactopyranosid (IPTG) induziert, sodass eine gute Kontrolle der Expression möglich ist. Außerdem tragen die Zellen keine lon- und OmpT-Protease. Das Fehlen dieser Proteasen reduziert die Zersetzung von heterolog exprimiertem Protein. Dieses ermöglicht die Expression der cDNA der Collybistin-Isoformen aus dem Spenderorganismus Ratte.

Zur Expression wurde von dem jeweiligen Transformanden eine Einzelkolonie gepickt und in einer $100 \mathrm{~mL}$ Übernachtkultur (LB-Medium) heran gezogen $\left(37^{\circ} \mathrm{C}\right.$, $150 \mathrm{rpm}, 12-16 \mathrm{~h}$ ). Es wurden 7.5 L LB-Medium mit $150 \mathrm{~mL}$ der Übernachtkultur inokuliert und bis zu einer optischen Dichte $O D_{600}=0.8-1.0$ wachsen gelassen $\left(37^{\circ} \mathrm{C}, 150 \mathrm{rpm}\right)$. Dabei wurde das durch die Transformation eingebrachte Gen als Fusionsprotein mit einem Intein-Tag exprimiert. Anschließend wurde die Transkription des gewünschten Gens durch die Zugabe von 0.5 mM IPTG induziert. Die Kultur wurde über Nacht bei $15^{\circ} \mathrm{C}$ und $150 \mathrm{rpm}$ geschüttelt. Durch das IPTG wurde der Lac-Repressor aus dem reprimierten in den aktivierten Zustand überführt, sodass die T7 RNA-Polymerase an die exprimierte DNA binden und damit die Transkription und Translation vom Gen zum Protein initiieren kann. Die gewachsenen Zellen wurde mittels Zentrifugation geerntet $\left(4500 \mathrm{rpm}, 20 \mathrm{~min}, 4^{\circ} \mathrm{C}\right.$ ) und das Zellpellet bei $-80{ }^{\circ} \mathrm{C}$ bis zur Lyse gelagert. 
Zur Zelllyse wurde das Zellpellet in $80 \mathrm{~mL}$ Lysepuffer mit $5 \mu \mathrm{g} / \mathrm{mL}$ DNase-I bei $4{ }^{\circ} \mathrm{C}$ durch Rühren resuspendiert, bis eine perfekt homogene Lösung entstanden ist. Anschließend wurden die E. coli Zellen über das Prinzip der Hochdruckhomogenisierung lysiert. Dazu wurden die gelösten Zellen in dem mit Lysepuffer äquilibrierten Mikrofluidizer (LM 10, Microfluidics, Westwood, MA) aufgeschlossen (1 kbar, 3 Zyklen). Das Lysat wurde mittels Ultrazentrifugation von den Zelltrümmern getrennt $\left(75.000 \mathrm{x} g, 30 \mathrm{~min}, 4^{\circ} \mathrm{C}\right)$.

Lysepuffer: $250 \mathrm{~mm} \mathrm{NaCl}$

20 mM HEPES/NaOH, pH 8.0

2 mM EDTA

$10 \%$ Glycerol

Für die Aufreinigung von $\mathrm{CB} 22_{\mathrm{SH} 3-}$ wurde $20 \mathrm{~mm}$ TRIS/HCl anstatt von $20 \mathrm{~mm}$ HEPES als Puffersubstanz im Lysepuffer verwendet.

\subsubsection{Affinitätschromatographische Aufreinigung der Intein-fusionierten}

\section{Proteine}

Die Collybistin-Isoformen wurden als Fusionsprotein mit einem selbstspaltenden Inteintag exprimiert. Dabei liegt das jeweilige Zielprotein als N-Extein bei der Verwendung des pTXB1-Vektors und als C-Extein bei der Verwendung des pTYB12-Vektors vor. Am jeweils anderen Terminus des Fusionsproteins wird am Ende des Inteintags die Chitin-bindende Domäne (CBD) als eigentlicher Affinitätstag exprimiert. 


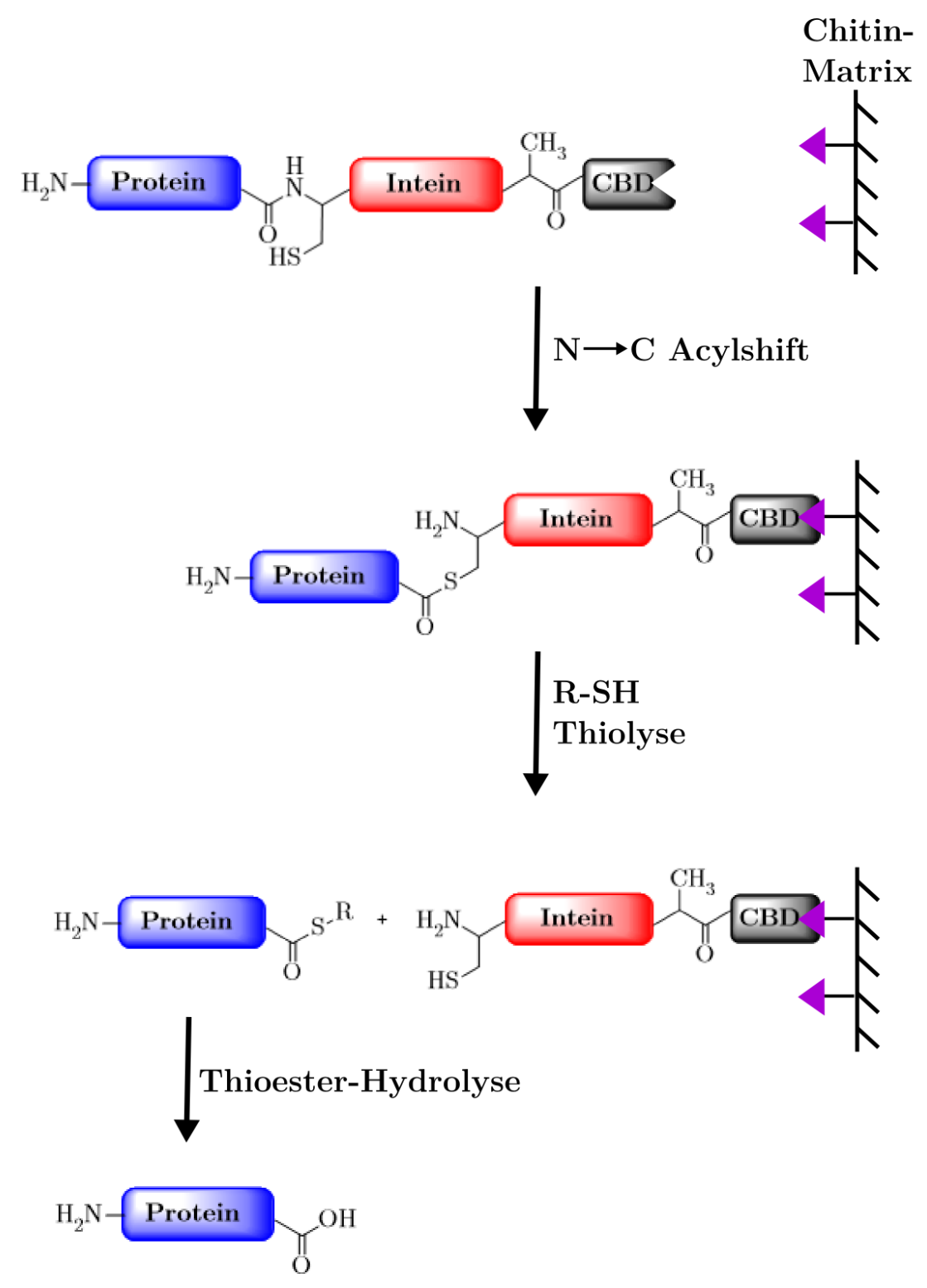

Abbildung 7: Schema der Affinitätschromatographie mit einem Intein-Fusionsprotein. Das Protein bindet über die Chitin-bindende Domäne (CBD) an die Chitin-Matrix. Es kommt zu einem N-C Acylshift zwischen dem Intein und dem Zielprotein. Durch Zugabe eines Thiols wird das Zielprotein durch Thiolyse vom Intein gespalten. In wässriger Lösung hydrolysiert der Thioester spontan zur freien Carbonsäure. Der abgespaltene Inteintag verbleibt auf der Chitin-Matrix. ${ }^{[39]}$

Bei der affinitätschromatographischen Aufreinigung bindet die CBD an die Chitin-Matrix. Es erfolgt ein N-C Acylshift zwischen dem Intein und dem Zielprotein. Durch eine Thiolyse mit Hilfe eines hochkonzentrierten Thiols wird das Zielprotein als Thioester von dem Inteintag abgespalten. Der Thioester hydrolysiert 
in wässriger Lösung spontan zur freien Carbonsäure, sodass das gewünschte Zielprotein ohne Affinitätstag vorliegt.

Für die Proteinaufreinigung wurden $50 \mathrm{~mL}$ Chitin-Suspension in eine Säule gegeben und mit $500 \mathrm{~mL}$ Reinstwasser gewaschen. Anschließend wurde die Matrix mit $1 \mathrm{~L}$ Waschpuffer (Tabelle 3) äquilibriert. Nachdem das Protein durch die Ultrazentrifugation von den unlöslichen Zellbestandteilen getrennt wurde, wurde es auf die äquilibrierte Chitin-Matrix gegeben. Die Bindung des Proteins an die Matrix wurde durch Inkubation auf dem Rollenmischer erreicht $\left(1 \mathrm{~h}, 4{ }^{\circ} \mathrm{C}\right)$. Anschließend wurde der Durchlauf aufgefangen und die Säule erneut mit 1 L Waschpuffer gespült, um unspezifisch gebundene Verunreinigungen zu entfernen. Die Spaltung des Inteintags vom Zielprotein wurde durch Inkubation in DTT-haltigem Grundpuffer initiiert $\left(50 \mathrm{~mm}\right.$ DTT, $\left.40-60 \mathrm{~h}, 4{ }^{\circ} \mathrm{C}\right)$. Anschließend wurde das Zielprotein mit DTT-haltigem Grundpuffer $(5 \mathrm{~mm})$ in $8-12$ Fraktionen à $10 \mathrm{~mL}$ eluiert. Die Reinheit und die Menge des erhaltenen Proteins in jeder Fraktion wurden mittels SDS-PAGE überprüft. Die Zusammensetzung der verwendeten Puffer ist in Tabelle 3 dargestellt.

Tabelle 3: Zusammensetzung der Wasch- und Grundpuffer für die verschiedenen Protein-Isoformen.

$\mathrm{CB2}_{\mathrm{PH}} \quad \mathrm{CB}_{\mathrm{SH} 3-} \quad \mathrm{CB} 2_{\mathrm{SH} 3+}$

$\mathrm{CB}_{\mathrm{SH} 3+} / \mathrm{W} 24 \mathrm{~A}-\mathrm{E} 262 \mathrm{~A}$

$1 \mathrm{M} \mathrm{NaCl} \quad 1 \mathrm{M} \mathrm{NaCl} \quad 1 \mathrm{M} \mathrm{NaCl}$

$20 \mathrm{~mm}$ HEPES/NaOH, $20 \mathrm{~mm}$ TRIS/HCl, $20 \mathrm{mM}$ HEPES/NaOH,

Waschpuffer

pH 8.0

pH 8.0

pH 8.0

$2 \mathrm{mM}$ EDTA

2 mM EDTA

2 mM EDTA

$10 \%$ Glycerol 


\begin{tabular}{|c|c|c|c|}
\hline \multirow{4}{*}{ Grundpuffer } & $250 \mathrm{mM} \mathrm{NaCl}$ & $250 \mathrm{mM} \mathrm{NaCl}$ & $250 \mathrm{mM} \mathrm{NaCl}$ \\
\hline & 20 mM HEPES/NaOH, & $20 \mathrm{mM}$ TRIS/HCl, & 20 mM HEPES/NaOH, \\
\hline & $\mathrm{pH} 8.0$ & $\mathrm{pH} 8.0$ & $\mathrm{pH} 8.0$ \\
\hline & $2 \mathrm{mM}$ EDTA & $2 \mathrm{~mm}$ EDTA & 2 mM EDTA \\
\hline & & & $10 \%$ Glycerol \\
\hline
\end{tabular}

\subsubsection{Anionenchromatographische Proteinaufreinigung über das $\ddot{A} K \mathrm{TA}^{\circledR}{ }_{-}$ System}

Nach der affinitätschromatographischen Reinigung der Proteine waren im SDSGel noch Verunreinigungen zu erkennen. Um die Verunreinigungen zu entfernen, wurde im Anschluss eine Ionenaustauschchromatographie durchgeführt. Dabei werden Moleküle aufgrund ihrer Nettoladung getrennt. Bei Proteinen wird die Nettoladung durch die Ladung der enthaltenen Aminosäuren in Abhängigkeit vom pH-Wert bestimmt. Hochgeladene Moleküle binden bei der Ionenaustauschchromatographie durch elektrostatische Wechselwirkungen stärker an die entgegengesetzt geladene stationäre Phase als Moleküle mit einer geringeren Nettoladung. Zur Elution wird nach der erfolgten Proteinanbindung die Ionenstärke in der mobile Phase erhöht. Dies führt zu einer sukzessiven Verdrängung der Moleküle von der stationären Phase, wobei schwächer geladene Moleküle zuerst eluiert werden. Die Trennleistung ist dabei abhängig vom Durchmesser und dem Volumen der verwendeten Säule.

Im Rahmen dieser Arbeit wurde die Anionenaustauschchromatographie zur Aufreinigung der Proteine an einem ÄKTA Purifier 10 System (GE Healthcare Europe, Freiburg, Deutschland) über eine MonoQ 10/100 GL Säule durchgeführt. Die Säulenmatrix besteht dabei aus monodispersen, porösen 
Polystyrol/Divinylbenzol-Kugeln, die mit einem quartären Ammonium-Liganden funktionalisiert sind (Ligand: O- $\mathrm{CH}_{2}-\mathrm{CHOH}-\mathrm{CH}_{2}-\mathrm{O}-\mathrm{CH}_{2}-\mathrm{CHOH}-\mathrm{CH}_{2}-\mathrm{N}^{+}\left(\mathrm{CH}_{3}\right)_{3}$ ). Alle Puffer und Proteinlösungen wurden vor der Verwendung filtriert $(0.2 \mu \mathrm{m})$, um ein Verstopfen des Systems zu verhindern.

Die Säule wurde für die Aufreinigung mit dem fünffachen Säulenvolumen an Niedrigsalzpuffer (Puffer A, 50 mm Salz) äquilibriert. Die proteinhaltigen Fraktionen aus der Affinitätschromatographie wurden vereinigt und mit Verdünnungspuffer auf $50 \mathrm{~mm}$ Salzkonzentration verdünnt. Anschließend wurde die Proteinlösung mit $3 \mathrm{~mL} / \mathrm{min}$ auf die Säule aufgetragen und erneut mit 2 Säulenvolumen Puffer A gespült, um schwach gebundene Moleküle von der Säule zu waschen. Durch einen linearen Gradienten über 12 Säulenvolumen von 50 mm Salzkonzentration (Puffer A) bis $1 \mathrm{~m}$ Salzkonzentration (Puffer B) bei $2 \mathrm{~mL} / \mathrm{min}$ wurden das Protein und die Verunreinigungen eluiert. Der Verlauf der Elution wurde dabei mittels UV/visAbsorption $(\lambda=280 \mathrm{~nm})$ und Leitfähigkeitsmessung verfolgt. Die Waschfraktionen wurden mit Hilfe eines Fraktionssammlers in $4 \mathrm{~mL}$ Fraktionen und das Eluat in $1 \mathrm{~mL}$ Fraktionen aufgefangen. Die UV/vis-aktiven Fraktionen wurden anschließend zur Identifikation mittels einer SDS-PAGE analysiert. Die proteinhaltigen Fraktionen wurden vereinigt und bei $4{ }^{\circ} \mathrm{C}$ gelagert. Die Zusammensetzung der verwendeten Puffer ist in Tabelle 4 dargestellt. 
Tabelle 4: Zusammensetzung der verwendeten Puffer für die Anionenaustauschchromatographie

$\begin{array}{lll}\mathrm{CB}_{\mathrm{PH}} & \mathrm{CB} 2_{\mathrm{SH} 3+} \\ \mathrm{CB} 2_{\mathrm{SH} 3-} & \mathrm{CB} 2_{\mathrm{SH} 3+} / \mathrm{W} 24 \mathrm{~A}-\end{array}$

E262A

\begin{tabular}{|c|c|c|c|}
\hline \multirow{4}{*}{$\begin{array}{l}\text { Verdüinnungs- } \\
\text { puffer }\end{array}$} & $\begin{array}{l}20 \text { mM HEPES/NaOH, } \\
\text { pH } 8.0\end{array}$ & $\begin{array}{l}20 \mathrm{~mm} \text { TRIS/HCl, } \\
\mathrm{pH} 8.0\end{array}$ & $\begin{array}{l}20 \text { mM HEPES/NaOH, } \\
\text { pH } 8.0\end{array}$ \\
\hline & $2 \mathrm{~mm}$ EDTA & $2 \mathrm{mM}$ EDTA & $2 \mathrm{mM}$ EDTA \\
\hline & $2 \mathrm{mM} \beta-\mathrm{ME}$ & $2 \mathrm{mM} \beta-\mathrm{ME}$ & $2 \mathrm{mM} \beta-\mathrm{ME}$ \\
\hline & & & $10 \%$ Glycerol \\
\hline \multirow{6}{*}{ Puffer A } & $50 \mathrm{mM} \mathrm{NaCl}$ & $50 \mathrm{mM} \mathrm{NaCl}$ & $50 \mathrm{mM} \mathrm{NaCl}$ \\
\hline & 20 mM HEPES/NaOH, & $20 \mathrm{mM}$ TRIS/HCl, & $20 \mathrm{mM}$ HEPES/NaOH, \\
\hline & $\mathrm{pH} 8.0$ & $\mathrm{pH} 8.0$ & $\mathrm{pH} 8.0$ \\
\hline & $2 \mathrm{~mm}$ EDTA & $2 \mathrm{mM}$ EDTA & $2 \mathrm{~mm}$ EDTA \\
\hline & $2 \mathrm{mM} \beta-\mathrm{ME}$ & $2 \mathrm{mM} \beta-\mathrm{ME}$ & $2 \mathrm{mM} \beta-\mathrm{ME}$ \\
\hline & & & $10 \%$ Glycerol \\
\hline \multirow{6}{*}{ Puffer B } & $1 \mathrm{M} \mathrm{NaCl}$ & $1 \mathrm{M} \mathrm{NaCl}$ & $1 \mathrm{M} \mathrm{NaCl}$ \\
\hline & 20 mM HEPES/NaOH, & $20 \mathrm{mM}$ TRIS/HCl, & 20 mM HEPES/NaOH, \\
\hline & $\mathrm{pH} 8.0$ & $\mathrm{pH} 8.0$ & $\mathrm{pH} 8.0$ \\
\hline & $2 \mathrm{mM}$ EDTA & $2 \mathrm{mM}$ EDTA & $2 \mathrm{mM}$ EDTA \\
\hline & $2 \mathrm{~mm} \beta-\mathrm{ME}$ & $2 \mathrm{mM} \beta-\mathrm{ME}$ & $2 \mathrm{mM} \beta-\mathrm{ME}$ \\
\hline & & & $10 \%$ Glycerol \\
\hline
\end{tabular}




\subsubsection{SDS-PAGE nach Laemmli / Schägger}

Zur qualitativen Analyse der erhaltenen Fraktionen aus der Affinitäts- und Anionenaustauschchromatographie wurde eine SDS-Polyacrylamid-Gelelektrophorese (SDS-PAGE) im diskontinuierlichen Verfahren nach Laemmli durchgeführt. ${ }^{[40]}$ Das anionische Detergenz Natriumdodecylsulfat (SDS) bindet dabei nicht-kovalent an Proteine und überdeckt die Ladungen des Proteins. Dadurch wird eine negative Nettoladung erzeugt, die relativ zur molaren Masse des Proteins zunimmt. SDS führt zusätzlich zu einer Denaturierung der Proteine, welche durch Hitzeeinfluss unterstützt wird. Während der Auftrennung ist die elektrophoretische Mobilität des Proteins nur noch durch das Ladung-zu-Masse Verhältnis des Proteins und durch die Porengröße des Polyacrylamidgels bestimmt.

In dieser Arbeit wurde ein vertikales Mini-PROTEAN® Elektrophorese-System zur Analyse der Proteinfraktionen verwendet (Bio-Rad, München, Deutschland). Die Polyacrylamid-Gele wurden durch radikalische Polymerisation von Acrylamid und Bisacrylamid hergestellt. Diese wurde durch den Initiator Ammoniumperoxodisulfat (APS) und den Stabilisator $N, N, N^{\natural}, N^{6}$-Tetramethylethylendiamin (TEMED) ausgelöst. Für die Analyse der Fraktionen von $\mathrm{CB}_{\mathrm{SH}_{3},}, \mathrm{CB} 2_{\mathrm{SH} 3+}$ und $\mathrm{CB}_{\mathrm{SH} 3+} / \mathrm{W} 24 \mathrm{~A}-$ E262A wurden Trenngele mit einer Polyacrylamid-Konzentration von $12.5 \%$ und Sammelgele mit $5 \%$ verwendet.

Zur Auftrennung des kleineren CB2 $\mathrm{PH}$ wurde das TRIS-Tricin-Puffersystem nach Schägger verwendet. ${ }^{[41]}$ Die Zusammensetzung der jeweiligen Gele ist in Tabelle 5 zusammengefasst. Das Trenngel wurde laut Anleitung gegossen, mit Isopropanol überschichtet und in $30 \mathrm{~min}$ auspolymerisiert. Anschließend wurde das Isopropanol entfernt und die Sammelgellösung auf das Trenngel pipettiert. Für die Probentaschen wurde ein Kamm in das noch flüssige Sammelgel gesteckt. Nach 
45 min war das Gel komplett auspolymerisiert und wurde in das ElektrophoreseSystem eingesetzt. Die Kammer wurde mit Elektrophoresepuffer gefüllt und der Kamm aus den Probentaschen entfernt. Im Falle des Schägger-Gels wurden zwei verschiedene Puffer verwendet. Der Kathodenpuffer wurde dabei zwischen die Gele und der Anodenpuffer außen in die Kammer gegossen. Für die Probenvorbereitung wurden $15 \mu \mathrm{L}$ der zu untersuchenden Fraktion mit $15 \mu \mathrm{L}$ 2x-Probenpuffer gemischt. Zur Denaturierung wurden die Proben unter Schütteln erhitzt $\left(85^{\circ} \mathrm{C}, 5 \mathrm{~min}\right.$, $300 \mathrm{rpm})$ und anschließend auf das Gel aufgetragen. Zusätzlich wurde eine Probentasche des Gels mit einem Größenstandard (PageRuler Prestained Protein Ladder, Thermo Scientific, Schwerte, Deutschland) beladen. Es wurde eine Spannung von $250 \mathrm{~V}$ angelegt. Nach ca. 45 min war die elektrophoretische Auftrennung beendet. Das Trenngel wurde zweimal in Reinstwasser in der Mikrowelle aufgekocht und jeweils für 1 min geschwenkt. Anschließend wurde das Gel kurz in Färbelösung aufgekocht und für 5 min auf dem Schwenkbrett inkubiert. Die Färbelösung wurde entfernt und das Gel für 30 min in Entfärbelösung eingelegt. Nach dem Entfärben wurde das Gel zwischen zwei Cellophanfolien getrocknet. Die verwendeten Lösungen sind in Tabelle 5 zusammen gefasst.

Tabelle 5: Lösungen und Zusammensetzungen der Gele für die SDS-PAGE.

Name

Probenpuffer (2x)

Trenngel-Stammlösung
Zusammensetzung

$125 \mathrm{~mm}$ TRIS/HCl, pH 6.8, $100 \mathrm{mM}$ DTT, $20 \%(v / v)$ Glycerol, $2 \% \quad(w / v) \quad$ SDS, $0.02 \% \quad(w / v) \quad$ Bromphenolblau

$258 \mathrm{mM}$ TRIS/HCl, pH 6.8, $12.5 \%(w / v)$ Acrylamid/

Bisacrylamid (37.5:1), $0.1 \%(w / v)$ SDS 
Sammelgel-Stammlösung $127 \mathrm{mM}$ TRIS/HCl, pH 6.8, $5.2 \%(w / v)$ Acrylamid/ Bisacrylamid (37.5:1), $0.1 \%(w / v)$ SDS

Ammoniumperoxodisulfat $\quad 10 \%(w / v)$ APS in Reinstwasser

$12.5 \%$ Trenngel

$4 \mathrm{~mL}$ Trenngel-Stammlsg., $40 \mu \mathrm{L}$ APS, $2 \mu \mathrm{L}$ TEMED

$5 \%$ Sammelgel

$2 \mathrm{~mL}$ Sammelgel-Stammlsg., $20 \mu \mathrm{L}$ APS, $2 \mu \mathrm{L}$ TEMED

Elektrophoresepuffer

$25 \mathrm{~mm}$ TRIS, $192 \mathrm{~mm}$ Glycin, $0.1 \%(w / v)$ SDS

Schägger-Gelpuffer

$3 \mathrm{M}$ TRIS/HCl pH 8.45, $0.3 \%(w / v)$ SDS

Schägger-Trenngel (10 \%) $1.66 \mathrm{~mL} \quad$ Acrylamid/Bisacrylamid $\quad(37.5: 1), \quad 1.67 \mathrm{~mL}$

Gelpuffer, 1.06 mL $50 \%$ Glycerin, $570 \mu \mathrm{L}$ Reinstwasser, $50 \mu \mathrm{L}$ APS, $6 \mu \mathrm{L}$ TEMED

Schägger-Sammelgel (4 \%) $\quad 1.23 \mathrm{~mL} \quad$ Reinstwasser, $\quad 500 \mu \mathrm{L} \quad$ Gelpuffer, $\quad 266 \mu \mathrm{L}$ Acrylamid/Bisacrylamid (37.5:1), $13 \mu \mathrm{L} \quad$ APS, $5 \mu \mathrm{L}$ TEMED

Schägger-Anodenpuffer $200 \mathrm{mM}$ TRIS/HCl, pH 8.9

Schägger-Kathodenpuffer

$100 \mathrm{~mm}$ TRIS, $100 \mathrm{~mm}$ Tricin, $0.1 \%(w / v)$ SDS

Coomassie-Färbelösung $94 \mu \mathrm{M}$ Coomassie Brilliant Blau G-250, $35 \mathrm{~mm} \mathrm{HCl}$

Entfärbelösung $5 \%(v / v)$ Methanol, $7.5 \%(v / v)$ Essigsäure 


\subsubsection{Western-Blot}

Zum immunologischen Nachweis des isolierten $\mathrm{CB} 2_{\mathrm{SH} 3-}$ wurde in dieser Arbeit ein Western-Blot durchgeführt. Dazu wurde eine SDS-PAGE mit einem $12.5 \%$ Trenngel durchgeführt. Die Protein- und Markerbanden aus dem Gel wurden anschließend auf eine Nitrocellulosemembran übertragen, da sie im Gel nicht für Antikörper zugänglich sind. Dazu wurde das Gel auf eine Nitrocellulosemembran gelegt und das System mit jeweils zwei Filterpapieren auf jeder Seite eingefasst. Vor dem Zusammenbau der Blotting-Apparatur wurden alle Bestandteile für 30 min in Blotting-Puffer inkubiert. Das eigentliche Blotten wurde durch Anlegen einer Spannung (15 V, $45 \mathrm{~min})$ induziert. Die Proteine bleiben durch hydrophobe Wechselwirkungen an der Nitrocellulosemembran haften. Die Membran wurde durch dreiminütiges Einlegen in $0.2 \%(w / v)$ PonceauS-Lösung angefärbt und die sichtbar gewordenen Markerbanden markiert. Die nicht besetzten Bindungsstellen auf der Membran wurden durch Schwenken in einer $5 \%(w / v)$ Magermilch-Lösung in TBTPuffer blockiert (1 h, RT). Dabei hat sowohl die Magermilch, als auch das im Puffer enthaltene Tween 20 blockierende Eigenschaften. ${ }^{[42]}$ Anschließend wurde die Membran mit dem Primärantikörper, einem polyklonalen anti-Collybistin-Antikörper (rabbit anti-Collybistin, $\mathbf{c}=1: 1000$, Synaptic Systems, Göttingen), in $5 \%(w / v)$ Magermilch/TBT-Puffer über Nacht bei $4{ }^{\circ} \mathrm{C}$ inkubiert. Durch dreimaliges Waschen mit TBT-Puffer wurde ungebundener Antikörper entfernt. Die Membran wurde für $1 \mathrm{~h}$ mit dem Sekundärantikörper in TBT-Puffer mit $5 \%(w / v)$ Magermilch inkubiert (goat anti-rabbit IgG-HRP, c = 1:2000, Santa Cruz Biotechnology, Heidelberg, Deutschland). Nach dreimaligem Spülen mit TBT-Puffer und Reinstwasser wurde der Blot in der Dunkelkammer entwickelt. Dabei findet eine Oxidation von Luminol statt, die durch eine Peroxidase-Funktionalität (POD) am Sekundärantikörper katalysiert wird. Die resultierende Chemilumineszenz wird mittels Röntgenfilm 
detektiert. Zur Entwicklung wurde die Membran für zwei Minuten mit einer frischen Lösung aus je $1 \mathrm{~mL}$ ECL-1- und ECL-2-Lösung benetzt. Der Röntgenfilm wurde aufgelegt und für $10 \mathrm{~s}$ belichtet. Der Film wurde nacheinander in Entwickler- und Fixierlösung geschwenkt und anschließend getrocknet. Die Zusammensetzungen der verwendeten Puffer und Lösungen sind in Tabelle 6 dargestellt.

Tabelle 6: Puffer und Lösungen für den Western-Blot.

\begin{tabular}{|c|c|}
\hline Name & Zusammensetzung \\
\hline \multirow[t]{4}{*}{ Blotting-Puffer } & $20 \mathrm{mM}$ TRIS \\
\hline & $150 \mathrm{~mm}$ Glycin \\
\hline & $0.05 \%(w / v) \operatorname{SDS}$ \\
\hline & $20 \%(v / v)$ Methanol \\
\hline \multirow[t]{3}{*}{ TBT-Puffer } & 10 mM TRIS/HCl, pH 7.4 \\
\hline & $150 \mathrm{~mm} \mathrm{NaCl}$ \\
\hline & $0.2 \%(v / v)$ Tween 20 \\
\hline \multirow[t]{3}{*}{ ECL-1-Lösung } & 100 mM TRIS/HCl, pH 8.5 \\
\hline & $2.5 \mathrm{mM}$ Luminol \\
\hline & $0.4 \mathrm{mM}$ Coumarinsäure \\
\hline \multirow[t]{2}{*}{ ECL-2-Lösung } & 100 mM TRIS/HCl, pH 8.5 \\
\hline & $0.06 \%(v / v) \mathrm{H}_{2} \mathrm{O}_{2}$ \\
\hline
\end{tabular}




\subsubsection{Lipid-overlay Assay}

Die Collybistin-Isoformen CB2 $2_{\mathrm{SH} 3-}$ und $\mathrm{CB}_{\mathrm{SH} 3+} / \mathrm{W} 24 \mathrm{~A}-\mathrm{E} 262 \mathrm{~A}$ wurden, wie in 3.1.6 beschrieben, aufgereinigt. Um die Phosphatidylinositolphosphat (PIP)-Spezifität dieser Isoform zu detektieren, wurden inositol snooper (Avanti Polar Lipids, Alabama, USA) genutzt. Dabei handelt es sich um eine Nitrocellulosemembran, auf der verschiedene Phosphatidylinositolphosphate und Referenzlipide aus organischem Lösungsmittel eingetrocknet wurden. Die nicht besetzten Bindungsstellen auf der Membran wurden mit $1 \%(w / v)$ Magermilch oder $3 \%(w / v)$ BSA in TBS-Puffer (Tabelle 7) blockiert. Anschließend wurden verschiedene Proteinkonzentrationen in TBS-T Puffer mit $1 \%(w / v)$ Magermilch oder $3 \%(w / v)$ BSA zugegeben und für $1.5 \mathrm{~h}$ auf dem Schwenkbrett inkubiert. Die Membranen wurden dreimal mit TBS-TPuffer gespült. Zur Immunodetektion wurde der Primärantikörper, ein polyklonaler anti-Collybistin-Antikörper (rabbit anti-Collybistin, $c=1: 1000$, Synaptic Systems, Göttingen, Deutschland) in TBS-T-Puffer mit $1 \%(w / v)$ Magermilch/ oder $3 \%$ $(w / v)$ BSA zugegeben. Nach einer Inkubationszeit von $1.5 \mathrm{~h}$ wurde erneut dreimal mit TBS-T-Puffer gespült. Die Membranen wurden für 45 min mit dem Sekundärantikörper (goat anti-rabbit IgG-HRP, $\quad c=1: 10.000$, Santa Cruz Biotechnology, Heidelberg, Deutschland) in TBS-T-Puffer mit $1 \%(w / v)$ Magermilch oder $3 \%(w / v)$ BSA inkubiert. Die gebundenen Proteine wurden analog der in 3.1.9 beschriebenen Methode über die Chemilumineszenz von Luminol detektiert. 
Tabelle 7: Zusammensetzung von TBS- und TBS-T-Puffer

Name Zusammensetzung

TBS $\quad 0.8 \% \mathrm{NaCl}, 20 \mathrm{~mm}$ TRIS/HCl, pH 7.4, 1 mM EDTA

TBS-T

$0.8 \% \mathrm{NaCl}, 20 \mathrm{~mm}$ TRIS/HCl, pH 7.4, 1 mM EDTA, $0.1 \%(v / v)$ Tween

\subsubsection{Bestimmung der Proteinkonzentration}

Die Proteinkonzentration wurde über die UV-Absorption bei $\lambda=280 \mathrm{~nm}$ bestimmt. Hierbei wird die Absorbanz $A_{280}$ der Proteine vor allem durch die aromatischen Aminosäure Tryptophan und Tyrosin und zu kleinerem Anteil von Phenylalanin bestimmt. ${ }^{[43]}$ Diese Methode hat den Vorteil, dass keine zusätzlichen Reagenzien notwendig sind, sodass das Protein nach der Messung weiter verwendet werden kann. Das Lambert-Beersche Gesetz (Gl. (2)) beschreibt das Verhältnis zwischen der Intensität von Licht vor und nach dem Durchtritt durch eine Probe. Die resultierende Absorbanz $A$ ist linear von der Konzentration der Proteinlösung $c$ und der Schichtdicke $l$ abhängig:

$$
A=-\lg \frac{I}{I_{0}}=\varepsilon \cdot l \cdot c
$$

$\varepsilon$ ist der molare Extinktionskoeffizient des jeweiligen Proteins. Tabelle 8 zeigt die molaren Extinktionskoeffizienten der Collybistin-Isoformen. Diese wurden über ProtParam bestimmt. ${ }^{[4]}$ Nukleinsäuren absorbieren, wie unter 3.1.3 beschrieben, bei 
$\lambda=260 \mathrm{~nm}$. Bei der Überprüfung des Proteins auf Verunreinigungen mit DNA sollte das Verhältnis von $A_{260} / A_{280}$ bei sauberem Protein ungefähr 0.5 betragen.

Tabelle 8: Molare Extinktionskoeffizienten der Collybistin-Isoformen

\begin{tabular}{ccccc}
\hline & $\mathrm{CB}_{\mathrm{PH}}$ & $\mathrm{CB} 2_{\mathrm{SH} 3-}$ & $\mathrm{CB}_{\mathrm{SH} 3+}$ & $\mathrm{CB}_{\mathrm{SH} 3+} / \mathrm{W} 24 \mathrm{~A}-\mathrm{E} 262 \mathrm{~A}$ \\
\hline $\boldsymbol{\varepsilon}\left[\mathrm{M}^{-1} \mathbf{c m}^{-1}\right]$ & 37.930 & 70.000 & 98.945 & 93.445 \\
\hline
\end{tabular}




\subsection{Präparative Methoden}

\subsubsection{Herstellung von Lipidfilmen}

In dieser Arbeit wurde das Lipid 1-Palmitoyl-2-oleoyl-sn-glycero-3-phosphocholin (POPC) als Matrixlipid für alle Messungen verwendet. Zusätzlich wurden 1Palmitoyl-2-oleoyl-sn-glycero-3-phospho-L-serin (POPS) als negativ geladenes Lipid, 1-Palmitoyl-2-oleoyl-sn-glycero-3-phospho-(1'-rac-glycerol) (POPG) als negativ geladenes Lipid mit freien Hydroxylgruppen in der Kopfgruppe und L- $\alpha$ Phosphatidylinositol (Soja, PI) als nicht-phosphorylierte Referenz für die Phosphatidylinositolphosphate eingesetzt. Weiterhin wurden die in Tabelle 9 gezeigten Phosphatidylinositolphosphate (PIPs) mit gesättigten C-16 Fettsäureketten (Echelon Biosciences, Salt Lake City, USA) verwendet.

Tabelle 9: Struktur und Namen der verwendeten Phosphatidylinositolphosphate als Natriumsalze.

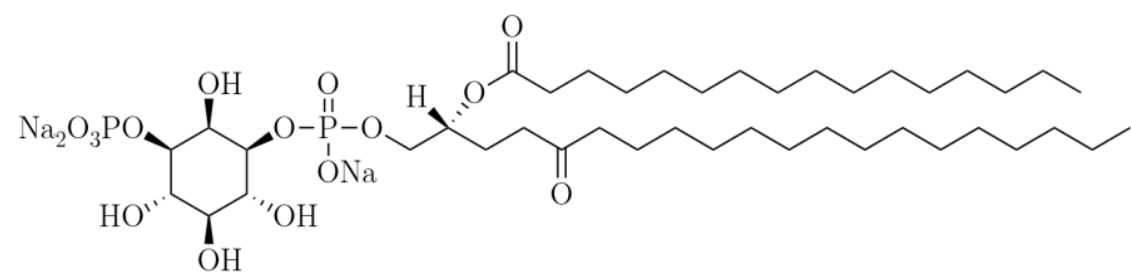

Phosphatidylinositol-3-phosphat, PI(3)P

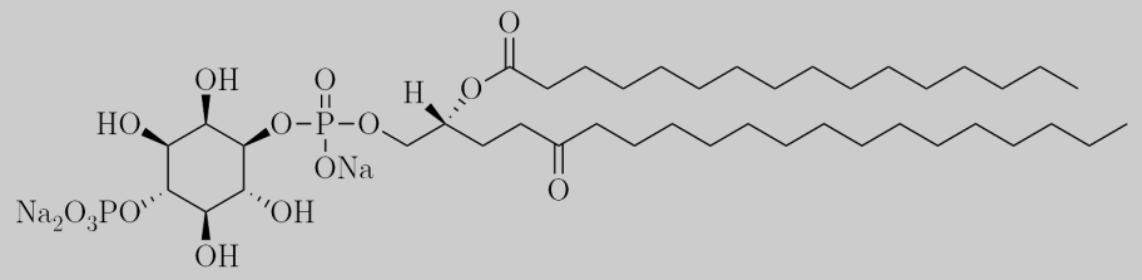

Phosphatidylinositol-4-phosphat, PI(4)P 


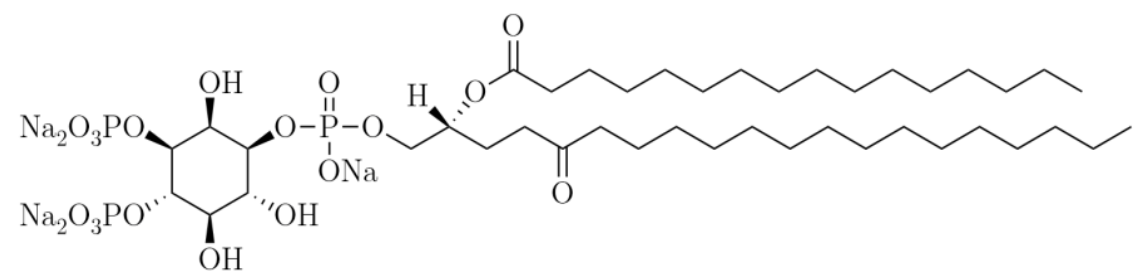

Phosphatidylinositol-3,4-bisphosphat, $\mathrm{PI}(3,4) \mathrm{P}_{2}$

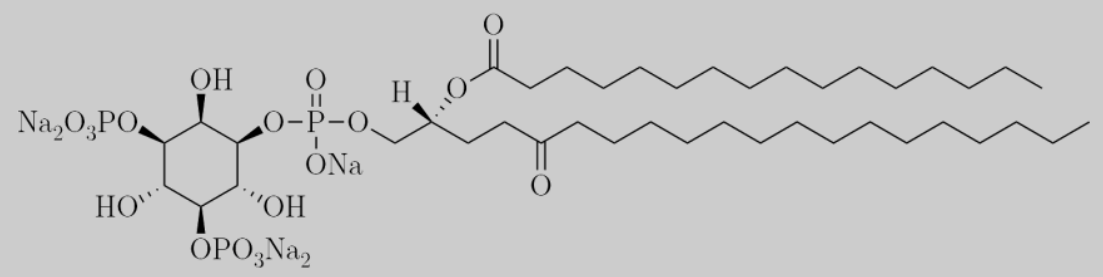

Phosphatidylinositol-3,5-bisphosphat, $\mathrm{PI}(3,5) \mathrm{P}_{2}$

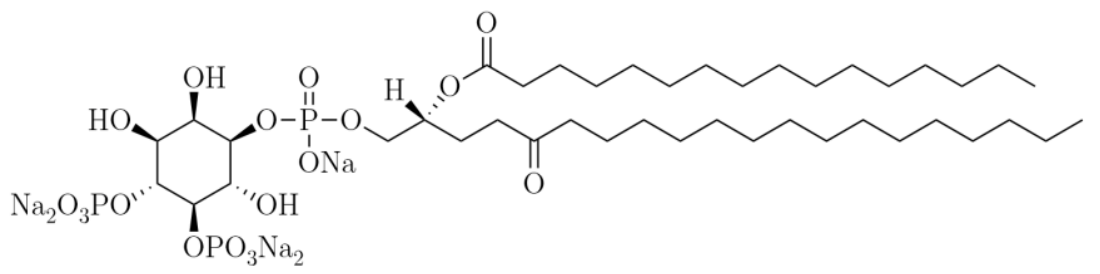

Phosphatidylinositol-4,5-bisphosphat, $\mathrm{PI}(4,5) \mathrm{P}_{2}$

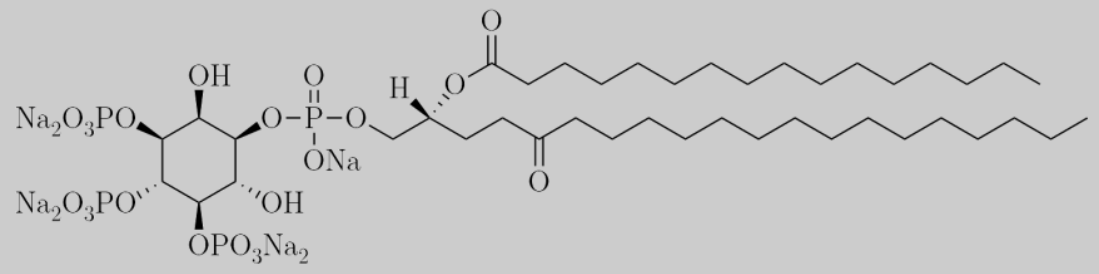

Phosphatidylinositol-3,4,5-trisphosphat, $\mathrm{PI}(3,4,5) \mathrm{P}_{3}$

Es wurden Stammlösungen der verschiedenen Lipide mit Konzentrationen zwischen $1 \mathrm{mg} / \mathrm{mL}$ und $10 \mathrm{mg} / \mathrm{mL}$ in Chloroform hergestellt. Die Phosphatidylinositolphosphate (PIPs) wurde in der vom Hersteller für jedes Molekül spezifizierten Chloroform/Methanol/Wasser-Mischung gelöst. Die Stammlösungen wurden zur Herstellung eines Lipidfilms im benötigten molaren Verhältnis in ein Reagenzglas mit $200 \mu \mathrm{L}$ Chloroform pipettiert. Wenn nicht anders angegeben, 
wurden Lipidfilme mit einer Gesamtlipidmenge von $0.4 \mathrm{mg}$ und einem molaren Verhältnis von 9:1 verwendet, wobei POPC als Matrixlipid diente. Die organischen Lösungsmittel wurden erst im Stickstoffstrom bei Raumtemperatur verblasen und anschließend im Vakuum $\left(32{ }^{\circ} \mathrm{C}, \geq 3 \mathrm{~h}\right)$ rückstandslos entfernt. Die Lagerung erfolgte bis zur Verwendung bei $4{ }^{\circ} \mathrm{C}$.

\subsubsection{Vesikelpräparation}

Es wurden kleine unilamellare Vesikel (small unilamellar vesicles, SUVs) über die Ultraschallmethode hergestellt. Dazu wurden $500 \mu \mathrm{L}$ des entsprechenden Spreitpuffers auf den Lipidfilm gegeben und dieser für 20 min hydratisiert. Die Suspension wurde auf dem Vortex-Mixer geschüttelt ( $3 \mathrm{x} 30 \mathrm{~s}$, mit 5 min Pause). Dies führte zur Ausbildung von multilamellaren Vesikeln, die durch $30 \mathrm{~min}$ Ultraschallbehandlung (Sonopuls HD 2070 Becherresonator, Bandelin, Berlin, Deutschland) in kleine unilamellare Vesikel überführt wurden.

\subsubsection{Hydrophilisierung von $\mathrm{Si}$-Wafern}

Für die RIfS-Messungen wurden Silicium-Wafer (P/Bor, $<100>, 5000 \mathrm{~nm} \pm 5 \%$ $\mathrm{SiO}_{2}$, Active Business Company GmbH, Brunnthal, Deutschland) mit einer $5 \mu \mathrm{m}$ dicken Oxid-Schicht verwendet. Die Silicium-Wafer wurden mithilfe eines faseroptischen Ritzgriffels auf eine Größe von $2 \mathrm{~cm}$ x $1 \mathrm{~cm}$ zugeschnitten und mit Ethanol p.a und Reinstwasser gespült. Um auf den Si-Wafern durch Spreiten von kleinen unilamellaren Vesikeln eine Lipiddoppelschicht zu erzeugen, wurden diese hydrophilisiert. Die Wafer wurden in einem Bad aus Reinstwasser, $25 \%$ wässriger 
Ammoniaklösung und 30 \%iger Wasserstoffperoxidlösung $(5: 1: 1)$ inkubiert $\left(75^{\circ} \mathrm{C}\right.$, 20 min). Die Wafer wurden mit Reinstwasser gespült, im Stickstoffstrom getrocknet und für $1 \mathrm{~min}$ im Sauerstoffplasma (ZEPTO, Diener electronic GmbH, Ebhausen, Deutschland) oxidiert. Bis zur Verwendung konnten sie bis zu 3 Tage in Reinstwasser gelagert werden.

\subsubsection{Verwendete Puffer}

\section{Phosphat-Puffer:}

$250 \mathrm{mM} \mathrm{KCl}, 20 \mathrm{mM} \mathrm{KH}_{2} \mathrm{PO}_{4} / \mathrm{K}_{2} \mathrm{HPO}_{4}, 2 \mathrm{mM}$ EDTA, pH 7.4

\section{TRIS-Puffer:}

$150 \mathrm{~mm} \mathrm{NaCl}, 20 \mathrm{~mm}$ TRIS/HCl, pH 7.4

\section{HEPES-Puffer:}

$100 \mathrm{~mm} \mathrm{NaCl}, 25 \mathrm{~mm}$ HEPES/NaOH, $0.5 \mathrm{~mm}$ EDTA, $0.5 \mathrm{~mm}$ DTT, pH 7.2

\section{Citratpuffer-4.8/Citratpuffer-6.4}

$50 \mathrm{~mm} \mathrm{KCl}, 20 \mathrm{~mm}$ Citrat, $0.1 \mathrm{~mm}$ EDTA, $0.1 \mathrm{~mm} \mathrm{NaN}_{3}$, pH 4.8 bzw. pH 6.4 


\subsection{Biophysikalische Methoden}

\subsubsection{Reflektometrische Interferenzspektroskopie}

Die reflektometrische Interferenzspektroskopie (RIfS) wurde in dieser Arbeit als nicht-invasiver biochemischer Sensor zur Bestimmung von Schichtdicken genutzt. Die Methode basiert auf dem Prinzip der Weißlichtinterferenz.

\section{Theoretische Grundlagen}

Wenn Weißlicht mit einem bestimmten Einfallswinkel auf ein Objekt fällt, muss das Licht die Oberfläche der Probe durchdringen, um mit dem Material des Objekts zu wechselwirken, wobei mehrere physikalische Phänomene auftreten:

- Transmission T, d.h. Durchtritt durch die Probe

- Reflektion R, d.h. Spiegelung an der Probe

- Diffuse Streuung S

- Absorption A an der Probenoberfläche oder im Probenvolumen

Sie sind durch das Verhältnis der eingestrahlten Lichtintensität $I_{\mathrm{I}}$ z.B. zur reflektierten Lichtintensität $I_{\mathrm{R}}$ definiert: ${ }^{[45]}$

$$
R \equiv \frac{I_{R}}{I_{I}}
$$

Die Transmission, die Streuung und die Absorption sind analog zu Gl. (3) definiert:

$$
T \equiv \frac{I_{T}}{I_{I}}(4 \mathrm{a}) \quad S \equiv \frac{I_{S}}{I_{I}}(4 \mathrm{~b}) \quad A \equiv \frac{I_{A}}{I_{I}}(4 \mathrm{c})
$$


Durch den Energieerhaltungssatz im System gilt außerdem Gl. (5):

$$
T+R+A+S=1
$$

Für die reflektometrische Interferenzspektroskopie werden ausschließlich die Reflektion und die Transmission an einem transparenten Substrat betrachtet. Trifft ein Lichtstrahl aus einem Medium mit dem Brechungsindex $n_{1}$ auf ein Medium mit dem Brechungsindex $n_{2}$, werden drei Fällen unterschieden (Abbildung 8).
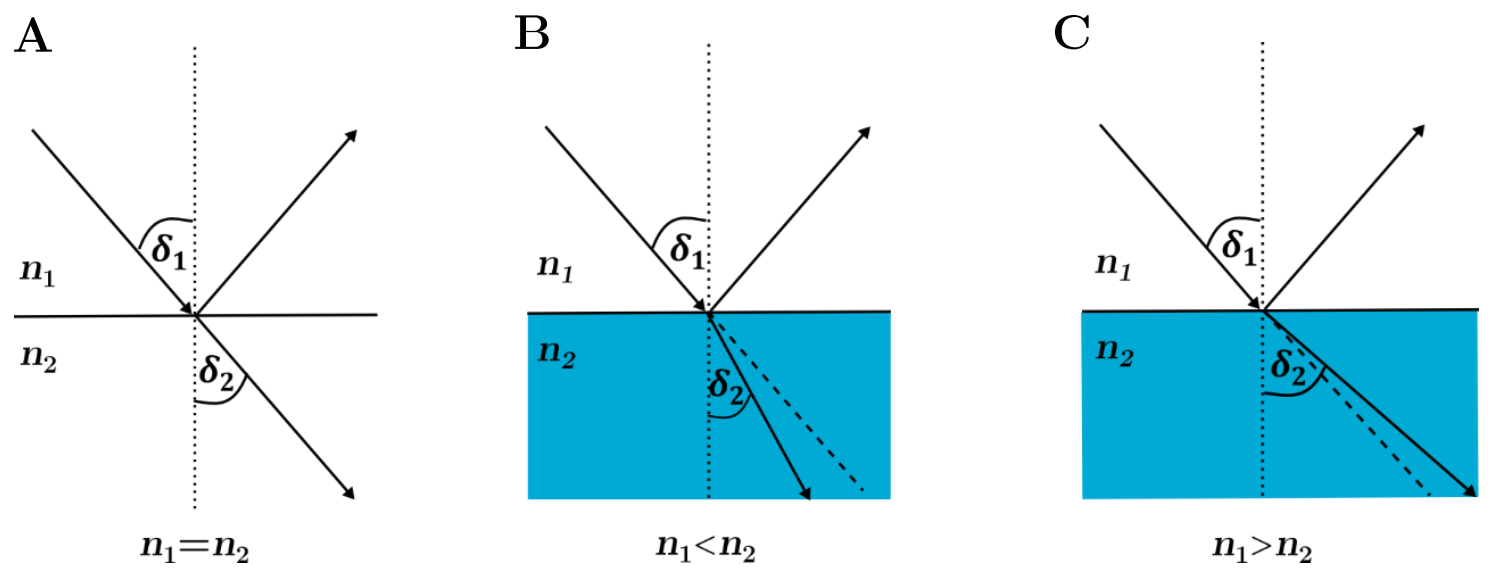

Abbildung 8: Die Brechung von unter dem Winkel $\delta_{1}$ einfallendem Licht aus einem Medium mit dem Brechungsindex $n_{1}$ in ein Medium mit dem Brechungsindex $n_{2}$ unter dem Brechungswinkel $\delta_{2}$. $\underline{A}$ : Wenn beiden Medien den gleichen Brechungsindex aufweisen $\left(n_{1}=n_{2}\right)$, wird das Licht nicht gebrochen. Es gilt: $\delta_{1}=\delta_{2}$. B: Ist der Brechungsindex des Ausgangsmediums $n_{1}$ kleiner als $n_{2}$, wird das Licht zum Lot hin gebrochen $\left(\delta_{1}>\delta_{2}\right)$. $\underline{\text { : Wenn }} n_{1}>n_{2}$, wird das Licht vom Lot weg gebrochen. Es gilt: $\delta_{1}<\delta_{2}$.

Der Einfallswinkel und der Brechungswinkel des Lichts werden im Snelliusschen Brechungsgesetz durch den Quotienten der Brechungsindices dargestellt (Gl. (6): ${ }^{[4]}$

$$
\frac{n_{2}}{n_{1}}=\frac{\sin \delta_{1}}{\sin \delta_{2}}
$$

Im Messsystem tritt eine Lichtwelle aus dem umgebenden Medium (Puffer, $\left.n_{1}=1.33\right)^{[47]}$ in einem bestimmten Winkel $\delta_{1}$ auf die Grenzfläche zu einer Siliciumdioxidschicht $\left(n_{2}=1.46\right)^{[48]}$ mit der Schichtdicke $d$. Dabei wird die Lichtwelle 
sowohl unter dem Winkel $\delta_{1}$ reflektiert, als auch im Winkel $\delta_{2}$ zum Lot gebrochen. Die transmittierte Lichtwelle trifft nach dem Durchlaufen von $d$ auf eine totalreflektierende Siliciumoberfläche $\left(n_{3}=3.44\right)$ und wird beim Austritt aus der Siliciumdioxidschicht erneut gebrochen.

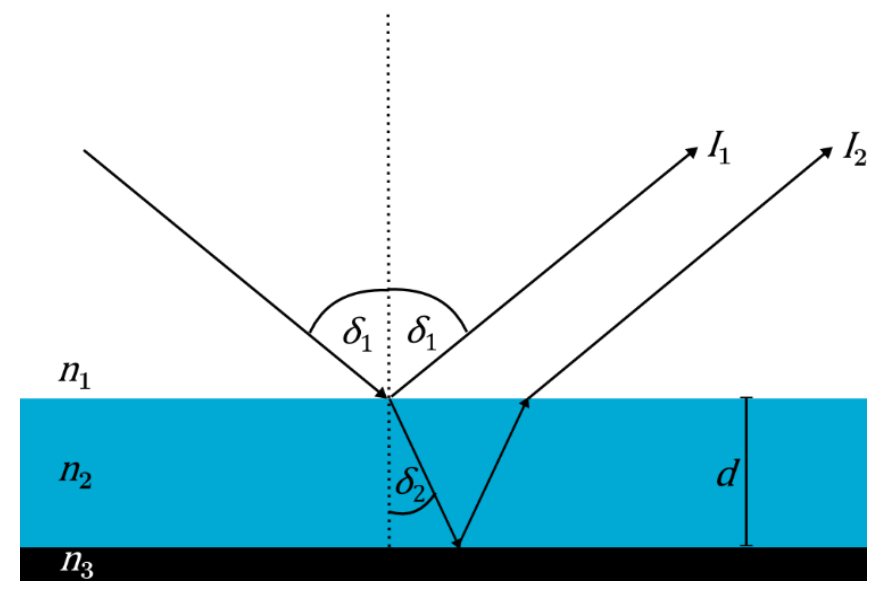

Abbildung 9: Strahlengang bei der reflektometrischen Interferenzspektroskopie. Weißlicht trifft unter dem Einfallswinkel $\delta_{1}$ aus dem Medium mit dem Brechungsindex $n_{1}$ auf die Interferenzschicht mit dem Brechungsindex $n_{2}$. Dabei wird ein Teil der Lichtwelle unter dem Winkel $\delta_{1}$ reflektiert, ein anderer Teil wird in die Siliciumdioxidschicht transmittiert und aufgrund des höheren Brechungsindices $n_{2}$ zum Lot gebrochen. Die transmittierte Lichtwelle wird an der totalreflektierenden Siliciumoberfläche $\left(n_{3}\right)$ reflektiert und an der Grenze zwischen Siliciumdioxidschicht und dem umgebenden Medium erneut gebrochen.

Die transmittierte Lichtwelle mit der Intensität $I_{2}$ hat beim Austritt aus dem Medium einen um die Strecke $s$ längeren Weg zurückgelegt, als die anfangs reflektierte Lichtwelle mit der Intensität $I_{1}$.

$$
s=\frac{2 d}{\cos \delta_{2}}
$$

Für die optische Weglänge $L$ der transmittierten Lichtwelle ergibt sich:

$$
L=n_{2} s=\frac{2 n_{2} d}{\cos \delta_{2}}
$$

Bei einem Einfallswinkel $\delta_{1}=0=\delta_{2}$ vereinfacht sich Gleichung (8) zu: 


$$
L=2 n_{2} d
$$

Die Lichtwellen mit den Intensitäten $I_{1}$ und $I_{2}$ haben eine unterschiedliche optische Weglänge zurückgelegt. Daraus resultiert ein Gangunterschied $\Delta s$, sodass die Maxima und Minima der Lichtwellen gegeneinander verschoben sind. Die Verschiebung und die daraus resultierende Interferenz der Lichtwellen wird durch den Phasenunterschied $\Delta \varphi$ zwischen den Wellen beschrieben.

$$
\Delta \varphi=\frac{\Delta s}{\lambda} 2 \pi
$$

Die maximale konstruktive Interferenz tritt auf, wenn die optische Weglänge ein Vielfaches $j$ der eingestrahlten Wellenlänge ist. ${ }^{[49]}$

$$
j \lambda_{\text {max }}=2 n_{2} d \quad \text { mit } j \in \mathbb{N}
$$

Das Interferenzmuster in den Experimenten ist damit vom Brechungsindex $n_{2}$ und der physikalischen Schichtdicke $d$ der Siliciumdioxidschicht abhängig. Adsorbieren Moleküle auf der Siliciumdioxidschicht, so verändert sich die physikalische Schichtdicke und der Brechungsindex der Interferenzschicht. Das Interferenzmuster wird zu höheren Wellenlängen verschoben. Das verwendete Weißlicht zeichnet sich dabei durch eine kurze Kohärenzlänge aus, sodass die auftretenden Interferenzen einen geringeren Gangunterschied als die Kohärenzlänge haben müssen. Der Abstand der Interferenzschichten muss deshalb zwischen $0.5-30 \mu \mathrm{m}$ liegen und damit viel kleiner sein, als die Kohärenzlänge des eingestrahlten Lichts: ${ }^{[50]}$

$$
d \ll \frac{\lambda^{2}}{2 \pi n \Delta \lambda}
$$

Dies wird im Experiment durch die Verwendung von $5 \mu \mathrm{m}$ dicken, transparenten Siliciumdioxidschichten als Transmissionsmedium erreicht. 
Auswertung der aufgenommenen Reflektivitätsspektren

Die Messungen wurden mit einem NanoCalc-2000 vis/NIR-Spektrometer (Ocean Optics, Dunedin, USA) durchgeführt und über die geräteeigene Software SPECTRA SuITE aufgezeichnet. Dabei wurden zeitaufgelöst Intensitätsspektren aufgenommen. Aus dem gemessenen Intensitätsspektrum und Referenzspektren wurde über Gl. (13) ein Reflektivitätsspektrum berechnet. ${ }^{[51]}$

$$
R=\frac{I_{m}-I_{d}}{I_{r}-I_{d}}
$$

Dabei ist $I_{\mathrm{m}}$ das aktuelle Intensitätsspektrum, $I_{\mathrm{d}}$ ein Dunkelspektrum bei geschlossenem Shutter und $I_{\mathrm{r}}$ ein Referenzspektrum. Das Referenzspektrum wurde auf einer hochspiegelnden Aluminiumoberfläche in Reinstwasser gemessen.

A

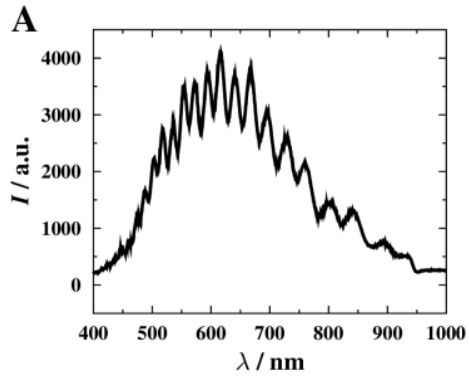

B

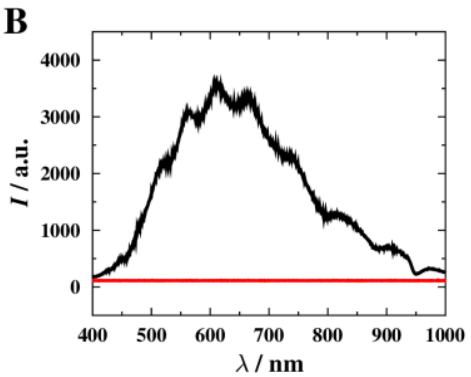

C

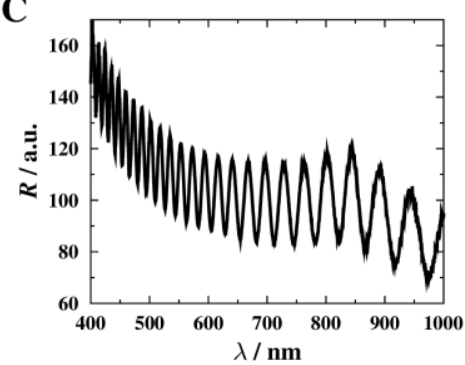

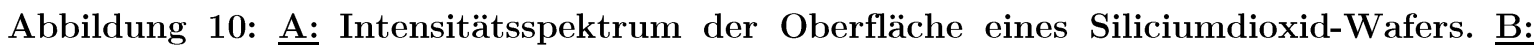
Referenzspektrum $I_{\mathrm{r}}$ (schwarz), aufgenommen auf einer hochpolierten Aluminiumoberfläche, und Dunkelspektrum $I_{\mathrm{d}}$ (rot) bei geschlossenem Shutter. C: Aus den Intensitätsspektren resultierendes Reflektivitätsspektrum (nach Gl. (13).

An das Reflektivitätsspektrum wurde innerhalb des Wellenlängenbereichs von $\lambda=(500-700) \mathrm{nm}$ ein Polynomfit angepasst. Dieser basiert auf der Phasenverschiebung $\varphi$ der reflektierten Lichtwellen, welche nach dem Superpositionsprinzip ein spezifisches Interferenzmuster zeigen (Gl. (14):[46]

$$
\varphi=\frac{2 \pi}{\lambda} d n_{2} \cos \delta_{1}
$$


Da der Einfallswinkel $\delta_{1}=0$ ist, wird $\cos \left(\delta_{1}\right)=1$. Das Produkt aus Brechungsindex $n_{2}$ und physikalischer Schichtdicke $d$ wird als optische Schichtdicke OT bezeichnet, sodass sich Gleichung (14) vereinfacht zu:

$$
\varphi=\frac{2 \pi}{\lambda} n_{2} d=\frac{2 \pi}{\lambda} O T
$$

Betrachtet man eine Welle mit gleicher Amplitude, aber unterschiedlicher Energie, so wird die Reflektivität im vorliegenden Fall von nicht-absorbierenden dünnen Schichten durch Gleichung (16) beschrieben:

$$
R=\frac{r_{12}^{2}+r_{23}^{2}+2 r_{12} r_{23} \cos 2 \varphi}{1+r_{12}^{2} r_{23}^{2}+2 r_{12} r_{23} \cos 2 \varphi}=\frac{r_{12}^{2}+r_{23}^{2}+2 r_{12} r_{23} \cos \left(\frac{4 \pi}{\lambda} O T\right)}{1+r_{12}^{2} r_{23}^{2}+2 r_{12} r_{23} \cos \left(\frac{4 \pi}{\lambda} O T\right)}
$$

Die Fresnel-Koeffizienten $r_{12}$ und $r_{23}$ beschreiben dabei das Teilungsverhältnis des einfallenden Lichts. Dieses wird durch das Verhältnis der Differenzen der Brechungsindices zur Summe der Brechungsindices bestimmt (Gl. (17)):

$$
r_{12}=\frac{n_{1}-n_{2}}{n_{1}+n_{2}} \quad r_{23}=\frac{n_{2}-n_{3}}{n_{2}+n_{3}}
$$

Alle aufgenommenen Reflektivitätsspektren werden im Wellenlängenbereich $\lambda=(500-700) \mathrm{nm}$ nach Gleichung (16) angepasst, sodass sich für jedes Spektrum eine optische Schichtdicke OT ergibt. Diese wird über eine MATLAB-Routine zeitaufgelöst dargestellt. ${ }^{[49]}$ 
Messaufbau und experimentelle Durchführung

Der Aufbau eines RIfS-Experiments ist in Abbildung 11 schematisch dargestellt. Die Messzelle besteht aus einem Aluminiumboden und wird über einen Acrylglasdeckel abgedichtet. Außerdem ist das System über den Acrylglasdeckel mit dem Schlauchsystem verbunden. Die Flüssigkeit wird hierbei über eine Peristaltikpumpe zur Messzelle gepumpt.

Auf den Aluminiumboden der Messzelle wird ein Siliciumwafer mit $5 \mu \mathrm{m}$ Oxidschichtdicke gelegt. Über dem in die Messzelle eingebauten Wafer wird eine gegabelte, optische Faser installiert. Diese besteht aus sechs kreisförmig angeordneten beleuchteten Fasern einer Wolfram-Halogenlampe $(\lambda=(350-950) \mathrm{nm})$ und einer mittig angeordneten sammelnden Faser. Über die sammelnde Faser kommt das Reflektivitätssignal zum Spektrometer. Hier wird das ankommende Signal nach Wellenlängen separiert und zum UV/Vis-Silicium-CCD-Detektor (2048 Pixel) geleitet. Das Probenvolumen wird über einen eingefrästen Kanal im Acrylglasdeckel auf die Siliciumdioxidschicht geleitet. Der flüssigkeitsgefüllte Bereich ist dabei etwa $30 \mathrm{~mm}^{2}$ groß. Die optische Faser detektiert etwa $1 \mathrm{~mm}^{2}$ der Probenfläche.

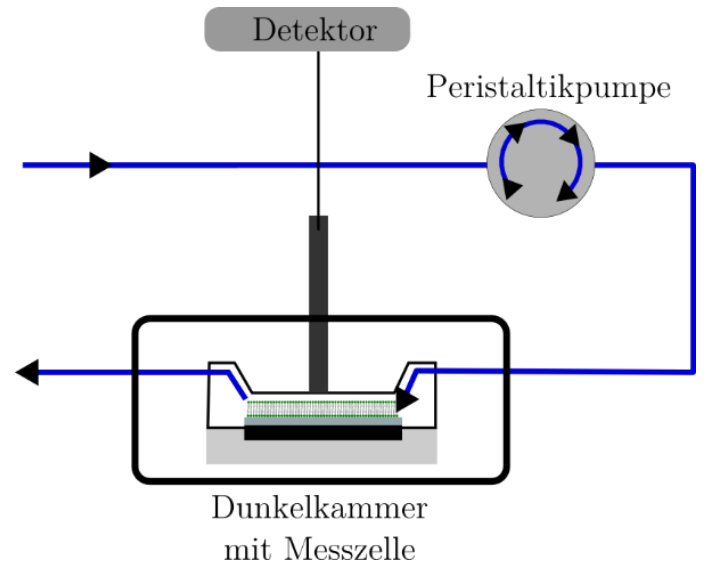

Abbildung 11: Schematischer Aufbau des RIfS-Experiments. Die Messzelle aus einem Aluminiumboden und einem Acryglasdeckel wird mit dem Schlauchsystem verbunden. Dieses wird über eine Peristaltikpumpe gesteuert. Unter dem Acrylglasdeckel wird ein 
Siliciumwafer als Substrat eingebaut. Eine optische Faser beleuchtet die Probe und leitet das Reflektivitätssignal zum Detektor weiter.

Zu Beginn jeder RIfS-Messung wurde ein zuvor hydrophilisierter Siliciumwafer in die Messkammer eingebaut und die Messung über das Programm SPECTRA Suite gestartet. Das System wurde mit Reinstwasser und anschließend mit dem jeweiligen Spreitpuffer bis zum Erreichen einer stabilen Basislinie gespült. Zur Ausbildung einer festkörperunterstützten Membran wurden die Vesikel in das System gegeben und der resultierende Spreitprozess im geschlossenen System mit Hilfe einer MATLAB Routine zeitaufgelöst verfolgt. Nach dem erneuten Erreichen einer Basislinie war die Ausbildung einer Lipiddoppelschicht beendet. Das System wurde im offenen Kreislauf gespült, um überschüssiges Lipidmaterial zu entfernen. Anschließend wurde eine BSA-Lösung (1 mg/mL, Rinderserumalbumin, bovine serum albumin) eingeleitet, um etwaige hydrophobe Fehlstellen innerhalb der Membran zu füllen. ${ }^{[52]}$ Nach erneutem Spülen wurde mit der Proteinzugabe im geschlossenen System begonnen. Dazu wurden fünf bis sechs verschiedene Proteinkonzentrationen in das System gegeben und die Anbindung des Proteins an die Membran ebenfalls zeitaufgelöst verfolgt. Die Zugabe von Protein mit der nächsthöheren Konzentration erfolgte erst nach dem Erreichen einer neuen stabilen Basislinie. Nach der letzten Proteinzugabe wurde das System erneut mit Puffer gespült, um die Reversibilität der Protein-Membran-Bindung zu untersuchen. Zur Reinigung wurden alle Schläuche mit Reinstwasser gespült. Die Acrylglasdeckel wurden zudem im Ultraschallbad mit Mucasol gereinigt. 

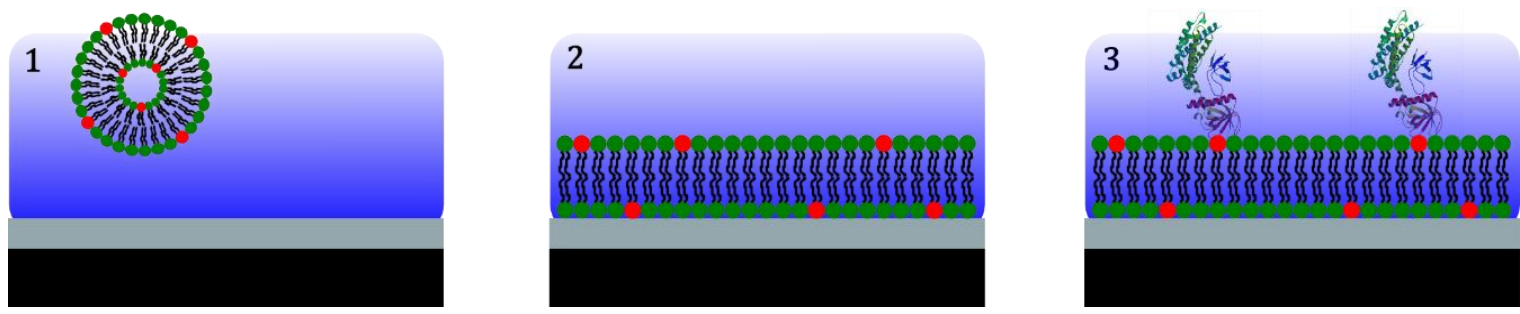

Abbildung 12: Schematische Darstellung des Ablaufs eines RIfS-Experiments. Es wurden Vesikel auf einen zuvor hydrophilisierten Siliciumwafer geleitet (1). Diese bilden durch einen spontanen Spreitprozess eine festkörperunterstützte Lipiddoppelschicht (2). Nachdem das System gespült und mit BSA abgesättigt wurde, wurde Protein auf die Membran gegeben. Dieses bindet an manche Lipide innerhalb der Lipidmembran (3).

\subsubsection{CD-Spektroskopie}

Die Circulardichroismus (CD)-Spektroskopie wurde in dieser Arbeit zur Bestimmung der Sekundärsturkturanteile der verwendeten Collybistin-Isoformen genutzt. Das Phänomen des Circulardichroismus beruht auf der unterschiedlichen Wechselwirkung von rechts- und linkszirkular polarisiertem Licht mit optisch aktiver Materie, wie z.B. Proteinen. Nach Fresnel wird das in das Medium eintretende linear polarisierte Licht als Summe zweier Wellen mit gleicher Amplitude $E_{0}$ und zirkularer Polarisation beschrieben.

$$
E_{L, R}(t, r)=1 / 2\left(i E_{0} \sin (\omega t+k r)+j E_{0} \cos (w t+k r)\right)
$$

Dabei sind die Richtungsvektoren $i$ und $j$ senkrecht zur Ausbreitungsrichtung. $t$ bezeichnet die Zeit-, $r$ die Raumkoordinate. $\omega$ beschreibt die Kreisfrequenz, $\lambda$ die Wellenlänge des Lichts und $k$ den Wellenzahlvektor. Ein optisch aktives Medium besitzt sowohl unterschiedliche Brechungsindices $\left(n_{\mathrm{L}} \neq n_{\mathrm{R}}\right)$, als auch unterschiedliche Extinktionskoeffizienten $\left(\varepsilon_{\mathrm{L}} \neq \varepsilon_{\mathrm{R}}\right)$ für die beiden zirkular polarisierten Komponenten des Lichts. ${ }^{[53]}$ 


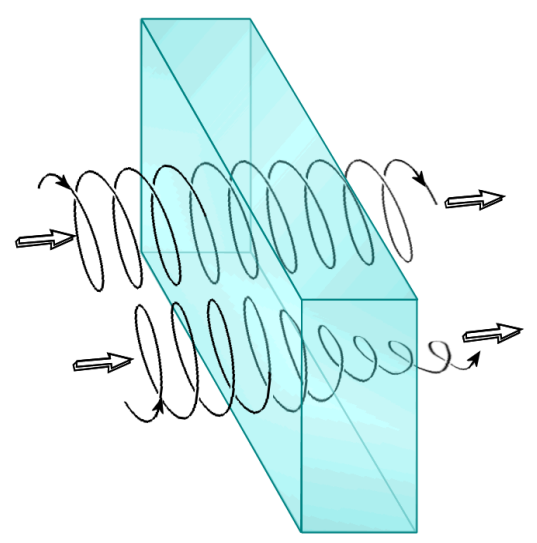

Abbildung 13: Rechts- und linkszirkular polarisiertes Licht wird in einem optisch aktiven Medium unterschiedlich beeinflusst. ${ }^{[54]}$

Bei der Transmission des Lichts durch das Medium mit der Dicke $d$ ergibt sich dadurch eine zeitliche Verschiebung $\Delta t$ der Wellen zueinander. Dieser Phasenunterschied führt zu einer Drehung der Polarisationsebene um den Winkel $\alpha$ im austretenden Licht (Gl. (19).

$$
\alpha=\frac{1}{2} \omega \Delta t=\frac{180^{\circ}}{\lambda}\left(n_{L}-n_{R}\right) d
$$

Durch die unterschiedlichen Extinktionskoeffizienten kommt es zu einer unterschiedlichen Absorption der zirkular polarisierten Wellenanteile. ${ }^{[55]}$ Dies führt zu einer elliptischen Polarisation im austretenden Licht. Die Elliptizität $\Theta$ ist definiert als:

$$
\Theta=\arctan \frac{\sqrt{I_{L}}-\sqrt{I_{R}}}{\sqrt{I_{L}}+\sqrt{I_{R}}}=\frac{180^{\circ} \ln 10}{4 \pi}\left(\varepsilon_{L}-\varepsilon_{R}\right) d
$$

Die Intensitäten $I_{\mathrm{L}}$ und $I_{\mathrm{R}}$ können über das Lambert-Beersche Gesetz (Gl. (2) berechnet werden. Um die Vergleichbarkeit zwischen verschiedenen Messungen zu gewährleisten, wird die molare Elliptizität $[\Theta]$ mit Hilfe der Schichtdicke des Mediums $L[\mathrm{~cm}]$ und der Konzentration des optisch aktiven Mediums $c[\mathrm{~mol} / \mathrm{L}]$ angegeben: 


$$
[\Theta]=100 \frac{\Theta}{c L}
$$

In Proteinen sind vor allem elektronische Übergänge innerhalb der Amidgruppen $\left(\mathrm{n} \rightarrow \pi^{*}\right.$ und $\left.\pi \rightarrow \pi^{*}\right)$ für die unterschiedliche Absorption verantwortlich. Die räumliche Struktur des Polypeptidrückgrats beeinflusst die energetische Lage der elektronischen Übergänge dabei besonders, sodass eine hohe Sensitivität für die Sekundärstrukturelemente des Proteins gegeben ist. ${ }^{[56]}$ In dieser Arbeit wurde mit Licht der Wellenlänge $\lambda=(190-260) \mathrm{nm}$ gearbeitet. In diesem fernen UV-Bereich werden durch die verschiedenen Sekundärstrukturelemente eines Proteins verschiedene Elliptizitäten gezeigt (Abbildung 14).

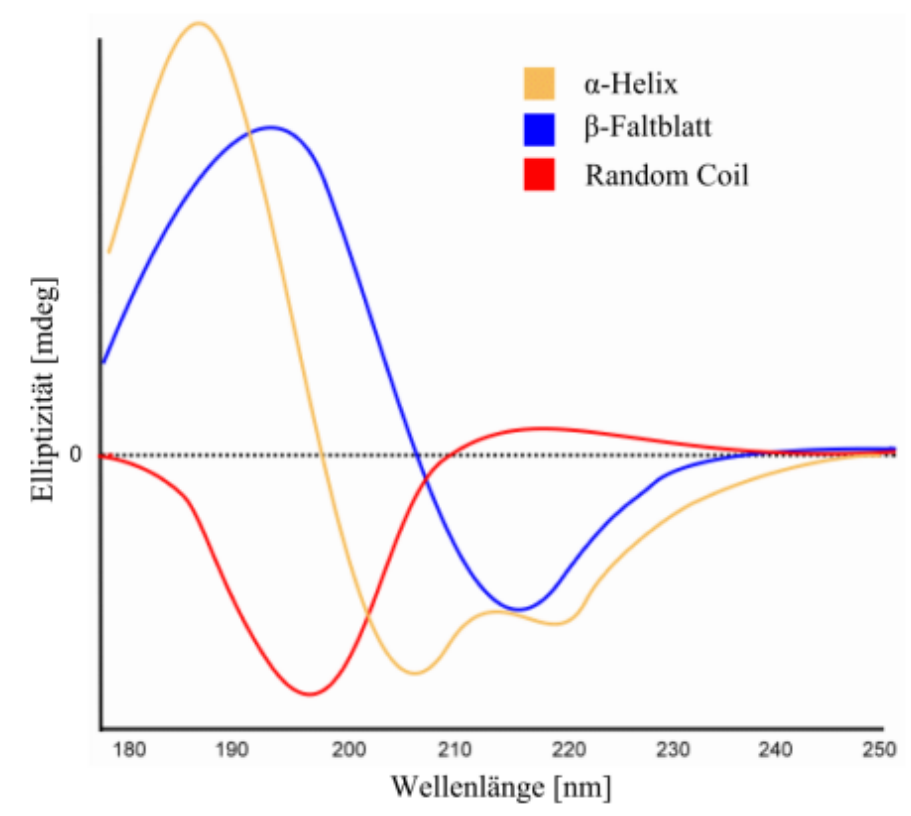

Abbildung 14: CD-Spektren der verschiedenen Sekundärstrukturelemente von Proteinen im fernen UV-Bereich. ${ }^{[57]}$

Die aufgenommenen CD-Spektren der Proteine müssen zur Auswertung dekonvuliert werden. Das CD-Signal bei einer Wellenlänge ergibt sich dabei als Linearkombination der Beiträge von $\alpha$-Helices $(\mathrm{H}), \beta$-Faltblättern (B), kurze 
Schleifenbereiche zwischen zwei $\beta$-Faltblättern (Turns, T) und Proteinbereichen ohne erkennbare Sekundärstruktur (Random Coil, R).

$$
\Theta(\lambda)=a_{H} H(\lambda)+a_{B} B(\lambda)+a_{T} T(\lambda)+a_{R} R(\lambda)
$$

Im Rahmen dieser Arbeit wurde zur Auswertung das online verfügbare Programm DichroWeB genutzt. ${ }^{[58]}$ Dabei wurde der CDSSTR-Algorihmus mit dem Referenzdatensatz 4 genutzt. $^{[59]}$ Dieser Algorithmus basiert auf der Grundlage einfacher Matrixmultiplikation.

\section{Experimentelle Durchführung}

Für die CD-Messung wurden die Proteine direkt vor der Messung mit Hilfe von Vivaspin 500-Zentrifugalkonzentratoren (Sartorius, Göttingen) in den HEPES-Puffer (100 mM NaCl, 25 mM HEPES, 0.5 mm EDTA, 0.5 mm DTT, pH 7.2) überführt und die Proteinkonzentration bestimmt.

Die Messungen für diese Arbeit wurden an einem CD-Spektrometer J-1500 (JASCO, Groß-Umstadt) durchgeführt. Es wurde bei $20^{\circ} \mathrm{C}$ und einem konstanten Stickstoffstrom gearbeitet. Dabei wurden Dünnschichtküvetten mit einer optischen Weglänge von $L=0.01 \mathrm{~cm}$ verwendet. Diese wurden vor Gebrauch mit Hellmanex, Reinstwasser und Ethanol gereinigt. Die Messungen wurden im Wellenlängenbereich $\lambda=(190-260) \mathrm{nm}$ mit einer Messgeschwindigkeit $v=10 \mathrm{~nm} \mathrm{~min}^{-1}$ mit einer Sensitivität von 100 mdeg durchgeführt und jeweils fünf Einzelmessungen für das jeweilige Spektrum akkumuliert.

$\mathrm{Zu}$ Beginn der Messung wurde ein Hintergrundspektrum mit reinem HEPESPuffer aufgenommen. Im Falle der Messungen mit Vesikeln wurde zusätzlich ein Hintergrundspektrum mit Vesikeln in HEPES-Puffer aufgezeichnet. Anschließend wurden die Spektren der reinen Proteine $(c=5 \mu \mathrm{M})$ gemessen. Für $\mathrm{CB}_{\mathrm{SH} 3-}$ und 
CB2 ${ }_{\mathrm{SH} 3+} /$ W24A-E262A wurden zusätzlich Messungen in Gegenwart von PI(3)Phaltigen SUVs aufgenommen. Die Proteinkonzentration betrug ebenfalls $5 \mu \mathrm{M}$ und es wurde ein molares Lipid-zu-Protein Verhältnis von 600:1 eingestellt. Zur Auswertung über DICHROWEB wurden vorher die zugehörigen Hintergrundspektren subtrahiert und die erhaltenen Rohdaten auf die Proteinkonzentration $c$ und die Anzahl der Aminosäuren $n$ normiert.

\subsubsection{Thermofluor-Experimente mittels real-time PCR}

Die Thermofluor-Methode ist eine sehr schnelle, temperaturbasierte Methode zur Bestimmung der Stabilität von Proteinen. Sie wurde in dieser Arbeit zur Bestimmung der Proteinstabilität in verschiedenen Puffern genutzt. Dabei werden Schmelzkurven der Proteine über die Fluoreszenzintensität des Farbstoffes SYPRO ${ }^{\circledR}$ Orange $\left(\lambda_{\mathrm{ex}}=470 \mathrm{~nm}, \lambda_{\mathrm{em}}=570 \mathrm{~nm}\right.$, Stammlsg. 5000x in DMSO, Life Technologies, Darmstadt) detektiert. Die Fluoreszenz des Farbstoffs wird nach der Bindung an hydrophobe Bereiche des Proteins stärker. Während der Erhöhung der Temperatur denaturiert das Protein, sodass mehr hydrophobe Bereiche für den Farbstoff zugänglich werden (Abbildung 15).[60] Die im Experiment detektierte Fluoreszenzintensität steigt an. 


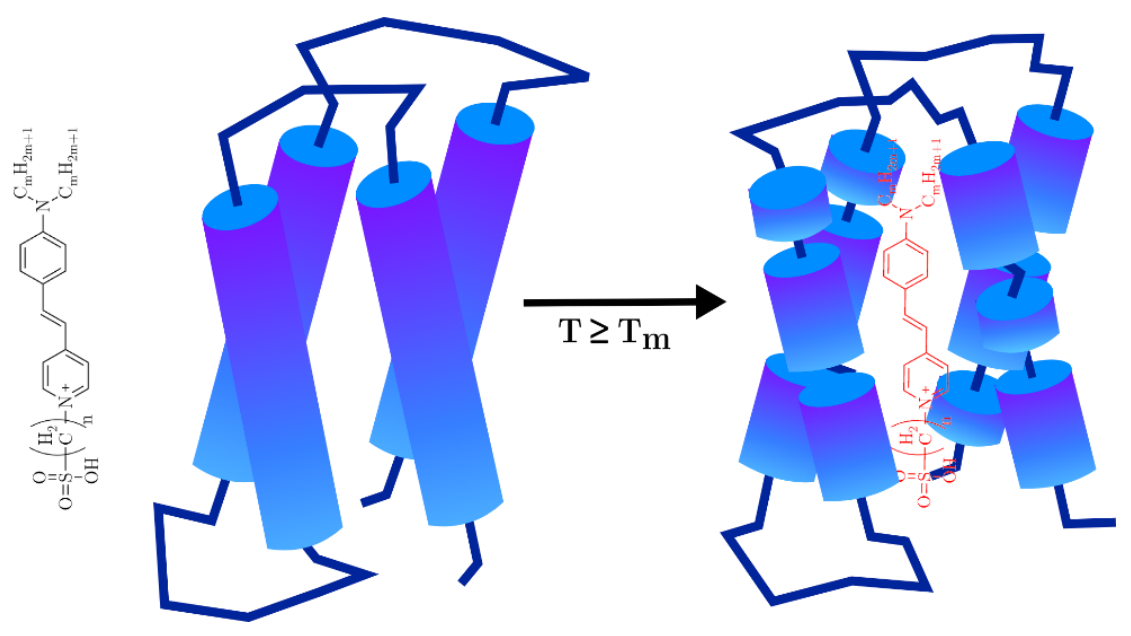

Abbildung 15: Der Farbstoff $\mathrm{SYPRO}^{\circledast}$ Orange bindet nur an hydrophobe Bereiche des Proteins. Diese sind im nativen Zustand nicht zugänglich. Wird die Temperatur über die Schmelztemperatur des Proteins erhöht, führt dies zur Denaturierung des Proteins. Der Farbstoff lagert sich nun an die exponierten hydrophoben Bereiche des Proteins an. ${ }^{[61],[60]}$

Die Messungen wurde an einem CFX96 real-time PCR-Gerät (Bio-Rad, München) in Mikrotiterplatten mit 96 Wells (4titude Ltd., Berlin) durchgeführt. Die Proteine wurden frisch in den zu testenden Puffer dialysiert und die Konzentration bestimmt. In jedes Well wurden $12.5 \mu \mathrm{L}$ der Proteinlösung $(5 \mu \mathrm{M})$ und $2.5 \mu \mathrm{L}$ SYPRO $^{\circledR}$ Orange-Farbstoff (200x in dem jeweiligen Puffer) pipettiert. Außerdem wurde als Hintergrund $12.5 \mu \mathrm{L}$ reiner Puffer mit 2.5 $\mathrm{LL}$ Farbstoff vermessen. Dabei wurde jede Probe dreifach hergestellt. Die Mikrotiterplatte wurde mit $1{ }^{\circ} \mathrm{C} / \mathrm{min}$ von $25^{\circ} \mathrm{C}$ auf $99^{\circ} \mathrm{C}$ erhitzt und das Fluoreszenzsignal aufgezeichnet. Das Fluoreszenzsignal in Abhängigkeit von der Temperatur zeigt die Schmelzkurve des Proteins im jeweiligen Puffer. Außerdem wurde von jeder Schmelzkurve die 1. Ableitung gebildet, sodass das Minimum der erzeugten Ableitung die Schmelztemperatur angibt. 


\section{Aufreinigung und Charakterisierung der Collybistin-}
Isoformen
$\mathrm{CB}_{\mathrm{PH}}$,
$\mathrm{CB}_{\mathrm{SH} 3-}$,
$\mathrm{CB}_{\mathrm{SH} 3+}$
und

\section{$\mathrm{CB}_{\mathrm{SH}_{3}+} / \mathrm{W} 24 \mathrm{~A}-\mathrm{E} 262 \mathrm{~A}$}

Die im Rahmen dieser Arbeit verwendeten Proteine wurden mittels rekombinanter, heterologer Genexpression aus E. coli isoliert. Neben der PHDomäne des Collybistin $2\left(\mathrm{CB} 2_{\mathrm{PH}}\right)$ wurden die Isoformen $\mathrm{CB} 2_{\mathrm{SH} 3-}$ und $\mathrm{CB} 2_{\mathrm{SH} 3+}$ isoliert. Außerdem wurde die Mutante CB2 ${ }_{\mathrm{SH} 3+} / \mathrm{W} 24 \mathrm{~A}-\mathrm{E} 262 \mathrm{~A}$ der Isoform $\mathrm{CB} 2_{\mathrm{SH} 3+}$ exprimiert, welche eine geöffnete Form der Proteinstruktur aufweisen soll. ${ }^{[13]}$ Für alle $\mathrm{zu}$ isolierenden Proteine wurde im Vorfeld eine Plasmidvermehrung und aufreinigung durchgeführt (Kapitel 3.1.2, 3.1.3). Alle Proteine wurden, wie in Abschnitt 3.1.5 beschrieben, als Fusionsprotein mit einem Inteintag exprimiert. Dieser dient zur Stabilisierung des Proteins während der Expression und zur affinitätschromatographischen Reinigung. Er wurde während der Affinitätschromatographie von den Proteinen abgespalten. Die Proteine wurden nach der Affinitätschromatographie über eine Anionenaustauschchromatographie weiter aufgereinigt und aufkonzentriert. Nach der Durchführung der jeweiligen Chromatographieschritte wurden Proben aus den einzelnen Fraktionen genommen und diese anschließend mit Hilfe der SDS-PAGE (Kapitel 3.1.8) analysiert. 


\subsection{Plasmidisolierung aller Isoformen}

Für die Plasmidisolierung wurde das jeweilige Plasmid in zuvor präparierte chemisch kompetente E. coli Zellen des Stammes DH5 $\alpha$ transformiert. Nach der Vermehrung in LB-Medium wurden die Plasmide, wie in Abschnitt 3.1.3 beschrieben, aus den Zellen extrahiert und aufgereinigt. Der Erfolg der Plasmidisolierung wurde mit Hilfe einer Agarose-Gelelektrophorese (3.1.4) überprüft. Abbildung 16 zeigt das resultierende, mit Gel-Red angefärbte Agarosegel. Die Plasmide besitzen eine Größe von $8594 \mathrm{kbp}$ (CB2 $\left.{ }_{\mathrm{SH} 3}\right), 7907 \mathrm{kbp}$ (CB2 $\left.2_{\mathrm{PH}}\right)$ und $8077 \mathrm{kbp}\left(\mathrm{CB}_{\mathrm{SH} 3+} / \mathrm{CB}_{\mathrm{SH} 3+} / \mathrm{W} 24 \mathrm{~A}-\mathrm{E} 262 \mathrm{~A}\right)$. Alle Plasmide weisen im Agarosegel eine Größe von 5000-6000 kbp auf und erscheinen damit viel kleiner als erwartet. Dies lässt sich durch eine superspiralisierte Struktur der Plasmide erklären. Eine Linearisierung der Strukturen vor der Elektrophorese würde zu den erwarteten Plasmidgrößen führen.
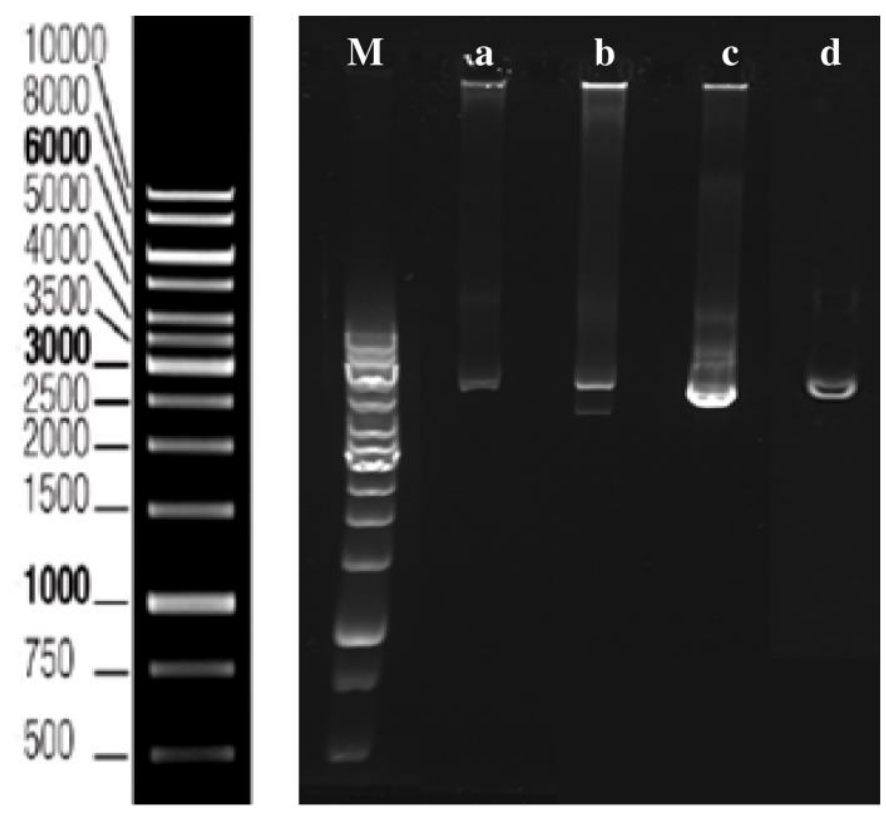

Abbildung 16: Agarosegel der aufgereinigten Plasmide. M: Größenstandard (GeneRulerTM 1kb DNA Ladder, Thermo Scientific, Schwerte, Deutschland), a: CB2 $2_{\mathrm{SH} 3+}(8077 \mathrm{kbp})$, b: CB2 $2_{\mathrm{SH} 3-}(8594 \mathrm{kpb})$, c: $\mathrm{CB}_{\mathrm{PH}}(7907 \mathrm{kbp})$, d: $\mathrm{CB}_{\mathrm{SH} 3+} / \mathrm{W} 24 \mathrm{~A}-$ E262A (8077 kbp) 


\subsection{Expression und Aufreinigung von $\mathrm{CB} 2_{\mathrm{PH}}$}

Für die Isolierung der PH-Domäne des Collybistin $2\left(\mathrm{CB} 2_{\mathrm{PH}}, \mathrm{M}=20.96 \mathrm{kDa}\right)$ wurde das zugehörige Plasmid (pTYB12-CB2 ${ }_{\mathrm{PH}}$ ) in den E. coli-Stamm BL21(DE3) transformiert. Anschließend wurde eine Einzelkolonie, wie in Abschnitt 3.1.5 beschrieben, in 7.5 L LB-Medium mit $100 \mu \mathrm{g} / \mathrm{mL}$ Ampicillin über Nacht exprimiert. Die Zellen wurden geerntet und mit Hilfe des Mikrofluidizers lysiert. Bei der folgenden Aufreinigung über die Chitin-Intein-Affinitätschromatographie wurden 8 Fraktionen à $10 \mathrm{~mL}$ aufgefangen. Zusätzlich wurden Proben aus dem Durchlauf nach der Bindung an die Chitin-Matrix, aus der Waschfraktion und aus dem Durchlauf des Spaltungspufffers (Grundpuffer mit $50 \mathrm{~mm}$ DTT) genommen. Die SDSGelelektrophorese nach Schägger zeigte für alle Fraktionen die gewünschte Proteinbande bei ca. $20 \mathrm{kDa}$ auf, wobei das Protein in den Fraktionen 1-3 die höchste Konzentration aufwies (Abbildung $17 \mathrm{~A}$ ). Es sind außerdem höhermolekulare Verunreinigungen mit einer Größe von 60-70 kDa zu erkennen. Im Durchlauf ist eine Vielzahl von Banden zu erkennen. Eine Bande des Fusionsproteins $(80 \mathrm{kDa})$ ist nicht erkennbar. Das Protein wurde erfolgreich an die Matrix gebunden.

Die Waschfraktion und der Durchlauf des Spaltungspuffers zeigen kaum Banden.
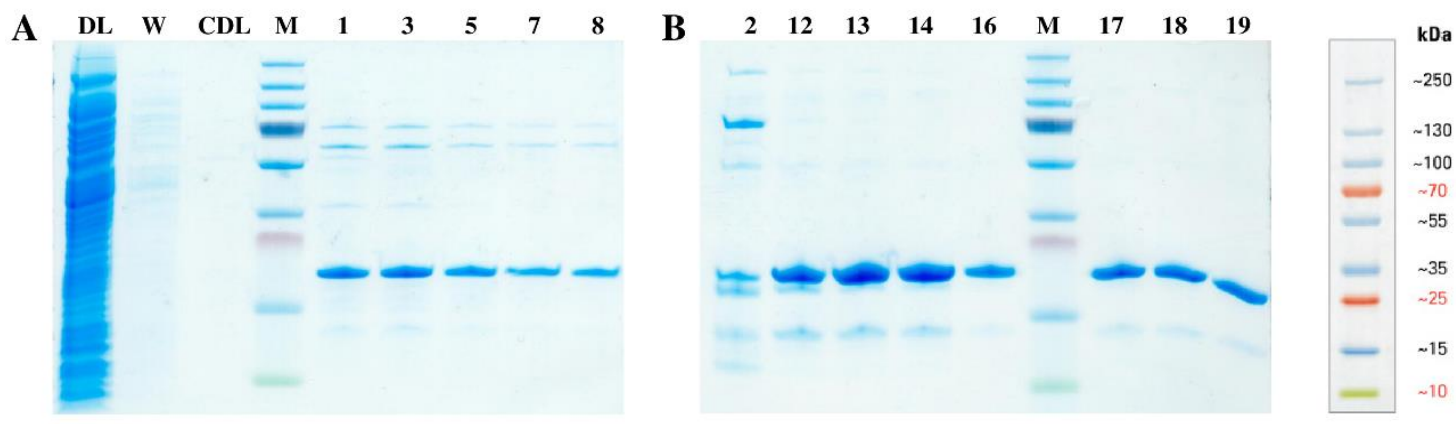

Abbildung 17: SDS-Gele nach Schägger für die Aufreinigung des CB2 $2_{\mathrm{PH}} \underline{\mathrm{A}}$ : Analyse der während der Affinitätschromatographie aufgefangenen Fraktionen. DL: Durchlauf, $\underline{W}$ : Waschfraktion, CDL: Durchlauf des DTT-haltigen Puffers zur Abspaltung des InteinTags, M: Marker (PageRuler Plus Prestained Protein Ladder, Thermo Scientific, 
Schwerte, Deutschland), 1-8: aufgefangene Fraktionen. B: Analyse der Fraktionen des zum CB2 $2_{\text {PH }}$ gehörenden UV-Peaks aus der Ionenaustauschchromatographie.

Für die Entfernung der höhermolekularen Verunreinigungen wurden alle acht Fraktionen vereinigt und das Protein auf die MonoQ 10/100 GL-Säule aufgetragen. Es wurde ein linearer Konzentrationsgradient von Puffer A zu Puffer B (siehe Kapitel 3.1.7) über 12 Säulenvolumen verwendet, um das Protein von der Säule zu eluieren. Abbildung 18 A zeigt das daraus resultierende Chromatogramm. Schon vor Beginn des Konzentrationsgradienten bei ca. $10 \mathrm{~mL}$ gab es einen hohen Peak im UVSignal. Dieser ist Fraktion 2 in Abbildung 17 (Spur 1) zugeordnet. In dieser Fraktion ist die Konzentration des $\mathrm{CB} 2_{\mathrm{PH}}$ sehr gering. Es wurde ein großer Teil der nach der Affinitätschromatographie beschriebenen, höhermolekularen Verunreinigung bei $70 \mathrm{kDa}$ eluiert. Im zweiten UV-Peak bei ca. $35 \mathrm{~mL}$ und einer Leitfähigkeit von ungefähr $20 \mathrm{mS} / \mathrm{cm}$ wurde das Protein eluiert (Abbildung $18 \mathrm{~B}$ ). Die während der Elution aufgefangenen Fraktionen wurden zur Analyse auf das SDS-Gel aufgetragen (Abbildung $17 \mathrm{~B}$ ). Alle Fraktionen enthielten dabei CB2 $2_{\mathrm{PH}}$, wobei die Proteinkonzentration in den Fraktionen 12-14 am höchsten war. Alle nachfolgenden UV-Peaks bei höheren Leitfähigkeiten zeigten keine Proteinbande und wurden verworfen (Gel nicht gezeigt). Die Fraktionen 12-19 wurden vereinigt und bis zur Verwendung im Experiment ohne weitere Aufreinigungsschritte bei $4^{\circ} \mathrm{C}$ gelagert. Die Proteinausbeute betrug je nach Isolierung zwischen $1.5-2.0 \mathrm{mg} / \mathrm{L}$. 
A

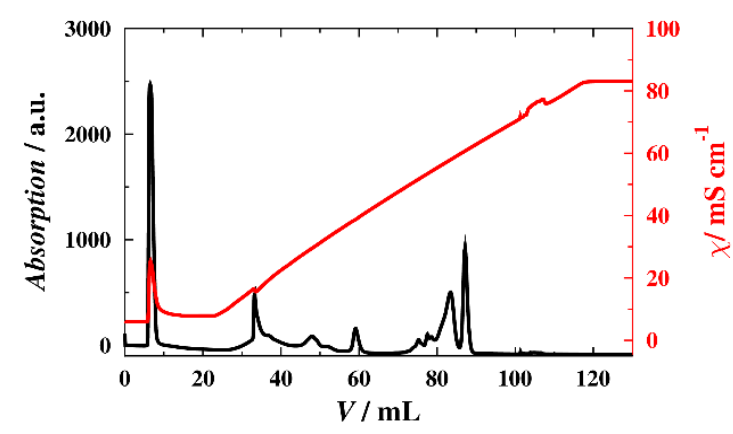

B

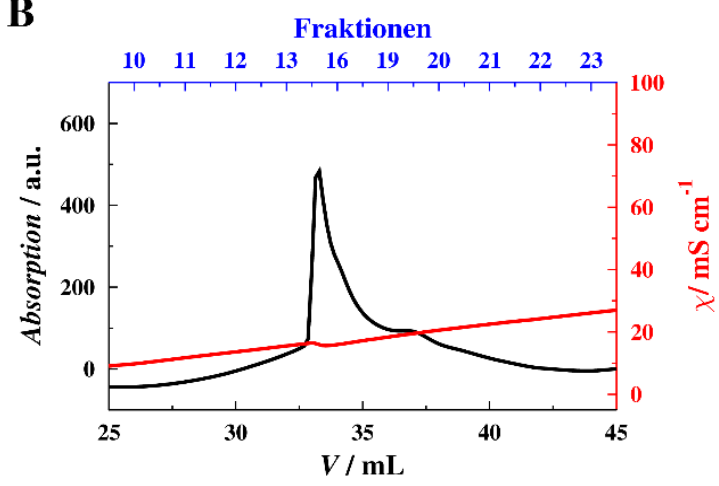

Abbildung 18: A: Chromatogramm der Anionenaustauschchromatographie von CB2 $\mathrm{PH}$. Es ist das UV-Signal bei $\lambda=280 \mathrm{~nm}$ (schwarz) und die im System vorliegende Leitfähigkeit (rot) dargestellt. $\underline{B}$ : Vergrößerung des UV-Peaks aus $\underline{A}$, der die Elution des CB2 $2_{\mathrm{PH}}$ zeigt.

\subsection{Expression und Aufreinigung von $\mathrm{CB} 2_{\mathrm{SH} 3-}$}

Für die Isolierung der Isoform $\mathrm{CB}_{\mathrm{SH} 3-} \quad(\mathrm{M}=49.16 \mathrm{kDa})$ wurde eine Transformation des zugehörige Plasmids (pTYB12-CB2 ${ }_{\mathrm{SH} 3}$ ) in E. coli-Zellen des Stammes BL21(DE3) vorgenommen. Eine gewachsene Einzelkolonie wurde, wie in Abschnitt 3.1.5 beschrieben, in 7.5 L LB-Medium mit $100 \mu \mathrm{g} / \mathrm{mL}$ Ampicillin über Nacht kultiviert. Die Zellen wurden geerntet und mit Hilfe des Mikrofluidizers lysiert. Bei der Chitin-Intein-Affinitätschromatographie (3.1.6) wurden 12 Fraktionen à $10 \mathrm{~mL}$ aufgefangen. Zusätzlich wurden Proben von der Chitin-Matrix vor der Elution $(100 \mu \mathrm{L})$ und aus der Waschfraktion entnommen. Die Probe von der Chitin-Matrix wurde mit $100 \mu \mathrm{L}$ 2x Probenpuffer versetzt, nach dem Aufkochen zentrifugiert und $20 \mu \mathrm{L}$ des Überstands zusammen mit den übrigen Proben auf ein SDS-Gel nach Laemmli (3.1.8) aufgetragen. In der ersten Spur (Abbildung 19 A) ist der Überstand aus der Chitin-Matrixprobe aufgetragen Dabei ist eine dicke Bande bei ca. $50 \mathrm{kDa}$ zu erkennen. Diese ist dem Zielprotein $\mathrm{CB} 2_{\mathrm{SH} 3-}$ zuzuordnen. Weiterhin ist bei ca. $100 \mathrm{kDa}$ eine Bande des ungespaltenen Proteins sichtbar. Alle zwölf 
eluierten Fraktionen wiesen die gewünschte Proteinbande bei ca. 50 kDa auf. Es sind höhermolekulare Verunreinigungen mit einer Größe von 60 und 70 kDa zu erkennen. Die Waschfraktion zeigt einen kleinen Anteil an nicht-gebundenem Protein bei ca. $100 \mathrm{kDa}$. Hier war der Inteintag noch nicht vom Zielprotein abgespalten.
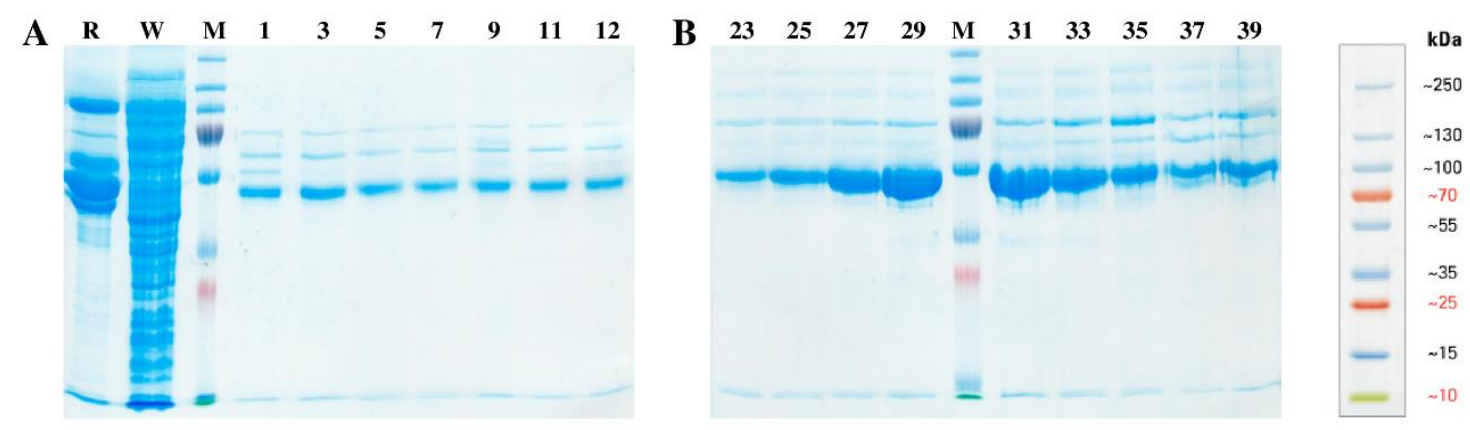

Abbildung 19: SDS-Gele nach Laemmli für die Aufreinigung des CB2 ${ }_{\mathrm{SH} 3-} \underline{\mathrm{A}}$ : Analyse der während der Affinitätschromatographie aufgefangenen Fraktionen. $\underline{R}$ : Probe der ChitinMatrix vor der Elution (Resin), $\underline{\mathrm{W}}$ : Waschfraktion, $\underline{\mathrm{M}}$ : Marker, 1-12: eluierte Fraktionen. B: Analyse der Fraktionen des zum Protein gehörenden UV-Peaks aus der Ionenaustauschchromatographie.

Für die weitere Aufreinigung wurden alle zwölf proteinhaltigen Elutionsfraktionen vereinigt und das Protein auf die MonoQ 10/100 GL-Säule gegeben. Es wurde ein linearer Konzentrationsgradient von Puffer A zu Puffer B (siehe 3.1.7) über 12 Säulenvolumen verwendet, um das Protein von der Säule zu eluieren. Abbildung 20 zeigt das resultierende Chromatogramm der Ionenaustauschchromatographie. Das Chromatogramm weist einen Hauptpeak bei $45-50 \mathrm{~mL}$ und einer Leitfähigkeit von ca. $30 \mathrm{mS} / \mathrm{cm}$ auf. Im SDS-Gel (Abbildung $19 \mathrm{~B}$ ) wird sichtbar, dass dieser UVPeak zur Elution des Proteins gehört. Die Fraktionen 23-39 enthielten alle das gewünschte Zielprotein $\mathrm{CB}_{\mathrm{SH} 3-}$, wobei eine hohe Konzentration in den Fraktionen 27-33 erkennbar ist. Außerdem ist eine Zunahme der Konzentration einer höhermolekularen Verunreinigung des Proteins mit ca. $70 \mathrm{kDa}$ zu erkennen. Diese konnte durch die Ionenaustauschchromatographie nicht vom Protein getrennt werden. Alle nachfolgenden Peaks bei höheren Leitfähigkeiten zeigten keine 
Proteinbande und wurden verworfen (Gel nicht gezeigt). Die Fraktionen 23-33 wurden vereinigt und bis zur Verwendung bei $4{ }^{\circ} \mathrm{C}$ gelagert. Die proteinhaltigen Fraktionen 34-39 wurden aufgrund höherer Anteile von Verunreinigungen verworfen. Die Ausbeute für das $\mathrm{CB}_{\mathrm{SH}}$ - betrug je nach Güte der Proteinisolierung zwischen $0.7-1.0 \mathrm{mg} / \mathrm{L}$.

A

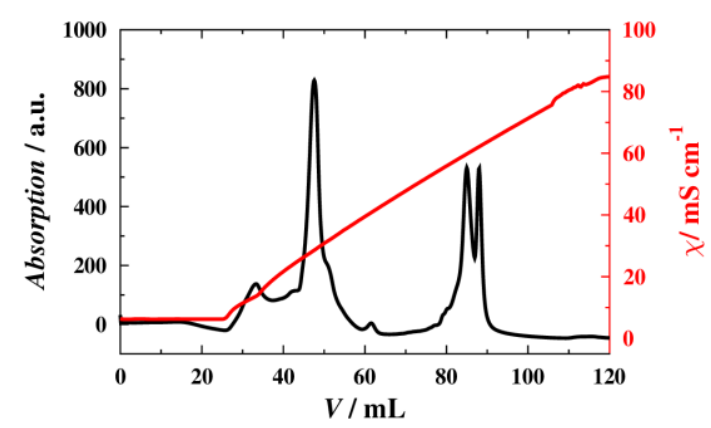

B

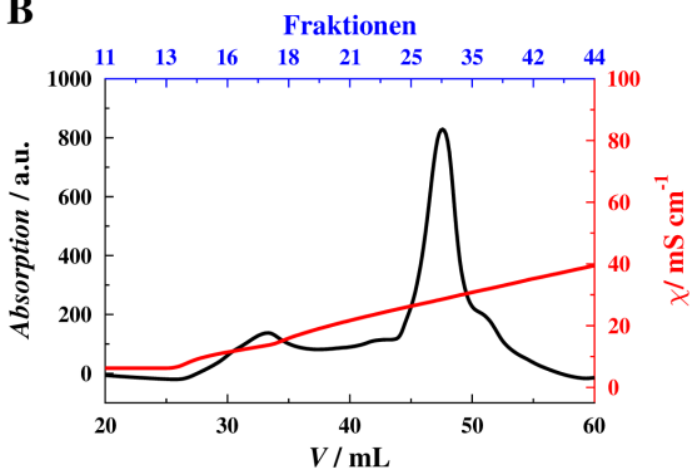

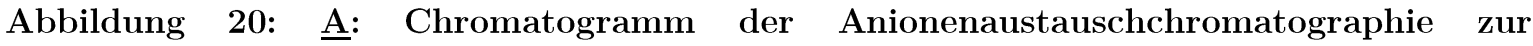
Reinigung von $\mathrm{CB} 2_{\mathrm{SH} 3-}$. Es ist das UV-Signal (schwarz) und die im System vorliegende Leitfähigkeit (rot) dargestellt. B-: Vergrößerung des UV-Peaks bei einer Leitfähigkeit von ca. $30 \mathrm{mS} / \mathrm{cm}$ aus $\underline{\mathrm{A}}$, der die Elution des $\mathrm{CB} 2_{\mathrm{SH} 3-}$ zeigt.

Zum Nachweis des isolierten Proteins wurde zusätzlich zur SDS-Page ein Western Blot durchgeführt. Dabei wird das Zielprotein über eine spezifische AntigenAntikörper-Reaktion detektiert. Das Protein wurde nach der gelelektrophoretischen Auftrennung auf eine Nitrocellulosemembran übertragen. Die nicht besetzten Bindungsstellen auf der Membran wurden durch Magermilchpulver und Tween-20 blockiert. Anschließend wurde das $\mathrm{CB} 2_{\mathrm{SH} 3-}$ über einen spezifisch gegen Collybistin wirkenden Antikörper detektiert. Das Proteinsignal wurde über Chemilumineszenz mit Hilfe des Meerrettich-Peroxidase funktionalisierten Sekundärantikörpers sichtbar gemacht. 


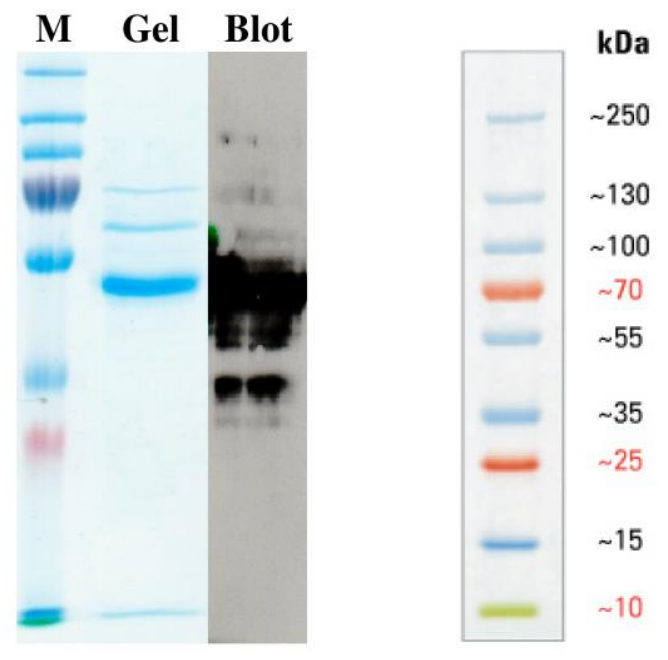

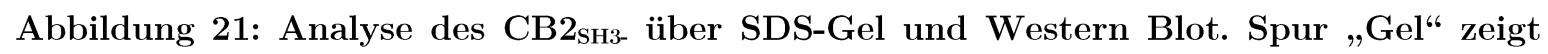
die elektrophoretische Auftrennung des Proteins, Spur „Blot“ zeigt das Ergebnis des Western-Blot Experiments. Die Hauptbande im SDS-Gel bei $50 \mathrm{kDa}$ korrespondiert mit dem Zielprotein und damit mit der stärksten Bande auf dem Röntgenfilm des Western Blots.

Abbildung 21 zeigt das Ergebnis des Western-Blots. Dabei ist in Spur „M“ der Marker zur Größenbestimmung gezeigt. Spur „Gel“ zeigt die Banden des isolierten $\mathrm{CB} 2_{\mathrm{SH} 3}$ im SDS-Gel nach Laemmli. Die prominenteste Bande bei einer molaren Masse von ca. $50 \mathrm{kDa}$ entspricht der molaren Masse des Zielproteins. Weiterhin sind höhermolekulare Verunreinigungen sichtbar. Das Ergebnis des Western-Blots in Spur „Blot" zeigt, dass die Hauptbande bei $50 \mathrm{kDa}$ vom Zielprotein stammt. Hier ist eine starke Chemilumineszenz auf dem Röntgenfilm sichtbar. Die höhermolekularen Verunreinigungen werden durch den Primärantikörper nicht erkannt. Im WesternBlot wird zusätzlich eine niedermolekulare Bande sichtbar. Im SDS-Gel konnte diese aufgrund der geringeren Nachweisgrenze der Coomassie-Färbelösung nicht detektiert werden. 


\subsection{Expression und Aufreinigung von $\mathrm{CB} 2_{\mathrm{SH} 3+}$}

Für die Isolierung der Isoform $\mathrm{CB} 2_{\mathrm{SH} 3+}(\mathrm{M}=55.93 \mathrm{kDa})$ wurde das zugehörige Plasmid (pTXB1-CB22 $\mathrm{SH}_{3+}$ ) in den E. coli-Stamm BL21(DE3) transformiert. Eine gewachsene Einzelkolonie wurde, wie in Abschnitt 3.1.5 beschrieben, in 7.5 L LBMedium mit $100 \mu \mathrm{g} / \mathrm{mL}$ Ampicillin über Nacht kultiviert. Die Zellen wurden geerntet und mit Hilfe des Mikrofluidizers lysiert. Dabei enthielten alle verwendeten Puffer zur Stabilisierung des Proteins $10 \%$ Glycerol. Bei der Chitin-InteinAffinitätschromatographie (3.1.6) wurden 12 Fraktionen à $10 \mathrm{~mL}$ eluiert. Zusätzlich wurden Proben von der Chitin-Matrix nach der Elution des Proteins, von dem Durchlauf nach der Inkubation mit dem Zelllysat und aus der Waschfraktion entnommen. Die Probe der Chitin-Matrix wurde mit $100 \mu \mathrm{L}$ 2x Probenpuffer versetzt, nach dem Aufkochen zentrifugiert und $20 \mu \mathrm{L}$ des Überstands zusammen mit den übrigen Proben auf ein SDS-Gel nach Laemmli (3.1.8) aufgetragen. Alle 12 Fraktionen enthalten das Zielprotein. Dies ist in den Spuren „1“-,11“ mit einer Bande bei etwa $55 \mathrm{kDa}$ zu erkennen (Abbildung $22 \mathrm{~A}$ ). Der Durchlauf enthält neben einem kleinen Anteil ungebundenem Zielprotein alle anderen Bestandteile des Zelllysats, die nicht an die Chitin-Matrix binden. Die Waschfraktion zeigt hingegen kaum Banden, was auf eine sehr spezifische Bindung des Zielproteins an die Matrix hindeutet. In Spur 1 ist der Überstand aus der Chitin-Matrixprobe nach der Proteinelution aufgetragen. Hier wird sichtbar, dass nach der Elution noch Zielprotein $(55 \mathrm{kDa})$ an der Säulenmatrix gebunden ist. Zusätzlich ist eine Bande des ungespaltenen Proteins mit einer Größe von 85 kDa erkennbar. Den Erfolg der durchgeführten Spaltung zeigt der auf der Matrix verbliebende Inteintag. Dieser weist eine Größe von ungefähr $30 \mathrm{kDa}$ auf und ist in Spur 1 deutlich als Bande erkennbar. 

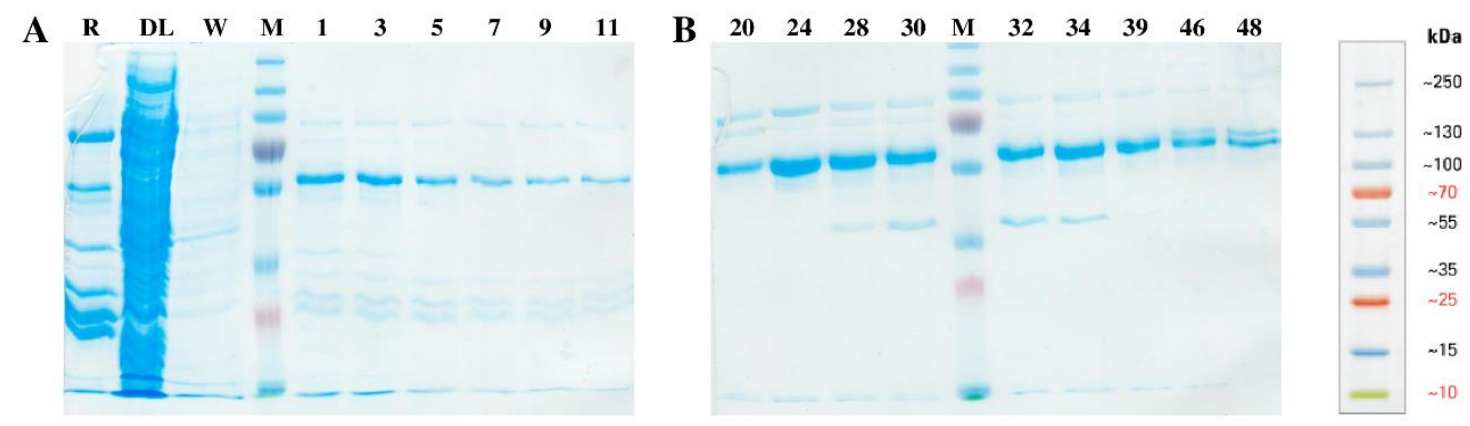

Abbildung 22: SDS-Gele nach Laemmli für die Aufreinigung des CB2 ${ }_{\mathrm{SH} 3+}$ A der während der Affinitätschromatographie aufgefangenen Fraktionen. $\underline{R}$ : Probe der Chitin-Matrix nach der Elution (Resin), DL: Durchlauf, $\underline{\text { W: }}$ Waschfraktion, M: Marker, 1-11: eluierte Fraktionen. B: Analyse der Fraktionen des zum Protein korrespondierenden UV-Peaks aus der Ionenaustauschchromatographie.

Für die weitere Aufreinigung wurden alle zwölf proteinhaltigen Elutionsfraktionen vereinigt und das Protein auf die MonoQ 10/100 GL-Säule aufgetragen. Es wurde ein linearer Konzentrationsgradient von Puffer A zu Puffer B (siehe 3.1.7) über 12 Säulenvolumen verwendet, um das Protein von der Säule zu eluieren. Abbildung 23 zeigt das resultierende Chromatogramm aus der Ionenaustauschchromatographie. Das Chromatogramm weist einen sehr breiten Hauptpeak bei $45-55 \mathrm{~mL}$ und einer Leitfähigkeit von ca. $30 \mathrm{mS} / \mathrm{cm}$ auf. Der Peak weist dabei zwei Maxima auf. Im SDS-Gel (Abbildung 22 B) wird sichtbar, dass der gesamte UV-Peak mit der Elution des Proteins korrespondiert. Außerdem sind sowohl höher- als auch niedermolekulare Verunreinigungen zu erkennen. Alle nachfolgenden Peaks bei höheren Leitfähigkeiten zeigten keine Proteinbande und wurden verworfen (Gel nicht gezeigt). Die Fraktionen 20-39 wurden vereinigt und bis zur Verwendung im Experiment bei $4{ }^{\circ} \mathrm{C}$ gelagert. Die proteinhaltigen Fraktionen 40-48 wurden aufgrund des Vorhandenseins eines zusätzlichen Proteins der Masse $60 \mathrm{kDa}$ verworfen. Die Ausbeute an $\mathrm{CB} 2_{\mathrm{SH} 3+}$ betrug je nach Güte der Proteinisolierung zwischen $0.5-0.7 \mathrm{mg} / \mathrm{L}$. 
A

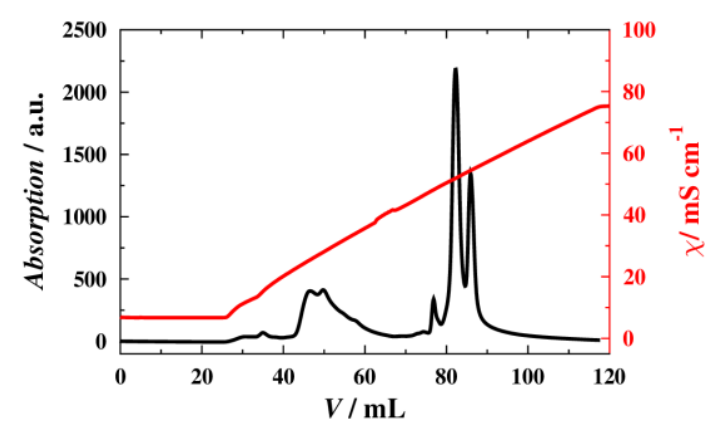

B

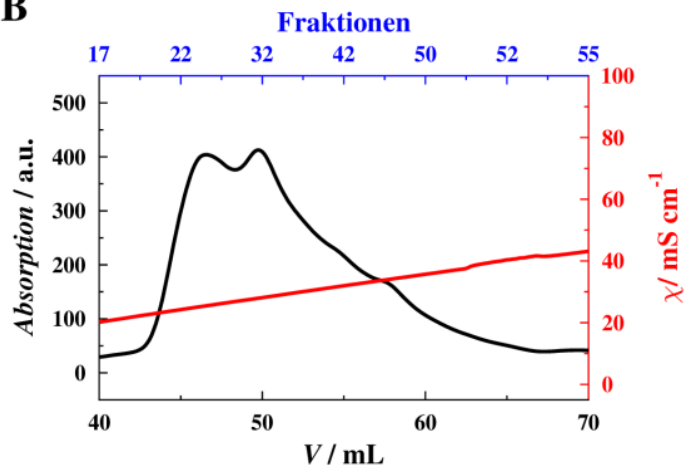

Abbildung 23: A : Chromatogramm der Anionenaustauschchromatographie zur Reinigung von CB2 ${ }_{\mathrm{SH} 3+}$. Es ist das UV-Signal (schwarz) und die im System vorliegende Leitfähigkeit (rot) dargestellt. B: Vergrößerung des UV-Peaks bei einer Leitfähigkeit von ca. $30 \mathrm{mS} / \mathrm{cm}$ aus $\underline{\mathrm{A}}$, der die Elution des $\mathrm{CB} 2_{\mathrm{SH} 3+}$ zeigt.

\subsection{Expression und Aufreinigung von CB2 $2_{\mathrm{SH} 3+} / \mathrm{W} 24 \mathrm{~A}-\mathrm{E} 262 \mathrm{~A}$}

Für die Isolierung der Isoform $\mathrm{CB} 2_{\mathrm{SH} 3+} / \mathrm{W} 24 \mathrm{~A}-\mathrm{E} 262 \mathrm{~A}(\mathrm{M}=55.76 \mathrm{kDa})$ wurde das zugehörige Plasmid (pTXB1-CB2 ${ }_{\mathrm{SH} 3+} / \mathrm{W} 24 \mathrm{~A}-\mathrm{E} 262 \mathrm{~A}$ ) in den E. coli-Stamm BL21(DE3) transformiert. Eine gewachsene Einzelkolonie wurde, wie in 3.1 .5 beschrieben, in 7.5 L LB-Medium mit $100 \mu \mathrm{g} / \mathrm{mL}$ Ampicillin über Nacht kultiviert. Die Zellen wurden geerntet und mit Hilfe des Mikrofluidizers lysiert. Dabei enthielten alle verwendeten Puffer zur Stabilisierung des Proteins $10 \%$ Glycerol. Bei der Chitin-Intein-Affinitätschromatographie (3.1.6) wurden 10 Fraktionen à $10 \mathrm{~mL}$ eluiert. Zusätzlich wurden Proben von der Chitin-Matrix vor und nach der Spaltung des Proteins auf der Säule und von dem Durchlauf nach der Inkubation mit dem Zelllysat entnommen. Die Probe der Chitin-Matrix wurde mit $100 \mu \mathrm{L} 2 \mathrm{x}$ Probenpuffer versetzt, nach dem Aufkochen zentrifugiert und $20 \mu \mathrm{L}$ des Überstands zusammen mit den übrigen Proben auf ein SDS-Gel nach Laemmli (3.1.8) aufgetragen. In Spur „ $R_{\text {vor }}$ " ist die Chitin-Matrixprobe vor der Spaltung des Inteintags vom Protein aufgetragen. Hier wird sichtbar, dass das exprimierte 
Fusionsprotein $(85 \mathrm{kDa})$ an die Säulenmatrix gebunden ist. Zusätzlich sind niedermolekulare Verunreinigungen zu erkennen, die ebenfalls spezifisch an die Chitin-Matrix gebunden haben. Nach der Spaltung des Zielproteins vom Inteintag über Thiolyse ist in Spur „ $\mathrm{R}_{\text {nach }}$ " eine Bande des Zielproteins mit einer Größe von $55 \mathrm{kDa}$ erkennbar. Der auf der Matrix gebundene Inteintag (Bande bei $30 \mathrm{kDa}$ ) zeigt den Erfolg der Spaltung des Zielproteins vom Affinitätstag. Der Durchlauf vor der Spaltung enthält neben einem kleinen Anteil ungebundenen Zielproteins (85 kDa) alle anderen Bestandteile des Zelllysats, die nicht spezifisch an die Chitin-Matrix binden konnten. Alle 10 eluierten Fraktionen enthalten das Zielprotein in abnehmender Konzentration. Dies ist in den Spuren 5-10 mit einer Bande bei etwa $55 \mathrm{kDa}$ zu erkennen (Abbildung $24 \mathrm{~A}$ ).
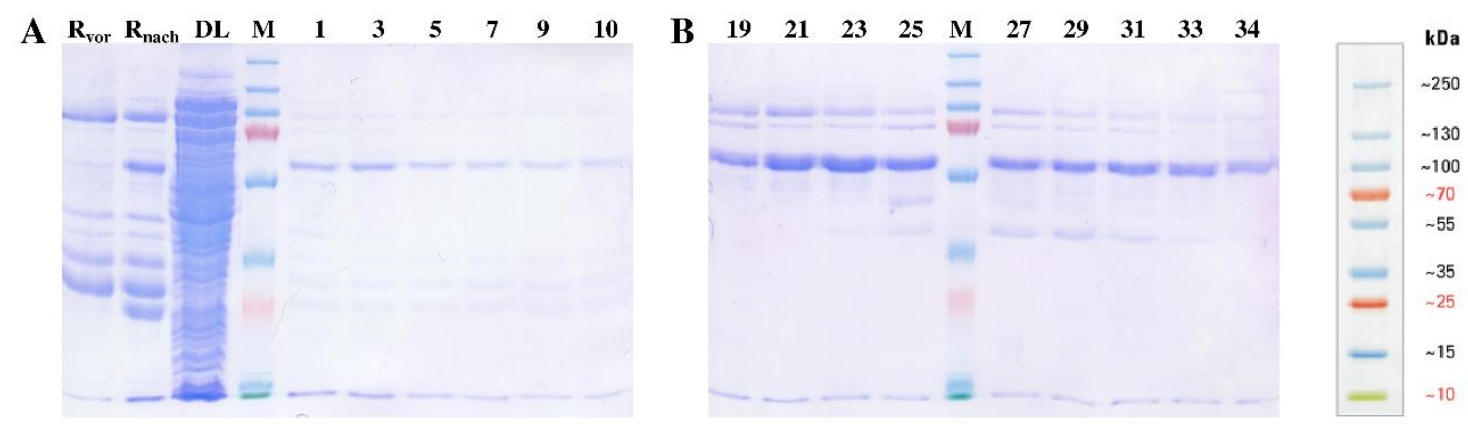

Abbildung 24: SDS-Gele nach Laemmli für die Aufreinigung des CB2 SH3+ $_{3} /$ W24A-E262A. $\underline{\text { A}}$ : Analyse der während der Affinitätschromatographie aufgefangenen Fraktionen. $\underline{\mathbf{R}}_{\mathrm{vor}}$ : Probe der Chitin-Matrix vor der Spaltung, $\underline{R}_{n a c h}$ : Probe der Chitin-Matrix nach der Spaltung, DL: Durchlauf, M: Marker, 1-10: eluierte Fraktionen (je $10 \mathrm{~mL})$. $\underline{\text { B: Analyse }}$ der Fraktionen des zum Protein korrespondierenden UV-Peaks aus der Ionenaustauschchromatographie.

Für die weitere Aufreinigung wurden alle zehn proteinhaltigen Elutionsfraktionen vereinigt und das Protein auf die MonoQ 10/100 GL-Säule aufgetragen. Es wurde ein linearer Konzentrationsgradient von Puffer A zu Puffer B (siehe 3.1.7) über 12 Säulenvolumen zur Elution verwendet. Abbildung 25 zeigt das resultierende Chromatogramm aus der Ionenaustauschchromatographie. Das Chromatogramm weist einen sehr breiten Hauptpeak bei 45-55 mL und einer Leitfähigkeit von ca. 
$30 \mathrm{mS} / \mathrm{cm}$ auf. Der Peak weist neben dem Maximum bei $46 \mathrm{~mL}$ eine Schulter bei $50 \mathrm{~mL}$ auf. Im SDS-Gel (Abbildung $24 \mathrm{~B}$ ) wird sichtbar, dass der gesamte UV-Peak mit der Elution des Proteins korrespondiert. Außerdem sind höhermolekulare Verunreinigungen mit abnehmender Konzentration zu erkennen. Alle nachfolgenden Peaks bei höheren Leitfähigkeiten zeigten keine Proteinbande und wurden verworfen (Gel nicht gezeigt).

A

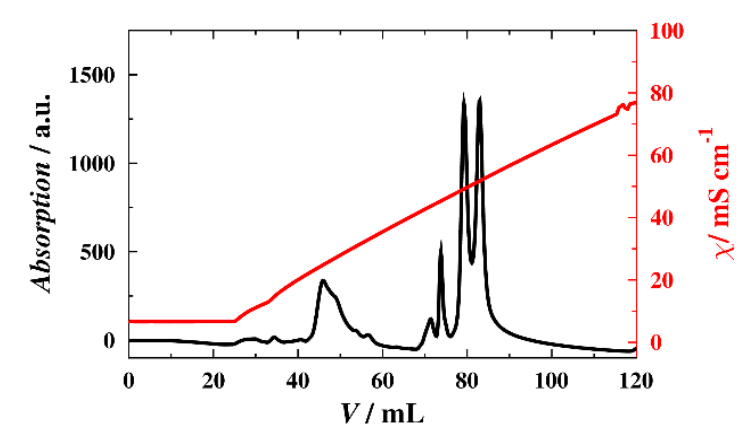

B

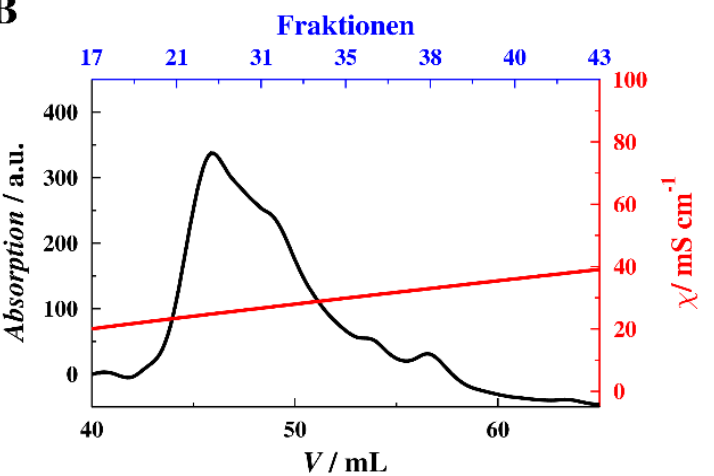

Abbildung 25: $\underline{\text { A}}$ : Chromatogramm der Anionenaustauschchromatographie zur Reinigung von CB2 ${ }_{\mathrm{SH} 3+} / \mathrm{W} 24 \mathrm{~A}-\mathrm{E} 262 \mathrm{~A}$. Es ist das UV-Signal (schwarz) und die im System vorliegende Leitfähigkeit (rot) dargestellt. B: Vergrößerung des UV-Peaks bei einer Leitfähigkeit von ca. $30 \mathrm{mS} / \mathrm{cm}$ aus $\underline{\mathrm{A}}$, der die Elution des CB2 ${ }_{\mathrm{SH} 3+} / \mathrm{W} 24 \mathrm{~A}-\mathrm{E} 262 \mathrm{~A}$ zeigt.

Die Fraktionen 19-34 wurden vereinigt und bei $4{ }^{\circ} \mathrm{C}$ gelagert. Die Ausbeute an $\mathrm{CB}_{\mathrm{SH} 3+} / \mathrm{W} 24 \mathrm{~A}-\mathrm{E} 262 \mathrm{~A}$ betrug je nach Güte der Proteinisolierung zwischen $0.3-$ $0.5 \mathrm{mg} / \mathrm{L}$. 


\subsection{Untersuchung der Stabilität der aufgereinigten CB-}

\section{Isoformen in verschiedenen Puffern}

Die thermische Stabilität der verschiedenen Isoformen des Collybistin 2 wurde mittels eines Thermofluor-Assays untersucht. Die Proteine CB2 ${ }_{\mathrm{PH}}, \mathrm{CB}_{\mathrm{SH}}$ - und $\mathrm{CB}_{\mathrm{SH} 3+}$ wurden mit Hilfe von Zentrifugalkonzentratoren in den jeweiligen Puffer (Zusammensetzung siehe 3.2.4) dialysiert. Es wurden Proteinlösungen mit einer Konzentration $c=5 \mu \mathrm{M}$ hergestellt. Wie in 3.3.3, beschrieben, wurden anschließend jeweils $12.5 \mu \mathrm{L}$ der Proteinlösung mit $2.5 \mu \mathrm{L}$ des Farbstoffs im gewünschten Puffer in eine 96-Well Mikrotiterplatte pipettiert. Jede Probe wurde dreifach hergestellt. Es wurden Schmelzkurven der Proteine aufgenommen. Dabei wurde die Erhöhung der Fluoreszenz in der Probe durch die Anlagerung des Farbstoffs an die hydrophoben Bereiche des entfalteten Proteins detektiert. Die resultierenden Schmelzkurven wurden zusammengefasst. Zur Auswertung wurden sowohl die Schmelzkurven, als auch deren erste Ableitung verwendet. Dabei geben die Minima der ersten Ableitung die Wendepunkte der Schmelzkurven und damit die Schmelztemperatur $T_{\mathrm{m}}$ der Proteine wieder.

Abbildung 26 A zeigt die Schmelzkurven für das Protein $\mathrm{CB}_{\mathrm{PH}}$ in den drei verschiedenen Puffern. Es ist erkennbar, dass die Schmelzkurve im TRIS-Puffer schon zu Beginn eine höhere Fluoreszenz aufweist, als mit den anderen Puffern. Dies bedeutet, dass ein größerer Anteil des CB2 ${ }_{\mathrm{PH}}$ im TRIS-Puffer (150 mM NaCl, $20 \mathrm{mM}$ TRIS, pH 7.4) im Vergleich zu den Messungen in den anderen Puffern schon vor dem Erhitzen im denaturierten Zustand vorlag. Die Schmelztemperatur im TRISund im HEPES-Puffer (100 mM NaCl, 25 mM HEPES, 0.5 mM EDTA, 0.5 mM DTT, $\mathrm{pH} \quad 7.2)$ liegt bei $T_{\mathrm{m}}=40^{\circ} \mathrm{C}$, im Phosphat-Puffer $(250 \mathrm{mM} \mathrm{KCl}, 20 \mathrm{mM}$ 
$\mathrm{KH}_{2} \mathrm{PO}_{4} / \mathrm{K}_{2} \mathrm{HPO}_{4}, 2$ mM EDTA, $\mathrm{pH}$ 7.4) ist diese zu $45{ }^{\circ} \mathrm{C}$ verschoben (Abbildung 26 B). Die Stabilität des CB2PH ist somit im Phosphat-Puffer am höchsten.

A

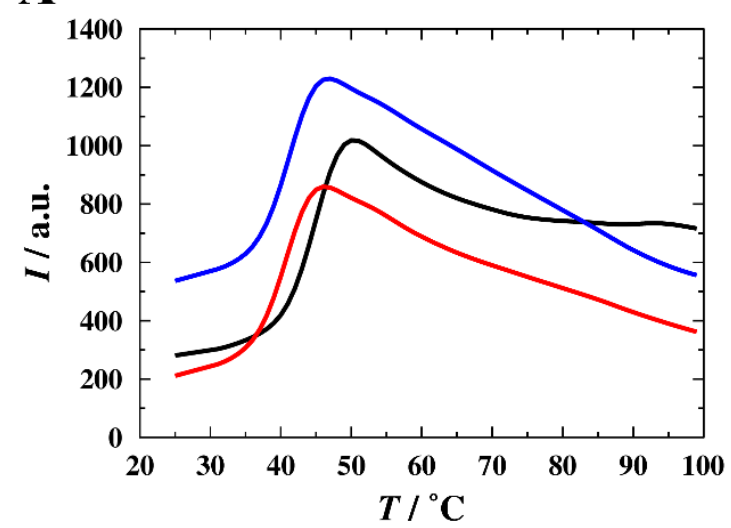

B

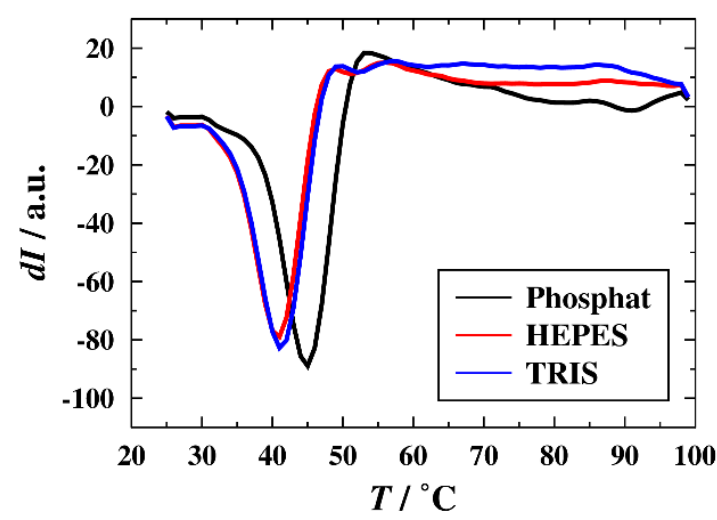

Abbildung 26: $\underline{A}$ : Darstellung der Schmelzkurven für das $\mathrm{CB}_{\mathrm{PH}}$ in den drei untersuchten Puffern. Die Denaturierung und der damit verbundene Anstieg der

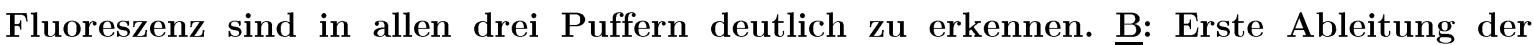
gemessenen Schmelzkurven. Aus dem Minimum der ersten Ableitung wird die Schmelztemperatur bestimmt. Die Schmelztempratur von CB2 ${ }_{\mathrm{PH}}$ beträgt im TRIS- und im HEPES-Puffer etwa $40{ }^{\circ} \mathrm{C}$, im Phosphatpuffer $45^{\circ} \mathrm{C}$.

Es wurden auch Schmelzkurven für die Proteinisoform $\mathrm{CB} 2_{\mathrm{SH} 3}$ in den drei Puffern gemessen. Dabei zeigt sich ebenfalls eine erhöhte Startfluoreszenz im TRIS-Puffer (Abbildung 27 A). Allerdings liegen die Startfluoreszenzen insgesamt in allen Puffern deutlich höher als im Falle des $\mathrm{CB}_{\mathrm{PH}}$. Trotzdem sind die Schmelzkurven im Experiment noch deutlich erkennbar, weisen jedoch keine optimale sigmoidale Form auf. Dieser Effekt wird durch Proteinaggregation oder einen mehrstufigen Entfaltungsprozess des Proteins hervorgerufen. Da die Stufen in allen getesteten Puffern detektiert wurden, werden sie für die weitere Auswertung vernachlässigt. Die Schmelztemperatur liegt für das $\mathrm{CB} 22_{\mathrm{SH} 3-}$ in allen untersuchten Puffern bei etwa $43{ }^{\circ} \mathrm{C}$ (Abbildung $27 \mathrm{~B}$ ) und damit im Bereich des CB2 ${ }_{\mathrm{PH}}$. 
A

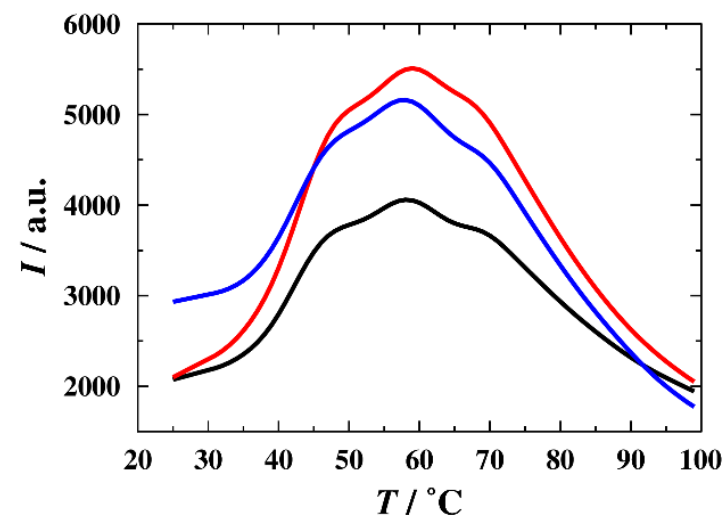

B

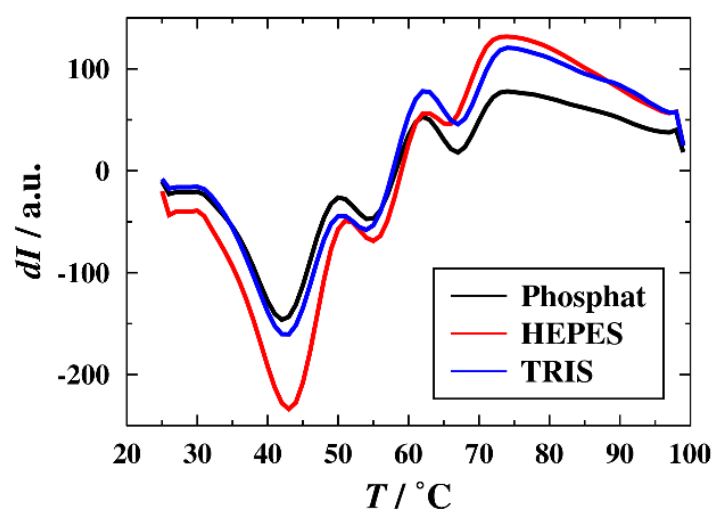

Abbildung 27: $\underline{\text { A}}$ : Darstellung der Schmelzkurven für $\mathrm{CB}_{\mathrm{SH}_{3-}}$ in den drei getesteten Puffern. Die Denaturierung und der damit verbundene Anstieg der Fluoreszenz sind in allen drei Puffern deutlich zu erkennen. B: Erste Ableitung der gemessenen Schmelzkurven. Das Minimum der ersten Ableitung repräsentiert die Schmelztemperatur. CB2 SH3- $_{\text {hat }}$ in allen Puffern eine Schmelztemperatur von etwa $43{ }^{\circ} \mathrm{C}$.

Die Stabilität des $\mathrm{CB} 2_{\mathrm{SH} 3+}$ in Puffern mit unterschiedlicher Zusammensetzung und Salzkonzentration wurde ebenfalls mit Hilfe der Thermofluor-Methode bestimmt. In Abbildung 28 A sind die erhaltenen Schmelzkurven dargestellt. Es zeigt sich eine sehr hohe Startintensität der Fluoreszenz des SYPRO Orange bei Raumtemperatur. Dennoch sind die Schmelzkurven in allen drei Puffern deutlich zu erkennen. Die erste Ableitung der Schmelzkurven liefert für alle drei Puffer eine Schmelztemperatur des CB2 $2_{\mathrm{SH} 3+}$ von $T_{\mathrm{m}}=48{ }^{\circ} \mathrm{C}$. Die gemessene Schmelztemperatur ist damit höher als die Schmelztemperaturen des CB2 ${ }_{\mathrm{PH}}$ und $\mathrm{CB} 2_{\mathrm{SH} 3}$. 
A

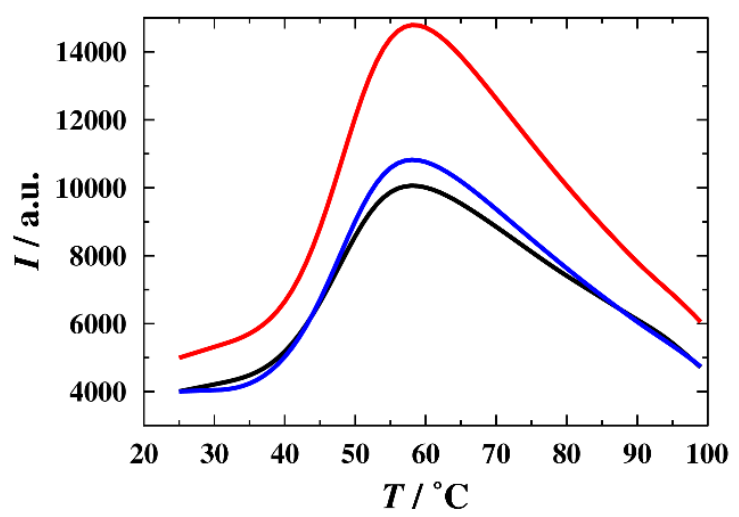

B

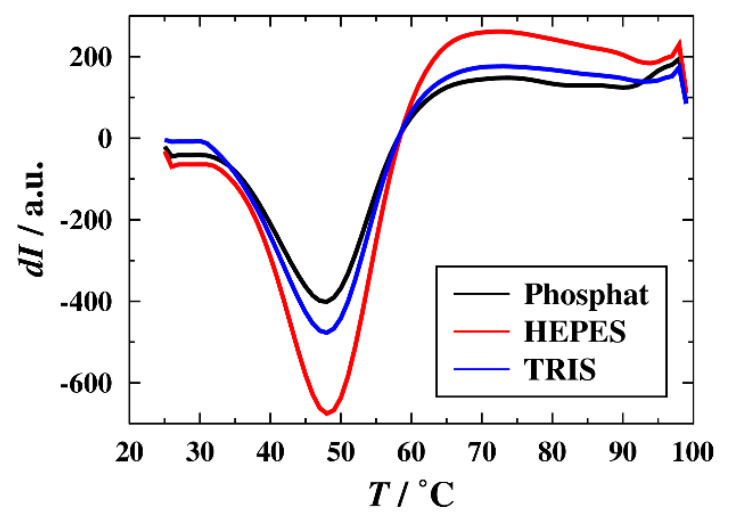

Abbildung $28 \underline{\text { A}}$ : Darstellung der Schmelzkurven für $\mathrm{CB}_{\mathrm{SH} 3+}$ in den drei verschiedenen Puffern. Die Entfaltung des Proteins und der damit verbundene Anstieg der Fluoreszenz sind in allen drei Puffern deutlich zu erkennen. B: Erste Ableitung der gemessenen Schmelzkurven. Aus dem Minimum der ersten Ableitung wird die Schmelztemperatur bestimmt. $\mathrm{CB} 2_{\mathrm{SH} 3+}$ weist in allen Puffern eine Schmelztemperatur von $48{ }^{\circ} \mathrm{C}$ auf.

\subsection{Bestimmung der Sekundärstrukturelemente der}

\section{aufgereinigten Proteine}

Alle für diese Arbeit aufgereinigten Proteine wurden CD-spektroskopisch charakterisiert, um Informationen über die ausgebildeten Sekundärstrukturelemente zu gewinnen. Für die Messungen wurden die Proteine mit Hilfe von Zentrifugalkonzentratoren in HEPES-Puffer (100 mM NaCl, 25 mM HEPES, 0.5 mM EDTA, 0.5 mM DTT, pH 7.2) überführt und die Konzentration über UV/VisAbsorptionsmessungen bestimmt. Es wurden CD-Spektren in einer Schichtküvette mit $d=0.01 \mathrm{~mm}$ im Wellenlängenbereich $\lambda=(190-260) \mathrm{nm}$ aufgenommen. 


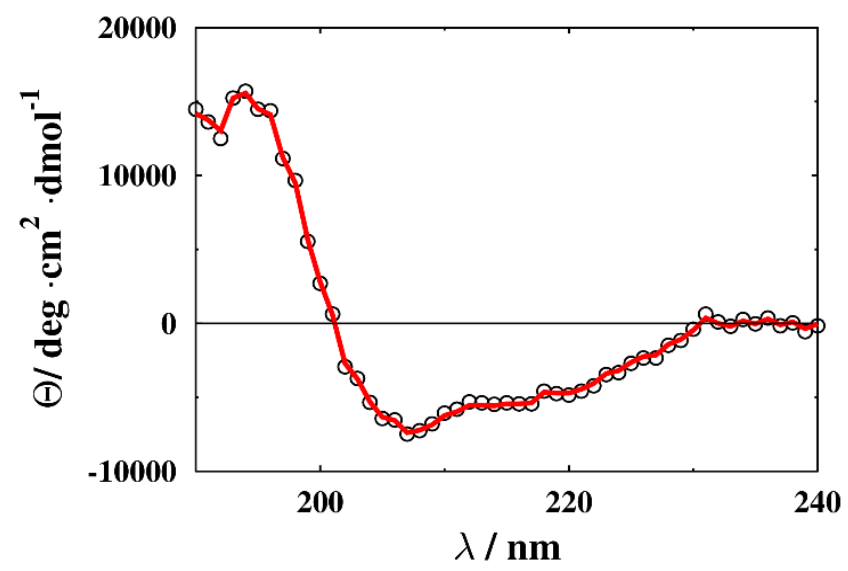

Abbildung 29: CD-Spektrum (o) von CB2 ${ }_{\mathrm{PH}}$ in HEPES-Puffer (100 $\mathrm{mM} \mathrm{NaCl}, 25 \mathrm{mM}$ HEPES, $0.5 \mathrm{mM}$ EDTA, $0.5 \mathrm{mM}$ DTT, pH 7.2). Rekonstruktion der Daten (rot) mit Hilfe des Programms DichroWeB, Algorithmus CDSSTR, Referenzdatensatz 4. $\mathrm{NRMSD}=0.021$.

Es wurden für jedes Protein fünf Messungen durchgeführt und diese zur Auswertung akkumuliert. Zusätzlich wurde das Signal des reinen Puffers als Hintergrund vom Messsignal abgezogen. Anschließend wurden die gemessenen Spektren mit Hilfe des online verfügbaren Programms DichroWEB analysiert. Abbildung 29 zeigt exemplarisch das CD-Spektrum des CB2 $2_{\mathrm{PH}}$. Die über das Programm DichroWeB unter Verwendung des Algorithmus CDSSTR (Referenzdatensatz 4) vorgenommene Anpassung der Daten ist als rote Linie gezeigt. Neben den prozentualen Beiträgen der Sekundärstrukturelemente an der Gesamtstruktur des Proteins konnte zusätzlich die Abweichung (NRMSD, normalized root mean squared deviation) der berechneten von der gemessenen Struktur bestimmt werden. Sie stellt ein Maß für die Qualität der Ergebnisse dar und sollte $<0.1$ sein. ${ }^{[62]}$ Dies war für alle in dieser Arbeit vorgenommenen Anpassungen an die gemessenen Spektren gegeben. 
Abbildung 30 zeigt die aufgenommenen CD-Spektren der vier isolierten Proteine. Alle Spektren weisen sowohl im Bereich von $\lambda=(190-210) \mathrm{nm}$, der auf $\alpha$-helicale Strukturen im Protein hinweist, als auch im Bereich von $\lambda=(210-230) \mathrm{nm}(\beta-$ Faltblatt) Minima auf. Es wurde für jedes Spektrum eine Dekonvolution des Datensatzes durchgeführt, um die Einzelbeiträge der verschiedenen Sekundärstrukturelemente an der Gesamtstruktur zu ermitteln.
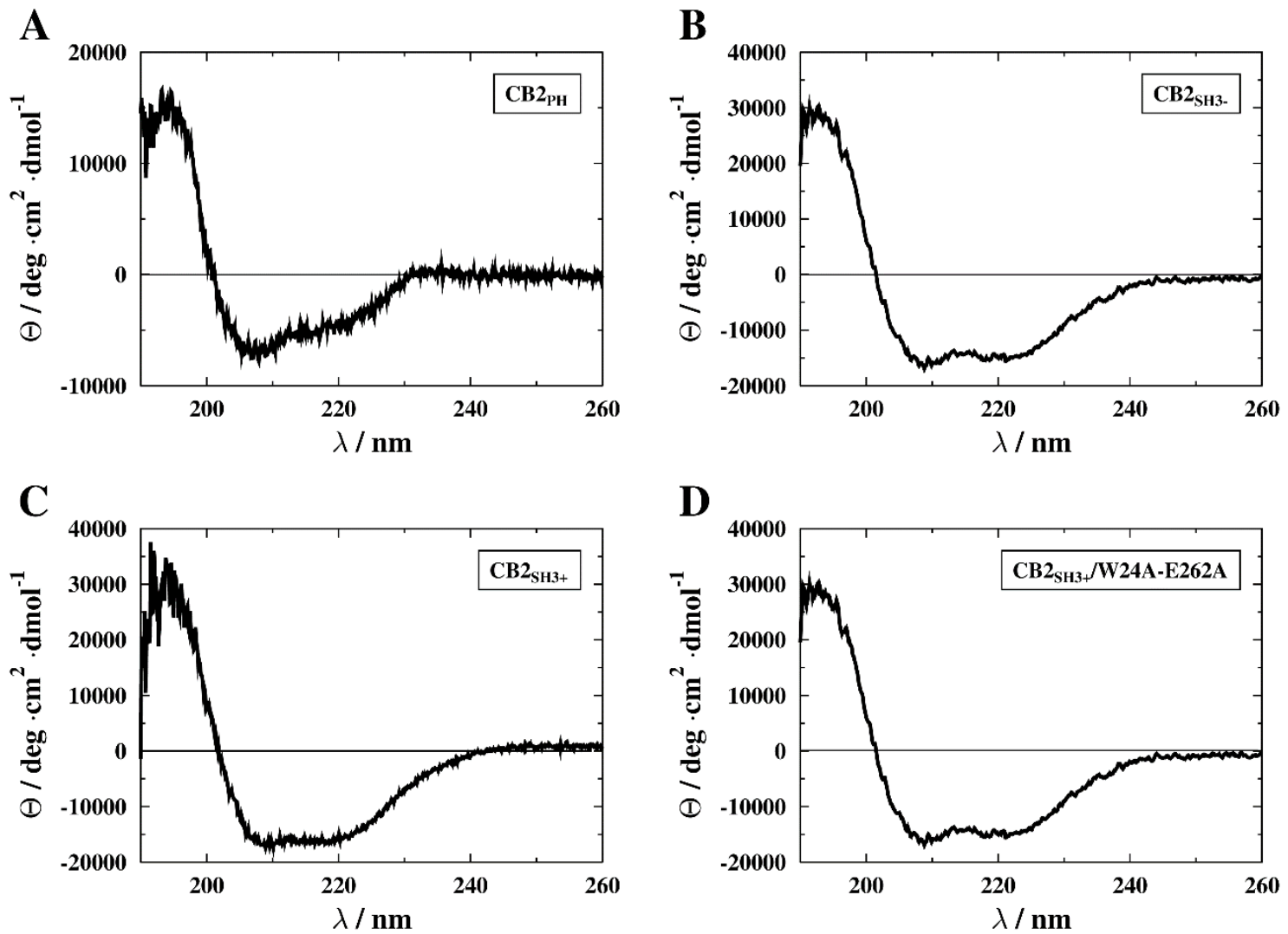

Abbildung 30: Gemittelte CD-Spektren von $\mathrm{CB} 2_{\mathrm{PH}}(\underline{\mathrm{A}}), \mathrm{CB} 2_{\mathrm{SH} 3-}(\underline{\mathrm{B}}), \mathrm{CB} 2_{\mathrm{SH} 3+}(\underline{\mathrm{C}})$ und $\mathrm{CB}_{\mathrm{SH}_{3}+} / \mathrm{W} 24 \mathrm{~A}-\mathrm{E} 262 \mathrm{~A}(\underline{\mathrm{D}})$ in HEPES-Puffer $(100 \mathrm{mM} \mathrm{NaCl}, 25 \mathrm{mM}$ HEPES, $0.5 \mathrm{mM}$ EDTA, 0.5 mM DTT, pH 7.2).

Die Dekonvolution der gemessenen Spektren führt zu den in Tabelle 10 dargestellten Anteilen der verschiedenen Sekundärstrukturelemente. Das Protein $\mathrm{CB}_{\mathrm{PH}}$ weist einen großen Anteil von $\beta$-Faltblattstrukturen auf. Zusätzlich sind $18 \%$ des Proteins in Haarnadelschleifen (turns) angeordnet. Nur $15 \%$ des Proteins liegen in einer $\alpha$-helicalen Struktur vor. Im Gegensatz dazu weist $\mathrm{CB}_{\mathrm{SH} 3-}$ einen sehr hohen 
Anteil an $\alpha$-helicalen Bereichen (53\%) auf. Hier sind lediglich $9 \%$ der Proteinstruktur in $\beta$-Faltblättern angeordnet. Die Anteile von Haarnadelschleifen (13\%) und ungeordneter Struktur $(24 \%)$ sind im CB2 $2_{\mathrm{SH} 3-}$ vergleichbar derer vom $\mathrm{CB}_{\mathrm{PH}}$. $\mathrm{CB}_{\mathrm{SH} 3+}$ zeigt neben einem dem $\mathrm{CB}_{\mathrm{SH} 3-}$ vergleichbar hohen Anteil an $\alpha-$ helicalen Strukturen (51\%) auch einen höheren Anteil an Regionen mit $\beta$ Faltblattstruktur (23\%). Lediglich $7 \%$ des Proteins sind in Haarnadelschleifen angeordnet. Im Vergleich mit dem $\mathrm{CB} 2_{\mathrm{SH} 3-}$ und dem $\mathrm{CB} 2_{\mathrm{PH}}$ besitzt das $\mathrm{CB}_{\mathrm{SH} 3+}$ einen kleineren Anteil ungeordneter Bereiche (18\%). Die beiden Punktmutationen in $\mathrm{CB}_{\mathrm{SH}_{3}+} / \mathrm{W} 24 \mathrm{~A}-\mathrm{E} 262 \mathrm{~A}$ haben im Vergleich zum Wildtyp von CB2 ${ }_{\mathrm{SH} 3+}$ geringe Änderungen in der Sekundärstruktur zur Folge. Der Anteil des Proteins mit $\beta$ Faltblattstruktur nimmt ab (11\%), der prozentuale Anteil an Haarnadelschleifen nimmt zu (14\%). Der $\alpha$-helicale Anteil und der Anteil an ungeordneten Bereichen der Proteinstruktur zeigen keine signifikante Änderung.

Tabelle 10: Zusammenfassung der über DiChROWeB (CDSSTR, Referenzdatensatz 4) ermittelten Anteile der Sekundärstrukturelemente in den verschiedenen Proteinen.

\begin{tabular}{ccccc}
\hline Protein & $\boldsymbol{\alpha}$-Helix & $\boldsymbol{\beta}$-Faltblatt & turns & ungeordnet \\
\hline CB2 $_{\mathrm{PH}}$ & 0.15 & 0.38 & 0.18 & 0.28 \\
\hline CB2 ${ }_{\mathrm{SH} 3-}$ & 0.54 & 0.09 & 0.13 & 0.23 \\
\hline CB2 ${ }_{\mathrm{SH} 3+}$ & 0.51 & 0.23 & 0.07 & 0.18 \\
\hline $\mathrm{CB}_{\mathrm{SH} 3+} / \mathrm{W} 24 \mathrm{~A}-\mathrm{E262A}$ & 0.53 & 0.11 & 0.14 & 0.22 \\
\hline
\end{tabular}




\section{8 Änderung der Sekundärstruktur durch Phosphatidyl-}

\section{inositolbindung}

Neben der Bestimmung der Anteile der Sekundärstrukturelemente von reinen Proteinlösungen wurden für $\mathrm{CB} 2_{\mathrm{SH} 3-}$ und $\mathrm{CB} 2_{\mathrm{SH} 3+} / \mathrm{W} 24 \mathrm{~A}-\mathrm{E} 262 \mathrm{~A}$ Experimente zur Änderung der Sekundärstruktur durch die Bindung an Phosphatidylinositolphosphat-haltige Vesikel durchgeführt. Wie in 3.2.2 beschrieben, wurden PI(3)P-haltige Vesikel in HEPES-Puffer hergestellt. Die Proteine wurden ebenfalls in HEPES-Puffer überführt. Die CD-Spektren wurden in einer Schichtküvette mit $\quad d=0.01 \mathrm{~mm}$ im Wellenlängenbereich $\lambda=(190-260) \mathrm{nm}$ aufgenommen. Es wurden CD-Spektren vom reinen Puffer und von Vesikeln in Puffer als Referenzspektren gemessen. Anschließend wurden die Vesikel mit dem jeweiligen Protein für $1 \mathrm{~h}$ im Verhältnis $n_{\text {Lipid }} / n_{\text {Protein }}=600: 1$ inkubiert. Das CDSpektrum des an die Vesikel gebundenen Proteins wurde aufgenommen. Zur Auswertung wurde das Referenzspektrum der Vesikel in Lösung vom Messspektrum subtrahiert und die CD-Spektren des reinen und des an Vesikel gebundenen Proteins verglichen. Abbildung 31 zeigt die erhaltenen Ergebnisse für $\mathrm{CB}_{\mathrm{SH} 3-}(\mathrm{A})$ und für $\mathrm{CB}_{\mathrm{SH}_{3+}} / \mathrm{W} 24 \mathrm{~A}-\mathrm{E} 262 \mathrm{~A}(\mathrm{~B})$. Beide Spektren zeigen, dass die Bindung der Proteine an PI(3)P-haltige Vesikel keine Änderung der Sekundärstruktur der Proteine hervorruft. Das CD-Spektrum des $\mathrm{CB}_{\mathrm{SH} 3}$ zeigt nach Bindung an die Vesikel lediglich ein etwas schwächeres Signal. Dies ist auf eine kleine Änderung der Proteinkonzentration zwischen der Messung des reinen und des an Vesikel gebundenen Proteins zurück zu führen. 

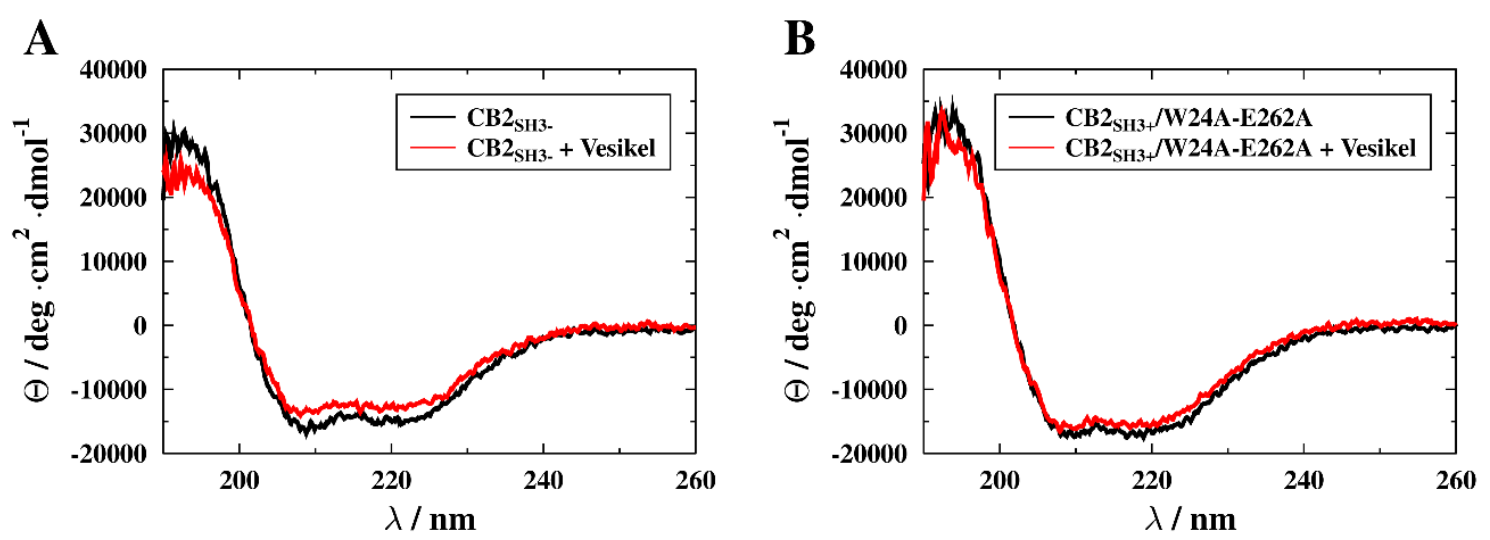

Abbildung 31: CD-Spektren des reinen (schwarz) und des an PI(3)P-haltige Vesikel gebundenen $\mathrm{CB}_{\mathrm{SH}_{3}-}$ (rot) ( $\left.\underline{\mathrm{A}}\right)$ und $\mathrm{CB}_{\mathrm{SH}_{3}+} / \mathrm{W} 24 \mathrm{~A}-\mathrm{E} 262 \mathrm{~A}(\underline{\mathrm{B}})$. Die Bindung an PI(3)Phaltige Vesikel ruft in beiden Proteinen keine Änderung der Sekundärstruktur hervor.

\subsection{Diskussion}

Die Isolierung der verwendeten Proteine $\mathrm{CB}_{\mathrm{PH}}, \mathrm{CB}_{\mathrm{SH} 3}, \mathrm{CB} \mathrm{S}_{\mathrm{H} 3+}$ und CB2 ${ }_{\mathrm{SH} 3+} / \mathrm{W} 24 \mathrm{~A}-\mathrm{E} 262 \mathrm{~A}$ wurde ähnlich dem Protokoll von Soykan et al. und Xiang et al. durchgeführt. ${ }^{[13],[16]}$ Die Aufreinigung erfolgte zunächst über eine Affinitätschromatographie mittels einer Chitin-Matrix, sodass alle Zielproteine über den als Fusionsprotein exprimierten Inteintag spezifisch gebunden wurden. Anschließend wurden die Proteinlösungen über eine Ionenaustauschchromatographie weiter aufgereinigt. In der Literatur wird eine Größenausschlusschromatographie als dritter Reinigungsschritt durchgeführt. Dies ist allerdings für die exprimierten Proteine nicht notwendig, da alle Proteinlösungen nach der Ionenaustauschchromatographie eine Reinheit von mindestens $90 \%$ aufwiesen. Im Fall der PH-Domäne des Collybistin 2 (CB2 $\left.{ }_{\mathrm{PH}}\right)$ konnte über diese Reinigungsstrategie eine Reinheit von nahezu $100 \%$ erhalten werden, was über eine SDS-PAGE durch den Erhalt einer sehr starken Proteinbande bei ca. $20 \mathrm{kDa}$ nachgewiesen werden konnte. Sowohl das Protein $\mathrm{CB} 2_{\mathrm{SH} 3}$, als auch $\mathrm{CB}_{\mathrm{SH} 3+}$ zeigten 
dagegen in den Elutionsfraktionen der Ionenaustauschchromatographie einen geringen Anteil höhermolekularer Proteinbanden. Über die Intensität der Banden in den Gelen bei $50 \mathrm{kDa}\left(\mathrm{CB} 2_{\mathrm{SH} 3}\right)$ bzw. $55 \mathrm{kDa}\left(\mathrm{CB} 2_{\mathrm{SH} 3+}\right)$ kann jedoch abgeschätzt werden, dass eine Reinheit von mindestens $90 \%$ vorlag. Die Expression und Aufreinigung des $\mathrm{CB} 2_{\mathrm{SH} 3+} / \mathrm{W} 24 \mathrm{~A}-\mathrm{E} 262 \mathrm{~A}$ ist im Vergleich zu den anderen Isoformen des Proteins schwierig. Es konnte eine geringere Ausbeute erzielt werden. Weiterhin ist im Gel der Elutionsfraktionen nach der Ionenaustauschchromatographie eine größere Zahl von nieder- und höhermolekularen Verunreinigungen mit höherer Intensität als bei den anderen Proteinen erkennbar. Diese Beobachtung wird von Soykan et al. ebenfalls beschrieben..$^{[13]}$

Die Bestimmung der Schmelzpunkte der Proteine wurde über einen fluoreszenzbasierten Assay durchgeführt. Dabei wurden die Proteine $\mathrm{CB} 2_{\mathrm{PH}}, \mathrm{CB} 2_{\mathrm{SH} 3-}$ und $\mathrm{CB} 2_{\mathrm{SH} 3+}$ auf ihre thermische Stabilität in verschiedenen Puffern getestet. Es konnte gezeigt werden, dass die Schmelztemperatur nur im Falle des CB2 $\mathrm{PH}$ eine geringe Abhängigkeit von der Pufferzusammensetzung aufweist. Allerdings wurde im Fall des $\mathrm{CB}_{\mathrm{PH}}$ eine erhöhte Startfluoreszenz im TRIS-Puffer detektiert. Dies wird durch die Bindung des Fluoreszenzfarbstoffs an die hydrophoben Bereiche der bei Raumtemperatur denaturierten Proteine ausgelöst. Dieser Effekt wurde auch für CB2 $2_{\mathrm{SH} 3-}$ beobachtet. TRIS-Puffer ist demnach nicht für die Lagerung der Proteine oder als Messpuffer geeignet. Für $\mathrm{CB} 2_{\mathrm{SH} 3-}$ und $\mathrm{CB}_{\mathrm{SH} 3+}$ wurde für alle verwendeten Puffer eine erhöhte Startfluoreszenz detektiert. Da die Schmelztemperaturen in allen Puffern im Vergleich zum $\mathrm{CB} 2_{\mathrm{PH}}$ höher waren, kann dieser Effekt nicht durch denaturierte Proteinmoleküle ausgelöst werden. Es müssen demnach hydrophobe Bereiche in den beiden Proteinen im nativen Zustand für den Farbstoff zugänglich sein. Xiang et al. beschreiben den Interaktionsbereich für die Bindung der RhoGTPase Cdc42 im Bereich der DH-Domäne des Proteins als teilweise hydrophoben 
Bereich. ${ }^{[16]} \mathrm{CB}_{\mathrm{PH}}$ besteht lediglich aus der PH-Domäne des Proteins. Im Gegensatz dazu besitzen $\mathrm{CB} 2_{\mathrm{SH} 3}$ und $\mathrm{CB} 2_{\mathrm{SH} 3+}$ die Tandemdomänenstruktur aus $\mathrm{DH}-$ und $\mathrm{PH}-$ Domäne, sodass hier eine erhöhte Startfluoreszenz durch die Bindung des Farbstoffs an den hydrophoben Bereich in der DH-Domäne auftritt. ${ }^{[63]}$

Die CD-spektroskopische Analyse sollte Erkenntnisse darüber liefern, ob die aufgereinigten Proteine den bekannten Kristallstrukturen entsprechen. Zudem sollte der Einfluss der beiden Punktmutationen an den Positionen 24 und 262 in $\mathrm{CB}_{\mathrm{SH} 3+} / \mathrm{W} 24 \mathrm{~A}-\mathrm{E} 262 \mathrm{~A}$ auf die native Struktur des $\mathrm{CB} 2_{\mathrm{SH} 3+}$ untersucht werden. Die CD-Spektroskopie zur Bestimmung der Sekundärstrukturanteile wurde in der Vergangenheit als weniger akkurat als eine Strukturaufklärung mittels NMR oder Röntgenstreuung angesehen. Für schlecht kristallisierbare Proteine bietet die CDSpektroskopie allerdings eine gute Alternative zur Strukturbestimmung. Die Röntgenstruktur des $\mathrm{CB}_{\mathrm{SH} 3}$ - wurde im Komplex mit RhoGTPase Cdc42 bestimmt (pdb code: 2DFK, Abbildung 32), sodass die erhaltenen Ergebnisse für CB2 $\mathrm{PH}$ und CB2 ${ }_{\mathrm{SH} 3}$ mit den vorliegenden Daten verglichen werden können. ${ }^{[16]}$

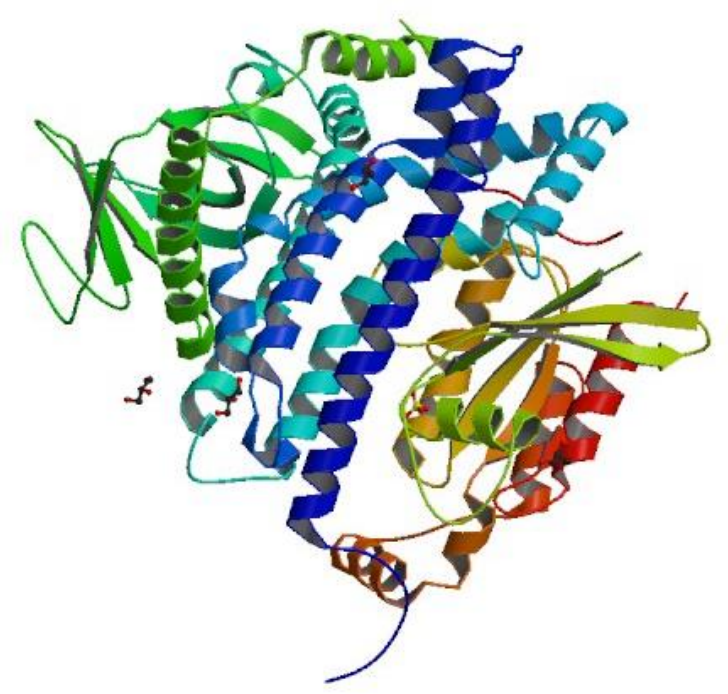

Abbildung 32: Kristallstruktur des Komplexes aus CB2 SH3- $_{-}$und RhoGTPase Cdc42 (pdb code: $\left.2 \mathrm{DFK}^{[16]}\right)$. Die PH-Domäne von $\mathrm{CB}_{\mathrm{SH} 3-}$ ist in grün dargestellt, die DH-Domäne in blau. 
Die PH-Domäne von Proteinen der Dbl-Proteinfamilie wird durch zwei antiparallele $\beta$-Faltblätter mit einer C-terminalen $\alpha$-Helix gebildet ${ }^{[64]}$ Für Collybistin wurden in der Kristallstruktur zusätzlich eine $\beta$-Schleife und eine $3_{10}$-Helix am NTerminus der PH-Domäne gefunden. ${ }^{[16]}$ Daraus resultiert eine Verteilung der Sekundärstrukturelemente von $31 \% \alpha$-Helix, $34 \% \beta$-Faltblatt und $4 \% \beta$-Schleifen. Ein Vergleich mit den CD-Experimenten zeigt, dass der Anteil der $\beta$-Faltblätter sehr gut übereinstimmt (Tabelle 11). Der Anteil der $\alpha$-Helices wurde um $50 \%$ kleiner als aus der röntgenkristallographischen Untersuchung bestimmt.

Tabelle 11: Vergleich der über CD-Spektroskopie ermittelten und aus den Kristallstrukturen berechneten Anteile der Sekundärstrukturelemente der verwendeten Collybistin-Isoformen.

\begin{tabular}{|c|c|c|c|c|}
\hline Protein & $\alpha$-Helix & $\beta$-Faltblatt & $\beta$-Schleife & ungeordnet \\
\hline $\mathrm{CB}_{\mathrm{PH}}$ & 0.14 & 0.39 & 0.17 & 0.29 \\
\hline Berechnet & 0.31 & 0.34 & 0.04 & 0.31 \\
\hline $\mathrm{CB}_{\mathrm{SH}-}$ & 0.54 & 0.09 & 0.13 & 0.23 \\
\hline Berechnet & 0.51 & 0.13 & 0.07 & 0.29 \\
\hline $\mathrm{CB}_{\mathrm{SH} 3+}$ & 0.51 & 0.23 & 0.07 & 0.18 \\
\hline $\begin{array}{l}\mathrm{CB}_{\mathrm{SH} 3+} / \\
\text { W24A-E262A }\end{array}$ & 0.53 & 0.11 & 0.14 & 0.22 \\
\hline Berechnet & 0.39 & 0.15 & 0.06 & 0.40 \\
\hline
\end{tabular}


Die in $\mathrm{CB} 2_{\mathrm{SH} 3}$ am N-Terminus der PH-Domäne stehende DH-Domäne wird durch ein helicales Bündel aus sechs $\alpha$-Helices gebildet. ${ }^{[65]}$ Dies führt in der Kristallstruktur zu einer Erhöhung des $\alpha$-helicalen Anteils auf $51 \%$. Der Anteil von $\beta$-Faltblättern reduziert sich auf $13 \%$. Dieser Effekt wurde auch in den gemessenen CD-Spektren gefunden. Die ermittelte Verteilung der Sekundärstrukturelemente stimmt sehr gut mit den Daten aus der Kristallstruktur überein.

Die Röntgenstruktur des $\mathrm{CB}_{\mathrm{SH} 3+}$ wurde von Soykan et al. bestimmt (pdb code: 4MT6, Abbildung 33).[13] Die SH3-Domäne zeichnet sich, ähnlich wie die PHDomäne, durch antiparallele $\beta$-Faltblattstrukturen mit langen ungeordneten Verbindungsschleifen aus. Bei der Kristallisation konnte der Bereich zwischen der DH- und der SH3-Domäne nicht erfolgreich aufgelöst werden, da die SH3-Domäne während des Kristallisationsprozesses vom übrigen Molekül abgespalten wurde.[13] Neben der Verbindung zwischen SH3- und DH-Domäne (33 Aminosäuren) fehlt in der Kristallstruktur ein Teil des C-Terminus des Proteins (17 Aminosäuren). Die Strukturhomologie zwischen dem aufgereinigten $\mathrm{CB}_{\mathrm{SH} 3+}$ und dem in der Kristallstruktur gezeigten $\mathrm{CB}_{\mathrm{SH} 3+}$ ist sehr hoch. Die Isoformen unterscheiden sich lediglich in ihrem C-Terminus, sodass ein Vergleich zwischen Kristallstruktur und CD-spektroskopischen Daten möglich ist. Aus der Kristallstruktur ergibt sich ein Verhältnis der Sekundärstrukturelemente von $39 \% \alpha$-Helix, $15 \% \beta$-Faltblatt, $6 \%$ $\beta$-Schleifen und $40 \%$ ungeordneten Bereichen. Im Vergleich zu den experimentell ermittelten Daten aus Abschnitt 4.7 zeigt sich, dass im Experiment insgesamt höhere Anteile an $\alpha$-Helix- und $\beta$-Faltblattstrukturen gefunden wurden. Zusätzlich wurde der ungeordnete Teil des Proteins auf $18 \%$ bestimmt. Diese Abweichungen werden durch die im Kristallisationsprozess gespaltenen Bereiche des Proteins im Kristall hervorgerufen. Insgesamt stimmen die im CD-Experiment ermittelten Anteile der Sekundärstrukturelemente gut mit denen der Kristallstrukturen überein. 


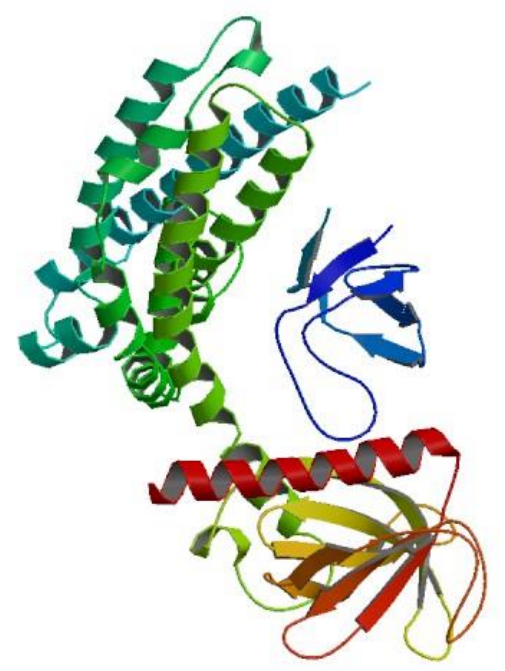

Abbildung 33: Kristallstruktur des $\mathrm{CB} 1_{\mathrm{SH} 3+}$ (pdb code: $4 \mathrm{MT} 6^{[13]}$ ). Die PH-Domäne von $\mathrm{CB}_{\mathrm{SH}_{3+}}$ ist in rot, die DH-Domäne in grün und die SH3-Domäne in blau dargestellt. Während der Kristallisation wird die SH3-Domäne von der DH/PH-Tandemdomäne abgespalten.

Es wurde bisher keine Kristallisation des $\mathrm{CB} 2_{\mathrm{SH} 3+} / \mathrm{W} 24 \mathrm{~A}-\mathrm{E} 262 \mathrm{~A}$ dokumentiert. Ein Austausch der Aminosäuren an Position 262 im $\mathrm{CB} 2_{\mathrm{SH} 3+}$ führt zu einer höheren Flexibilität des Proteins in Lösung und zu einer eher gestreckten Struktur des Proteins. ${ }^{[13]}$ Diese Änderung der Tertiärstruktur ist bei CD-Experimenten im Wellenlängenbereich von $\lambda=(190-260) \mathrm{nm}$ nicht detektierbar. Durch CDExperimente wurden lediglich kleine Änderungen in den Anteilen von $\beta$-Faltblattund $\beta$-Schleifenstrukturen gefunden. Dies könnte auf eine kleine Änderung der Struktur in der SH3- oder PH-Domäne hindeuten.

Die CD-Experimente in Gegenwart von PI(3)P-haltigen Vesikeln zeigten keine Änderung der Sekundärstrukturelemente im CB2 $2_{\mathrm{SH} 3-}$ und im $\mathrm{CB} 2_{\mathrm{SH} 3+} / \mathrm{W} 24 \mathrm{~A}-\mathrm{E} 262 \mathrm{~A}$. Ferguson et al. lokalisieren die Lipidbindungsstelle in der PH-Domäne der Phospholipase $\mathrm{C}$ in den Verbindungsschleifen zwischen den Faltblättern $\beta 1 / \beta 2$ und $\beta 3 / \beta 4$. $^{[64]}$ Soykan et al. postulieren die Verbindungsschleife zwischen den $\beta 3 / \beta 4$ Faltblättern als Bindungsstelle für $\mathrm{PI}(3) \mathrm{P}$ in Collybistin. ${ }^{[13]}$ Eine Lipidbindung über 
die ungeordneten Verbindungsschleifen sollte demnach keine Änderung der Verteilung der Sekundärstrukturelemente hervorrufen. 


\section{Festkörperunterstützte Membranen}

\subsection{Herstellung von festkörperunterstützten PIP-haltigen}

\section{Membranen}

Für die Untersuchung der Bindung der aufgereinigten Collybistin-2 Isoformen an Phosphatidylinositolphosphate (PIPs) mittels reflektometrischer Interferenzspektroskopie wurden im ersten Schritt PIP-haltige Membranen auf SiliciumdioxidWafern hergestellt. Es wurden kleine unilamellare Vesikel mit POPC als Matrixlipid und einem Phosphatidylinositolphosphat im molaren Verhältnis 9:1 in Citratpuffer4.8 (50 mM KCl, $20 \mathrm{~mm}$ Citrat, $0.1 \mathrm{~mm}$ EDTA, $0.1 \mathrm{mM} \mathrm{NaN}_{3}$, pH 4.8) hergestellt. Die Vesikel wurden auf die zuvor hydrophilisierten Siliciumwafer gegeben und der daraus resultierende Spreitprozess zeitaufgelöst verfolgt. Für die zwei- und dreifach phosphorylierten Phosphatidylinositole $\quad \mathrm{PI}(3,4) \mathrm{P}_{2}, \quad \mathrm{PI}(3,5) \mathrm{P}_{2}, \quad \mathrm{PI}(4,5) \mathrm{P}_{2} \quad$ und $\mathrm{PI}(3,4,5) \mathrm{P}_{3}$ konnten unter den beschriebenen Bedingungen kinetische Prozesse beobachtet werden, die typisch für die Ausbildung einer Lipiddoppelschicht sind. Diese zeichnen sich durch einen sprunghaften Anstieg des Messsignals direkt nach Zugabe der Vesikel gefolgt von dem Erreichen einer neuen Basislinie aus, die eine Sättigung der Oberfläche mit Lipidmaterial beschreibt. Exemplarisch ist der Spreitprozesses von $\mathrm{PI}(3,4,5) \mathrm{P}_{3}$-haltigen Vesikeln in Citratpuffer-4.8 in Abbildung 34 gezeigt. Ein schneller Anstieg der optischen Schichtdicke $\triangle O T$ zu Beginn des Prozesses führt zu einer Sättigung der Oberfläche mit Lipidmaterial und damit zu einer neuen Basislinie im Messignal. 


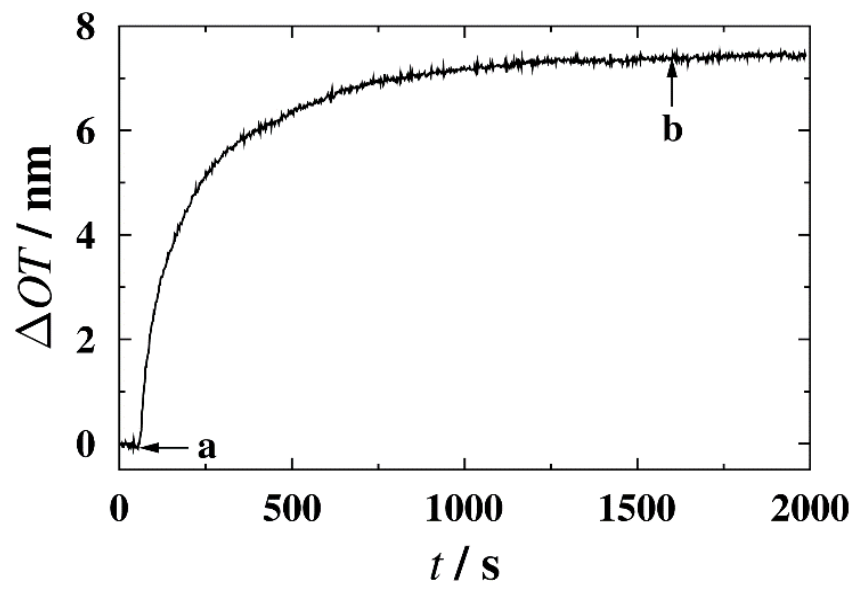

Abbildung 34: Zeitaufgelöster Spreitprozess von $\mathrm{PI}(3,4,5) \mathrm{P}_{3}$-haltigen Vesikeln auf einem hydrophilisierten Siliciumdioxidwafer. (a) Zugabe der Vesikel (POPC/PI(3,4,5) $\mathrm{P}_{3}, 9: 1$, $\left.c_{\text {Lipid }}=0.4 \mathrm{mg} / \mathrm{mL}\right)$ in Citratpuffer-4.8 $(50 \mathrm{mM} \mathrm{KCl,} 20 \mathrm{mM}$ Citrat, $0.1 \mathrm{mM}$ EDTA, $0.1 \mathrm{mM} \mathrm{NaN}_{3}, \mathrm{pH}$ 4.8). (b) Spülen mit HEPES-Puffer (100 mM NaCl, $25 \mathrm{mM}$ HEPES, $0.5 \mathrm{mM}$ EDTA, $0.5 \mathrm{mM}$ DTT, $\mathrm{pH}$ 7.2).

Die erhaltenen Werte der optischen Schichtdicke $\Delta O T$ wurden über den Zusammenhang $d=\Delta O T / n$ mit dem Brechungsindex $n_{\text {Lipid }}=1.5^{[66]}$ in die physikalische Schichtdicke $d$ umgerechnet. Im Beispiel wurde eine Lipiddoppelschicht mit einer physikalischen Schichtdicke von $d=4.8 \mathrm{~nm}$ erhalten (Abbildung $35 \mathrm{~A}$ ). Abbildung $35 \mathrm{~B}$ zeigt den Spreitprozess von PI(3)P-haltigen Vesikeln. Der Spreitprozess der Vesikel, die monophosphorylierte Phosphatidylinositole enthalten, zeigte keine Sättigung der Oberfläche durch Erreichen einer neuen Basislinie. Nach einem schnellen Anstieg der physikalischen Schichtdicke $d$ auf etwa $3.5 \mathrm{~nm}$ kommt es zu einem langsameren, aber stetigen Anstieg. Nach dem Spülen des Systems mit HEPES-Puffer (100 mM NaCl, 25 mM HEPES, $0.5 \mathrm{~mm}$ EDTA, $0.5 \mathrm{~mm}$ DTT, $\mathrm{pH}$ 7.2) wurde eine physikalische Schichtdicke der Lipiddoppelschicht von $d=5.3$ erreicht. 
A

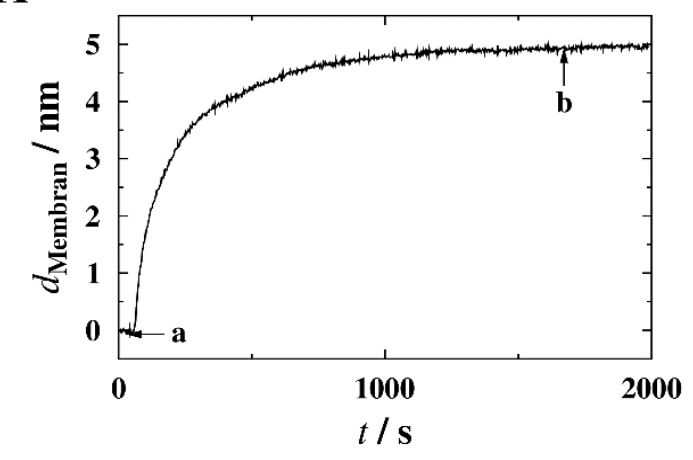

B

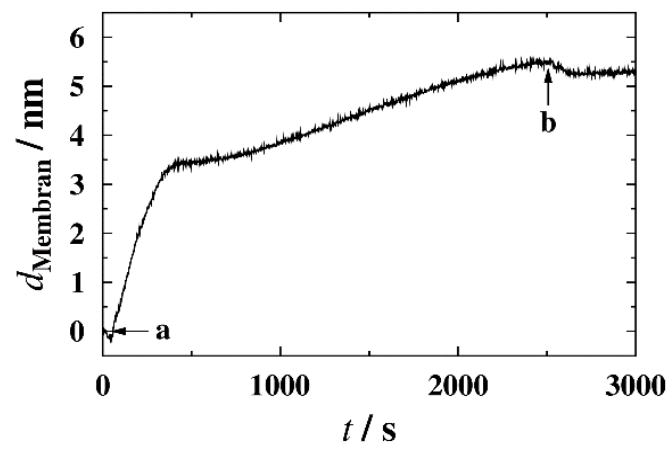

Abbildung 35: (스) Zeitaufgelöster Spreitprozess von $\mathrm{PI}(3,4,5) \mathrm{P}_{3}$-haltigen Vesikeln auf einem hydrophilisierten Siliciumdioxidwafer. (a) Zugabe der Vesikel $\left(\mathrm{POPC} / \mathrm{PI}(3,4,5) \mathrm{P}_{3}, 9: 1, \quad c_{\text {Lipid }}=0.4 \mathrm{mg} / \mathrm{mL}\right)$ in Citratpuffer-4.8 $(50 \mathrm{mM} \mathrm{KCl}, 20 \mathrm{mM}$ Citrat, $0.1 \mathrm{mM}$ EDTA, $0.1 \mathrm{mM} \mathrm{NaN}_{3}$, pH 4.8). (b) Spülen mit HEPES-Puffer (100 mM $\mathrm{NaCl}, 25 \mathrm{mM}$ HEPES, $0.5 \mathrm{mM}$ EDTA, $0.5 \mathrm{mM}$ DTT, pH 7.2). (吕) Zeitaufgelöster Spreitprozess von PI(3)P-haltigen Vesikeln auf einem hydrophilisierten Siliciumdioxidwafer. (a) Zugabe der Vesikel (POPC/PI(3)P, 9:1, $c_{\text {Lipid }}=0.4 \mathrm{mg} / \mathrm{mL}$ ) in Citratpuffer-4.8. (b) Spülen mit HEPES-Puffer.

Die Vesikelpräparation und der Spreitprozess der monophosphorylierten Phosphatidylinositole $\mathrm{PI}(3) \mathrm{P}$ und $\mathrm{PI}(4) \mathrm{P}$ wurden aufgrund der nicht optimalen Spreitkinetik bei pH 4.8 in Citratpuffer-6.4 $(50 \mathrm{~mm} \mathrm{KCl,} 20 \mathrm{~mm}$ Citrat, $0.1 \mathrm{~mm}$ EDTA, $0.1 \mathrm{mM} \mathrm{NaN}_{3}$, pH 6.4) durchgeführt. Durch den höheren pH-Wert wurde die negative Nettoladung der PIP-haltigen Vesikel nicht so stark minimiert wie bei $\mathrm{pH}$ 4.8. Dies führte zu einer Verlangsamung der Kinetik des Spreitprozesses. Allerdings konnte unter diesen Bedingungen eine Sättigung der Oberfläche mit Lipidmaterial erreicht werden (Abbildung 36). Weiterhin wurde zur Absättigung von hydrophoben Fehlstellen in den Membranen nach dem Spülen mit HEPES-Puffer eine Rinderserumalbumin-Lösung (BSA, $1 \mathrm{mg} / \mathrm{mL}$ ) in das System gegeben. ${ }^{[52]}$ Die Zugabe von BSA veränderte im Falle der mehrfach phosphorylierten Phosphatidylinositole die physikalische Schichtdicke $d$ nicht. Im Gegensatz dazu konnte eine Bindung von BSA an die PI(3)P- und PI(4)P-haltigen Membranen detektiert werden (Abbildung 36 c). Nach Erreichen einer neuen Basislinie wurde das Messsystem erneut mit HEPES-Puffer gespült. Anschließend konnten die präparierten Membranen zur 
Untersuchung der Wechselwirkung zwischen dem Phosphatidylinositolphosphat in der Membran und den verschiedenen Collybistin-2 Isoformen genutzt werden.

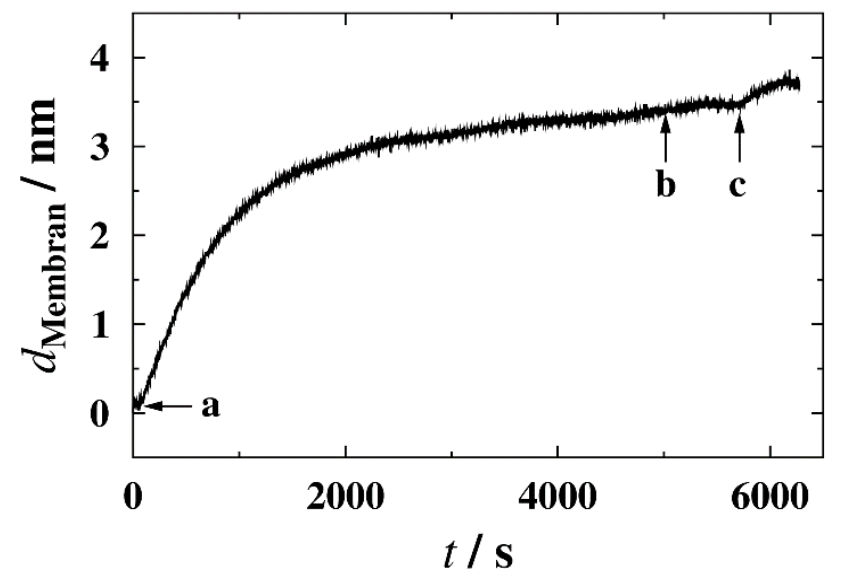

Abbildung 36: Zeitaufgelöster Spreitprozess von PI(3)P-haltigen Vesikeln auf einem hydrophilisierten Siliciumdioxidwafer. (a) Zugabe der Vesikel (POPC/PI(3)P, 9:1, $\left.c_{\text {Lipid }}=0.4 \mathrm{mg} / \mathrm{mL}\right)$ in Citratpuffer-6.4 $(50 \mathrm{mM} \mathrm{KCl,} 20 \mathrm{mM}$ Citrat, $0.1 \mathrm{mM}$ EDTA, $0.1 \mathrm{mM} \mathrm{NaN}_{3}, \mathrm{pH}$ 6.4). (b) Spülen mit HEPES-Puffer.

Die ermittelten Membranschichtdicken der verschiedenen Lipidmischungen sind in Abbildung 37 zusammengefasst dargestellt. Eine Membran aus reinem POPC weist eine physikalische Schichtdicke $d=4.28 \pm 0.04 \mathrm{~nm}$ auf. Im Vergleich waren die unmittelbar nach dem Spreitprozess ermittelten Schichtdicken der mit monophosphorylierten Phosphatidylinositolen dotierten Membranen (PI(3)P: $3.8 \pm 0.4 \mathrm{~nm}, \quad \mathrm{PI}(4) \mathrm{P}: 3.7 \pm 0.7 \mathrm{~nm})$ deutlich kleiner. Die mit den mehrfach $\begin{array}{llll}\text { phosphorylierten Phosphatidylinositolen dotierten } & \text { Membranen } & \mathrm{PI}(3,4) \mathrm{P}_{2}\end{array}$ $(d=4.3 \pm 0.3 \mathrm{~nm}), \quad \operatorname{PI}(3,5) \mathrm{P}_{2} \quad(d=4.5 \pm 0.4 \mathrm{~nm}), \quad \operatorname{PI}(4,5) \mathrm{P}_{2} \quad(d=4.4 \pm 0.3 \mathrm{~nm})$ und $\mathrm{PI}(3,4,5) \mathrm{P}_{3}(d=4.4 \pm 0.4 \mathrm{~nm})$ zeigen höhere Membranschichtdicken als das reine $\mathrm{POPC}$. 


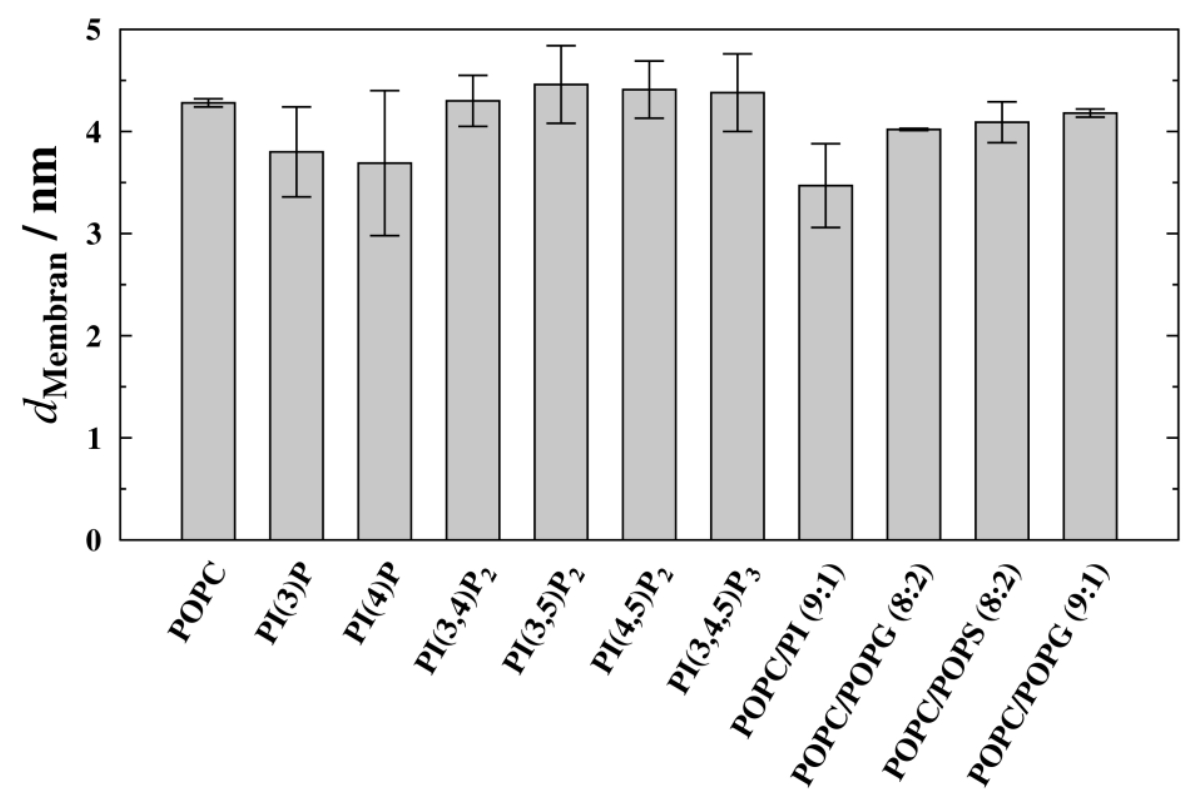

Abbildung 37: Physikalische Schichtdicken der präparierten festkörperunterstützten Membranen. Die Membranen wurden, wenn nicht anders angegeben, aus dem Matrixlipid POPC und einem Rezeptorlipid im molaren Verhältnis 9:1 hergestellt. Die Fehlerbalken stellen die Standardabweichung vom Mittelwert aus allen durchgeführten Messungen dar.

Neben PIP-dotierten Membranen wurden die negativ geladenen Lipide POPS, POPG und PI als Rezeptorlipide für Vergleichsmessungen verwendet. Die mit diesen Lipiden dotierten Vesikel wurden in HEPES-Puffer hergestellt und gespreitet. Es konnten Spreitprozesse mit einem Sättigungsverhalten beobachtet werden. Die Schichtdicke der mit Phosphatidylinositol (PI) dotierten Membran $(d=3.5 \pm 0.4 \mathrm{~nm})$ ist mit den Ergebnissen für die monophosphorylierten PIPs vergleichbar. Auch hier konnten Fehlstellen in der Membran durch die Zugabe von BSA blockiert werden. Die mit POPG oder POPS dotierten Membranen weisen physikalische Schichtdicken im Bereich der reinen POPC-Membranen auf $\left(d_{\mathrm{POPS}}=4.1 \pm 0.2 \mathrm{~nm}, d_{\mathrm{POPG}, 8: 2}=4.02 \pm 0.01 \mathrm{~nm}, d_{\mathrm{POPG}} 9: 1=4.18 \pm 0.04 \mathrm{~nm}\right)$. 


\subsection{Diskussion}

Mit Hilfe der reflektometrischen Interferenzspektroskopie konnte die Bildung von PIP-haltigen planaren Membranen aus Vesikeln zeitaufgelöst und markierungsfrei beobachtet werden. Bisher wurden die Untersuchungen der Bindung von Proteinen an verschiedene Phosphatidylinositolphosphate über die Immobilisierung von Vesikeln auf Hydrogelmatrizen durchgeführt. ${ }^{[67],[68],[69]}$ Die in dieser Studie verwendeten planaren Membranen imitieren die durch das Cytoskelett gestützten Zellmembranen in lebenden Zellen besser. Die Lipidmischung in der Membran wurde in den Experimenten stark vereinfacht, um Einflüsse von anderen Lipiden auf die Anbindung eines Proteins an Phosphatidylinositolphosphate zu verhindern. Es wurden PIP-haltige Vesikel in Citratpuffer mit einem $\mathrm{pH}$-Wert unterhalb des physiologischen Bereichs hergestellt. Dieser pH-Wert reduziert durch Protonierung der Phosphatgruppen in der Inositolkopfgruppe die negative Ladung der Lipide. ${ }^{[0]}$ Bei einem physiologischen pH-Wert beträgt die Nettoladung des PI(4,5) $\mathrm{P}_{2}$-Moleküls -4. Diese wird auf -3 bei einem pH-Wert von 4.8 gesenkt. ${ }^{[71],[72]}$ Weiterhin wird die negative Ladung der Siliziumoberfläche um den Faktor 3 reduziert, sodass ein Spreiten der Vesikel durch eine Reduktion der repulsiven Wechselwirkung zwischen Oberfläche und Vesikeln vereinfacht wird. ${ }^{[73]}$ Braunger et al. konnten zeigen, dass nur bei einem pH-Wert von 4.8 nach dem Spreiten von Vesikeln auf Siliziumdioxid eine homogene Verteilung von $\mathrm{PI}(4,5) \mathrm{P}_{2}$-Molekülen auf der Oberfläche vorliegt. ${ }^{[0]}$ Zusätzlich wurde unter den beschriebenen Spreitbedingungen die Bildung von $\mathrm{PI}(4,5) \mathrm{P}_{2}$-Clustern auf der Oberfläche verhindert. ${ }^{[74,[75]}$ Für die monophosphorylierten Phosphatidylinositole PI(3)P und PI(4)P konnte bei pH 4.8 kein Sättigungsverhalten der Spreitkinetik beobachtet werden. Diese Moleküle besitzen aufgrund ihres niedrigeren Phosphorylierungsgrads im Vergleich mit den mehrfach phosphorylierten PIPs eine um den Faktor 1.5 geringere Nettoladung bei $\mathrm{pH}$ 7. Aus den $\mathrm{pK}_{\mathrm{S}}$-Werten 
der Phosphatgruppen ergibt sich bei $\mathrm{pH} 7.0$ für $\mathrm{PI}(4,5) \mathrm{P}_{2}$ eine Ladung $\mathrm{Q}=-$ 3.99. ${ }^{[76,[77]}$ Für PI(3)P beträgt diese $\mathrm{Q}=-2.52 \cdot{ }^{[76]}$ Zur Reduktion der Oberflächenladung der PIP-haltigen Vesikel werden für PI(3)P- und PI(4)P-haltige Vesikel demnach weniger Protonen als für die mit mehrfach phosphorylierten Phosphatidylinositolen dotierten Vesikel benötigt. Die Reduktion der repulsiven Kräfte während des Spreitprozesses war bei einem pH-Wert von 6.4 ausreichend, sodass eine Spreitkinetik mit einem für die Ausbildung einer Lipiddoppelschicht typischen Sättigungsverhalten erhalten wurde.

Nach dem Spreitprozess wurden die festkörperunterstützten Membranen durch Spülen mit HEPES-Puffer in einen physiologisch relevanten pH-Wert überführt. Die statistische Verteilung der Phosphatidylinositolphosphate in der Membran soll dabei erhalten bleiben ${ }^{[70]}$ Im Gegensatz dazu zeigen bei physiologischem pH-Wert erzeugte PIP-haltige Lipidmonoschichten Phasenseperation. ${ }^{[78]}$ Dabei sind die PI-Moleküle in der fluiden und das Matrixlipid DSPC in der flüssigkristallinen Phase lokalisiert. In den Monoschichtexperimenten wird deutlich, dass die Fläche pro Molekül mit steigender PIP-Konzentration bei einem lateralen Druck von $30 \mathrm{mN} / \mathrm{m}$ zunimmt. ${ }^{[79]}$ Diese Beobachtung ist auch auf die durch Vesikelspreiten erzeugten Lipiddoppelschichten übertragbar.

Eine gute Kontrolle über die Güte der präparierten festkörperunterstützten Membranen bieten die ermittelten physikalischen Schichtdicken. Kucerka et al. haben die Dicke einer reinen POPC-Membran über Röntgenbeugung auf $d=(3.98 \pm 0.08) \mathrm{nm}$ bestimmt. ${ }^{[80]}$ Dieser Wert stimmt mit dem im Experiment ermittelten Wert von $d=4.28 \pm 0.04 \mathrm{~nm}$ gut überein. Die mit mehrfach phosphorylierten Phosphatidylinositolen dotierten Membranen zeigen höhere physikalische Schichtdicken. Lupyan et al. haben gezeigt, dass die Inositolkopfgruppen um $(0.6 \pm 0.1) \mathrm{nm}$ aus der Oberfläche einer Lipiddoppelschicht 
heraus ragen. ${ }^{[81]}$ Dieser Effekt wird auch für das Phosphatidylinositol PI und die monophosphorylierten Phosphatidylinositole erwartet. Im Experiment wurden dennoch Schichtdicken unterhalb der Dicke einer reinen POPC-Membran beobachtet. Dies deutet an, dass die ausgebildeten Membranen Fehlstellen aufwiesen. Der Anstieg der physikalischen Schichtdicke $d$ nach Zugabe des Rinderserumalbumins (BSA) weist darauf hin, dass die Fehlstellen in der Membran mit Hilfe von BSA aufgefüllt wurden. ${ }^{[52]}$ Unter der Bedingung, dass die Membranen keine weiteren hydrophoben Fehlstellen aufweisen, sind im weiteren Verlauf der Messungen keine unspezifischen Wechselwirkungen zwischen den hydrophoben Membrandefekten und dem zugegebenen Protein zu erwarten.

Bradshaw et al. haben die relative Orientierung der Inositolkopfgruppe zu einer festkörperunterstützten Membran beschrieben. ${ }^{[82]}$ Sie konnten über die Neutronenstreuung und Röntgenbeugung belegen, dass die unphosphorylierte Kopfgruppe im Phosphatidylinositol senkrecht zur Membran steht, sodass die Hydroxylgruppe an der 4-Position des Inositolrings den höchsten Punkt des Moleküls bildet. Wenn die 4-Hydroxylgruppe phosphoryliert vorliegt (vgl. PI(4)P), dreht sich die Inositolkopfgruppe, sodass die 2-Hydroxylgruppe in Richtung der Membran zeigt und die 5-Hydroxylgruppe am weitesten von der Membran entfernt ist. Diese Orientierung der Kopfgruppe wird durch elektrostatische Wechselwirkungen zwischen der negativ geladenen 4-Phosphatgruppe am Inositolring und dem positiv geladenen Trimethylammoniumrest der Cholingruppe im Matrixlipid DMPC bevorzugt. ${ }^{[82]}$ Kishore et al. postulieren weitere mögliche Konformationen von $\mathrm{PI}(4) \mathrm{P}$ und $\mathrm{PI}(4,5) \mathrm{P}_{2}$ in Lipiddoppelschichten. Sie bestätigen die Tendenz der Beugung der phosphorylierten Inositolkopfgruppe zur Membranoberfläche. ${ }^{[83]}$ In dieser Studie konnte keine Aussage über die Konformation der Inositolkopfgruppe der verschiedenen PIPs in der festkörperunterstützten 
Membran betroffen werden. Allerdings könnte dies einen Einfluss auf die Zugänglichkeit der PIP-Kopfgruppen für das Protein CB2 haben. 


\section{Untersuchung der Wechselwirkung von CB2Рн mit PIP-haltigen Membranen}

\subsection{Etablierung des Messsystems für die Adsorption von}

\section{$\mathrm{CB}_{\mathrm{PH}}$ an Membranen}

Mit Hilfe des in 3.3.1 beschriebenen Messaufbaus wurden die Bindungseigenschaften der Proteine $\mathrm{CB} 2_{\mathrm{PH}}, \mathrm{CB} 2_{\mathrm{SH} 3}, \mathrm{CB} 2_{\mathrm{SH} 3+}$ und $\mathrm{CB} 2_{\mathrm{SH} 3+} / \mathrm{W} 24 \mathrm{~A}-$ E262A an mit Phosphatidylinositolphosphaten dotierten festkörperunterstützten Membranen untersucht. Die Membranen bestanden aus POPC als Matrixlipid und $10 \mathrm{~mol} \%$ PIP. Zur Auswertung der durchgeführten Adsorptionsstudien wurde das Adsorptionsmodell nach Langmuir verwendet. Die Theorie zur Beschreibung der Thermodynamik von Adsorptionsprozessen wird in 6.2.1 vorgestellt.

\subsubsection{Etablierung des Messsystems im Phosphat-Puffer}

Zur Untersuchung der Wechselwirkung zwischen Phosphatidylinositolphosphaten und den Collybistin-2 Isoformen mittels reflektometrischer Interferenzspektroskopie wurden zunächst festkörperunterstützte Membranen präpariert (Kapitel 5.1). Zur Etablierung eines Messsystems wurden Messungen mit der PH-Domäne ${ }_{\text {CB2 }} \mathrm{PH}$ durchgeführt. Diese konnte in guter Ausbeute aufgereinigt werden (Kapitel 4.2) und

stellt das Minimalsystem zur Bindung von Collybistin 2 an ein 
Phosphatidylinositolphosphat in einer Membran dar. ${ }^{[13]}$ Zur Detektion der Interaktion mit $\mathrm{CB}_{\mathrm{PH}}$ wurde das Messsystem nach der Herstellung der festkörperunterstützten Membran und der Absättigung von Fehlstellen mit Hilfe von BSA mit Phosphat-Puffer $\left(250 \mathrm{~mm} \mathrm{KCl}, 20 \mathrm{~mm} \mathrm{KH}_{2} \mathrm{PO}_{4} / \mathrm{K}_{2} \mathrm{HPO}_{4}, 2 \mathrm{~mm}\right.$ EDTA, pH 7.4) gespült. Das Protein wurde zuvor mittels Zentrifugalkonzentratoren ebenfalls in diesen Puffer überführt. Zur Analyse der Wechselwirkung zwischen dem Phosphatidylinositolphosphat in der Membran (POPC/PI(4,5) $\left.\mathrm{P}_{2}, 9: 1\right)$ und $\mathrm{CB}_{2 \mathrm{PH}}$ wurden $0.37 \mu \mathrm{M} \mathrm{CB} 2_{\mathrm{PH}}(\mathrm{c})$ im Phosphat-Puffer zu der Membran gegeben (Abbildung 38). Es konnte keine Änderung der physikalischen Schichtdicke detektiert werden. Auch eine Erhöhung der CB2 $2_{\mathrm{PH}}-$ Konzentration auf $1.85 \mu \mathrm{M}$ (d) zeigte keine Bindung des Proteins an die festkörperunterstützte Membran. Zur Überprüfung der Zugänglichkeit der $\mathrm{PI}(4,5) \mathrm{P}_{2}$-Moleküle in der Lipiddoppelschicht wurde das Protein Ezrin zugegeben, Dieses Protein bindet selektiv an $\mathrm{PI}(4,5) \mathrm{P}_{2}$ in Membranen. ${ }^{[84]}$ Das System wurde mit E1-Puffer $(50 \mathrm{~mm} \mathrm{KCl,} 20 \mathrm{~mm}$ TRIS, $0.1 \mathrm{~mm}$ EDTA, $0.1 \mathrm{~mm}$ $\mathrm{NaN}_{3}, \mathrm{pH}$ 7.4) gespült (e) und es wurden $0.37 \mu \mathrm{M}$ Ezrin Wildtyp (f) zugegeben. Hier änderte sich die physikalische Schichtdicke um $\Delta d=4.4 \mathrm{~nm}$. Nach dem Spülen mit E1-Puffer (g) sank die physikalische Schichtdicke wieder ab. Dies zeigt, dass die Bindung des Ezrin an $\mathrm{PI}(4,5) \mathrm{P}_{2}$ teilweise reversibel war.
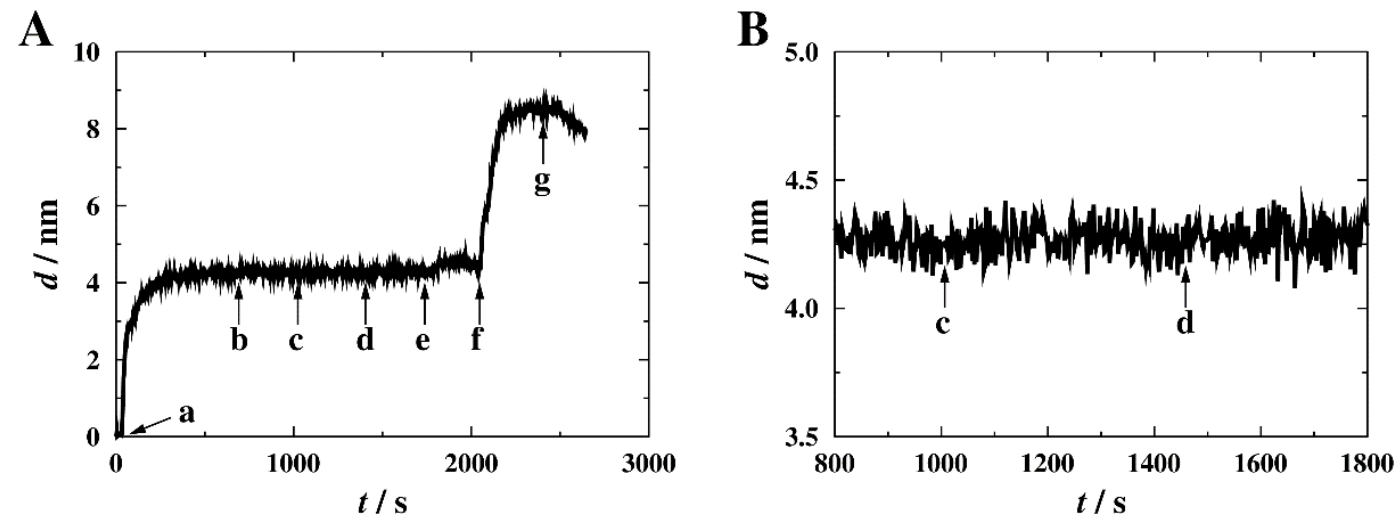

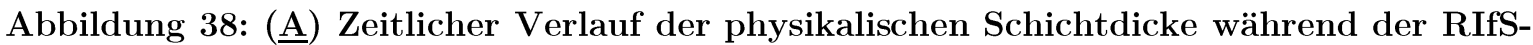
Messung. (a) Zugabe von $\mathrm{PI}(4,5) \mathrm{P}_{2}$-haltigen Vesikeln in Citratpuffer $4.8(50 \mathrm{mM} \mathrm{KCl}$, $20 \mathrm{~mm}$ Citrat, $0.1 \mathrm{mM}$ EDTA, $0.1 \mathrm{mM} \mathrm{NaN}_{3}$, pH 4.8) (b) Spülen mit Phosphat-Puffer 
$\left(250 \mathrm{mM} \mathrm{KCl}, 20 \mathrm{mM} \mathrm{KH} \mathrm{PO}_{4} / \mathrm{K}_{2} \mathrm{HPO}_{4}, 2 \mathrm{mM}\right.$ EDTA, $\mathrm{pH}$ 7.4). Zugabe von $0.37 \mu \mathrm{M}$ (c)

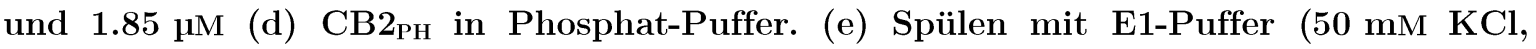
$20 \mathrm{mM}$ TRIS, $0.1 \mathrm{mM}$ EDTA, $0.1 \mathrm{mM} \mathrm{NaN}_{3}$, pH 7.4). (f) Zugabe von $0.37 \mu \mathrm{M}$ Ezrin Wildtyp. (g) Spülen mit E1-Puffer. (ㅌ) zeigt eine Vergrößerung der Messung bei der CB2 ${ }_{\mathrm{PH}}-\mathrm{Zugabe}$.

Die Anbindung des Ezrin Wildtyps an die PI $(4,5) \mathrm{P}_{2}$ dotierte Membran zeigt, dass die Zugänglichkeit der Inositolkopfgruppe in der Membran gewährleistet ist. Es konnte keine Bindung des $\mathrm{CB} 22_{\mathrm{PH}}$ an diese Membran detektiert werden. Es wird deutlich, dass der verwendete Phosphat-Puffer nicht zur Messung der Wechselwirkung zwischen festkörperunterstützten Membranen und CB2 $2_{\mathrm{PH}}$ geeignet ist.

\subsubsection{Etablierung des Messsystems im TRIS-Puffer}

Da im Phosphat-Puffer (250 mM KCl, 20 mM $\mathrm{KH}_{2} \mathrm{PO}_{4} / \mathrm{K}_{2} \mathrm{HPO}_{4}, 2 \mathrm{~mm}$ EDTA, pH 7.4) keine Bindung von $\mathrm{CB}_{2 \mathrm{PH}}$ an die $\mathrm{PI}(4,5) \mathrm{P}_{2}$-haltige Membran detektiert werden konnte, wurde im Folgenden ein TRIS-Puffer (150 mM NaCl, 20 mM TRIS, pH 7.4) für die Bindungsstudien eingesetzt. Der Puffer weist im Vergleich zum PhosphatPuffer eine geringere Salzkonzentration auf, sodass eine elektrostatische Abschirmung der Lipid-Proteinbindung verhindert werden soll. Zur Analyse der Wechselwirkung mit $\mathrm{PI}(4,5) \mathrm{P}_{2}$ wurden $0.37 \mu \mathrm{M}$ CB2 ${ }_{\mathrm{PH}}$ (Abbildung $39 \mathrm{c}$ ) direkt nach der Dialyse in den TRIS-Puffer auf die Membran gegeben. Es konnte keine Änderung der physikalischen Schichtdicke $\Delta d$ detektiert werden. Eine Erhöhung der Konzentration auf $1.85 \mu \mathrm{M} \quad \mathrm{CB} 2_{\mathrm{PH}}$ (d) zeigte ebenfalls keine Änderung der physikalischen Schichtdicke. Zudem konnten schon 1 Stunde nach der Dialyse des Proteins in den TRIS-Puffer Präzipitate in der Proteinlösung beobachtet werden. Diese Beobachtung macht deutlich, dass $\mathrm{CB}_{\mathrm{PH}}$ nach der Dialyse in den TRIS-Puffer nicht stabil ist. 
A

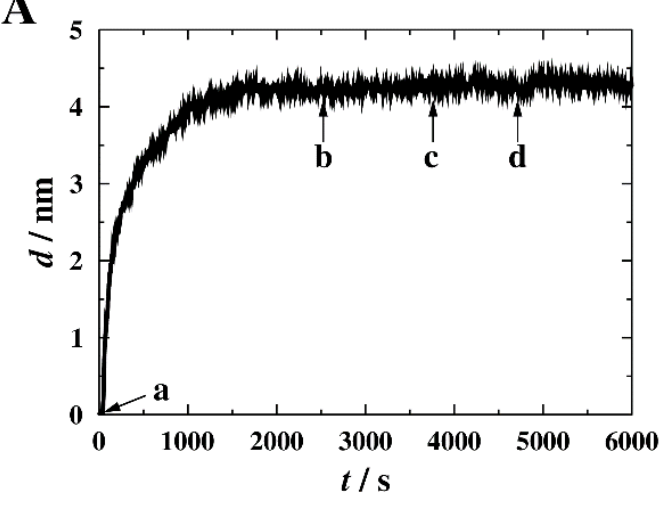

B

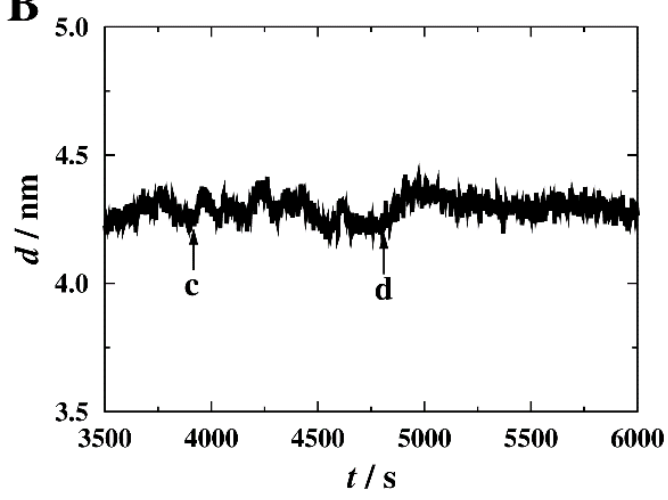

Abbildung 39: (스) Zeitlicher Verlauf der Schichtdickenänderung während der RIfSMessung. (a) Zugabe von $\mathrm{PI}(4,5) \mathrm{P}_{2}$-haltigen Vesikeln in Citratpuffer $4.8(50 \mathrm{mM} \mathrm{KCl}$, $20 \mathrm{~mm}$ Citrat, $0.1 \mathrm{mM}$ EDTA, $0.1 \mathrm{mM} \mathrm{NaN}_{3}$, pH 4.8) (b) Spülen mit TRIS-Puffer (150 mM NaCl, $20 \mathrm{mM}$ TRIS, pH 7.4). Zugabe von $0.37 \mu \mathrm{M}$ (c) und $1.85 \mu \mathrm{M}$ (d) CB2 $\mathrm{PH}$ in TRIS-Puffer. $(\underline{B})$ zeigt eine Vergrößerung des Messsignals bei der CB2 ${ }_{\mathrm{PH}}$-Zugabe.

Der TRIS-Puffer eignet sich nicht zur Quantifizierung der Wechselwirkung zwischen $\mathrm{CB} 2_{\mathrm{PH}}$ und Phosphatidylinositolphosphaten, da die Stabilität des $\mathrm{CB}_{\mathrm{PH}}$ in diesem Puffer nicht ausreichend war.

\subsubsection{Etablierung des Messsystems in HEPES-Puffer}

Die in Kapitel 6.1.1 und 6.1.2 dargestellten Ergebnisse zeigen, dass eine quantitative Untersuchung der Bindung von $\mathrm{CB} 22_{\mathrm{PH}}$ an PIP-dotierte Membranen weder im Phosphat- noch im TRIS-Puffer möglich war. Aus diesem Grund wurde versucht $\mathrm{CB}_{\mathrm{PH}}$ in HEPES-Puffer $(100 \mathrm{~mm} \mathrm{NaCl}, 25 \mathrm{~mm}$ HEPES, $0.5 \mathrm{~mm}$ EDTA, 0.5 mM DTT, pH 7.2,) an die festkörperunterstützte Membran zu binden. Der Puffer weist im Vergleich zum TRIS- und Phosphatpuffer eine geringere Salzkonzentration auf. Außerdem wurden zur Stabilisierung des Proteins DTT und EDTA hinzugefügt. ${ }^{[85]}$ Nach der Präparation der festkörperunterstützten Membran unter den in Abschnitt 5.1 beschriebenen Bedingungen wurde das System mit HEPES- 
Puffer gespült. Anschließend wurde das Protein $\mathrm{CB} 2{ }_{\mathrm{PH}}$ auf die Lipiddoppelschicht gegeben.

Abbildung 40 zeigt den Verlauf der Messung auf einer $\mathrm{PI}(4,5) \mathrm{P}_{2}$ dotierten festkörperunterstützten Membran im HEPES-Puffer. Die PI(4,5) $\mathrm{P}_{2}$-haltigen Vesikel wurden im Citratpuffer-4.8 $(50 \mathrm{mM} \mathrm{KCl,} 20 \mathrm{~mm}$ Citrat, $0.1 \mathrm{~mm}$ EDTA, $0.1 \mathrm{~mm}$ $\mathrm{NaN}_{3}$, pH 4.8) gespreitet (a) und das System anschließend mit HEPES-Puffer equilibriert (b). Die Zugabe von $0.37 \mu \mathrm{M} \mathrm{CB}_{\mathrm{PH}}$ (c) führte zu einer Zunahme der physikalischen Schichtdicken $\Delta d=0.8 \mathrm{~nm}$. Nach Erreichen einer neuen Basislinie wurde mit HEPES-Puffer gespült (d). Die physikalische Schichtdicke der Proteinschicht reduzierte sich auf $\Delta d=0.65 \mathrm{~nm}$.

A

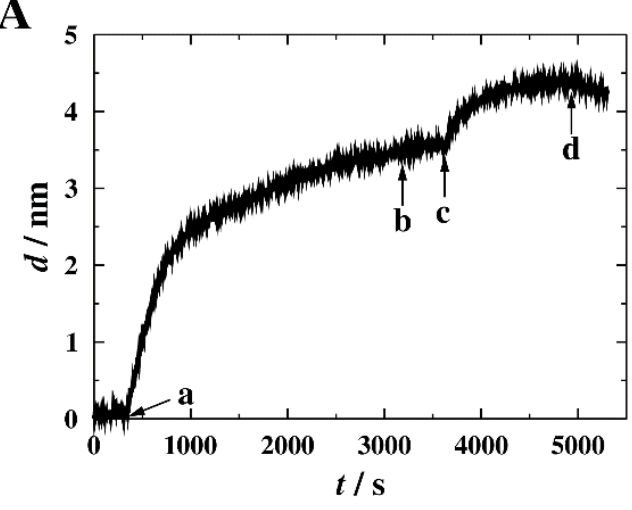

B

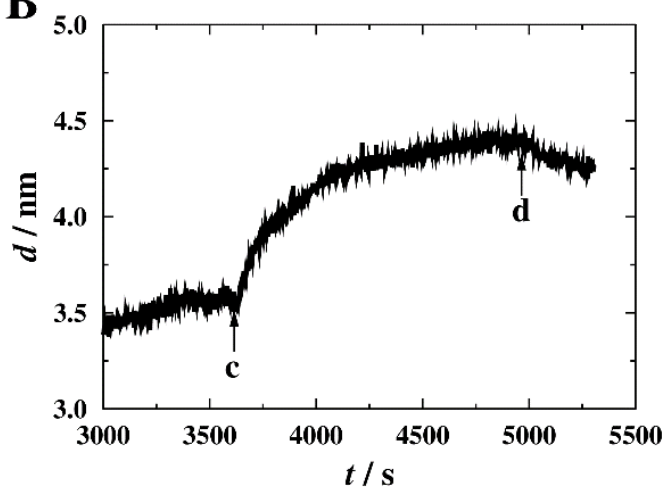

Abbildung 40: (스) Zeitlicher Verlauf der Schichtdickenänderung während der RIfSMessung. (a) Zugabe von $\mathrm{PI}(4,5) \mathrm{P}_{2}$-haltigen Vesikeln in Citratpuffer $4.8(50 \mathrm{mM} \mathrm{KCl}$, $20 \mathrm{mM}$ Citrat, $0.1 \mathrm{mM}$ EDTA, $0.1 \mathrm{mM} \mathrm{NaN}_{3}$, pH 4.8) (b) Spülen mit HEPES-Puffer (100 mM NaCl, $25 \mathrm{~mm}$ HEPES, $0.5 \mathrm{mM}$ EDTA, $0.5 \mathrm{mM}$ DTT, pH 7.2). (c) Zugabe von $0.37 \mu \mathrm{M} \mathrm{CB} 2_{\mathrm{PH}}$ in HEPES-Puffer. (d) Spülen mit HEPES-Puffer. (B) zeigt eine Vergrößerung des Messsignals bei der $\mathrm{CB}_{\mathrm{PH}_{\mathrm{PH}}}$ Zugabe.

Im HEPES-Puffer konnte eine deutliche Änderung der optischen Schichtdicke durch die Anbindung von $\mathrm{CB}_{\mathrm{PH}}$ an die $\mathrm{PI}(4,5) \mathrm{P}_{2}$-haltige Lipiddoppelschicht detektiert werden. Die Bindung des Proteins an das Phosphatidylinositolphosphat ist zudem partiell reversibel, da ein Teil des gebundenen Proteins beim Spülen mit Puffer von der Membran entfernt werden konnte. Der HEPES-Puffer stellt ein 
geeignetes Messsystem für die quantitative Untersuchung der Wechselwirkung zwischen $\mathrm{PI}(4,5) \mathrm{P}_{2}$ und den Collybistin-2 Isoformen dar.

\subsection{Theoretische Grundlagen der Proteinadsorption}

\section{Grenzflächen}

Im Rahmen dieser Arbeit wurden die thermodynamischen Parameter der Interaktion von verschiedenen Collybistin-Isoformen mit verschiedenen Phosphatidylinositolphosphaten (PIPs) unter Verwendung der reflektometrischen Interferenzspektroskopie (RIfS) bestimmt. Dazu wurden PIP-haltige festkörperunterstützte Membranen präpariert, an denen die verschiedenen Proteine über eine PIP-Bindungsstelle in der PH-Domäne angebunden wurden. Die Proteinkonzentration im Messsystem wurde sukzessive bis zur vollständigen Sättigung der Membran erhöht. Die ablaufenden Prozesse finden dabei an der FestFlüssig-Phasengrenze statt, sodass die thermodynamischen Parameter mittels des Ansatzes zur Beschreibung der Adsorption an Grenzflächen nach Langmuir bestimmt werden konnten.

\subsubsection{Langmuir-Adsorptionsisotherme}

Die Dissoziationskonstante $K_{\mathrm{D}}$ als thermodynamischer Parameter einer ProteinMembran-Interaktion kann mit Hilfe der Langmuirschen Adsorptionsisotherme bestimmt werden. Langmuir beschreibt die Reaktion an energetisch homogenen Oberflächen in Abhängigkeit von Temperatur und Konzentration. Dabei steht die 
Adsorption und Desorption eines Stoffes an einer Grenzfläche in einem dynamischen Gleichgewicht. Die Anbindung von Protein an eine festkörperunterstützte Membran wird als reversible Grenzflächenreaktion beschrieben. Für die Gültigkeit der Langmuir-Isotherme gelten folgende Voraussetzungen:

- Es wird bei der Adsorption maximal eine monomolekulare Schicht ausgebildet.

- Die Bindungsplätze sind alle energetisch gleichwertig und ihre Besetzung hängt nicht vom Bedeckungsgrad der Oberfläche ab, sodass die Adsorptionsenergie im gesamten Prozess konstant ist.

- Es gibt eine endliche Anzahl an Bildungsplätzen.

- Es gibt keine Wechselwirkungen zwischen schon adsorbierten Teilchen, d. h. die Wahrscheinlichkeit für die Besetzung einer Bindungsstelle ist immer gleich und nicht abhängig von den benachbarten Plätzen.

Neben dem eigentlichen Bindungsprozess muss bei der Beschreibung der Adsorption eines Liganden L (hier: Collybistin-Isoform) an einen Bindungsplatz B (hier: PIP-haltige Membran) auch der Transport des Liganden zur Grenzfläche berücksichtigt werden. Bei der Adsorption eines Ligandmoleküls an einen Bindungsplatz nimmt die Ligandenkonzentration $c_{\mathrm{L}}$ im Bereich der Wechselwirkungsschicht ab. Die Konzentration des Liganden in unmittelbarer Nähe zu den Bindungsplätzen kann nur als konstant betrachtet werden, wenn die Adsorption des Liganden L an den Bindungsplatz B der geschwindigkeitsbestimmende Schritt im System ist. Dazu muss diese ratenkontrollierte Reaktion mindestens zehnmal langsamer ablaufen als der Massentransport zur Oberfläche im Messsystem. Die Reaktion wird als diffusionskontrolliert betrachtet, wenn die 
Reaktion an der Oberfläche mindestens genauso schnell wie der Transport des Liganden zur Oberfläche ist. Das dynamische Gleichgewicht zwischen dem Liganden und dem an eine Bindungsstelle gebundenen Liganden L-B wird unter Berücksichtigung der Transportrate $k_{\text {tr }}$ des Liganden zur Oberfläche wie folgt beschrieben:

$$
L \stackrel{k_{\mathrm{rr}}}{\longrightarrow} L+B \underset{k_{\mathrm{des}}}{\stackrel{k_{\mathrm{ad}}}{\rightleftarrows}} L-B
$$

Dabei beschreibt $k_{\text {ad }}$ den Geschwindigkeitskoeffizienten der Adsorption und $k_{\text {des }}$ den Geschwindigkeitskoeffizienten der Desorption. Daraus ergibt sich für die Adsorptionsgeschwindigkeit des Liganden die Differentialgleichung:

$$
\frac{\mathrm{d} \Gamma_{\mathrm{L}-\mathrm{B}}(t)}{\mathrm{d} t}=k_{\mathrm{ad}} \Gamma_{\mathrm{B}}(t) c_{\mathrm{L}}(t)-k_{\mathrm{des}} \Gamma_{\mathrm{L}-\mathrm{B}}(t)
$$

$\Gamma_{\mathrm{L}-\mathrm{B}}(t): \quad$ Flächenkonzentration des gebundenen Liganden zum Zeitpunkt $t$

$\Gamma_{\mathrm{B}}(t): \quad$ Flächenkonzentration der freien Bindungsplätze zum Zeitpunkt $t$

$c_{\mathrm{L}}(\mathrm{t}): \quad$ Konzentration der freien Liganden in Lösung

Die Ligandenkonzentration $c_{\mathrm{L}}$ wird unter der Annahme einer ratenkontrollierten Reaktion und eines Überschusses des Liganden mit der Anfangskonzentration des Liganden $c_{\mathrm{L}, 0}$ gleichgesetzt. Die Konzentration der zum Zeitpunkt $t$ verfügbaren Bindungsplätze $\Gamma_{\mathrm{B}}(t)$ wird aus der Startkonzentration der Bindungsplätze $\Gamma_{\mathrm{B}, 0}$ und der schon besetzten Bindungsplätzen $\Gamma_{\mathrm{L}-\mathrm{B}}(t)$ über $\Gamma_{\mathrm{L}-\mathrm{B}}(t)=\Gamma_{\mathrm{B}, 0}-\Gamma_{\mathrm{L}-\mathrm{B}}(t)$ bestimmt.

$$
\frac{\mathrm{d} \Gamma_{\mathrm{L}-\mathrm{B}}(t)}{\mathrm{d} t}+\left(k_{\mathrm{ad}} c_{\mathrm{L}, 0}+k_{\mathrm{des}}\right) \Gamma_{\mathrm{L}-\mathrm{B}}(t)=k_{\mathrm{ad}} c_{\mathrm{L}, 0} \Gamma_{\mathrm{B}, 0}
$$

Die Ableitung der Flächenkonzentration des Liganden $\mathrm{d} \Gamma_{\mathrm{L}-\mathrm{B}} / \mathrm{d} t$ nimmt im Gleichgewicht den Wert Null an, da die Geschwindigkeiten der Adsorption und der Desorption gleich groß sind. Im Gleichgewichtszustand gilt: 


$$
k_{\mathrm{ad}} c_{\mathrm{L}, 0}\left(\Gamma_{\mathrm{B}, 0}-\Gamma_{\mathrm{L}-\mathrm{B}}\right)=k_{\mathrm{des}} \Gamma_{\mathrm{L}-\mathrm{B}}
$$

Der Quotient der Konzentration des gebundenen Liganden und der Anfangskonzentration der freien Bindungsstellen beschreibt den Belegungsgrad der Oberfläche $\vartheta$. Nach Langmuir gilt: $0 \leq \vartheta \leq 1$.

$$
\vartheta=\frac{\Gamma_{\mathrm{L}-\mathrm{B}}}{\Gamma_{\mathrm{B}, 0}}
$$

Außerdem wird die Dissoziationskonstante der Reaktion über die Geschwindigkeitskonstanten der Adsorption und Desorption bestimmt:

$$
K_{\mathrm{D}}=\frac{k_{\mathrm{des}}}{k_{\mathrm{ad}}}
$$

Durch Einsetzen der beiden Zusammenhänge in Gleichung (26) ergibt sich folgender Ausdruck für die Oberflächenbelegung im System:

$$
\vartheta=\frac{c_{\mathrm{L}, 0}}{K_{\mathrm{D}}+c_{\mathrm{L}, 0}}
$$

Die Oberflächenkonzentration wurde in dieser Arbeit über die reflektometrische Interferenzspektroskopie bestimmt. Dabei wird der Belegungsgrad durch die detektierte Änderung der optischen Schichtdicke $\triangle O T$ im Verhältnis zur maximal möglichen optischen Schichtdicke $O T_{\max }$ beschrieben. Die optische Schichtdicke $O T$ steht über den Brechungsindex $n$ im Bezug zur physikalischen Schichtdicke $d$. Die Oberflächenbelegung kann dementsprechend auch durch die detektierte physikalische Schichtdickenänderung $d$ im Verhältnis zur maximalen Änderung der physikalischen Schichtdicke $d_{\max }$ beschrieben werden. Es ergibt sich:

$$
d=d_{\max } \frac{c_{\mathrm{L}, 0}}{K_{\mathrm{D}}+c_{\mathrm{L}, 0}}
$$


Die Langmuir-Adsorptionsisotherme resultiert aus einer Auftragung der resultierenden Änderung der physikalischen Schichtdicke $d$ gegen die eingesetzte Proteinkonzentration $c_{\mathrm{L}, 0}$. Über die Anpassung von Gleichung (30) an die Datenpunkte können die Dissoziationskonstante $K_{\mathrm{D}}$ und die maximale physikalische Schichtdickenänderung $d_{\max }$ für die jeweilige Reaktion bestimmt werden.

\subsection{Quantifizierung der Wechselwirkung zwischen Phosphatidylinositolphosphaten und $\mathrm{CB} 2_{\mathrm{PH}}$}

Alle Proteine der Dbl-Proteinfamilie binden über eine PH-Domäne an Phosphatidylinositolphosphate in der Membran. ${ }^{[16]}$ Aus diesem Grund wurde zunächst die Adsorption der PH-Domäne $\mathrm{CB}_{\mathrm{PH}}$ an PIP-haltige festkörperunterstützte Membranen mittels reflektometrischer Interferenzspektroskopie untersucht. Hierbei wurden die Bindungsaffinitäten des Proteins zu den unterschiedlichen Phosphatidylinositolphosphaten sowie die maximale physikalische Schichtdicke der adsorbierten Proteinschicht bei vollständiger Sättigung des Systems quantifiziert. Nach der Präparation einer PIP-haltigen festkörperunterstützten Membran in Citratpuffer (Kapitel 5.1) wurden die Membranen mit dem HEPES-Puffer gespült und dadurch in einen physiologisch relevanten pH-Wert überführt. Nach Absättigung von Fehlstellen durch die Zugabe von BSA wurde die Proteinkonzentration des $\mathrm{CB} 2_{\mathrm{PH}}$ schrittweise erhöht. Eine Erhöhung der Proteinkonzentration wurde erst nach dem Erreichen eines Gleichgewichts durchgeführt. 

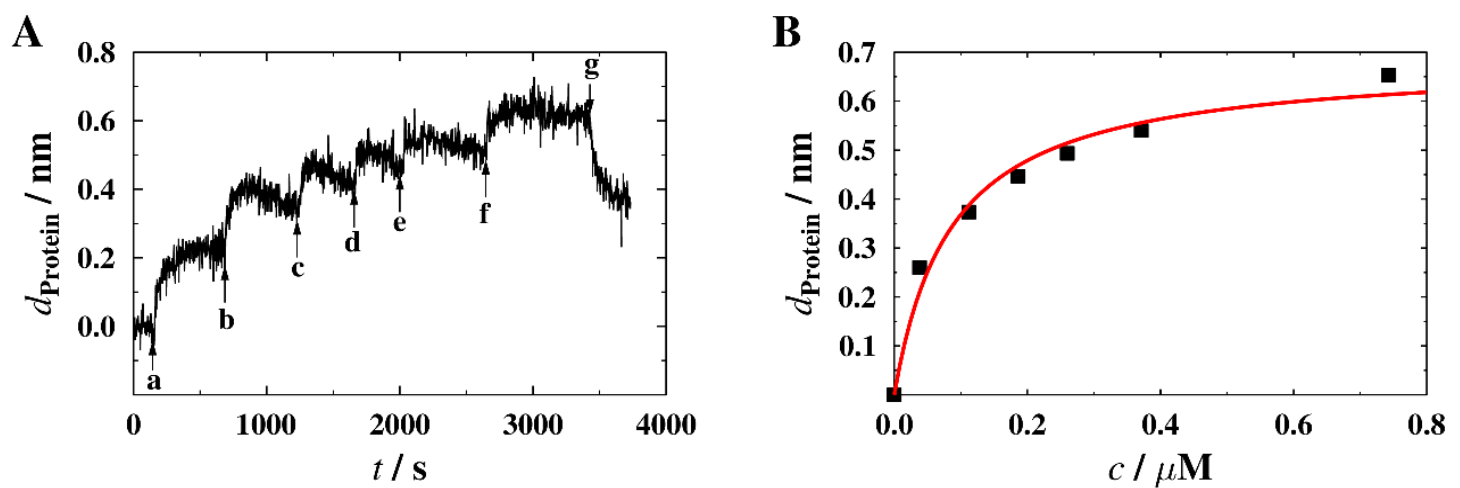

Abbildung 41: (ㅅ) Zeitaufgelöste Änderung der physikalischen Schichtdicke durch Bindung von $\mathrm{CB} 2_{\mathrm{PH}}$ an $\mathrm{PI}(3) \mathrm{P}$-haltige Membranen (a-f) und anschließendes Spülen (g) mit HEPES-Puffer (100 mM NaCl, $25 \mathrm{mM}$ HEPES/NaOH, $0.5 \mathrm{mM}$ EDTA, $0.5 \mathrm{mM}$ DTT, pH 7.2). Konzentrationen: $\mathrm{a}=0.04 \mu \mathrm{M} . \mathrm{b}=0.11 \mu \mathrm{M}, \mathrm{c}=0.19 \mu \mathrm{M}, \mathrm{d}=0.26 \mu \mathrm{M}$, $\mathrm{e}=0.37 \mu \mathrm{m}, \mathrm{f}=0.74 \mu \mathrm{M}$. $(\underline{B})$ Adsorptionsisotherme der in $(\mathrm{A})$ gezeigten Bindung von $\mathrm{CB}_{\mathrm{PH}}$ an eine $\mathrm{PI}(3) \mathrm{P}$-haltige festkörperunterstützte Membran. Die rote Linie ist die Anpassung einer Langmuir-Isotherme an die Datenpunkte.

In Abbildung $41 \mathrm{~A}$ ist eine repräsentative RIfS-Messkurve der Bindung von $\mathrm{CB}_{\mathrm{PH}}$ an eine PI(3)P-haltige Membran gezeigt. Die Änderung der physikalischen Schichtdicke nach Zugabe verschiedener Konzentrationen von $\mathrm{CB} 2_{\mathrm{PH}}$ zur festkörperunterstützten Membran ist zeitabhängig aufgetragen. Es ist erkennbar, dass die physikalische Dicke der Proteinschicht bei schrittweiser Erhöhung der $\mathrm{CB} 2_{\mathrm{PH}}-$ Konzentration bis $\mathrm{zu}$ einer Dicke von $d=0.65 \mathrm{~nm}$ zunimmt. Das anschließende Spülen der Oberfläche mit Puffer bewirkt eine Abnahme der physikalischen Schichtdicke auf $d=0.35 \mathrm{~nm}$. Hierbei wurde ein Teil des gebundenen Proteins $(\sim 50 \%)$ von der festkörperunterstützten Membran abgelöst. Dies deutet auf eine partielle Reversibilität der Bindung hin. Die Auftragung der Änderung der physikalischen Schichtdicke $d$ im Gleichgewicht gegen die jeweils im System vorliegende Proteinkonzentration $c$ liefert eine Adsorptionsisotherme (Abbildung $41 \mathrm{~B})$. Über die Anpassung des Langmuir-Adsorptionsmodells (Gleichung (30)) an die Daten kann neben der maximalen physikalischen Schichtdicke der Proteinschicht auch die Dissoziationskonstante der Bindung des Proteins an die Membran bestimmt werden. 
Zur Bestimmung der maximalen physikalischen Schichtdicke und der Dissoziationskonstante der Bindung von $\mathrm{CB}_{\mathrm{PH}}$ an die verschiedenen Phosphatidylinositolphosphate wurden für jedes PIP mindestens drei voneinander unabhängige Messungen durchgeführt. Die erhaltenen Schichtdickenänderungen für jede Konzentration wurden gemittelt und die Standardabweichung vom Mittelwert berechnet. In Abbildung 42 sind die daraus resultierenden Adsorptionsisothermen von $\mathrm{CB} 2 \mathrm{PH}$ und den verschiedenen Phosphatidylinositolphosphaten gezeigt.

A

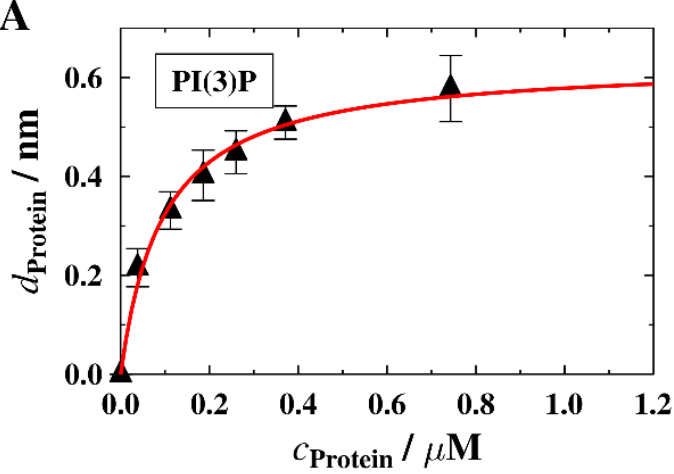

C
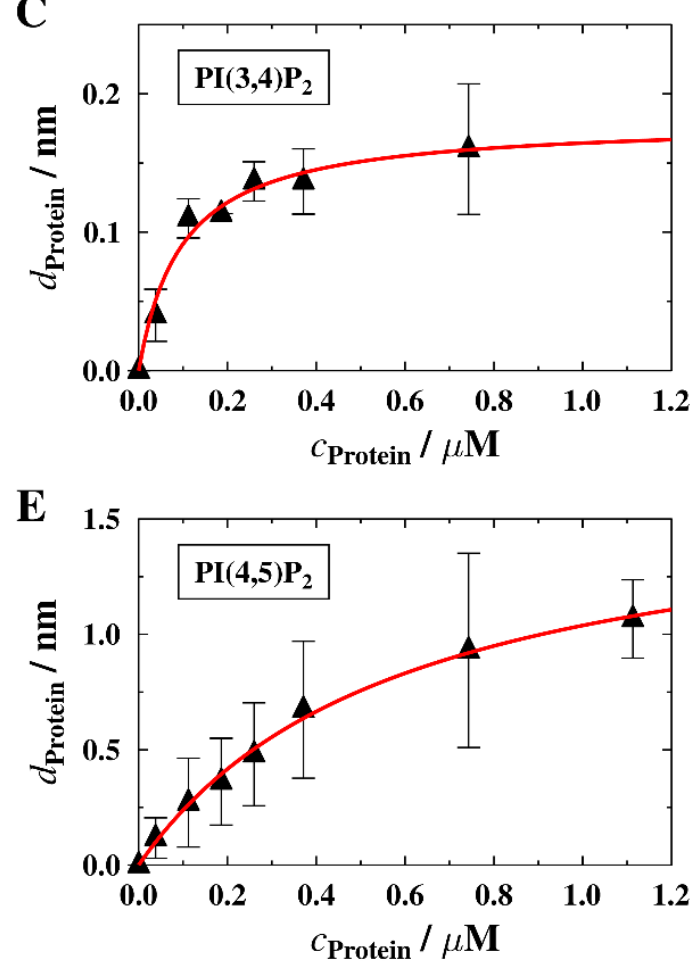

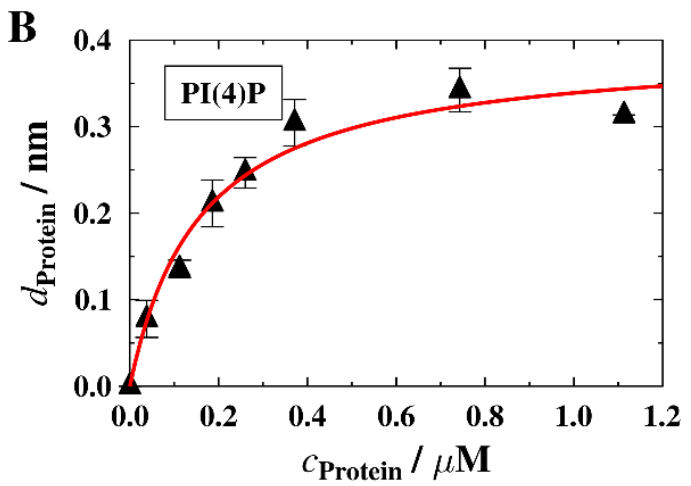

D
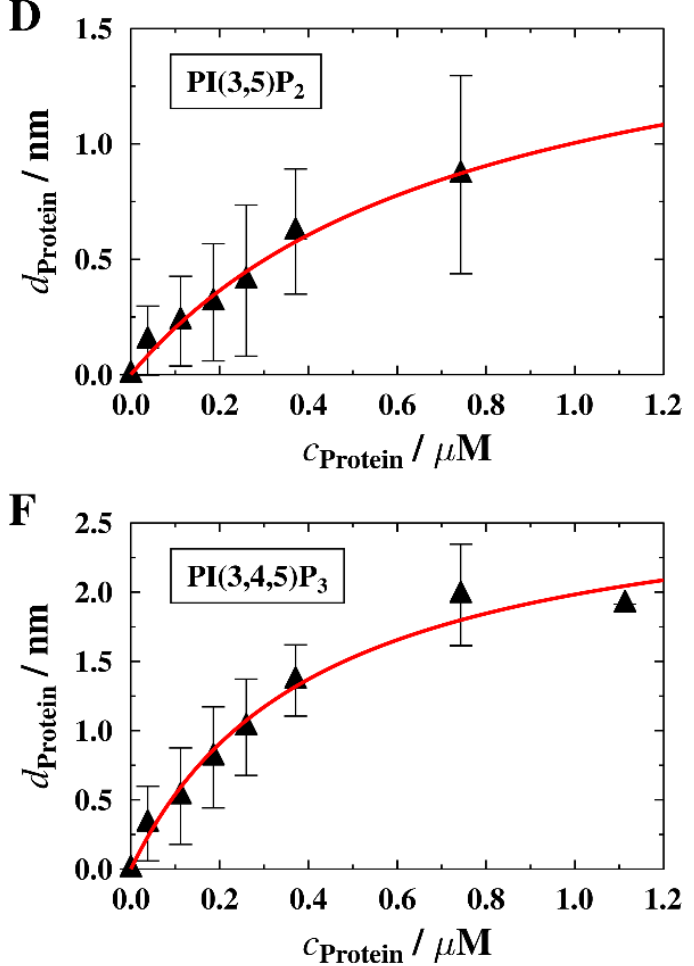

Abbildung 42: Auftragung der Änderung der physikalischen Schicktdicke $d_{\text {Protein }}$ als Funktion der eingesetzten Proteinkonzentration $c_{\text {Protein }}$ bei der Bindung von $\mathrm{CB}_{\mathrm{PH}}$ an PIP-haltige Membranen (POPC/PIP, 9:1). Die roten Linien repräsentieren eine 
Anpassung nach dem Langmuir-Adsorptionsmodell an die Adsorptionsisothermen. Die ermittelten Werte für die Dissoziationskonstante $K_{\mathrm{D}}$ und der maximalen Schichtdickenänderung $d_{\max }$ sind in Tabelle 12 aufgeführt.

Das Modell der Langmuir-Adsorptionsisotherme beschreibt die aus den Messungen erhaltenen Daten gut. Die aus der Anpassung des Modells ermittelten Werte der Dissoziationskonstante und der maximalen Schichtdicke der adsorbierten Proteinmoleküle sind in Tabelle 12 dargestellt. Die Dissoziationskonstanten zeigen, dass eine Bindung zwischen $\mathrm{CB}_{\mathrm{PH}}$ und den monophosphorylierten Phosphatidylinositolphosphaten bevorzugt stattfindet. Die Bindung an $\mathrm{PI}(3,5) \mathrm{P}_{2}$, $\mathrm{PI}(4,5) \mathrm{P}_{2}$ und $\mathrm{PI}(3,4,5) \mathrm{P}_{3}$ ist 4 bis 8-fach schwächer. Die ermittelten physikalischen Schichtdicken der Proteinschicht $d_{\max }$ nehmen mit zunehmendem Phosphorylierungsgrad der Inositolkopfgruppe zu. Im Gegensatz zu allen anderen Phosphatidylinositolphosphaten bindet $\mathrm{CB}_{\mathrm{PH}}$ kaum an $\mathrm{PI}(3,4) \mathrm{P}_{2}$-dotierte Membranen. Die ermittelte maximale Schichtdicke $d_{\max }=(0.18 \pm 0.01) \mathrm{nm}$ weist auf eine sehr geringe Anzahl von gebundenen Proteinmolekülen hin.

Tabelle 12: Dissoziationskonstanten $K_{\mathrm{D}}$ und maximale physikalische Schichtdicken $d_{\max }$ aus den Adsorptionsisothermen der Bindung von $\mathrm{CB}_{\mathrm{PH}}$ an die verschiedenen Phosphatidylinositolphosphate.

\begin{tabular}{|c|c|c|c|c|c|c|}
\hline $\mathbf{P I P}$ & $\mathbf{P I}(\mathbf{3}) \mathbf{P}$ & $\mathbf{P I}(\mathbf{4}) \mathbf{P}$ & $\mathbf{P I}(\mathbf{3 , 4}) \mathbf{P}_{2}$ & $\mathbf{P I}(\mathbf{3}, \mathbf{5}) \mathbf{P}_{2}$ & $\mathbf{P I}(\mathbf{4 , 5}) \mathbf{P}_{2}$ & $\mathbf{P I}(\mathbf{3 , 4 , 5}) \mathbf{P}_{\mathbf{3}}$ \\
\hline $\boldsymbol{K}_{\mathrm{D}} / \mathbf{\mu M}$ & $0.10 \pm 0.01$ & $0.16 \pm 0.03$ & $0.10 \pm 0.02$ & $0.8 \pm 0.2$ & $0.60 \pm 0.06$ & $0.42 \pm 0.09$ \\
\hline $\boldsymbol{d}_{\text {max }} / \mathbf{n m}$ & $0.63 \pm 0.03$ & $0.39 \pm 0.03$ & $0.18 \pm 0.01$ & $1.8 \pm 0.3$ & $1.65 \pm 0.08$ & $2.8 \pm 0.3$ \\
\hline
\end{tabular}




\subsection{Diskussion}

Die Untersuchung der Wechselwirkung von $\mathrm{CB} 2 \mathrm{PH}$ mit PIP-haltigen Modellmembranen erfolgte mit Hilfe der reflektometrischen Interferenzspektroskopie. Diese Methode ermöglicht die zeitaufgelöste und sensitive Beobachtung des Adsorptionsprozesses des Proteins an der Grenzfläche ohne Markierung der Bindungspartner. In der Literatur wurde die Affinität von PH-Domänen für Phosphatidylinositolphosphate bisher oft über lipid-overlay Assays (vgl. 3.1.10) vorgenommen. Dabei werden Phosphatidylinositolphosphate ohne kontrollierbare Orientierung eingetrocknet und das gebundene Protein wird über Chemilumineszenz detektiert. Diese Methode wies in mehrfach durchgeführten Experimenten stark unterschiedliche Intensitäten der Spots auf, sodass nur eine qualitative Aussage über die Bindefähigkeit von Proteinen getroffen werden konnte. Sie diente daher eher zur Klassifizierung der getesteten Proteine. ${ }^{[86]}$ In dieser Studie konnte durch das Spreiten von Vesikeln eine gerichtete Orientierung der Phosphatidylinositolphosphate erreicht werden. Diese entspricht der Ausrichtung von Lipiden in der Zellmembran und ermöglicht die quantitative Analyse der Wechselwirkung zwischen Proteinen und Phosphatidylinositolphosphaten. ${ }^{[80]}$

Nachdem eine festkörperunterstützte Membran (vgl. 5.1) präpariert wurde, konnte die Anbindung der Proteine detektiert werden. Es wurden Adsorptionsisothermen an festkörperunterstützten Membranen mit 10 mol \% Phosphatidylinositolphosphat aufgenommen. Anhand dieser Studien sollte analysiert werden, mit welcher Affinität das Protein Collybistin über die PH-Domäne an die verschiedenen Phosphatidylinositolphosphate bindet.

Zunächst wurde ein geeignetes Puffersystem für die Bindung des CB2 ${ }_{\mathrm{PH}}$ an PIPdotierte Membranen erarbeitet. Die Bindung der PH-Domäne an 
Phosphatidylinositolphosphate wird über eine basische Aminosäureregion in der Schleife zwischen dem $\beta 3$ und $\beta 4$-Faltblatt vermittelt. ${ }^{[13],[64]}$ Zudem hat der CTerminus der PH-Domäne des Collybistin 2 durch einen Bereich mit positiv geladenen Aminosäureresten (Lys162-Gln-Lys-Val-Thr-Gln-Arg-Lys-Trp-His-Tyr) einen Einfluss auf die PIP-Bindung. ${ }^{[16]}$ Die ladungsvermittelte Bindung des Proteins wird in dem Phosphat-Puffer und im TRIS-Puffer durch die hohe Ionenstärke $I$ der Puffer $\left(I_{\text {Phosphat }}=302 \mathrm{mM}, \quad I_{\text {TRIS }}=166 \mathrm{mM}\right)$ verhindert. Der HEPES-Puffer besitzt eine geringere Ionenstärke $I_{\mathrm{HEPES}}=107 \mathrm{mM}$ und maskiert dadurch die Ladungen in den Bindungsregionen weniger stark. In HEPES-Puffer wurde eine Bindung des $\mathrm{CB}_{\mathrm{PH}}$ an $\mathrm{PI}(4,5) \mathrm{P}_{2}$ detektiert, sodass dieser Puffer als geeigneter Messpuffer für alle Interaktionsstudien in dieser Arbeit verwendet wurde.

Über die Annahme der dichtesten Kugelpackung und einer Größe der Lipidkopfgruppen von $70 \AA$ können maximal $56 \%$ der Oberfläche mit Protein besetzt werden. ${ }^{[80]}$ Zusammen mit der Höhe der PH-Domäne aus der Kristallstruktur von $42 \AA$ ergibt sich eine zu erwartende maximale Änderung der physikalischen Schichtdicke von $d_{\max }=2.4 \mathrm{~nm} \cdot{ }^{[13]}$ Dieser Wert wird im Experiment lediglich bei der Bindung des Proteins an $\mathrm{PI}(3,4,5) \mathrm{P}_{3}$ erreicht. Die $\mathrm{PI}(4,5) \mathrm{P}_{2^{-}}$und $\mathrm{PI}(3,5) \mathrm{P}_{2}$-haltigen Membranen weisen rechnerisch eine Oberflächenbelegung des Proteins von $39 \%$ bzw. $42 \%$ auf. Die monophosphorylierten Phosphatidylinositole haben eine Oberflächenbelegung von $15 \%(\mathrm{PI}(3) \mathrm{P})$ und $9 \%(\mathrm{PI}(4) \mathrm{P})$. Im Experiment wurde demnach eine Abhängigkeit der Oberflächenbelegung von der Nettoladung der Oberfläche und damit der Phosphatidylinositolphosphate beobachtet (Abbildung 43). Die Ladungsdichte der Membran wurde über die $\mathrm{pK}_{S^{-}}$Werte der funktionellen Gruppen in der Kopfgruppe und der Phosphatgruppe am C-3 des Glycerins im Phospholipid berechnet. Es wird deutlich, dass unter Berücksichtigung aller Phosphatidylinositolphosphate außer $\mathrm{PI}(3,4) \mathrm{P}_{2}$ eine lineare Abhängigkeit der 
Oberflächenbelegung von der Ladungsdichte der Membran besteht. An PI(3,4) $\mathrm{P}_{2^{-}}$ haltige Membranen wurde keine spezifische Proteinbindung beobachtet.

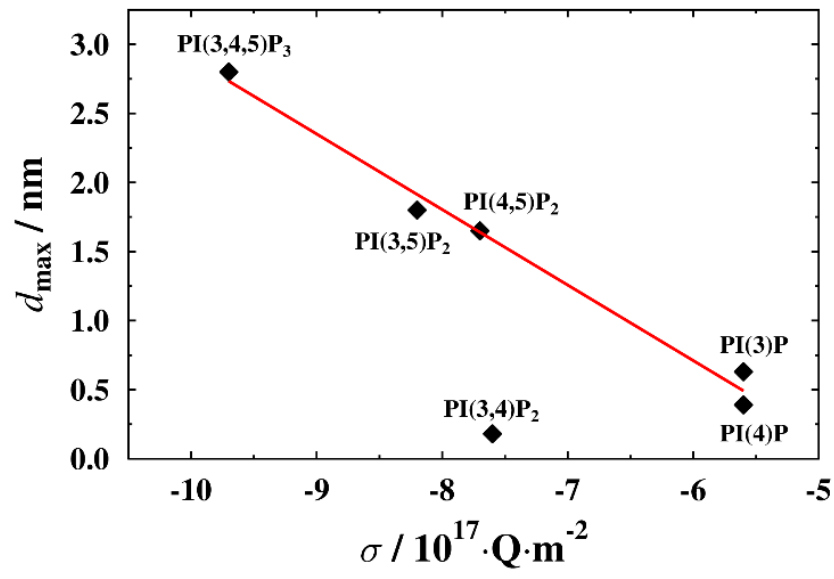

Abbildung 43: Auftragung der maximalen Änderung der physikalischen Schichtdicke $d_{\max }$ für $\mathrm{CB}_{\mathrm{PH}}$ gegen die Oberflächenladungsdichte der PIP-haltigen Membranen.

In einer Referenzmessung auf einer negativ geladenen Membran ohne Inositolkopfgruppe (POPC/POPS, 8:2) wurde keine Bindung des Proteins an die Membran detektiert (Daten nicht gezeigt). Die Ladungsdichte der Referenzmembran entspricht dabei der Ladungsdichte einer mit einem monophosphorylierten Phosphatidylinositol dotierten Membran. Dies weist auf eine Veränderung der Bindungsplätze auf der Oberfläche durch die unterschiedliche Ladung der Phosphatidylinositolphosphate hin. Eine $\mathrm{PI}(3,4,5) \mathrm{P}_{3}$-dotierte Membran weist bei pH 7.0 unter der Annahme der Größe einer PIP-Kopfgruppe von $70 \AA^{2}$ eine Ladungsdichte von $\quad-9.7 \cdot 10^{17} \mathrm{Q} / \mathrm{m}^{2} \quad$ auf. ${ }^{[87],[76]}$ Membranen mit $10 \mathrm{~mol} \%$ PI(3)P/PI(4)P haben dagegen eine um den Faktor zwei geringere Ladungsdichte ($\left.5.6 \cdot 10^{17} \mathrm{Q} / \mathrm{m}^{2}\right)^{\left[{ }^{[77]}\right.}$ Der elektrostatische Beitrag zur Proteinbindung wird durch die geringere Ladung der PIPs in der Membran verringert. Dies könnte zu den beobachteten niedrigeren Belegungsgraden der Oberfläche bei der Bindung an monound diphosphorylierte Phosphatidylinositole führen. Eine weitere Verringerung der 
Ionenstärke des Puffers würde diesen Effekt weiter abschwächen, sodass auf Membranen mit niedriger Ladungsdichte mehr Protein gebunden werden könnte.

Die Dissoziationskonstante $K_{\mathrm{D}}$ weist ein der physikalischen Schichtdicke $d$ entgegen verlaufendes Ergebnis auf. Die stärkste Bindung des Proteins wurde an PI(3)P- und PI(4)P-dotierte festkörperunterstütze Membranen festgestellt. Die bevorzugte Bindung des Proteins an $\mathrm{PI}(3) \mathrm{P}$ wurde in der Literatur übereinstimmend gezeigt. ${ }^{[7],[9]}$ Die Phosphatidylinositolphosphat-Bindung von PH-Domänen wurde auch für andere Proteine beschrieben. ${ }^{[67],[86],[88]}$ Die Dissoziationskonstanten $K_{\mathrm{D}}$ wurden dabei über isothermale Titrationskalorimetrie und Sedimentationsexperimente mit Hilfe von Vesikeln bestimmt. Lemmon et al. bestimmten die Dissoziationskonstante

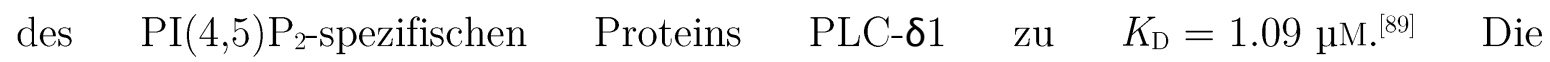
Dissoziationskonstante von PI(4,5) $\mathrm{P}_{2}$ und der PH-Domäne des Ras-Austauschers Sos beträgt $K_{\mathrm{D}}=1.5 \mu \mathrm{M} \cdot{ }^{[90]}$ Die in dieser Arbeit bestimmten Dissoziationskonstanten des $\mathrm{CB}_{\mathrm{PH}}$ bei der Bindung an Phosphatidylinositolphosphate sind bis zu 10-fach kleiner. Dieser Unterschied könnte neben der spezifischeren Wechselwirkung des CB2 $2_{\mathrm{PH}}$ auf die starke Krümmung einer Vesikelmembran zurückzuführen sein. Hier können keine kooperativen Effekte zwischen den Proteinmolekülen auftreten. Das Protein Ezrin, welches spezifisch mit $\mathrm{PI}(4,5) \mathrm{P}_{2}$ wechselwirkt, weist hingegen eine Dissoziationskonstante $K_{\mathrm{D}}=32 \pm 6 \mathrm{nM}$ auf. ${ }^{[84]}$ Die Affinität von Ezrin für PI(4,5) $\mathrm{P}_{2}$ ist demnach mehr als dreifach so stark wie die Bindung des CB2 ${ }_{\mathrm{PH}}$ an $\mathrm{PI}(3) \mathrm{P}$.

Das zugrunde gelegte Adsorptionsmodell nach Langmuir beschreibt die aufgenommenen Daten sehr gut. Es beruht allerdings auf der Annahme, dass die Bindung des Adsorbats an die Oberfläche vollständig reversibel ist. Im Experiment konnte für die Bindung von $\mathrm{CB} 22_{\mathrm{PH}}$ an Phosphatidylinositolphosphate ein reversibel gebundener Anteil von CB2 2 rh zwischen $10-70 \%$ gefunden werden. Somit ist die Langmuir-Isotherme für die beobachtete Wechselwirkung streng genommen nicht 
gültig. Die Langmuir-Anpassung wird in dieser Studie als erste Approximation zur Bestimmung der maximalen Schichtdicke der Proteinschicht $d_{\max }$ und der Dissoziationskonstante $K_{\mathrm{D}}$ verwendet. 


\section{Quantifizierung der Wechselwirkung zwischen Collybistin-Isoformen und Phosphatidylinositol- phosphaten}

\subsection{Wechselwirkung von CB2 SH3- mit $_{\text {Phosphatidyl- }}$ inositolphosphaten}

Über die Anbindung der PH-Domäne von Collybistin-2 an Phosphatidylinositolphosphate in festkörperunterstützten Membranen wurde ein Modellsystem für die Untersuchung der Wechselwirkung von zellulären Collybistin-2 Isoformen mit PIPs etabliert (vgl. Kapitel 6.1.3). Die Isoform CB2 ${ }_{\mathrm{SH}}$ - besitzt am NTerminus der in Abschnitt 6.3 untersuchten PH-Domäne eine DH-Domäne. Über die Untersuchung der Wechselwirkung von $\mathrm{CB} 2_{\mathrm{SH}}$ - mit PIP-dotierten Membranen wurde der Einfluss der DH-Domäne auf die Bindung an die verschiedenen Phosphatidylinositolphosphate ermittelt.

\subsubsection{Wechselwirkung von CB2 ${ }_{\mathrm{SH} 3-}$ mit PIP-haltigen Membranen}

Die Adsorption von $\mathrm{CB} 2_{\mathrm{SH} 3-}$ an PIP-haltige festkörperunterstützte Membranen wurde mittels reflektometrischer Interferenzspektroskopie untersucht. Es wurden die Bindungsaffinitäten des Proteins zu den unterschiedlichen Phosphatidylinositolphosphaten sowie die maximale physikalische Schichtdicke der adsorbierten 
Proteinschicht bei vollständiger Sättigung des Systems quantifiziert. Nach der Präparation einer PIP-haltigen festkörperunterstützten Membran (POPC/PIP, 9:1) in Citratpuffer (Kapitel 5.1) wurden die Membranen mit HEPES-Puffer gespült. Nach der Besetzung der hydrophoben Fehlstellen durch Rinderserumalbumin wurde die Proteinkonzentration des $\mathrm{CB} 2{ }_{\mathrm{SH} 3}$ schrittweise erhöht. Eine Erhöhung der Proteinkonzentration wurde erst nach dem Erreichen eines Gleichgewichts durchgeführt. Abbildung $44 \mathrm{~A}$ zeigt eine RIfS-Messkurve der Bindung von CB2 SHз- $_{\text {- }}$ an eine PI(3)P-haltige Membran. Die Änderung der physikalischen Schichtdicke

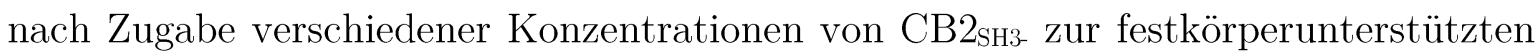
Membran im Durchfluss ist zeitabhängig aufgetragen. Die physikalische Schichtdicke der Proteinschicht nahm bei schrittweiser Erhöhung der $\mathrm{CB}_{\mathrm{SH} 3}-$ Konzentration bis zu einer Dicke von $d=1.25 \mathrm{~nm}$ zu. Das anschließende Spülen der Oberfläche mit Puffer bewirkte eine Abnahme der physikalischen Schichtdicke auf $d=0.7 \mathrm{~nm}$. Hierbei wurden $55 \%$ des gebundenen Proteins von der festkörperunterstützten Membran abgelöst. Dies deutet auf eine partielle Reversibilität der Proteinbindung hin. Im Gegensatz zur Messung an PI(3)P änderte sich die physikalische Schichtdicke an $\mathrm{PI}(3,4) \mathrm{P}_{2}$-dotierten Membranen bei Proteinzugabe kaum (Abbildung 44 C). Bei schrittweiser Erhöhung der Proteinkonzentration wurde eine Änderung der physikalischen Schichtdicke von $d=0.25 \mathrm{~nm}$ detektiert. Durch das Spülen der Membran wurde die physikalische Schichtdicke auf $d=0.15 \mathrm{~nm}$ reduziert. Es wurden $60 \%$ des Proteins von der Membran entfernt. 
A

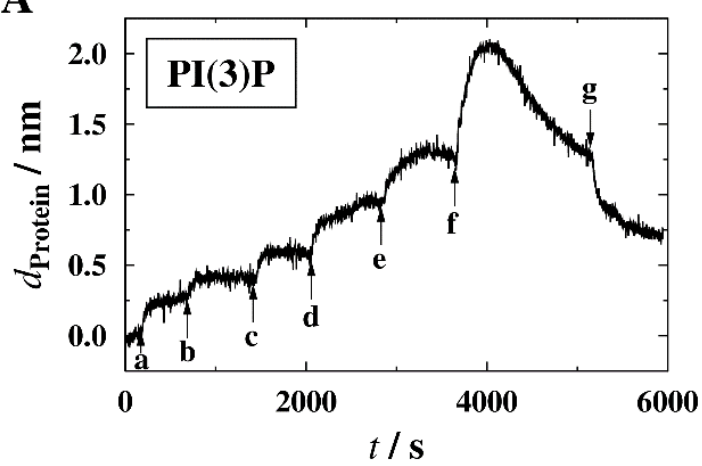

C

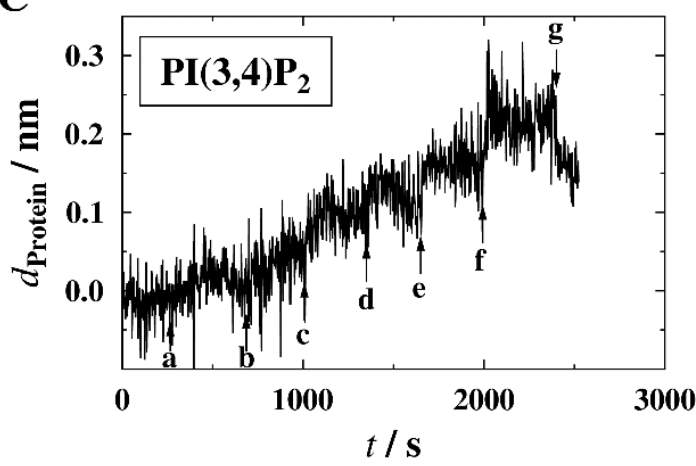

$\mathbf{E}$

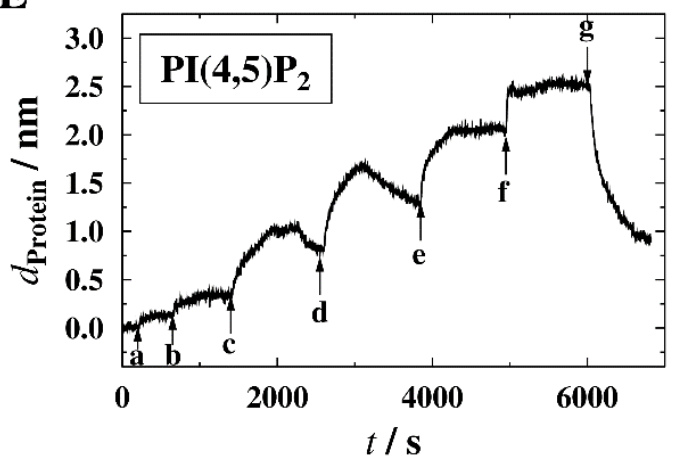

B

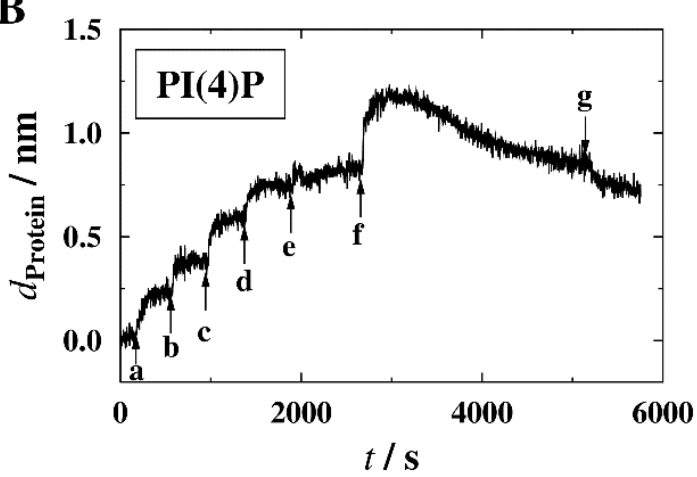

D

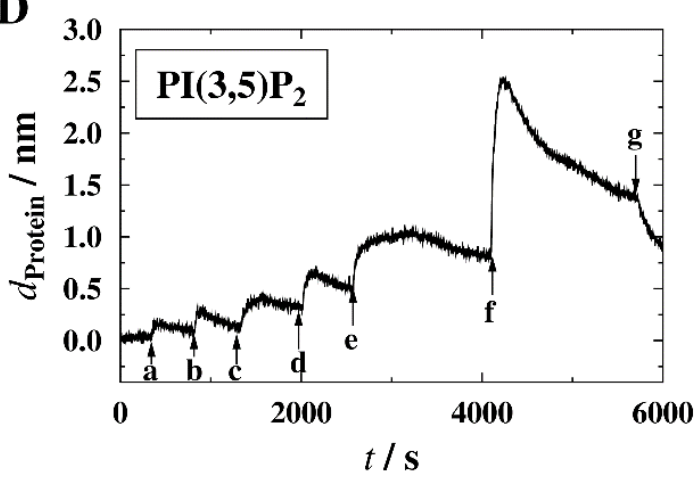

D

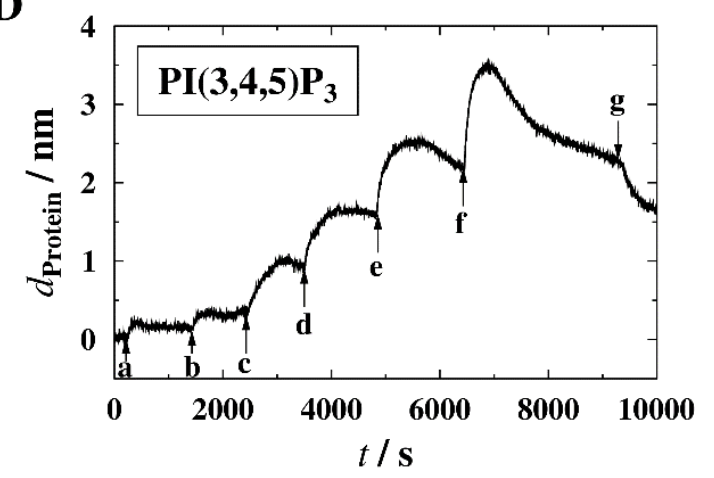

Abbildung 44: Zeitaufgelöste Änderung der physikalischen Schichtdicke durch Bindung

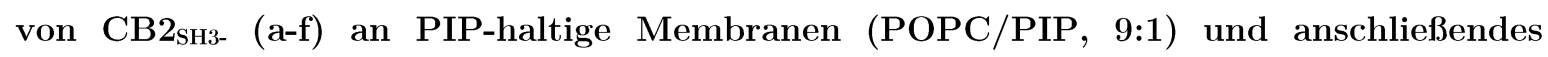
Spülen (g) mit HEPES-Puffer (100 mM NaCl, $25 \mathrm{mM}$ HEPES, $0.5 \mathrm{mM}$ EDTA, $0.5 \mathrm{mM}$ DTT, $\mathrm{pH}$ 7.2). Konzentrationen: $\mathrm{a}=0.04 \mu \mathrm{M} . \mathrm{b}=0.11 \mu \mathrm{M}, \mathrm{c}=0.19 \mu \mathrm{M}, \mathrm{d}=0.26 \mu \mathrm{M}$, $\mathrm{e}=0.37 \mu \mathrm{m}, \mathrm{f}=0.74 \mu \mathrm{M}$.

Die Auftragung der Änderung der physikalischen Schichtdicke $d$ im Gleichgewicht gegen die jeweils im System vorliegende Proteinkonzentration $c_{\text {Protein }}$ liefert die Adsorptionsisotherme. Zur Bestimmung der maximalen physikalischen Schichtdicke und der Dissoziationskonstante der Bindung von $\mathrm{CB}_{\mathrm{SH} 3-}$ an die verschiedenen Phosphatidylinositolphosphate wurden für jedes PIP mindestens drei voneinander 
unabhängige Messungen durchgeführt. Die erhaltenen Schichtdickenänderungen für jede Konzentration wurden gemittelt und die Standardabweichung vom Mittelwert berechnet. Über die Anpassung des Langmuir-Adsorptionsmodells (Gleichung (30)) an die Daten kann neben der maximalen physikalischen Schichtdicke der Proteinschicht auch die Dissoziationskonstante der Bindung des Proteins an die Membran bestimmt werden. In Abbildung 45 sind die daraus resultierenden Adsorptionsisothermen von $\mathrm{CB}_{\text {Sнз }}$ und den verschiedenen Phosphatidylinositolphosphaten gezeigt. 

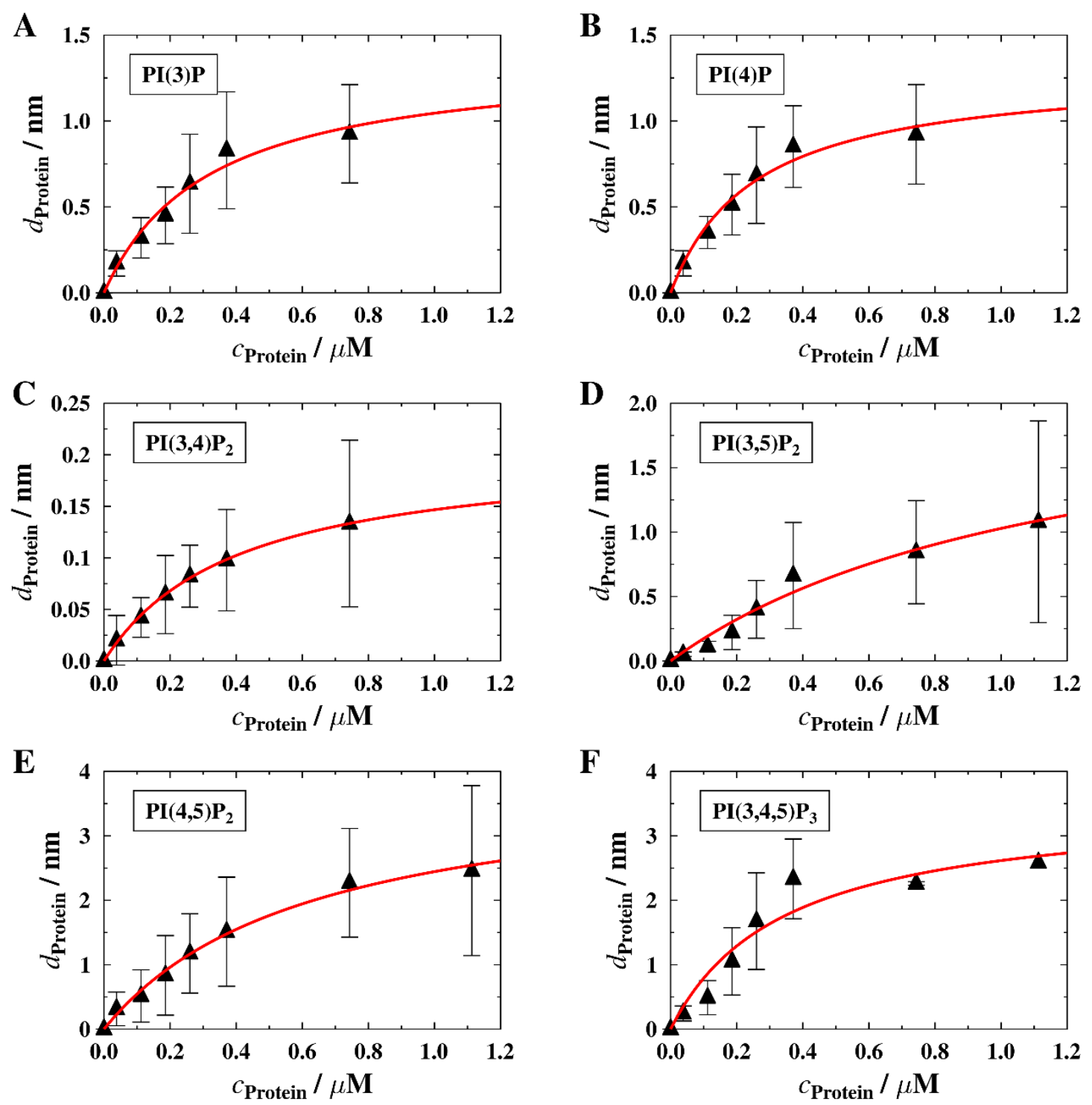

Abbildung 45: Auftragung der Änderung der physikalischen Schichtdicke $d_{\text {Protein }}$ als Funktion der eingesetzten Proteinkonzentration $c_{\text {Protein }}$ bei der Bindung von $\mathrm{CB}_{\mathrm{SH}_{3}-}$ an PIP-haltige Membranen (POPC/PIP, 9:1). Die roten Linien repräsentieren eine Anpassung nach dem Langmuir-Adsorptionsmodell an die Adsorptionsisothermen. Die ermittelten Dissoziationskonstanten $K_{\mathrm{D}}$ und die maximale physikalische Schichtdickenänderungen $d_{\max }$ für die verschiedenen Phosphatidylinositolphosphate sind in Tabelle 13 dargestellt.

Die aus der Anpassung des Modells ermittelten Werte der Dissoziationskonstante und der maximalen Schichtdicke der adsorbierten Proteinmoleküle sind in Tabelle 13 dargestellt. 
Tabelle 13: Dissoziationskonstanten $K_{\mathrm{D}}$ und maximale physikalische Schichtdicken $\boldsymbol{d}_{\max }$ aus den Adsorptionsisothermen der Bindung von $\mathrm{CB}_{\mathrm{SH} 3-}$ an Phosphatidylinositolphosphate in festkörperunterstützten Membranen.

\begin{tabular}{|c|c|c|c|c|c|c|}
\hline $\mathbf{P I P}$ & $\mathbf{P I}(\mathbf{3}) \mathbf{P}$ & $\mathbf{P I}(\mathbf{4}) \mathbf{P}$ & $\mathbf{P I}(\mathbf{3}, \mathbf{4}) \mathrm{P}_{2}$ & $\mathbf{P I}(\mathbf{3}, \mathbf{5}) \mathrm{P}_{2}$ & $\mathbf{P I}(\mathbf{4 , 5}) \mathrm{P}_{2}$ & $\mathbf{P I}(\mathbf{3}, \mathbf{4}, \mathbf{5}) \mathbf{P}_{\mathbf{3}}$ \\
\hline $\boldsymbol{K}_{\mathrm{D}} / \mathbf{\mu M}$ & $0.32 \pm 0.08$ & $0.26 \pm 0.06$ & $0.41 \pm 0.02$ & $1.2 \pm 0.5$ & $0.63 \pm 0.09$ & $0.3 \pm 0.1$ \\
\hline $\boldsymbol{d}_{\text {max }} / \mathbf{n m}$ & $1.4 \pm 0.2$ & $1.3 \pm 0.1$ & $0.21 \pm 0.01$ & $2.3 \pm 0.6$ & $4.0 \pm 0.3$ & $3.5 \pm 0.6$ \\
\hline
\end{tabular}

Die Dissoziationskonstanten weisen darauf hin, dass $\mathrm{CB}_{\mathrm{SH} 3-}$ mit einer hohen Affinität an die monophosphorylierten Phosphatidylinositole und an das dreifach phosphorylierte $\mathrm{PI}(3,4,5) \mathrm{P}_{3}$ bindet. Allerdings sind die Dissoziationskonstanten von $\mathrm{PI}(3,5) \mathrm{P}_{2}$ und $\mathrm{PI}(4,5) \mathrm{P}_{2}$ lediglich um den Faktor $2\left(\mathrm{PI}(4,5) \mathrm{P}_{2}\right)$ bzw. um den Faktor $4\left(\mathrm{PI}(3,5) \mathrm{P}_{2}\right)$ höher. Alle ermittelten Bindungsaffinitäten von CB22 ${ }_{\mathrm{SH} 3-}$ für die verschiedenen Phosphatidylinositolphosphate, außer $\mathrm{PI}(3,5) \mathrm{P}_{2}$, befinden sich demnach etwa im gleichen Bereich. Die Dissoziationskonstante von PI $(3,4) \mathrm{P}_{2}$ $\left(K_{\mathrm{D}}=0.41 \pm 0.02 \mu \mathrm{M}\right)$ liegt etwas über dem Wert $\left(K_{\mathrm{D}} \sim 0.3 \mu \mathrm{M}\right)$ für die Phosphatidylinositolphosphate mit einer hohen Bindungsaffinität. In Kombination mit der ermittelten maximalen Schichtdickenänderung $d_{\max }=0.21 \pm 0.01 \mathrm{~nm}$ wird deutlich, dass nur sehr wenig $\mathrm{CB} 2_{\mathrm{SH}_{3}-}$ an $\mathrm{PI}(3,4) \mathrm{P}_{2}$-dotierte Membranen bindet.

Die maximale physikalische Schichtdicke $d_{\max }$ ist für $\mathrm{PI}(3) \mathrm{P}-$ und $\mathrm{PI}(4) \mathrm{P}$-haltige Membranen nahezu identisch. Die mit den proteinbindenden zweifach phosphorylierten Phosphatidylinositolen $\quad \mathrm{PI}(3,5) \mathrm{P}_{2} \quad\left(d_{\max }=2.3 \pm 0.6 \mathrm{~nm}\right) \quad$ und $\mathrm{PI}(4,5) \mathrm{P}_{2} \quad\left(d_{\max }=4.0 \pm 0.3 \mathrm{~nm}\right) \quad$ dotierten Membranen weisen hingegen sehr unterschiedliche physikalische Schichtdickenänderungen auf. $\mathrm{CB}_{\mathrm{SH} 3-}$ führt auf $\mathrm{PI}(3,4,5) \mathrm{P}_{3}$-haltigen Membranen zu einer Änderung der physikalischen Schichtdicke von $d_{\max }=3.5 \pm 0.6 \mathrm{~nm}$. Diese liegt im Bereich der diphosphorylierten 
Phosphatidylinositole. Insgesamt nehmen die ermittelten physikalischen Schichtdicken der Proteinschicht $d_{\max }$ mit stärkerer negativer Ladung der Oberflächen (zunehmender Phosphorylierungsgrad der Inositolkopfgruppe) zu. Es wird zudem über die große Abweichung zwischen gemessenen Werten und der vorgenommenen Anpassung deutlich, dass die Langmuir-Anpassung die Isothermen von $\mathrm{CB} 2_{\mathrm{SH} 3}$ an $\mathrm{PI}(3,5) \mathrm{P}_{2}$ und $\mathrm{PI}(3,4,5) \mathrm{P}_{3}$ im Bereich bis $0.5 \mu \mathrm{M}$ nicht ausreichend beschreiben.

\subsubsection{Erkennungsmotiv in den Membranen}

Die Adsorptionsisothermen von $\mathrm{CB} 2_{\mathrm{SH} 3-}$ auf den verschiedenen Phosphatidylinositolphosphaten zeigen sehr ähnliche Bindungsaffinitäten. CB2 $2_{\mathrm{SH} 3}$ unterscheidet demnach nicht zwischen den PIPs. Um herauszufinden welche Eigenschaft der PIPs als Erkennungsmotiv in den Membranen dient, wurden weitere RIfS-Messungen durchgeführt. Es wurden festkörperunterstützte Membranen mit $10 \mathrm{~mol} \% \mathrm{PI}_{\text {soy }}$ bzw. $20 \mathrm{~mol} \%$ POPS oder POPG als Rezeptorlipid in HEPES-Puffer (100 mM NaCl, 25 mM HEPES, 0.5 mM EDTA, 0.5 mM DTT, pH 7.2) hergestellt. Die folgenden Proteinzugaben wurden unter den gleichen Messbedingungen (siehe Kapitel 6.1.3) durchgeführt. In Abbildung 46 sind die erhaltenen Adsorptionsisothermen mit der Anpassung nach der Langmuir-Theorie dargestellt. 


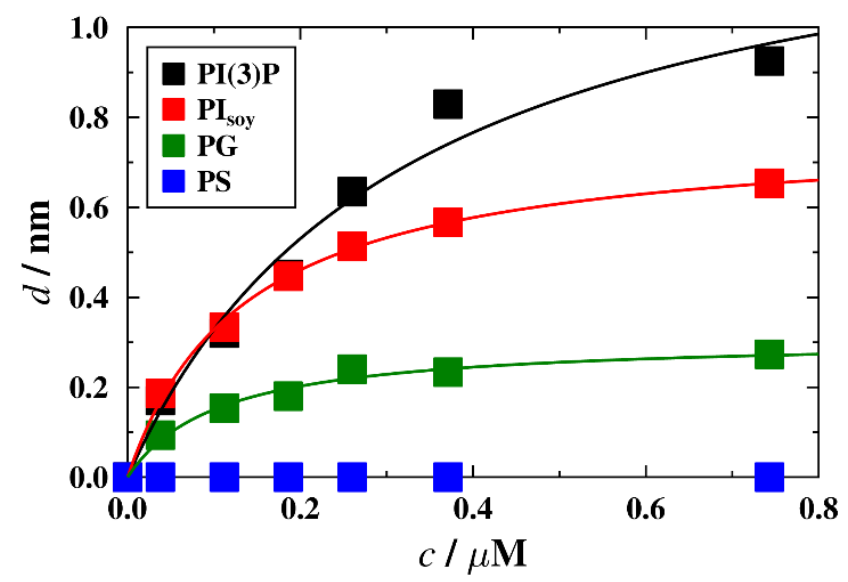

Abbildung 46: Auftragung der Änderung der physikalischen Schichtdicke $d_{\text {Protein }}$ als Funktion der eingesetzten Proteinkonzentration $c_{\text {Protein }}$ bei der Bindung von $\mathrm{CB}_{\mathrm{SH}_{3}-}$ an die festkörperunterstützten Membranen. Die durchgezogenen Linien zeigen eine Anpassung nach dem Langmuir-Adsorptionsmodell an die Adsorptionsisothermen.
POPC/PI(3)P, 9:1
$K_{\mathrm{D}}=(0.32 \pm 0.08) \mu \mathrm{M}$
$d_{\max }=(1.4 \pm 0.2) \mathrm{nm}$,
$\mathrm{POPC} / \mathrm{PI}_{\mathrm{soy}}, 9: 1$
$K_{\mathrm{D}}=(0.14 \pm 0.01) \mu \mathrm{M}$
$d_{\max }=(0.77 \pm 0.02) \mathrm{nm}$,
POPC/POPG, 8:2
$K_{\mathrm{D}}=(0.11 \pm 0.02) \mu \mathrm{M}$
$d_{\max }=(0.31 \pm 0.02) \mathrm{nm}$,

Die Dissoziationskonstanten der Bindung von $\mathrm{CB}_{\mathrm{SH} 3-}$ an POPG- bzw. PI-haltige Membranen sind sehr ähnlich $\quad\left(K_{\mathrm{D}, \mathrm{POPG}}=(0.11 \pm 0.02) \mu \mathrm{M} \quad\right.$ bzw. $\left.K_{\mathrm{D}, \mathrm{PI}}=(0.14 \pm 0.01) \mu \mathrm{M}\right)$ und zudem um den Faktor 2 kleiner als die Dissoziationskonstante $K_{\mathrm{D}}=(0.32 \pm 0.08) \mu \mathrm{M}$ von $\mathrm{CB} 2_{\mathrm{SH} 3}$ an $\mathrm{PI}(3) \mathrm{P}$. An POPShaltige Membranen wurde keine Bindung des Proteins detektiert. Die größte Änderung der physikalischen Schichtdicke $d_{\max }=(1.4 \pm 0.2) \mathrm{nm}$ wurde an PI(3)Phaltigen Membranen detektiert. Die physikalischen Schichtdicken des Proteins nach Bindung an PI $\left(d_{\max }=0.77 \pm 0.02 \mathrm{~nm}\right)$ und POPG $\left(d_{\max }=0.31 \pm 0.02 \mathrm{~nm}\right)$ sind um den Faktor 2 bzw. 4 geringer.

Es wird deutlich, dass eine negative Ladung der Membran durch das bei physiologischem pH-Wert zweifach negativ geladene POPS nicht zur Bindung des Proteins führt. Die Lipide POPG und PI weisen in der chemischen Struktur lediglich eine negative Ladung am Phosphorsäureester und 2 bzw. 5 freie Hydroxylgruppen in den Kopfgruppen auf. CB2 $2_{\mathrm{SH} 3}$ bindet im Experiment an diese schwächer geladenen Lipide. PI(3)P weist nur 4 freie Hydroxylgruppen auf. Es wird im Experiment 
dennoch eine höhere Oberflächenbelegung erreicht als mit PI. Dies zeigt, dass neben den freien Hydroxylgruppen auch der Phosphorylierungsgrad der Inositolkopfgruppe einen Einfluss auf die Oberflächenbelegung der Membran mit Protein hat.

\subsubsection{Lipid-overlay Assay}

Die Bindung von CB2 ${ }_{\mathrm{SH} 3-}$ an Phosphatidylinositolphosphate ist in der Literatur über das GST-getaggte Protein mit Hilfe eines lipid-overlay Assays beschrieben. ${ }^{[8],[9]}$ Um einen Vergleich mit den Literaturergebnissen herzustellen, wurde sowohl mit $\mathrm{CB}_{\mathrm{SH} 3-}$ (Isolierung siehe Kapitel 4.3) als auch mit GST-CB2 $2_{\mathrm{SH} 3-}$ ein lipid-overlay Assay durchgeführt. Das GST-getaggte Protein (GST-CB2 ${ }_{\mathrm{SH} 3-}$ ) wurde am MPI für experimentelle Medizin, Göttingen von T. Papadopoulos exprimiert und aufgereinigt. Die Membranen wurden mit $3 \%$ fettsäurefreiem BSA in TBS-Puffer blockiert. Anschließend wurden verschiedene Proteinkonzentrationen von $\mathrm{CB}_{\mathrm{SH}_{3-}}$ (6 nM, $60 \mathrm{nM})$ und GST-CB2 $2_{\mathrm{SH} 3}(6 \mathrm{nM})$ in TBS-T-Puffer mit $3 \%$ BSA auf den Membranen inkubiert. Die Chemilumineszenz wurde über einen spezifischen Anti-CollybistinAntikörper und einen passenden Sekundärantikörper mit HRP-Funktionalität auf Röntgenfilmen detektiert. In Abbildung 47 sind die Ergebnisse des lipid-overlay Assays dargestellt. Im Fall von 6 nM CB2 ${ }_{\mathrm{SH} 3}$ (B) wurde ein starkes Signal für PI(5)P detektiert (A). Weiterhin waren schwache Signale für alle Phosphatidylinositolphosphate sichtbar. Im Vergleich mit der mit 6 nM GST-CB2 $2_{\mathrm{SH} 3}$ inkubierten Membran wurde deutlich, dass die Signale für das GST-getaggte Protein größer waren. Das stärkste Signal wurde ebenfalls an PI(5)P detektiert. Weiterhin wurde eine Bindung von GST-CB2 ${ }_{\mathrm{SH} 3}$ an die monophosphorylierten PIPs und in abnehmender Intensität an $\mathrm{PI}(3,5) \mathrm{P}_{2}$ und $\mathrm{PI}(3,4,5) \mathrm{P}_{3}$ beobachtet. Die Bindung an $\mathrm{PI}(4,5) \mathrm{P}_{2}$ und $\mathrm{PI}(3,4) \mathrm{P}_{2}$ war im Verhältnis zu den anderen 
Phosphatidylinositolphosphaten sehr schwach. Eine um den Faktor 10 höhere Proteinkonzentration von $\mathrm{CB} 2_{\text {Снз }}(60 \mathrm{nM})$ zeigte GST-CB2 ${ }_{\mathrm{SH} 3}$ ähnliche Intensitäten auf dem Röntgenfilm (C). Die stärkste Intensität wurde erneut für $\mathrm{PI}(5) \mathrm{P}$ beobachtet. Eine etwas niedrigere Intensität wiesen $\mathrm{PI}(3,5) \mathrm{P}_{2}, \mathrm{PI}(4,5) \mathrm{P}_{2}, \mathrm{PI}(3,4,5) \mathrm{P}_{3}$ und $\mathrm{PI}(4) \mathrm{P}$ auf. Für PI(3)P war eine schwächere Intensität des Spots erkennbar. Für $\mathrm{PI}(3,4) \mathrm{P}_{2}$ konnte lediglich eine sehr schwache Bindung detektiert werden.

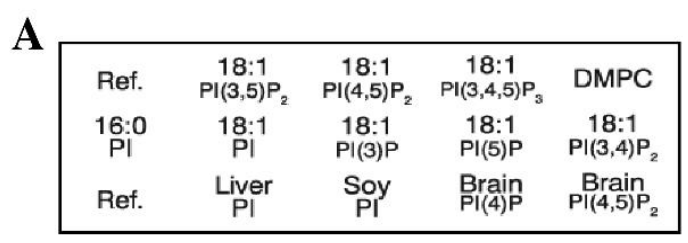

C

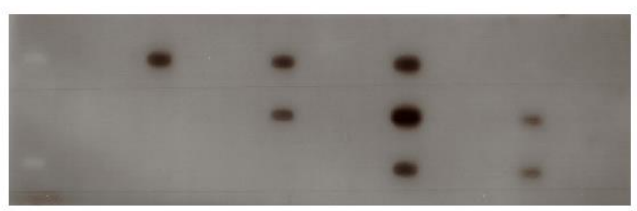

B

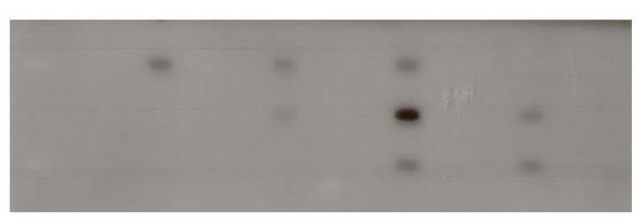

D

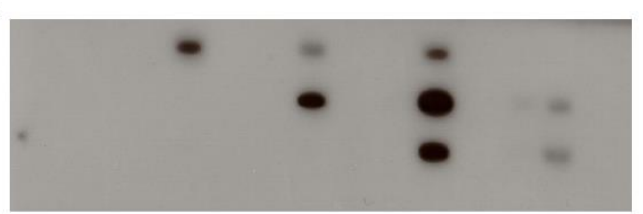

Abbildung 47: (A) Belegungsplan der inositol snooper (Avanti Polar Lipids, Alabama, USA). (B-D) Entwickelte Röntgenfilme der lipid-overlay Assays von 6 nM CB2 $2_{\mathrm{SH} 3-}$ (B), $60 \mathrm{nM} \mathrm{CB} 2_{\mathrm{SH}_{3}-}(\mathrm{C})$ und $6 \mathrm{nM}$ GST-CB2 ${ }_{\mathrm{SH} 3-}(\mathrm{D})$.

Zum Vergleich der im RIfS-Experiment erhaltenen Ergebnisse auf festkörperunterstützten Membranen und dem lipid-overlay Assay wurde die Intensität der auf dem Röntgenfilm detektierten Bindungen bestimmt. Diese Quantifizierung wurde mit Hilfe des "Gele" Plug-in des Programms ImageJ durchgeführt. Es wurde ein Intensitätsprofil der detektierten Spots erstellt und die Fläche unter dem Intensitätssignal bestimmt. Weiterhin wurden aus den über eine Langmuir-Anpassung ermittelten Werten (vgl. 7.1.1) die für $c=60 \mathrm{nM}$ zu erwartende physikalische Schichtdicke $d_{\text {Protein }}$ für die verschiedenen PIPs berechnet. Abbildung 48 zeigt die Korrelation von der Fläche unter dem Intensitätssignal $A_{\text {Int }}$ und der aus RIfS-Daten berechneten Schichtdicke des Proteins $d_{\text {Protein }}$ für $60 \mathrm{nM}$ CB2 $2_{\mathrm{SH} 3-}(\mathrm{A})$ und 6 nM GST-CB2 ${ }_{\mathrm{SH} 3 .}$. 
A

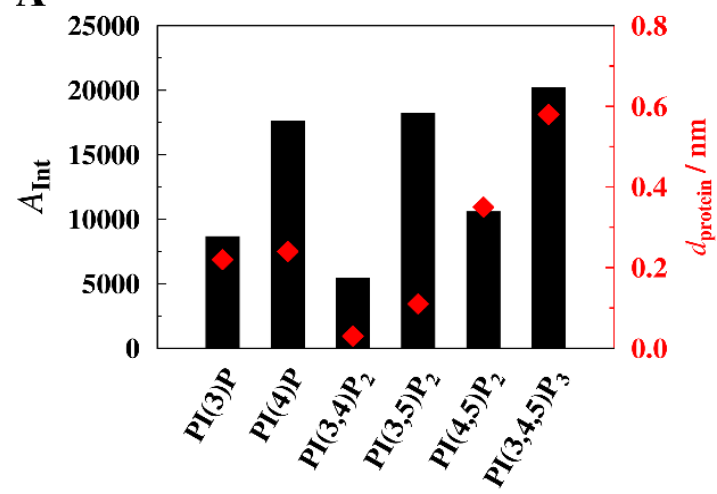

B

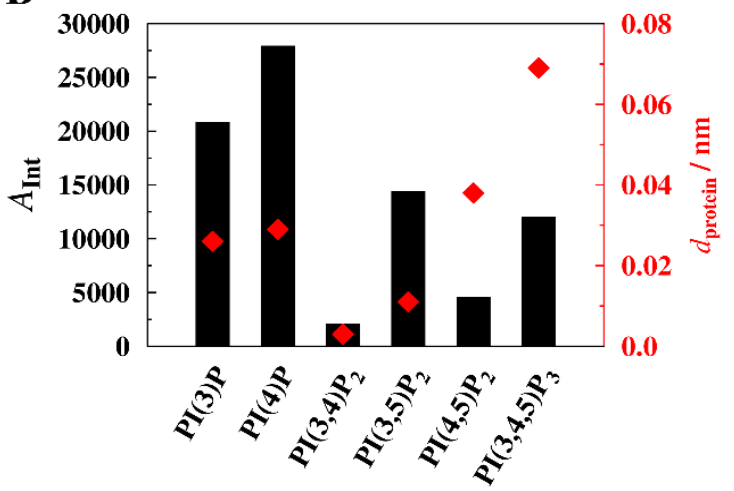

Abbildung 48: Korrelation zwischen der Fläche unter den Intensitätssignalen $A_{\text {Int }}$ der spots aus dem lipid-overlay Experiment und der zu erwartenden Schichtdicke $d_{\text {Protein }}$ für $60 \mathrm{nM} \mathrm{CB} 2_{\mathrm{SH} 3-}(\underline{\mathrm{A}})$ und $6 \mathrm{nM}$ GST-CB2 $2_{\mathrm{SH} 3}(\underline{B})$. Diese wurde mit Hilfe der im RIfSExperiment bestimmten Werte der maximalen physikalischen Schichtdicke $d_{\max }$, der Dissoziationskonstanten $K_{\mathrm{D}}$ und der eingesetzten Proteinkonzentration berechnet.

Die Ergebnisse aus dem RIfS-Experiment werden im Falle von 60 nM $\mathrm{CB}_{\mathrm{SH} 3-}$ mäßig von den Intensitätssignalen aus dem lipid-overlay Assay beschrieben. Eine Abweichung tritt vor allem bei $\mathrm{PI}(4) \mathrm{P}$ und $\mathrm{PI}(3,5) \mathrm{P}_{2}$ auf. Das Ergebnis des lipidoverlay Assays korreliert für $6 \mathrm{nM}$ GST-CB2 ${ }_{\mathrm{SH} 3-}$ sehr schlecht mit den berechneten Werten für die zu erwartende Schichtdicke von $\mathrm{CB} 2_{\mathrm{SH} 3}$ aus den RIfS-Experimenten. Die zu erwartende Schichtdicke bei einer Proteinkonzentration von $c=6 \mathrm{nM}$ ist zudem so klein, dass bei dieser Konzentration nahezu kein $\mathrm{CB}_{\mathrm{SH}_{\mathrm{S}}-}$ an die PIPdotierten Membranen bindet.

Der Vergleich der RIfS-Ergebnisse mit dem lipid-overlay Assay zeigt, dass der GST-Tag die Affinität der Bindung von $\mathrm{CB} 2_{\mathrm{SH} 3-}$ an Phosphatidylinositolphosphate verstärkt, sodass schon bei kleineren Konzentrationen eine stärkere Chemilumineszenz detektiert wurde. Auch die Spezifität für die verschiedenen PIPs wird verändert. Die Intensitäten der spots für die monophosphorylierten Phosphatidylinositole sind viel stärker als aus den RIfS-Daten erwartet. 


\subsection{Wechselwirkung von $\mathrm{CB} 22_{\mathrm{SH} 3+}$ mit PIP-haltigen}

\section{Membranen}

In den Abschnitten 6.3 und 7.1.1 wurden die Einflüsse der PH- und DH-Domäne auf die Bindung von Collybistin 2 an Phosphatidylinositolphosphate beschrieben. Die Collybistin-Isoform CB22 3 3+ weist N-terminal zur PH-/DH-Tandemdomäne eine zusätzliche SH3-Domäne auf. Der Einfluss der SH3-Domäne auf die PIP-Bindung wurde ebenfalls im RIfS-Experiment (vgl. 6.3 und 7.1.1) bestimmt. Der Aufbau der PIP-haltigen festkörperunterstützten Membran erfolgte unter Niedrig-pHBedingungen. Die Anbindung von $\mathrm{CB} 2_{\mathrm{SH} 3+}$ an die Membran wurde im HEPES-Puffer (vgl. Kapitel 6.1.3) untersucht. In Abbildung 49 ist eine repräsentative Messung für die Adsorption von $\mathrm{CB} 2_{\mathrm{SH} 3+}$ an eine $\mathrm{PI}(3) \mathrm{P}$-haltige Membran gezeigt.

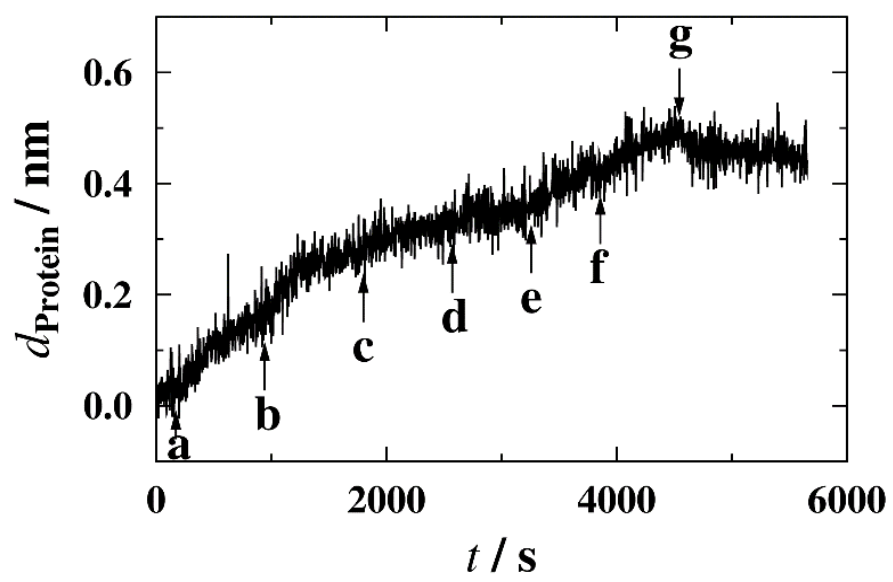

Abbildung 49: Zeitaufgelöste Änderung der physikalischen Schichtdicke durch Bindung von $\mathrm{CB}_{\mathrm{SH} 3+}$ an $\mathrm{PI}(3) \mathrm{P}$-haltige Membranen (a-f) und anschließendes Spülen (g) mit HEPES-Puffer (100 mM NaCl, $25 \mathrm{~mm}$ HEPES, $0.5 \mathrm{~mm}$ EDTA, $0.5 \mathrm{~mm}$ DTT, pH 7.2). Konzentrationen: $\mathrm{a}=0.04 \mu \mathrm{M} . \mathrm{b}=0.11 \mu \mathrm{M}, \mathrm{c}=0.19 \mu \mathrm{M}, \mathrm{d}=0.26 \mu \mathrm{M}, \mathrm{e}=0.37 \mu \mathrm{m}$, $\mathrm{f}=0.74 \mu \mathrm{M}$.

Die kontinuierliche Erhöhung der Proteinkonzentration bis $c_{\text {Protein }}=0.74 \mu \mathrm{M}$ führte zu einem Anstieg der physikalischen Schichtdicke von $d_{\max }=0.5 \mathrm{~nm}$. 
Anschließendes Spülen mit HEPES-Puffer resultierte in einer Desorption von $8 \%$ der Proteinmoleküle $\left(d_{\max }=0.46 \mathrm{~nm}\right)$. Es wird deutlich, dass die Änderungen der physikalischen Schichtdicke nach Proteinzugabe sehr gering sind und sehr nahe an der Auflösungsgrenze des Messaufbaus liegen. In den Messungen war eine Drift nur schlecht von einem Adsorptionsprozess des Proteins auf der Membran zu unterscheiden.

Dies wird ebenfalls in den in Abbildung 50 dargestellten Bindungsisothermen von $\mathrm{CB}_{\mathrm{SH} 3+}$ an die verschiedenen Phosphatidylinositolphosphate in festkörperunterstützten Membranen deutlich. Die über mindestens 3 Messungen gemittelten Änderungen der physikalischen Schichtdicke weisen vor allem für die mehrfach phosphorylierten Phosphatidylinositole $\mathrm{PI}(3,5) \mathrm{P}_{2}, \mathrm{PI}(4,5) \mathrm{P}_{2}$ und $\mathrm{PI}(3,4,5) \mathrm{P}_{3}$ sehr große Fehler auf (D-F). Die bei einer Proteinkonzentration $c_{\text {Protein }}=0.74 \mu \mathrm{M}$ erreichten Änderungen der physikalischen Schichtdicke sind in Tabelle 14 dargestellt.

Tabelle 14: Änderungen der physikalischen Schichtdicke resultierend aus der Adsorption von $0.74 \mu \mathrm{M} \mathrm{CB} 2_{\mathrm{SH} 3+}$ an PIP-haltige festkörperunterstützte Membranen.

\begin{tabular}{|c|c|c|c|c|c|c|}
\hline $\mathbf{P I P}$ & $\mathbf{P I}(\mathbf{3}) \mathbf{P}$ & $\mathbf{P I}(\mathbf{4}) \mathbf{P}$ & $\mathbf{P I}(\mathbf{3 , 4}) \mathbf{P}_{2}$ & $\mathbf{P I}(\mathbf{3 , 5}) \mathbf{P}_{2}$ & $\mathbf{P I}(\mathbf{4 , 5}) \mathbf{P}_{2}$ & $\mathbf{P I}(\mathbf{3 , 4}, \mathbf{5}) \mathbf{P}_{\mathbf{3}}$ \\
\hline $\boldsymbol{d}_{0.74} / \mathbf{n m}$ & $0.3 \pm 0.1$ & $0.23 \pm 0.05$ & $0.04 \pm 0.07$ & $0.2 \pm 0.2$ & $0.33 \pm 0.08$ & $0.6 \pm 0.5$ \\
\hline
\end{tabular}

Die Änderungen der physikalischen Schichtdicke für die mono- und diphosphorylierten Phosphatidylinositole außer $\mathrm{PI}(3,4) \mathrm{P}_{2}$ sind alle sehr ähnlich. Lediglich an $\mathrm{PI}(3,4,5) \mathrm{P}_{3}$ wurde eine doppelt so große Änderung der physikalischen Schichtdicke beobachtet. An $\mathrm{PI}(3,4) \mathrm{P}_{2}$ wurde keine Bindung detektiert. Die Dissoziationskonstante $K_{\mathrm{D}}$ für die Bindung von $\mathrm{CB}_{\mathrm{SH} 3+}$ an die verschiedenen Phosphatidylinositolphosphate wurden nicht bestimmt, da die maximalen 
Änderungen der physikalischen Schichtdicke bei einer Proteinkonzentration von $c_{\text {Prot }}=0.74 \mu \mathrm{M}$ alle unter Betrachtung der Fehlerbereiche unter $d_{0.74} \leq 0.5 \mathrm{~nm}$ betragen. Dieser Grenzwert für die physikalische Schichtdickenänderung durch Proteinzugabe definiert die Grenze zwischen spezifischer und unspezifischer Bindung des Proteins an die festkörperunterstützte Membran.
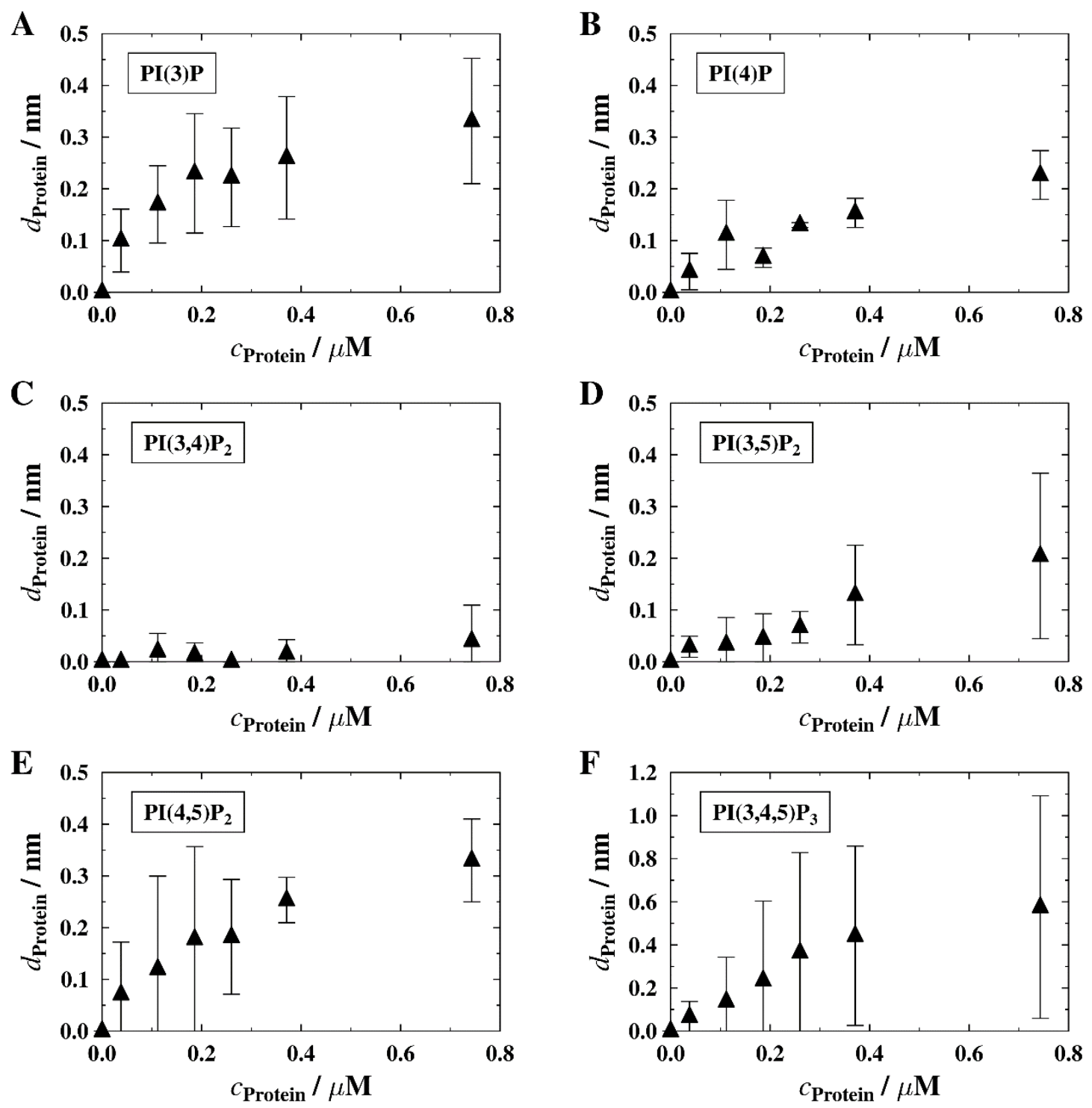

Abbildung 50: Auftragung der Änderung der physikalischen Schicktdicke $d_{\text {Protein }}$ als Funktion der eingesetzten Proteinkonzentration $c_{\text {Protein }}$ bei der Bindung von $\mathrm{CB}_{2 \mathrm{SH}}+$ an PIP-haltige festkörperunterstützte Membranen (POPC/PIP, 9:1). 


\subsection{Wechselwirkung von $\mathrm{CB}_{\mathrm{SH}_{3}} / \mathrm{W} 24 \mathrm{~A}-\mathrm{E} 262 \mathrm{~A}$ mit PIP-}

\section{haltigen Membranen}

Die Bindung von $\mathrm{CB}_{\mathrm{sH} 3+}$ wurde in Abschnitt 7.2 beschrieben. Soykan et al. postulieren, dass $\mathrm{CB}_{\mathrm{SH}_{3+}}$ durch Punktmutationen in der SH3-Domäne an Position 24 und am C-Terminus der DH-Domäne an Position 262 in eine geöffnete Konformation überführt wird. ${ }^{[13]}$ Die Adsorption von CB2 ${ }_{\mathrm{SH} 3+} / \mathrm{W} 24 \mathrm{~A}-\mathrm{E} 262 \mathrm{~A}$ an PIPhaltige Membranen wurde über die reflektometrische Interferenzspektroskopie im HEPES-Puffer (100 mM NaCl, 25 mM HEPES, 0.5 mm EDTA, 0.5 mM DTT, pH 7.2) verfolgt. Es wurden Adsorptionsisothermen mit sechs verschiedenen Proteinkonzentrationen an allen Phosphatidylinositolphosphaten gemessen.

In Abbildung 51 ist eine repräsentative RIfS-Messkurve der Bindung von $\mathrm{CB}_{\mathrm{SH}_{3+}} / \mathrm{W} 24 \mathrm{~A}-\mathrm{E} 262 \mathrm{~A}$ an eine PI(3)P-haltige Membran dargestellt. Die Änderung der physikalischen Schichtdicke nach Zugabe verschiedener Konzentrationen von CB2 ${ }_{\mathrm{SH} 3+} /$ W24A-E262A zur festkörperunterstützten Membran im Durchfluss ist zeitabhängig aufgetragen. Die physikalische Schichtdicke der Proteinschicht nahm bei schrittweiser Erhöhung der $\mathrm{CB} 2_{\mathrm{SH}_{3}}$-Konzentration bis $\mathrm{zu}$ einer Dicke von $d=1.1 \mathrm{~nm}$ zu. Das anschließende Spülen der Oberfläche mit Puffer bewirkte eine Abnahme der physikalischen Schichtdicke auf $d=0.95 \mathrm{~nm}$. Es wurden $86 \%$ des Proteins irreversibel auf der festkörperunterstützten Membran gebunden. 


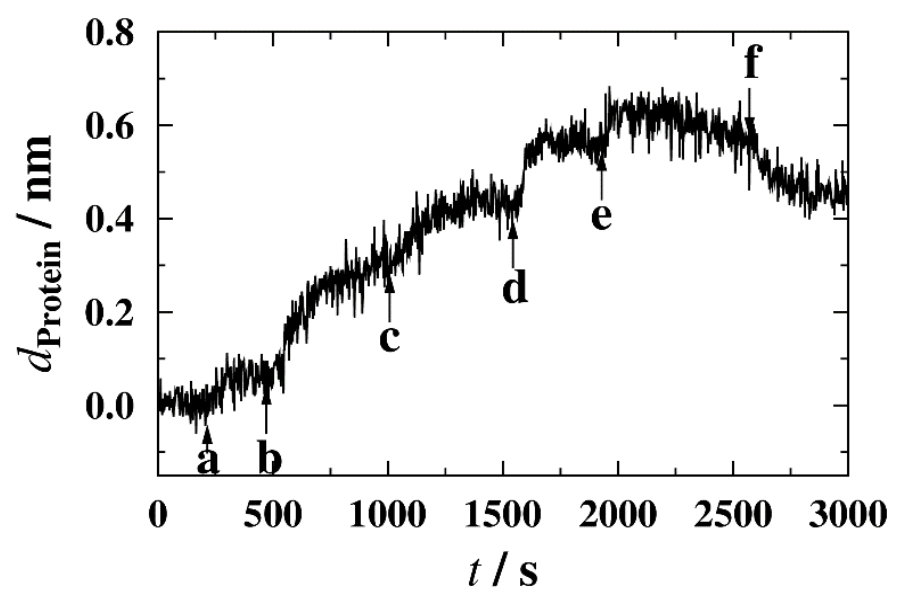

Abbildung 51: Zeitaufgelöste Änderung der physikalischen Schichtdicke $d$ durch Bindung von $\mathrm{CB}_{\mathrm{SH}_{3}} / \mathrm{W} 24 \mathrm{~A}-\mathrm{E} 262 \mathrm{~A}$ an eine $\mathrm{PI}(3) \mathrm{P}$-haltige Membran (a-e) und anschließendes Spülen (f) mit HEPES-Puffer (100 mM NaCl, $25 \mathrm{mM}$ HEPES, $0.5 \mathrm{mM}$ EDTA, $0.5 \mathrm{mM}$ DTT, $\mathrm{pH}$ 7.2). Konzentrationen von CB2 $\mathrm{SH}_{3+} / \mathrm{W} 24 \mathrm{~A}-\mathrm{E} 262 \mathrm{~A}$ : $\mathrm{a}=0.04 \mu \mathrm{M} . \mathrm{b}=0.11 \mu \mathrm{M}, \mathrm{c}=0.19 \mu \mathrm{M}, \mathrm{d}=0.26 \mu \mathrm{M}, \mathrm{e}=0.37 \mu \mathrm{M}$.

Die Auftragung der Änderung der physikalischen Schichtdicke $d$ im Gleichgewicht gegen die jeweils im System vorliegende Proteinkonzentration $c_{\text {Protein }}$ liefert die Adsorptionsisotherme. Zur Bestimmung der maximalen physikalischen Schichtdicke und der Dissoziationskonstante der Bindung von $\mathrm{CB} 2_{\mathrm{SH}_{3}+} / \mathrm{W} 24 \mathrm{~A}-\mathrm{E} 262 \mathrm{~A}$ an die verschiedenen Phosphatidylinositolphosphate wurden für jedes PIP mindestens drei voneinander unabhängige Messungen durchgeführt. Die erhaltenen Schichtdickenänderungen für jede Konzentration wurden gemittelt und die Standardabweichung vom Mittelwert berechnet. Über die Anpassung des LangmuirAdsorptionsmodells (Gleichung (30)) an die Daten kann neben der maximalen physikalischen Schichtdicke der Proteinschicht auch die Dissoziationskonstante der Bindung des Proteins an die Membran bestimmt werden. In Abbildung 52 sind die daraus resultierenden Adsorptionsisothermen von $\mathrm{CB} 2_{\mathrm{SH} 3+} / \mathrm{W} 24 \mathrm{~A}-\mathrm{E} 262 \mathrm{~A}$ und den verschiedenen Phosphatidylinositolphosphaten gezeigt. Es wird deutlich, dass die Messwerte alle einen relativ kleinen statistischen Fehler aufweisen. 

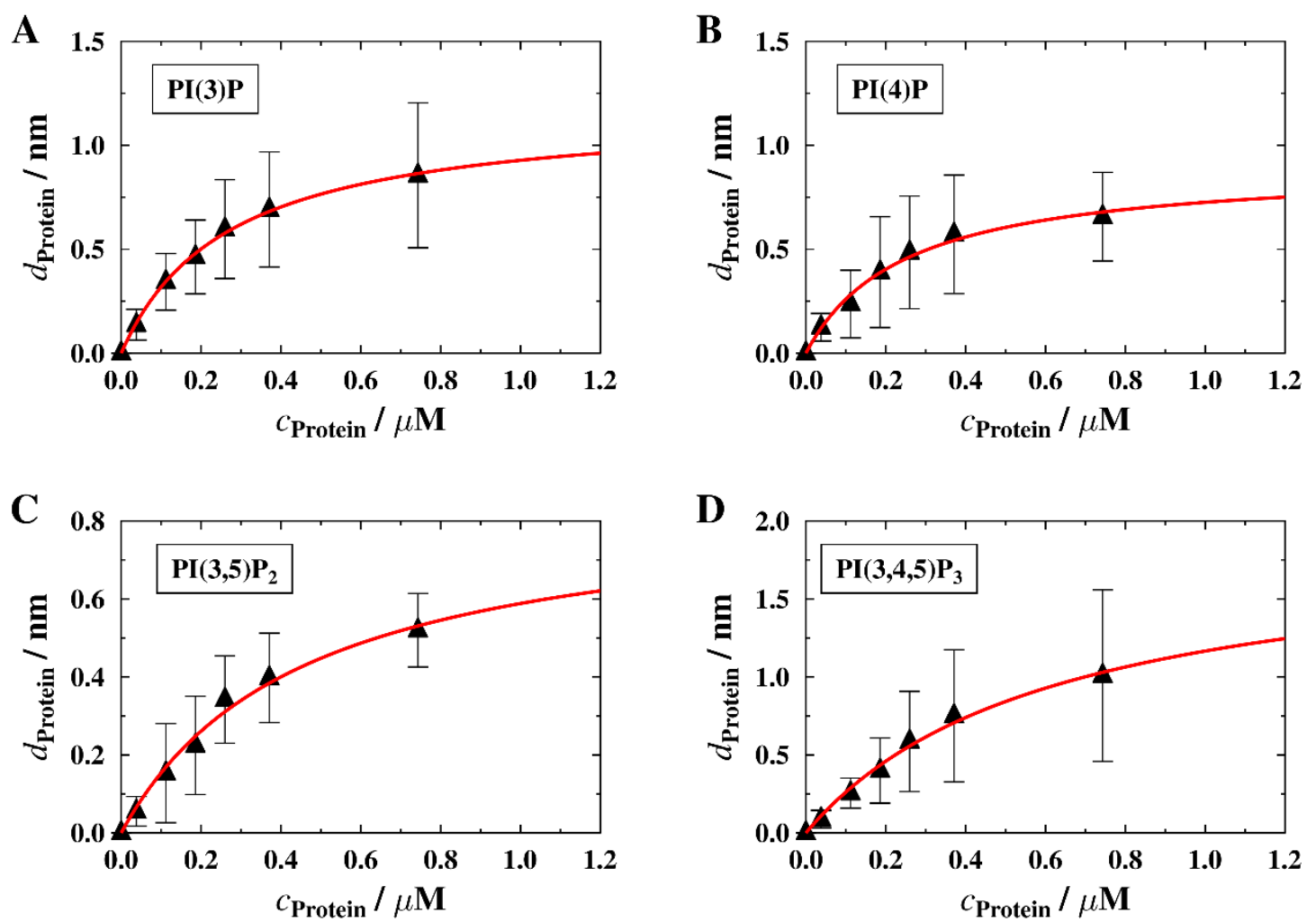

Abbildung 52: Auftragung der Änderung der physikalischen Schicktdicke $d_{\text {Protein }}$ als Funktion der eingesetzten Proteinkonzentration $c_{\text {Protein }}$ bei der Bindung von $\mathrm{CB}_{\mathrm{SH} 3+} / \mathrm{W} 24 \mathrm{~A}-\mathrm{E} 262 \mathrm{~A}$ an PIP-haltige Membranen (POPC/PIP, 9:1). Die roten Linien zeigen eine Anpassung des Langmuir-Adsorptionsmodells an die Adsorptionsisothermen. Die ermittelten Dissoziationskonstanten $K_{\mathrm{D}}$ und die maximale physikalische Schichtdickenänderungen $d_{\max }$ für die verschiedenen Phosphatidylinositolphosphate sind in Tabelle 15 dargestellt.

$\mathrm{CB}_{\mathrm{SH}_{3+}} / \mathrm{W} 24 \mathrm{~A}-\mathrm{E} 262 \mathrm{~A}$ bindet in den durchgeführten RIfS-Experimenten nicht an $\mathrm{PI}(3,4) \mathrm{P}_{2}$ und $\mathrm{PI}(4,5) \mathrm{P}_{2}$-haltige festkörperunterstützte Membranen. Die ermittelten Werte für die maximale Änderung der physikalischen Schichtdicke $d_{\max }$ und die Dissoziationskonstante $K_{\mathrm{D}}$ für die Bindung von $\mathrm{CB} 2_{\mathrm{SH} 3+} / \mathrm{W} 24 \mathrm{~A}-\mathrm{E} 262 \mathrm{~A}$ an die übrigen Phosphatidylinositolphosphate sind in Tabelle 15 dargestellt. 
Tabelle 15: Dissoziationskonstante $K_{\mathrm{D}}$ und maximale Änderung der physikalischen Schichtdicke $d_{\max }$ der Bindung von CB2 $2_{\mathrm{SH} 3+} /$ W24A-E262A an Phosphatidylinositolphosphate in festkörperunterstützten Membranen. k.B. = keine Bindung.

\begin{tabular}{|c|c|c|c|c|c|c|}
\hline $\mathbf{P I P}$ & $\mathbf{P I}(\mathbf{3}) \mathbf{P}$ & $\mathbf{P I}(\mathbf{4}) \mathbf{P}$ & $\mathbf{P I}(\mathbf{3}, \mathbf{4}) \mathbf{P}_{2}$ & $\mathbf{P I}(\mathbf{3}, \mathbf{5}) \mathbf{P}_{2}$ & $\mathbf{P I}(\mathbf{4}, \mathbf{5}) \mathbf{P}_{2}$ & $\mathbf{P I}(\mathbf{3}, \mathbf{4 , 5}) \mathbf{P}_{3}$ \\
\hline $\boldsymbol{K}_{\mathrm{D} / \mathbf{\mu M}}$ & $0.27 \pm 0.02$ & $0.25 \pm 0.04$ & k. B. & $0.46 \pm 0.09$ & k. B & $0.6 \pm 0.1$ \\
\hline $\boldsymbol{d}_{\text {max }} / \mathbf{n m}$ & $1.18 \pm 0.04$ & $0.91 \pm 0.07$ & k. B & $0.86 \pm 0.09$ & k. B & $1.9 \pm 0.2$ \\
\hline
\end{tabular}

Die Anpassung des Langmuir-Adsorptionsmodells beschreibt die gemessenen Isothermen für die Bindung von $\mathrm{CB}_{\mathrm{SH}_{3+}} / \mathrm{W} 24 \mathrm{~A}-\mathrm{E} 262 \mathrm{~A}$ an PIP-haltige festkörperunterstützte Membran sehr gut. Die Dissoziationskonstanten für die Bindung an monophosphorylierte Phosphatidylinositole sind mit $K_{\mathrm{D}, \mathrm{PI}(3) \mathrm{P}}=(0.27 \pm 0.02) \mu \mathrm{M} \quad$ und $\quad K_{\mathrm{D}, \mathrm{PI}(4) \mathrm{P}}=(0.25 \pm 0.04) \mu \mathrm{M} \quad$ sehr ähnlich. Das Protein weist demnach für $\mathrm{PI}(3) \mathrm{P}$ und $\mathrm{PI}(4) \mathrm{P}$ die höchste Bindungsaffinität auf. Die Bindung des Proteins an $\mathrm{PI}(3,5) \mathrm{P}_{2}$ weist eine etwa doppelt so hohe Dissoziationskonstante $K_{\mathrm{D}}=(0.46 \pm 0.09) \mu \mathrm{M}$ auf. CB2 ${ }_{\mathrm{SH} 3+} / \mathrm{W} 24 \mathrm{~A}-\mathrm{E} 262 \mathrm{~A}$ bindet an $\operatorname{PI}(3,4,5) \mathrm{P}_{3}$-haltige Membranen mit der höchsten Dissoziationskonstante $\left(K_{\mathrm{D}}=(0.6 \pm 0.1) \mu \mathrm{M}\right)$ und demnach mit der schwächsten Bindungsaffinität.

Die beobachteten Änderungen der physikalischen Schichtdicke bei der Bindung von CB2 ${ }_{\mathrm{SH} 3+} / \mathrm{W} 24 \mathrm{~A}-\mathrm{E} 262 \mathrm{~A}$ auf $\mathrm{PI}(4) \mathrm{P}-$ und $\mathrm{PI}(3,5) \mathrm{P}_{2}$-haltigen festkörperunterstützten Membranen sind mit $\quad d_{\max , \mathrm{PI}(4) \mathrm{P}}=(0.91 \pm 0.07) \mathrm{nm} \quad$ und $d_{\max , \mathrm{PI}(3,5) \mathrm{P} 2}=(0.86 \pm 0.09) \mathrm{nm}$ in einem ähnlichen Bereich. Auf PI(3)P-haltigen Membranen konnte eine maximale physikalische Schichtdicke $d_{\max }=(1.18 \pm 0.04) \mathrm{nm}$ beobachtet werden. Die höchste Änderung der physikalischen Schichtdicke bei Proteinzugabe wurde auf $\mathrm{PI}(3,4,5) \mathrm{P}_{3}$-haltigen Membranen gemessen $\left(d_{\max , \mathrm{P}(4) \mathrm{P}}=(1.9 \pm 0.2) \mathrm{nm}\right)$. 


\section{Diskussion der Wechselwirkung von Collybistin-}

\section{Isoformen mit Phosphatidylinositolphosphaten}

Im Rahmen dieser Arbeit wurde der Einfluss der verschiedenen Domänen von Collybistin 2 auf die Bindung an Phosphatidylinositolphosphate in Membranen analysiert. Ausgehend von der PH-Domäne, die eine Bindungsstelle für PIPs aufweist, wurden die Einzelbeiträge der DH- und der SH3-Domäne zum resultierenden Bindungsvermögen adressiert. Neben dem Wildtyp von CB2 $2_{\mathrm{SH} 3+}$ wurde eine Mutante $\mathrm{CB} 2_{\mathrm{SH} 3+} / \mathrm{W} 24 \mathrm{~A}-\mathrm{E} 262 \mathrm{~A}$ untersucht, die im Vergleich eine eher geöffnete Konformation aufweist. ${ }^{[13]}$

Die PH-Domäne des Collybistin 2 (CB2 $\left.2_{\mathrm{PH}}\right)$ wurde zum Aufbau und zur Etablierung des im Anschluss verwendeten Messsystems verwendet. Dieses wurde bereits in Abschnitt 6 gezeigt und diskutiert. Die Isoform CB2 $2_{\mathrm{PH}}$ kommt in lebenden Zellen allerdings nicht vor, sodass diese Ergebnisse keine direkte physiologische Relevanz haben. CB2 $2_{\mathrm{SH} 3}$ weist eine Tandemdomäne aus $\mathrm{PH}-$ und DH-Domäne auf und ist die kürzeste, physiologisch relevante Proteinisoform. Im Experiment wurde eine nahezu gleichstarke Affinität des Proteins $\mathrm{CB}_{\mathrm{SH}}$ - an alle Phosphatidylinositolphosphate außer $\mathrm{PI}(3,5) \mathrm{P}_{2}$ beobachtet. Die mittlere Dissoziationskonstante $K_{\mathrm{D}}=0.3 \mu \mathrm{M}$ der Bindung des Proteins an PIPs ist im Vergleich mit anderen PH-Domänen eher hoch. Die PH-Domäne von PLC- $\delta$ bindet mit $K_{\mathrm{D}}=6.6 \mathrm{nM}$ an $\mathrm{PI}(4,5) \mathrm{P}_{2}$-haltige Vesikel. ${ }^{[67]}$ Die Wechselwirkung der $\mathrm{PH}-$ Domäne des Proteins Cytohesin-3 mit $\mathrm{PI}(3,4,5) \mathrm{P}_{3}$-dotierten festkörperunterstützten Membranen weist einen um den Faktor 10 höhere Dissoziationskonstante 
$K_{\mathrm{D}}=60 \mathrm{nM}$ auf. ${ }^{[91]}$ Dieser Wert ist um den Faktor 5 kleiner, als die mittlere Dissoziationskonstante $K_{\mathrm{D}}=0.3 \mu \mathrm{M} \quad$ der $\quad$ Wechselwirkung von $\quad \mathrm{CB} 2_{\mathrm{SH} 3-}$ mit Phosphatidylinositolphosphaten. Die Affinität des Proteins für PIP-haltige festkörperunterstützten Membranen ist im Vergleich schwach.

Die detektierten Änderungen der physikalischen Schichtdicke $d_{\max }$ bei der Bindung von $\mathrm{CB} 2_{\text {знз }}$ an PIP-haltige Membranen wiesen große Unterschiede auf. Bei einer maximalen Länge von $\mathrm{CB} 2_{\text {SHз- von }} 78 \AA$ aus der Kristallstruktur ${ }^{[16]}$ und der Annahme der dichtesten Packung, die eine maximale Oberflächenbelegung von $56 \%$ ergibt, kann eine maximale Änderung der physikalischen Schichtdicke im gestreckten Zustand des Proteins von $4.4 \mathrm{~nm}$ erreicht werden. Dieser Wert wird lediglich für $\mathrm{PI}(4,5) \mathrm{P}_{2^{-}} \quad$ und $\quad \mathrm{PI}(3,4,5) \mathrm{P}_{3}$-haltige Membranen nahezu erreicht. An monophosphorylierten Phosphatidylinositolen konnte lediglich eine berechnete Oberflächenbelegung von $18 \%$ erreicht werden. Die ungleiche Belegungsdichte kann durch eine nicht-exakt statistische Verteilung des jeweiligen Rezeptorlipids in der festkörperunterstützten Membran ausgelöst werden. Die gleichmäßige Verteilung von $\mathrm{PI}(4,5) \mathrm{P}_{2}$ wurde unter den gewählten Spreitbedingungen $(\mathrm{pH} 4.8)$ von Braunger et al. beschrieben. ${ }^{[70]}$ Die Präparation der Membranen mit den weiteren zweifach- und dreifach phosphorylierten Phosphatidylinositole wurde unter identischen Bedingungen durchgeführt, sodass eine Gleichverteilung der PIP-Moleküle in den Membranen vorliegen sollte. Die mit monophosphorylierten Phosphatidylinositolen dotierten Vesikel wurden bei pH 6.4 gespreitet. Diese Membranen besitzen eine über die $\mathrm{pK}_{\mathrm{s}}$-Werte der Phosphatgruppen berechnete Ladung von $-5.6 \cdot 10^{17} \mathrm{Q} / \mathrm{m}^{2} \mathrm{im}$ Gegensatz zu der Ladung von $\mathrm{PI}(4,5) \mathrm{P}_{2}$-haltigen Membranen von $-7.7 \cdot 10^{17} \mathrm{Q} / \mathrm{m}^{2}$. Es wurden bei der Präparation der PI(3)P- und PI(4)P-dotierten Membranen demnach weniger Protonen in der Pufferlösung benötigt, um die repulsiven Kräfte beim Spreitvorgang zu minimieren. Die Spreitkinetiken weisen durch den schnellen 
Anstieg und den Sättigungscharakter ebenfalls auf eine mögliche Gleichverteilung der Rezeptorlipidmoleküle in der Membran hin. Weitere Informationen über die Verteilung der Lipidmoleküle würde eine Untersuchung der Membran mittels eines fluoreszierenden Markers für die PIP-Moleküle liefern.

Unter der Annahme der statistischen Verteilung der Rezeptorlipide muss die Stöchiometrie der Bindung der PH-Domäne an Phosphatidylinositolphosphate betrachtet werden. Für die Bindung der PH-Domänen der Proteine PLC- $\delta 1$ und $\beta$ Spectrin an $\mathrm{PI}(4,5) \mathrm{P}_{2}$ wurde eine 1:1-Verhältnis beschrieben. ${ }^{[11],[92]}$ Rameh et al. haben für die Wechselwirkung der $\mathrm{PH}-$ Domäne von Btk mit $\mathrm{PI}(3,4,5) \mathrm{P}_{3}$ ein Bindungsverhältnis von $0.9 \mathrm{~mol} \mathrm{PI}(3,4,5) \mathrm{P}_{3}$ pro mol Btk-PH ermittelt. ${ }^{[37]}$ Die sehr ähnliche Tertiärstruktur aller bisher charakterisierter PH-Domänen hüllt die Inositolkopfgruppe der Phosphatidylinositolphosphate nahezu komplett in der Bindungstasche zwischen den sieben $\beta$-Faltblättern ein. ${ }^{[91]}$ Dies weist darauf hin, dass auch bei der Bindung der PH-Domäne von CB2 ${ }_{\mathrm{SH} 3-}$ an PIP-haltige Membran eine 1:1 Stöchiometrie zwischen Protein und Lipid vorliegen sollte. Eine ungleiche Anzahl von gebundenen PIP-Molekülen pro Proteinmolekül erklärt die stark unterschiedlichen Änderungen der maximalen physikalischen Schichtdicke $d_{\max }$ demnach eher nicht. Dies könnte wie in Abschnitt 6.4 diskutiert, auf die elektrostatische Abschirmung der PIPs in der Membran durch die Ionenstärke des verwendeten Puffers hervorgerufen werden. Auf den $\mathrm{PI}(3) \mathrm{P}$ und $\mathrm{PI}(4) \mathrm{P}$-dotierten Membranen könnte vermutlich durch eine verringerte Ionenstärke des Puffers ebenfalls eine maximale Oberflächenbelegung erreicht werden. Die verwendeten Proteine sind unter diesen Pufferbedingungen allerdings nicht stabil.

Baraldi et al. beschrieben eine Tendenz von PH-Domänen zur Dimerisierung. Die Dimerisierung könne nach der Bindung an PIP-haltige Membranen erfolgen und soll für die Signalverarbeitung der Zelle relevant sein. ${ }^{[93]}$ Der Effekt der Dimerisierung 
wurde auch für FYVE-Proteindomänen beschrieben, die bevorzugt an $\mathrm{PI}(3) \mathrm{P}$ binden. ${ }^{[94]}$ Eine Dimerisierung von Proteinmolekülen würde zu einer Ungleichverteilung von Proteinen auf der Oberfläche führen. Dies könnte die beobachtete geringere Oberflächenbelegung bei der Bindung an monophosphorylierte Phosphatidylinositole erklären, wenn die Dimerisierung nur nach der Bindung an $\mathrm{PI}(3) \mathrm{P}$ und $\mathrm{PI}(4) \mathrm{P}$ erfolgen würde. Der Effekt des Proteinclustering an $\mathrm{PI}(4,5) \mathrm{P}_{2^{-}}$ haltigen Membranen wurde für das Protein Ezrin beschrieben. Die Dimerisierung von $\mathrm{CB} 22_{\mathrm{SH}}$ auf der Oberfläche könnte mittels Einzelmolekülfluoreszenzspektroskopie untersucht werden.

Einen weiteren Erklärungsansatz für die unterschiedliche Oberflächenbelegung der PIP-haltigen Membranen liefern Knight et al.. Sie beschreiben den Einfluss des negativ geladenen Lipids POPS auf die Diffusion der an $\mathrm{PI}(3,4,5) \mathrm{P}_{3}$ gebundenen $\mathrm{PH}-$ Domäne von Cytohesin-3 in der Lipiddoppelschicht. ${ }^{[91]}$ Die Diffusion des Proteins an der POPS- und PI $(3,4,5) \mathrm{P}_{3}$-haltigen Membran ist stark verlangsamt im Vergleich mit der POPS-freien Membran. POPS wird von kationischen Aminosäureseitenketten in der PH-Domäne gebunden. Knight et al. vermuten, dass POPS und andere schwach anionische Lipide zur Fixierung des Proteins an bestimmten Membranstellen dienen. ${ }^{[91]}$ Die monophosphorylierten Phosphatidylinositole PI(3)P und PI(4)P könnten im Gegensatz zu den mehrfach

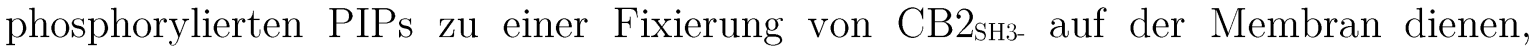
sodass mehr als ein Lipidmolekül an der Fixierung des Proteins beteiligt wären. Dies würde zu einer Reduktion der Anzahl der für die Proteinbindung zur Verfügung stehenden Rezeptorlipidmoleküle führen, was in einer reduzierten Oberflächenbelegung resultieren würde.

Im Vergleich der Bindung von $\mathrm{CB} 2_{\mathrm{SH}}$ - mit der Bindung von $\mathrm{CB} 2_{\mathrm{PH}}$ an PIP-haltige Membranen wird deutlich, dass die Affinität der Bindung von $\mathrm{CB} 2_{\mathrm{SH}}$ - vor allem an 
monophosphorylierte Phosphatidylinositole geringer ist (Abbildung $53 \mathrm{~A}$ ). Die Erhöhung der beobachteten physikalischen Schichtdicken $d_{\max }$ von CB2 $2_{\mathrm{PH}} \mathrm{zu}$ CB2 $2_{\mathrm{SH} 3}$ passt zur Größe der zusätzlichen DH-Domäne mit einer Länge von ungefähr $3.6 \mathrm{~nm}$ (B). Dies bedeutet unter der Annahme der maximalen Oberflächenbelegung von $56 \%$ eine Zunahme der physikalischen Schichtdicke um 2 nm. In beiden Fällen wird deutlich, dass die physikalische Schichtdickenänderung auf PI(3)P- und PI(4)Phaltigen Membranen kleiner ist als auf den höher geladenen, mehrfach phosphorylierten Phosphatidylinositolen $\mathrm{PI}(4,5) \mathrm{P}_{2}$ und $\mathrm{PI}(3,4,5) \mathrm{P}_{3}$. Beide Proteinisoformen zeigen keine Bindung an $\mathrm{PI}(3,4) \mathrm{P}_{2}$.
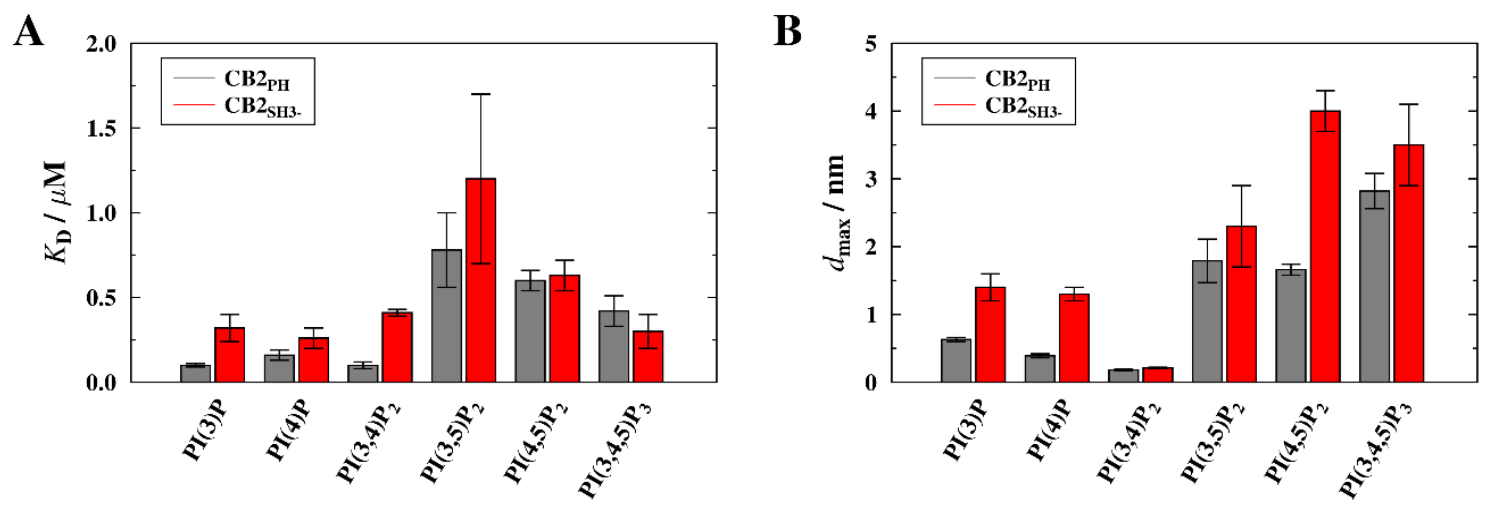

Abbildung 53: Vergleich der Dissoziationskonstante $K_{\mathrm{D}}$ (A) und der maximalen Änderung der physikalischen Schichtdicke $d_{\max }$ von CB2 $2_{\mathrm{PH}}$ und CB2 $2_{\mathrm{SH} 3}$ auf PIP-haltigen Membranen (POPC/PIP, 9:1).

Im CB2 $2_{\mathrm{PH}}$ liegt ausschließlich die PH-Domäne vor, sodass die Phosphatidylinositolphosphat-Bindungsstelle, repräsentiert durch die Aminosäuren R294 und R295 (in der Sequenz von CB2 ${ }_{\mathrm{SH} 3}$ ) in der Schleife zwischen $\beta 3$ - und $\beta 4$ Faltblatt, immer für die Membranbindung zur Verfügung steht. ${ }^{[95]}$ Xiang et al. haben gezeigt, dass im $\mathrm{CB}_{\mathrm{SH}}$ - eine Wechselwirkung zwischen der $\mathrm{PH}-$ und der DHDomäne stattfindet. ${ }^{[16]}$ In der bevorzugten offenen Konformation des Proteins interagiert die $\alpha_{6}$-Helix der DH-Domäne mit der $\beta$-Haarnadelschleife N-terminal zum $\beta_{1}$-Faltblatt und dem Bereich zwischen beiden C-terminalen $\alpha$-Helices der PHDomäne. ${ }^{[16]}$ Papadopoulos et al. beschreiben die Wechselwirkung in MD- 
Simulationen zwischen den Aminosäuren R228 in der DH-Domäne ( $\alpha_{6}$-Helix) und D368 in der PH-Domäne (zwischen beiden C-terminalen $\alpha$-Helices). ${ }^{[95]}$ Dabei ist die $\alpha$-Helix (AS I232-S241) am N-terminalen Ende der PH-Domäne für die Mobilität der PH-Domäne relativ zur DH-Domäne verantwortlich. Die Annahme der energetisch bevorzugten offenen, gestreckten Konformation des Proteins konnte durch das Erreichen der maximalen Oberflächenbelegung auf $\mathrm{PI}(4,5) \mathrm{P}_{2}$ und $\mathrm{PI}(3,4,5) \mathrm{P}_{3^{-}}$ haltigen Membranen gestützt werden. In einer geschlossenen Konformation würde das Protein nicht in der gestreckten Konformation vorliegen. Die PH- und DHDomäne wären eher aufeinander gefaltet. Dies würde zu einer geringeren physikalischen Schichtdicke auf den Membranen führen. Die Abnahme der Bindungsaffinitäten mit $\mathrm{CB} 2_{\mathrm{SH} 3}$ im Vergleich zu CB2 $2_{\mathrm{PH}}$ weist darauf hin, dass die Wechselwirkung zwischen den Domänen einen Einfluss auf die Zugänglichkeit der PIP-Bindungsstelle in der PH-Domäne hat. Das et al. haben die Wechselwirkung der PH- und DH-Domäne von verschiedenen Proteinen in Gegenwart von Phosphatidylinositolphosphaten untersucht. Sie konnten zeigen, dass die Wechselwirkung der DH- und PH-Domäne des Proteins Sos1 in Gegenwart von $\mathrm{PI}(4,5) \mathrm{P}_{2}$ deutlich schwächer ist als in Abwesenheit des Lipids. ${ }^{[96]}$ In der vorliegenden Studie konnten die $\mathrm{PH}-$ und die $\mathrm{DH}-\mathrm{Domäne}$ von $\mathrm{CB}_{\mathrm{SH} 3}$ in Lösung miteinander wechselwirken und die bevorzugte Konformation einnehmen. Diese vorangegangene Wechselwirkung könnte demnach einen Einfluss auf die Affinität vom Protein für PIPs haben.

Die Bindungsaffinitäten von $\mathrm{CB} 2_{\mathrm{SH} 3-}$ waren für alle Phosphatidylinositolphosphate außer $\mathrm{PI}(3,5) \mathrm{P}_{2}$ sehr ähnlich. Um den Einfluss der Ladung und der Anzahl der freien Hydroxylgruppen der verschiedenen PIPs auf die Membranbindung zu untersuchen, wurden RIfS-Messungen mit anderen Rezeptorlipiden durchgeführt. Die Ladung der mit $20 \mathrm{~mol} \%$ POPS dotierte Membran ist mit $-4.0 \cdot 10^{17} \mathrm{Q} / \mathrm{m}^{2}$ sehr ähnlich der 
Ladung der mit $10 \mathrm{~mol} \% \mathrm{PI}(3) \mathrm{P}$-dotierten Membran $\left(-5.6 \cdot 10^{17} \mathrm{Q} / \mathrm{m}^{2}\right)$. An POPShaltige Membranen (Nettoladung $\mathrm{Q}=-2$ ) konnte jedoch keine Bindung detektiert werden. Das Protein bindet somit vermutlich nicht ausschließlich durch Oberflächenladungsdichte, sondern über eine molekulare Erkennung an die PIPs. Weiterhin konnte eine schwache Bindung an 20 mol \% POPG detektiert werden. Dieses Lipid ist lediglich einfach negativ geladen, sodass im Vergleich mit den Messungen auf POPS-haltigen Membranen keine Bindung erwartet wurde. Die Bindung des Proteins erfolgt wahrscheinlich an die zwei freien Hydroxylgruppen innerhalb der Lipidkopfgruppe. Dieser Effekt wird durch die Bindung mit einer höheren Bindungskapazität an eine 10 mol \% PI-haltige Membran bestätigt. Das PI weist fünf freie Hydroxylgruppen in der Inositolkopfgruppe auf. CB2 $2_{\mathrm{SH} 3-}$ bindet mit vergleichbarer Affinität an PI(3)P. Die Bindungskapazität ist höher als für die Bindung des Proteins an PI-haltigen Membranen. Das Protein könnte demnach sowohl Bindungsstellen für die Phosphatgruppen in den PIPs, als auch für die nichtphosphorylierten Hydroxylgruppen in der Inositolkopfgruppe aufweisen. Die Bindungskapazität wurde durch den Phosphorylierungsgrad der Inositolkopfgruppe erhöht. Für Cytohesin-3 und andere Proteine mit PH-Domäne wurde weder eine Bindung an PS- noch an PI-haltige Membranen beobachtet. ${ }^{[91]}$ Für alle anderen untersuchten PH-Domänen war mindestens eine Phosphorylierung an der Inositolkopfgruppe für die Proteinbindung notwendig. ${ }^{[37,91,93,96]}$

Eine genaue Betrachtung der Aminosäuresequenz der PH-Domäne von Collybistin 2 verdeutlicht, dass dieser PH-Domäne die zwei für die PIP-Bindung wichtigen Aminosäuren Lysin und Arginin in der Schleife zwischen dem $\beta 1$ - und $\beta 2$-Faltblatt fehlen. ${ }^{[36]}$ Diese Aminosäuren liegen zum Beispiel im PLC-81 (K30/R40) und im Btk (K12/R28) vor und sind in diesen Proteinen für die Wechselwirkung mit den Phosphatgruppen der PIPs wichtig. ${ }^{[36]}$ Rameh et al. haben postuliert, dass PH- 
Domänen mit fünf oder weniger basischen Aminosäureresten im Bereich des $\beta 1$ - und $\beta 2$-Faltblatts keine starke Affinität für mehrfach phosphorylierte PIPs aufweisen. ${ }^{[37]}$ Dies wird im $\mathrm{CB} 2_{\mathrm{SH} 3}$ bestätigt. Es weist lediglich zwei Argininreste in diesem Bereich auf. Die Affinität des Proteins zu PI(3)P und $\mathrm{PI}(3,4,5) \mathrm{P}_{3}$ ist sehr ähnlich, jedoch eher schwach. Im Vergleich mit der Sequenz des Proteins Btk wird deutlich, dass der für die PIP-Bindung von $\mathrm{CB}_{\mathrm{SH} 3-}$ benötigte positive Ladungscluster im Bereich des $\beta 3$ - und $\beta 4$-Faltblatts lokalisiert ist (Abbildung 54). Papadopoulos et al. bestätigten dies über einen lipid-overlay Assay, der eine abgeschwächte PI(3)PBindung durch Mutation der Aminosäuren R294/R295 aufwies. ${ }^{[95]}{ }^{\mathrm{CB}}{ }_{\mathrm{SH} 3-}$ weist im Gegensatz zu Btk und PLC- $\delta 1$ jedoch eine hohe Anzahl basischer Aminosäurereste in der $\alpha 1$ - und $\alpha 2$-Helix am C-Terminus der PH-Domäne auf. ${ }^{[93]}$ Dies deutet auf eine Beteiligung der $\alpha$-Helices an der Proteinbindung an negativ geladene PIP-haltige Membranen hin.

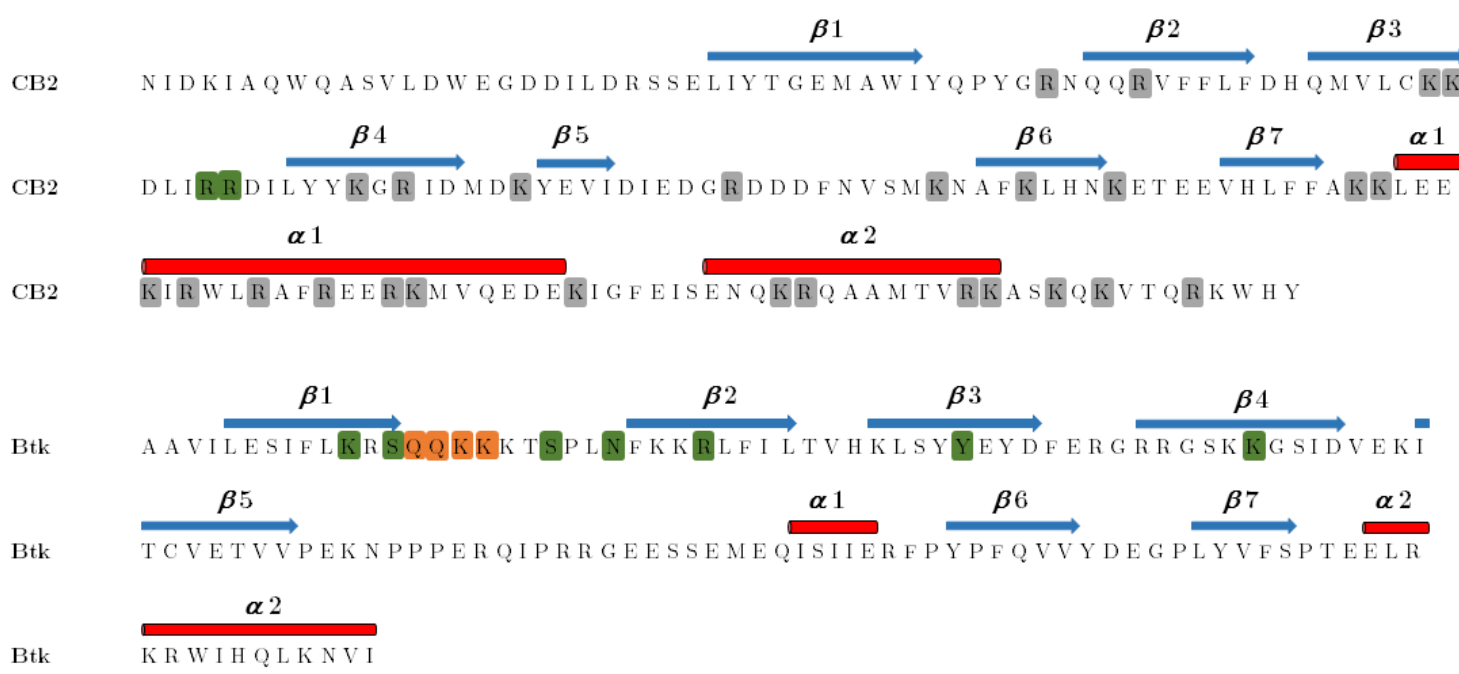

Abbildung 54: Vergleich der Aminosäuresequenzen der PH-Domänen von CB2 und Btk. Die Aminosäurereste, die mit Phosphatgruppen der PIPs über die Seitenkette wechselwirken, sind in grün markiert. Aminosäurereste, die eine Wechselwirkung mit PIPs über das Rückgrat eingehen, sind in orange markiert. ${ }^{[93]}$ Zusätzlich sind alle basischen Aminosäuren der PH-Domäne von CB2 grau hinterlegt. Diese stehen theoretisch für Wechselwirkung mit einem Phosphatidylinositolphosphat zur Verfügung. 
In der Literatur wurde PI(3)P über lipid-overlay Assays als vom GST-CB2 $2_{\mathrm{SH} 3-}$ bevorzugtes Phosphatidylinositolphosphat bestimmt..7-9] Zum Vergleich mit der Literatur wurde ein lipid-overlay Assay mit GST-CB2 $2_{\mathrm{SH} 3-}$ und Tag-freiem $\mathrm{CB} 2_{\mathrm{SH} 3-}$ auf inositol snooper-Membranen durchgeführt. Dabei wurde deutlich, dass der GSTTag am Protein einen Einfluss auf die Bindung des Proteins an Phosphatidylinositolphosphate ausübt. Die Bindungsaffinität von GST-CB2 $2_{\mathrm{SH} 3-}$ für PIPs ist größer als von $\mathrm{CB} 2_{\mathrm{SH} 3}$, da die Bindung schon bei einer zehnfach kleineren Konzentration detektiert werden konnte. Dies könnte durch eine Dimerisierung des Proteins durch den GST-Tag erklärt werden. Die zunehmende Affinität von Dimeren an $\mathrm{PI}(3) \mathrm{P}$ wurde für die FYVE-Proteindomäne beschrieben. ${ }^{[94]}$ Kutateladze et al. haben dazu die Bindungsaffinität der monomeren und dimeren Form der FYVEDomäne des Proteins EEA1 für PI(3)P mittels NMR-Spektroskopie bestimmt. Eine Dimerisierung der FYVE-Domäne konnten sie über die Expression als GSTFusionsprotein erreichen. ${ }^{[94]}$ Dabei soll die Dimerisierung die intramolekulare Wechselwirkung zwischen der FYVE-Domäne und der benachbarten $\alpha$-helikalen Region verstärken. Außerdem wurde im lipid-overlay Assay für GST-CB2 $2_{\mathrm{SH} 3-}$ eine etwas höhere Spezifität für die monophosphorylierten Phosphatidylinositole beobachtet. Allerdings konnte im Gegensatz zur Literatur keine klare Bevorzugung von GST-CB2 $2_{\mathrm{SH} 3}$ für PI(3)P gezeigt werden. Der Vergleich zwischen den Ergebnissen für die Bindung von CB2 $2_{\mathrm{SH} 3-}$ an Phosphatidylinositolphosphate aus der RIfS-Studie auf festkörperunterstützten Membranen und dem lipid-overlay Assay zeigt, dass im lipid-overlay Assay der gleiche Trend für die Bindung des Proteins an verschiedene PIPs detektiert wurde. Allerdings wird bei dem lipid-overlay Assay keine quantitative Information über die Bindungsaffinität und die Bindungskapazität erhalten. Es wurde lediglich die Fläche unter dem Intensitätsprofil der erhaltenen spots bestimmt. Beim Vergleich der RIfS-Ergebnisse mit dem lipid-overlay Assay von GST-CB2 $2_{\mathrm{SH} 3-}$ wird erneut bestätigt, dass der GST-Proteintag einen Einfluss auf die 
Lipidbindung des Proteins hat. Bei einer Proteinkonzentration $c\left(\right.$ GST-CB2 ${ }_{\mathrm{SH} 3-}$ ) $=6$ nM konnte im RIfS-Experiment keine Bindung von $\mathrm{CB}_{\mathrm{SH}_{\mathrm{S}-}}$ detektiert werden.

Soykan et al. haben den Anteil der verschiedenen Collybistin-Isoformen in Nervenzellen untersucht. ${ }^{[13]}$ Sie konnten zeigen, dass $\mathrm{CB}_{\mathrm{SH} 3-}$ nur in sehr kleinen Mengen in der Zelle vorliegt. Der Hauptanteil der Collybistin-Moleküle besitzt eine N-terminale SH3-Domäne. Die Kristallstruktur von $\mathrm{CB}_{\mathrm{SH} 3+}$ weist im Vergleich zum gestreckten $\mathrm{CB} 2_{\mathrm{SH} 3}\left(R_{\mathrm{g}}=28.3 \AA\right)$ eine eher kompakte Struktur auf $\left(R_{\mathrm{g}}=26.3 \AA\right)$. In den RIfS-Experimenten mit $\mathrm{CB}_{\mathrm{SH}_{3+}}$ wurde demnach eine ähnliche maximale Änderung der physikalischen Schichtdicke $d_{\max }$ wie in den Messungen mit CB2 $2_{\mathrm{SH} 3-}$

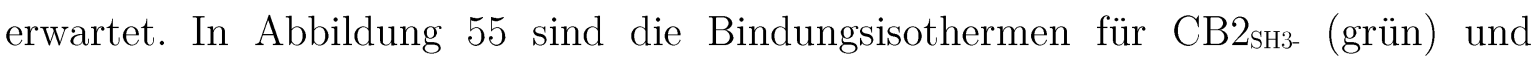
$\mathrm{CB}_{\mathrm{SH} 3+}$ (rot) dargestellt. Es wird deutlich, dass ein deutlich geringerer Anteil von $\mathrm{CB}_{\mathrm{SH} 3+}$ an die PIP-haltigen Membranen gebunden wird. Die maximalen Änderungen der physikalischen Schichtdicke lagen unter dem Grenzwert von $d \leq 0.5 \mathrm{~nm}$ für eine spezifische Bindung des Proteins. Dieser Effekt der nahezu vollständigen Inaktivität des Proteins durch die SH3-Domäne wurde in der Literatur sehr häufig in vivo beschrieben. ${ }^{[5,20,97]}$ In den Zellexperimenten wurden die Isoformen $\mathrm{CB}_{\mathrm{SH} 3}$ und $\mathrm{CB} 2_{\mathrm{SH} 3+}$ zusammen mit Gephyrin exprimiert. Fluoreszenzaufnahmen zeigten, dass Gephyrin mit $\mathrm{CB} 2_{\mathrm{SH} 3+}$ große cytoplasmatische Aggregate bildet. $\mathrm{CB} 2_{\mathrm{SH} 3-}$ führte neben einer Kolokalisation mit Gephyrin zu der Bildung von Mikroclustern unter der Plasmamembran. Dies verdeutlicht, dass $\mathrm{CB} 2_{\mathrm{SH} 3+}$ nicht in der Lage ist Gephyrin an der Plasmamembran zu verankern. ${ }^{[20]}$ Dieser Befund wird durch diese Studie unterstützt, da $\mathrm{CB} 2_{\mathrm{SH} 3+}$ lediglich unspezifisch an die PIP-dotierten Membranen gebunden hat. Soykan zeigte dies in vitro in einem lipid-overlay Assay. ${ }^{\left[{ }^{[8}\right.}$ Dabei wurden lipid-overlay Assays, wie in Abschnitt 3.1.10 beschrieben, mit den GST-getaggten Proteinisoformen GST-CB2 $2_{\mathrm{SH} 3-}$ und GST-CB2 $2_{\mathrm{SH} 3+}$ durchgeführt. Soykan beschrieb, dass GST-CB2 ${ }_{\mathrm{SH} 3-}$ mit einer hohen Spezifität an 
monophosphorylierte Phosphatidylinositole gebunden hat. GST-CB2 $2_{\mathrm{SH} 3+}$ wies keine Spezifität für ein Phosphatidylinositolphosphat auf. Zudem wurden sehr wenig gebundene Proteinmoleküle auf der Nitrocellulosemembran nachgewiesen. ${ }^{[8]}$ Dies bestätigt ebenfalls die in dieser Studie gefundenen unspezifischen Bindungen von $\mathrm{CB} 2_{\mathrm{SH} 3+}$ an PIP-haltige festkörperunterstützte Membranen.

$\mathrm{CB} 2_{\mathrm{SH} 3+}$ weist im RIfS-Experiment keine Präferenz für ein Phosphatidylinositolphosphat auf. Zudem wurde eine deutlich geringere Bindungskapazität für alle PIPs beobachtet. Dies verdeutlicht den großen Einfluss der SH3-Domäne auf die PIP-Bindung und die Selektivität. Die SH3-Domäne des Proteins ist in MD Simulation frei beweglich und führt zu einem Gleichgewicht zwischen offener/aktiver und der energetisch bevorzugten geschlossenen/inaktiven Konformation des Proteins. ${ }^{[95]}$ Die SH3-Domäne steht in der geschlossenen Konformation in Wechselwirkung mit der DH-/ PH-Tandemdomäne. In den RIfSExperimenten wurde dennoch eine Proteinbindung beobachtet. Diese könnte auf den geringen Anteil an Protein mit einer geöffneten/aktiven Konformation im Gleichgewicht zurück zu führen sein. 
$\mathbf{A}$

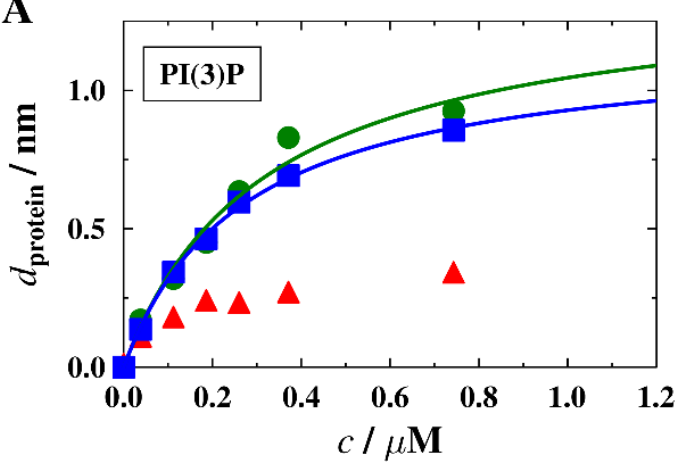

C

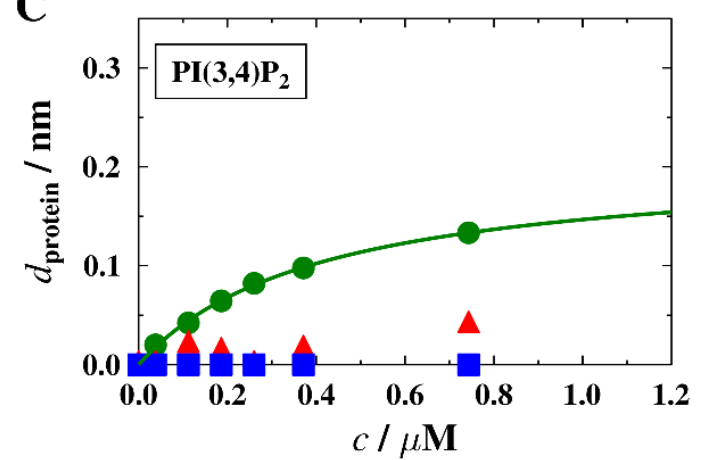

$\mathbf{E}$

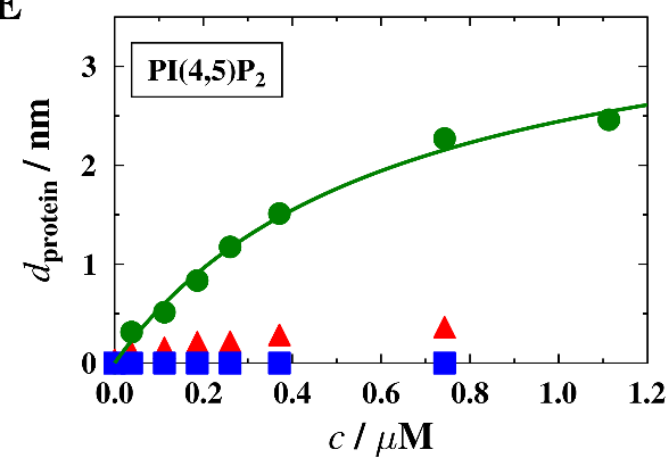

B

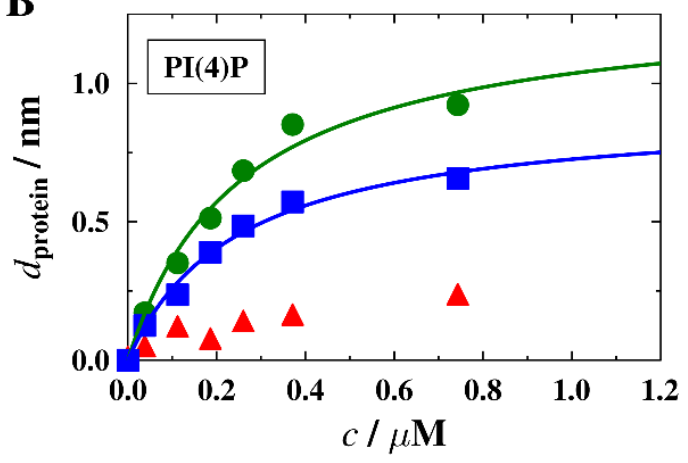

D

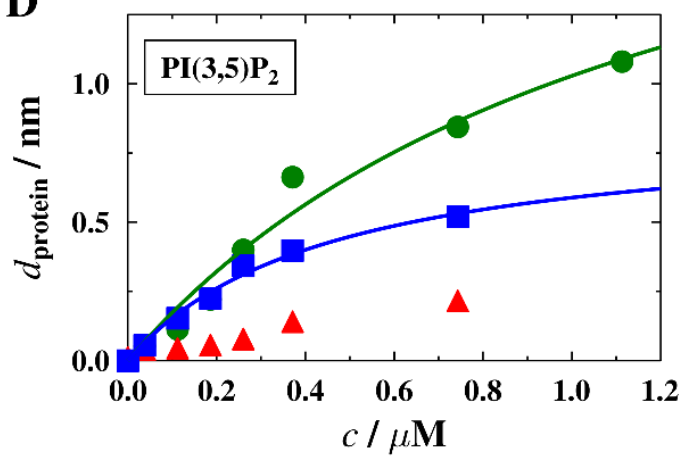

$\mathbf{F}$

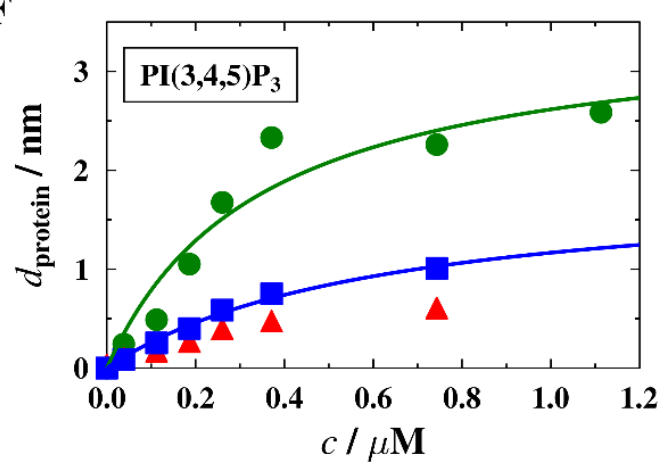

Abbildung 55: Bindungsisothermen von $\mathrm{CB} 2_{\mathrm{SH} 3-}$ (grüne Kreise), CB2 $2_{\mathrm{SH} 3+}$ (rote Dreiecke) und CB2 ${ }_{\mathrm{SH} 3+} / \mathrm{W} 24 \mathrm{~A}-\mathrm{E} 262 \mathrm{~A}$ (blaue Rechtecke) an Phosphatidylinositolphosphate in festkörperunterstützten Membranen (POPC/PIP, 9:1). Die farblich zugeordneten Linien repräsentieren die Anpassung nach dem Langmuir-Adsorptionsmodell an die jeweilige Bindungsisotherme.

Mitin et al. und Murayama et al. identifizierten die für die Wechselwirkung zuständigen Aminosäuren. ${ }^{[17,18]}$ Im Vergleich mit dem Guanin-NukleotidAustauschfaktor Asef (pdb code 2PZ1) wurden große strukturelle Übereinstimmungen mit Collybistin festgestellt. In Asef sind die Aminosäuren W203, R249 und E436 für die Wechselwirkung der Domäne verantwortlich. Diese Aminosäuren korrespondieren mit W24, R70 und E262 in CB2 ${ }_{\mathrm{SH} 3+}{ }^{[13]}$ Eine 
Aktivierung von $\mathrm{CB} 2_{\mathrm{SH} 3+}$ ist in der Zelle durch die Bindung an das Zelladhäsionsprotein Neuroligin 2 möglich. ${ }^{[95]}$ Die Aktivierung führt zu einer Öffnung des Proteins, sodass die Lipidbindungsstelle in der PH-Domäne für die PIPKopfgruppe in der Membran zugänglich wird. In dieser Studie wurde die Aktivierung durch Punktmutationen an den Positionen W24 und E262 durchgeführt. Die Tryptophan- bzw. Glutaminsäureseitenkette wurde gegen eine Alanin-Seitenkette ausgetauscht. $\mathrm{CB}_{\mathrm{SH}_{3}} / \mathrm{E} 262 \mathrm{~A}$ mit einer Punktmutation liegt in einer eher geöffneten Konformation vor. ${ }^{[13]}$ Zudem wurde in Zellexperimenten eine Bindung dieser Mutante an Phosphatidylinositolphosphate detektiert. ${ }^{[13]}$ In dieser Studie wurde die Isoform CB2 $\mathrm{SH}_{3+} / \mathrm{W} 24 \mathrm{~A}-\mathrm{E} 262 \mathrm{~A}$ in den RIfS-Messungen verwendet. Die Bindungsisothermen zeigen, dass dieses Protein eine spezifische Bindung an Phosphatidylinositolphosphate ausbildet (Abbildung 55, blaue Rechtecke). Im Gegensatz zum CB2 $2_{\mathrm{SH} 3-}$ konnte keine Bindung an $\mathrm{PI}(4,5) \mathrm{P}_{2}$ detektiert werden. Der Vergleich mit den Bindungsisothermen von $\mathrm{CB} 2_{\mathrm{SH} 3-}$ und $\mathrm{CB} 2_{\mathrm{SH} 3+}$ verdeutlicht, dass eine vollständige Aktivierung des Proteins nur an PI(3)P-haltigen Membranen beobachtet wurde. Die Bindungsisothermen von CB2 $2_{\mathrm{SH} 3+} / \mathrm{W} 24 \mathrm{~A}-\mathrm{E} 262 \mathrm{~A}$ zeigen im Vergleich zu CB2 $2_{\mathrm{SH} 3}$ eine schwächere Bindung des Proteins an $\mathrm{PI}(4) \mathrm{P}$ und $\mathrm{PI}(3,5) \mathrm{P}_{2}$. Für $\mathrm{PI}(3,4,5) \mathrm{P}_{3}$ konnte ebenfalls Proteinbindung detektiert werden. Diese liegt allerdings im Bereich des $\mathrm{CB} 2_{\mathrm{SH} 3+}$ und ist damit nicht durch die Aktivierung des Proteins ausgelöst. Die Bindung der PH-Domäne von CB22 $\mathrm{SH}_{3+} / \mathrm{W} 24 \mathrm{~A}-\mathrm{E} 262 \mathrm{~A}$ an Phosphatidylinositolphosphate ist demnach nur möglich, wenn die der Phosphorylierung benachbarte Position im Inositolring als freie Hydroxylgruppe vorliegt. Es wird deutlich, dass die Struktur der verwendeten Mutante zwischen der offenen und der geschlossenen Konformation liegt. ${ }^{[13]}$ Dies weist darauf hin, dass neben der freien Zugänglichkeit der Aminosäuren R363 und R364 in der PH-Domäne noch weitere Aktivierungsfaktoren wie z.B. Gephyrin oder Neuroligin 2 für die 
vollständige Öffnung der Proteinstruktur und die daraus resultierende Aktivierung des Proteins benötigt werden. ${ }^{[6,97]}$

In dieser Arbeit konnte das in der Literatur qualitativ beschriebene Bindungsverhalten der Collybistin-Isoformen in einem planaren Modellsystem mit Hilfe der reflektometrischen Interferenzspektroskopie quantitativ bestätigt werden. Das erarbeitete Bindungsmodell für die verschiedenen Proteinisoformen ist in Abbildung 56 dargestellt. Das Protein Collybistin 2 bindet über die C-terminale PHDomäne an Phosphatidylinositolphosphate in der Membran. Die möglichen Änderungen der physikalischen Schichtdicke durch die Adsorption der verschiedenen Proteinisoformen ist in Abbildung 56 A gezeigt. Die PH-Domäne weist die geringste

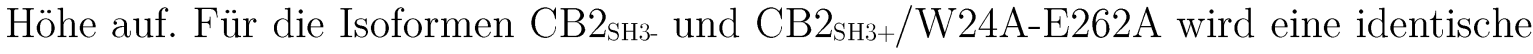
physikalische Schichtdicke erwartet, da die Moleküle durch ihre Faltung die gleiche maximale Höhe erreichen können. $\mathrm{CB} 2_{\mathrm{SH} 3+}$ liegt aufgrund der Wechselwirkung der PH/DH-Tandemdomäne mit der N-terminalen SH3-Domäne in einer geschlossenen Konformation vor. Die Maskierung der Lipidbindungsstelle führt dazu, dass keine Bindung an die PIP-haltige Membran detektiert wird. Die PH-Domäne (CB2 $\left.{ }_{\mathrm{PH}}, \mathrm{B}\right)$ bindet mit der Lipidbindungsstelle zwischen dem $\beta 3$ - und $\beta 4$-Faltblatt bevorzugt an die monophosphorylierten Phosphatidylinositolphosphate in der Membran. Mit zunehmender Nettoladung der festkörperunterstützten Membran, ausgelöst durch die mehrfach Phosphorylierung der PIPs, nimmt die Bindungsaffinität der PH-Domäne ab. Im Gegensatz dazu wurde unter den gegebenen Pufferbedingungen eine lineare Abhängigkeit der Bindungskapazität von der Oberflächenladungsdichte beobachtet. Eine Öffnung der Proteinkonformation wird durch zwei Punktmutationen im $\mathrm{CB}_{\mathrm{SH}_{3}+} / \mathrm{W} 24 \mathrm{~A}-\mathrm{E} 262 \mathrm{~A}$ erreicht. Die Wechselwirkung zwischen der DH-/PHTandemdomäne und der SH3-Domäne wird verhindert, sodass die Lipidbindungsstelle in der PH-Domäne für die Anbindung an 
Phosphatidylinositolphosphate in der Membran zur Verfügung steht (C). Die Proteinisoform zeigt eine hohe Spezifität für die folgenden drei Phosphatidylinositolphosphate mit absteigender Bindungskapazität: $\mathrm{PI}(3) \mathrm{P}>$ $\mathrm{PI}(4) \mathrm{P}>\mathrm{PI}(3,5) \mathrm{P} 2$. Eine Bindung an PIPs mit benachbarten Phosphatgruppen im Inositolring ist nicht möglich. 


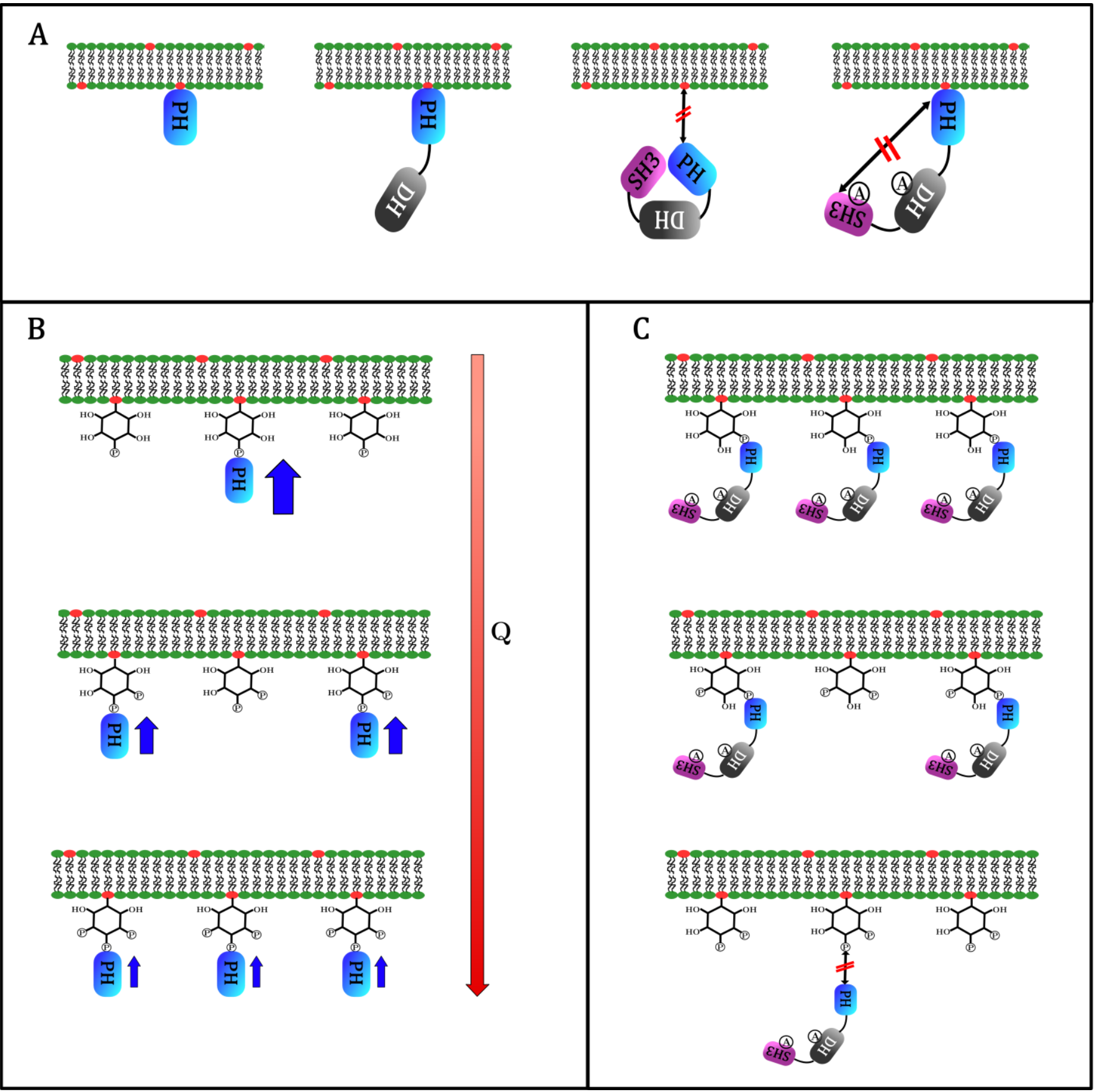

Abbildung 56: Schematische Darstellung der Bindung der verschiedenen Isoformen von Collybistin-2 an PIP-haltige festkörperunterstützte Membranen. Die Phosphatidylinositolphosphate in den Lipiddoppelschichten sind rot markiert. (A) Die Isoformen $\mathrm{CB} 2_{\mathrm{PH}}, \mathrm{CB} 2_{\mathrm{SH} 3-}$ und $\mathrm{CB} 2_{\mathrm{SH} 3+} / \mathrm{W} 24 \mathrm{~A}-\mathrm{E} 262 \mathrm{~A}$ binden über die Aminosäuren R64 und R65 in der PH-Domäne an die Membran. (B) Die PH-Domäne weist mit zunehmenden Phosphorylierungsgrad der Membran eine Abhängigkeit der Bindungskapazität auf. Die Bindungsaffinität nimmt ab (blaue Pfeile). (C) Die Punktmutationen im $\mathrm{CB}_{\mathrm{SH}_{3}} /$ W24A-E262A verhindern die Wechselwirkung zwischen der SH3- und der PH/DH-Tandemdomäne. Das Protein kann nicht an PIPs mit benachbarten Phosphatgruppen im Inositolring binden. 


\section{Zusammenfassung}

Im Rahmen dieser Arbeit wurde die Bindung von Collybistin 2, welches in vivo für die Verankerung des Gephyrin-Gerüsts an der Plasmamembran verantwortlich ist, anhand eines wohldefinierten Modellmembransystems detailliert untersucht. Dabei war es von besonderem Interesse, den Einfluss der einzelnen Proteindomänen zu analysieren und die Bindung der Proteinisoformen an die in der Zelle vorkommenden Phosphatidylinositolphosphate (PIP) zu quantifizieren. Die verwendeten planaren Modellmembranen enthielten dabei jeweils ein spezifisches PIP als möglichen natürlichen Bindungspartner von Collybistin. Die Charakterisierung der Bindung der Collybistin 2-Isoformen an festkörperunterstützte Membranen erfolgte mittels reflektometrischer Interferenzspektroskopie. Die reine PH-Domäne, die für die PIP-Bindung verantwortlich ist, wies eine mittlere Affinität für monophosphorylierte Phosphatidylinositole auf. Die Bindungen der PH-Domäne an höher phosphorylierte Phosphatidylinositole zeigte schwächere Affinitäten. Zudem konnte eine lineare Abhängigkeit der Belegungsdichte von der Oberflächenladungsdichte gezeigt werden. Für die Proteinisoform CB2 $2_{\mathrm{SH} 3}$ wurden im Vergleich zu CB2 ${ }_{\mathrm{PH}}$ schwächere Affinitäten für $\mathrm{PI}(3) \mathrm{P}$ und $\mathrm{PI}(4) \mathrm{P}$ gefunden. Die Bindungsaffinitäten von CB2 $2_{\mathrm{SH} 3}$ für alle PIPs außer $\mathrm{PI}(3,5) \mathrm{P}_{2}$ waren sehr ähnlich. Im Vergleich von Messungen mit $\mathrm{CB} 2_{\mathrm{SH} 3}$ und $\mathrm{CB}_{\mathrm{SH} 3+}$ wurde beobachtet, dass die SH3Domäne in vitro eine Bindung des Proteins an PIP-dotierte Membranen verhindert. Dies deutet darauf hin, dass das Protein in einer inaktiven/geschlossenen Konformation vorliegt. Die in vivo postulierte Aktivierung von $\mathrm{CB}_{\mathrm{SH} 3+}$ durch Neuroligin-2 wurde im Experiment durch zwei Punktmutationen im CB2 ${ }_{\mathrm{SH} 3+} / \mathrm{W} 24 \mathrm{~A}-$ E262A erfolgreich nachgebildet. Im Gegensatz zum autoaktivierten CB2 ${ }_{\mathrm{SH} 3}$, das mit 
einer ähnlichen Affinität an fast alle Phosphatidylinositolphosphate bindet, konnte für die Mutante eine Spezifität der Bindung mit abnehmender Affinität an PI(3)P, $\mathrm{PI}(4) \mathrm{P}$ und $\mathrm{PI}(3,5) \mathrm{P}_{2}$ nachgewiesen werden. Die von der teilaktivierte Mutante $\mathrm{CB}_{\mathrm{SH}_{3+}} / \mathrm{W} 24 \mathrm{~A}-\mathrm{E} 262 \mathrm{~A}$ gebundenen PIPs sind bis auf $\mathrm{PI}(4) \mathrm{P}$ nach den aktuellen Kenntnissen nicht in der Plasmamembran vorhanden, sodass der in der Literatur beschriebene Aktivierungsmechanismus an der Plasmamembran diskutiert werden sollte. 


\section{Literaturverzeichnis}

[1] H. Moehler, Journal of Receptors and Signal Transduction 2006, 26, 731-740.

[2] M. Kneussel, H. Betz, Trends in neurosciences 2000, 23, 429-435.

[3] S. J. Moss, T. G. Smart, Nature Reviews Neuroscience 2001, 2, 240-250.

[4] M. Sola, V. N. Bavro, J. Timmins, T. Franz, S. Ricard-Blum, G. Schoehn, R. W. H. Ruigrok, I. Paarmann, T. Saiyed, G. A. O'Sullivan, The EMBO journal 2004, 23, 2510-2519.

[5] S. Kins, H. Betz, J. Kirsch, Nature neuroscience 2000, 3, 22-29.

[6] A. Poulopoulos, G. Aramuni, G. Meyer, T. Soykan, M. Hoon, T. Papadopoulos, M. Zhang, I. Paarmann, C. Fuchs, K. Harvey, Neuron 2009, 63, 628-642.

[7] S. Reddy-Alla, B. Schmitt, J. Birkenfeld, V. Eulenburg, S. Dutertre, C. Böhringer, M. Götz, H. Betz, T. Papadopoulos, The European journal of neuroscience 2010, 31, 1173-1184.

[8] T. Soykan, Doctoral thesis, Göttingen, 2011.

[9] V. M. Kalscheuer, L. Musante, C. Fang, K. Hoffmann, C. Fuchs, E. Carta, E. Deas, K. Venkateswarlu, C. Menzel, R. Ullmann et al., Hum. Mutat. 2009, 30, $61-68$.

[10] W. Y. Jong, J. M. Mendrola, A. Audhya, S. Singh, D. Keleti, D. B. DeWald, D. Murray, S. D. Emr, M. A. Lemmon, Molecular cell 2004, 13, 677-688.

[11] M. Hyvönen, M. J. Macias, M. Nilges, H. Oschkinat, M. Saraste, M. Wilmanns, The EMBO journal 1995, 14, 4676-4685.

[12] P. Erlmann, Universitätsbibliothek der Universität Stuttgart, Stuttgart, 2009. 
[13] T. Soykan, D. Schneeberger, G. Tria, C. Buechner, N. Bader, D. Svergun, I. Tessmer, A. Poulopoulos, T. Papadopoulos, F. Varoqueaux et al., The EMBO journal 2014, 33, 2113-2133.

[14] M. J. Hart, A. Eva, D. Zangrilli, S. A. Aaronson, T. Evans, R. A. Cerione, Y. Zheng, Journal of Biological Chemistry 1994, 269, 62-65.

[15] T. Reid, A. Bathoorn, M. R. Ahmadian, J. G. Collard, Journal of Biological Chemistry 1999, 274, 33587-33593.

[16] S. Xiang, E. Y. Kim, J. J. Connelly, N. Nassar, J. Kirsch, J. Winking, G. Schwarz, H. Schindelin, Journal of molecular biology 2006, 359, 35-46.

[17] N. Mitin, L. Betts, M. E. Yohe, C. J. Der, J. Sondek, K. L. Rossman, Nat Struct Mol Biol 2007, 14, 814-823.

[18] K. Murayama, M. Shirouzu, Y. Kawasaki, M. Kato-Murayama, K. HanawaSuetsugu, A. Sakamoto, Y. Katsura, A. Suenaga, M. Toyama, T. Terada et al., The Journal of biological chemistry 2007, 282, 4238-4242.

[19] K. Harvey, I. C. Duguid, M. J. Alldred, S. E. Beatty, H. Ward, N. H. Keep, S. E. Lingenfelter, B. R. Pearce, J. Lundgren, M. J. Owen et al., The Journal of neuroscience : the official journal of the Society for Neuroscience 2004, 24, $5816-5826$.

[20] T. Papadopoulos, T. Soykan, Frontiers in cellular neuroscience 2011, 5, 11.

[21] M. Vicinanza, G. D'Angelo, A. Di Campli, De Matteis, Maria Antonietta, The EMBO journal 2008, 27, 2457-2470.

[22] D. Gillooly, A. SIMONSEN, H. STENMARK, Biochem. J 2001, 355, 249-258.

[23] A. Godi, A. Di Campli, A. Konstantakopoulos, G. Di Tullio, D. R. Alessi, G. S. Kular, T. Daniele, P. Marra, J. M. Lucocq, De Matteis, M Antonietta, Nature cell biology 2004, 6, 393-404. 
[24] R. R. Choudhury, N. Hyvola, M. Lowe (Hrsg.) Phosphoinositides and membrane traffic at the trans-Golgi network, London; Portland on behalf of The Biochemical Society; 1999, 2005.

[25] J. B. Morris, K. A. Hinchliffe, A. Ciruela, A. J. Letcher, R. F. Irvine, FEBS letters 2000, 475, 57-60.

[26] D. Sarkes, L. Rameh, Biochem. J 2010, 428, 375-384.

[27] D. Sbrissa, O. C. Ikonomov, R. Deeb, A. Shisheva, Journal of Biological Chemistry 2002, 277, 47276-47284.

[28] C. A. Barlow, R. S. Laishram, R. A. Anderson, Trends in cell biology 2010, 20, 25-35.

[29] D. Karathanassis, R. V. Stahelin, J. Bravo, O. Perisic, C. M. Pacold, W. Cho, R. L. Williams, The EMBO journal 2002, 21, 5057-5068.

[30] R. Currie, K. Walker, A. Gray, M. Deak, A. Casamayor, C. Downes, P. Cohen, D. Alessi, J. Lucocq, Biochem. J 1999, 337, 575-583.

[31] C. Whiteford, C. Brearley, E. Ulug, Biochem. J 1997, 323, 597-601.

[32] V. Niggli, Annu. Rev. Cell Dev. Biol. 2005, 21, 57-79.

[33] M. Lemmon, K. Ferguson, Biochem. J 2000, 350, 1-18.

[34] K. R. Auger, L. A. Serunian, S. P. Soltoff, P. Libby, L. C. Cantley, Cell 1989, 57, 167-175.

[35] W. S. Chen, P.-Z. Xu, K. Gottlob, M.-L. Chen, K. Sokol, T. Shiyanova, I. Roninson, W. Weng, R. Suzuki, K. Tobe, Genes $\&$ development 2001, 15, 2203-2208.

[36] D. A. Fruman, L. E. Rameh, L. C. Cantley, Cell 1999, 97, 817-820.

[37] L. E. Rameh, A.-k. Arvidsson, K. L. Carraway, A. D. Couvillon, G. Rathbun, A. Crompton, B. VanRenterghem, M. P. Czech, K. S. Ravichandran, S. J. Burakoff, Journal of Biological Chemistry 1997, 272, 22059-22066.

[38] G. Bertani, J Bacteriol 1951, 62, 293-300. 
[39] Henning D. Mootz, BIOspektrum 2007, 13, 165-167.

[40] U. K. Laemmli, nature 1970, 227, 680-685.

[41] H. Schägger, G. von Jagow, Analytical Biochemistry 1987, 166, 368-379.

[42] B. Batteiger, Newhall V, Wilbert J, R. B. Jones, Journal of immunological methods 1982, 55, 297-307.

[43] M. R. Eftink, Methods of Biochemical Analysis: Protein Structure Determination, Volume 35 1991, 127-205.

[44] J. M. Walker, The proteomics protocols handbook, Springer, 2005.

[45] O. Stenzel, The physics of thin film optical spectra: an introduction, Springer, 2005.

[46] O. S. Heavens, Optical properties of thin solid films, Courier Dover Publications, 1991.

[47] P. Schiebener, J. Straub, J. L. Sengers, J. S. Gallagher, Journal of physical and chemical reference data 1990, 19, 677-717.

[48] R. Resnick, D. Halliday, J. Walker, Fundamentals of physics, John Wiley, 1988.

[49] G. Kraus, G. Gauglitz, Fresenius' journal of analytical chemistry 1992, 344, $153-157$.

[50] G. Gauglitz, A. Brecht, G. Kraus, W. Mahm, Sensors and Actuators B: Chemical 1993, 11, 21-27.

[51] OceanOptics, "SpectraSuite Spectrometer Operating Software: Installation and Operation Manual.", zu finden unter http://oceanoptics.com/wpcontent/uploads/SpectraSuite.pdf, 2007.

[52] H. Nakajima, N. Kiyokawa, Y. U. Katagiri, T. Taguchi, T. Suzuki, T. Sekino, K. Mimori, T. Ebata, M. Saito, H. Nakao et al., The Journal of biological chemistry 2001, 276, 42915-42922. 
[53] G. Richter, Praktische Biochemie: Grundlagen und Techniken ; 19 Tabellen, Thieme, 2003.

[54] fffred, "Effect of a circular dichroism on a left- or right-handed circularly polarized wave", zu finden unter:

http://commons.wikimedia.org/wiki/File:Circular_dichroism.png, 2006.

[55] H.-J. Galla, H.-J. Müller, Spektroskopische Methoden in der Biochemie, Georg Thieme, 1988.

[56] L. Whitmore, B. A. Wallace, Biopolymers 2008, 89, 392-400.

[57] A. Maelicke, S. K. Hemschemeier, K.-D. Irrgang, "Lerneinheit: Circulardichroismus und Proteinstruktur", zu finden unter: http://www.chemgapedia.de/vsengine/vlu/vsc/de/ch/8/bc/vlu/proteindynami k/circulardichroismus.vlu/Page/vsc/de/ch/8/bc/proteindynamik/cd2.vscml.ht $\mathrm{ml}$.

[58] L. Whitmore, B. A. Wallace, Nucleic acids research 2004, 32, W668-W673.

[59] N. Sreerama, R. W. Woody, Analytical Biochemistry 2000, 287, 252-260.

[60] M. W. Pantoliano, E. C. Petrella, J. D. Kwasnoski, V. S. Lobanov, J. Myslik, E. Graf, T. Carver, E. Asel, B. A. Springer, P. Lane, Journal of biomolecular screening 2001, 6, 429-440.

[61] A. P. Demchenko, Advanced fluorescence reporters in chemistry and biology III: applications in sensing and imaging, Springer, 2011.

[62] D. Mao, E. Wachter, B. A. Wallace, Biochemistry 1982, 21, 4960-4968.

[63] Pham Thanh Van, "A collection and summary on Thermofluor assay", zu finden unter https://structuralbasisofbacterialinvasion.wordpress.com/2012/05/04/acollection-and-summary-on-thermofluor-assay/, 2012.

[64] K. M. Ferguson, M. A. Lemmon, J. Schlessinger, P. B. Sigler, Cell 1995, 83, $1037-1046$. 
[65] K. L. Rossman, D. K. Worthylake, J. T. Snyder, D. P. Siderovski, S. L. Campbell, J. Sondek, The EMBO journal 2002, 21, 1315-1326.

[66] Z. Salamon, G. Tollin, Biophysical journal 2001, 80, 1557-1567.

[67] C. G. Ferguson, R. D. James, C. S. Bigman, D. A. Shepard, Y. Abdiche, P. S. Katsamba, D. G. Myszka, G. D. Prestwich, Bioconjugate chemistry 2005, 16, $1475-1483$.

[68] S. James, C. Downes, R. Gigg, S. Grove, A. Holmes, D. Alessi, Biochem. J 1996, 315, 709-713.

[69] R. V. Stahelin, F. Long, K. Diraviyam, K. S. Bruzik, D. Murray, W. Cho, The Journal of biological chemistry 2002, 277, 26379-26388.

[70] J. A. Braunger, C. Kramer, D. Morick, C. Steinem, Langmuir : the ACS journal of surfaces and colloids 2013, 29, 14204-14213.

[71] S. McLaughlin, J. Wang, A. Gambhir, D. Murray, Annual review of biophysics and biomolecular structure 2002, 31, 151-175.

[72] F. Fernandes, Loura, Luís M S, A. Fedorov, M. Prieto, Journal of lipid research 2006, 47, 1521-1525.

[73] I. Larson, P. Attard, Journal of colloid and interface science 2000, 227, 152163.

[74] D. A. Redfern, A. Gericke, Journal of lipid research 2005, 46, 504-515.

[75] I. Liepina, C. Czaplewski, P. Janmey, A. Liwo, Biopolymers 2003, 71, 49-70.

[76] E. E. Kooijman, K. E. King, M. Gangoda, A. Gericke, Biochemistry 2009, 48, 9360-9371.

[77] van Paridon, Peter A, B. de Kruijff, R. Ouwerkerk, K. W. A. Wirtz, Biochimica et Biophysica Acta (BBA)-Lipids and Lipid Metabolism 1986, 877, 216-219.

[78] W. J. Foster, P. A. Janmey, Biophysical chemistry 2001, 91, 211-218. 
[79] C. DeWolf, S. Leporatti, C. Kirsch, R. Klinger, G. Brezesinski, Chemistry and physics of lipids 1999, 97, 129-138.

[80] N. Kučerka, M.-P. Nieh, J. Katsaras, Biochimica et biophysica acta 2011, $1808,2761-2771$.

[81] D. Lupyan, M. Mezei, D. E. Logothetis, R. Osman, Biophysical journal 2010, $98,240-247$.

[82] J. P. Bradshaw, R. J. Bushby, C. C. D. Giles, M. R. Saunders, Biochemistry 1999, 38, 8393-8401.

[83] A. I. Kishore, J. H. Prestegard, Biophysical journal 2003, 85, 3848-3857.

[84] S. Bosk, Dissertation, Göttingen, 2011.

[85] P. Dürrschmidt, Dissertation, Halle-Wittenberg, 2003.

[86] J. M. Kavran, D. E. Klein, A. Lee, M. Falasca, S. J. Isakoff, E. Y. Skolnik, M. A. Lemmon, Journal of Biological Chemistry 1998, 273, 30497-30508.

[87] J. F. Nagle, S. Tristram-Nagle, Biochimica et Biophysica Acta (BBA) Reviews on Biomembranes 2000, 1469, 159-195.

[88] M.-M. Zhou, K. S. Ravichandran, E. T. Olejniczak, A. M. Petros, R. P. Meadows, M. Sattler, J. E. Harlan, W. S. Wade, S. J. Burakoff, S. W. Fesik 1995.

[89] M. A. Lemmon, K. M. Ferguson, R. O’Brien, P. B. Sigler, J. Schlessinger, Proceedings of the National Academy of Sciences 1995, 92, 10472-10476.

[90] R. Chen, S. Corbalan-Garcia, D. Bar-Sagi, The EMBO journal 1997, 16, 13511359.

[91] J. D. Knight, J. J. Falke, Biophysical journal 2009, 96, 566-582.

[92] P. Garcia, R. Gupta, S. Shah, A. J. Morris, S. A. Rudge, S. Scarlata, V. Petrova, S. McLaughlin, M. J. Rebecchi, Biochemistry 1995, 34, 16228-16234.

[93] E. Baraldi, K. D. Carugo, M. Hyvönen, P. Lo Surdo, A. M. Riley, B. V. L. Potter, R. O’Brien, J. E. Ladbury, M. Saraste, Structure 1999, 7, 449-460. 
[94] T. G. Kutateladze, K. D. Ogburn, W. T. Watson, T. de Beer, S. D. Emr, C. G. Burd, M. Overduin, Molecular cell 1999, 3, 805-811.

[95] T. Papadopoulos, R. Schemm, H. Grubmüller, N. Brose, The Journal of biological chemistry 2015.

[96] B. Das, X. Shu, G.-J. Day, J. Han, U. M. Krishna, J. R. Falck, D. Broek, Journal of Biological Chemistry 2000, 275, 15074-15081.

[97] S. Mayer, R. Kumar, M. Jaiswal, T. Soykan, M. R. Ahmadian, N. Brose, H. Betz, J.-S. Rhee, T. Papadopoulos, Proceedings of the National Academy of Sciences 2013, 110, 20795-20800. 


\section{Anhang}

\subsection{Aminosäuresequenzen der Proteine}

SH3-Domäne, DH-Domäne, PH-Domäne

$\underline{\mathrm{CB} 2_{\mathrm{SH} 3+}}$

MQWIRGGSGMLITGDSIVSAEAVWDHVTMANRELAFKAGDVIKVLDASNKDWWWGQIDDE 60 EGWFPASFVRLWVNQEDGVEEGPSDVQNGHLDPNSDCLCLGRPLQNRDQMRANVINEIMS 120 TERHYIKHLKDICEGYLKQCRKRRDMFSDEQLKVIFGNIEDIYRFQMGFVRDLEKQYNND 180 DPHLSEIGPCFLEHQDGFWIYSEYCNNHLDACMELSKLMKDSRYQHFFEACRLIQQMIDI 240 AIDGFLLTPVQKICKYPLQLAELLKYTAQDHSDYRYVAAALAVMRNVTQQINERKRRLEN 300 IDKIAQWQASVLDWEGDDILDRSSELIYTGEMAWIYQPYGRNQQRVFFLFDHQMVLCKKD 360 LIRRDILYYKGRIDMDKYEVIDIEDGRDDDFNVSMKNAFKLHNKETEEVHLFFAKKLEEK 420 IRWLRAFREERKMVQEDEKIGFEISENQKRQAAMTVRKASKQKVTQRKWHY 471

\section{$\underline{\mathrm{CB}_{\mathrm{SH} 3+} / \mathrm{W} 24 \mathrm{~A}-\mathrm{E} 62 \mathrm{~A}}$}

MQWIRGGSGMLITGDSIVSAEAVADHVTMANRELAFKAGDVIKVLDASNKDWWWGQIDDE 60 EGWFPASFVRLWVNQEDGVEEGPSDVQNGHLDPNSDCLCLGRPLQNRDQMRANVINEIMS 120 TERHYIKHLKDICEGYLKQCRKRRDMFSDEQLKVIFGNIEDIYRFQMGFVRDLEKQYNND 180 
AIDGFLLTPVQKICKYPLQLAALLKYTAQDHSDYRYVAAALAVMRNVTQQINERKRRLEN 300 IDKIAQWQASVLDWEGDDILDRSSELIYTGEMAWIYQPYGRNQQRVFFLFDHQMVLCKKD 360 LIRRDILYYKGRIDMDKYEVIDIEDGRDDDFNVSMKNAFKLHNKETEEVHLFFAKKLEEK 420 IRWLRAFREERKMVQEDEKIGFEISENQKRQAAMTVRKASKQKVTQRKWHY 471

\section{$\underline{\mathrm{CB} 2} 2_{\mathrm{SH} 3-}$}

MLWVNQEDGVEEGPSDVQNGHLDPNSDCLCLGRPLQNRDQMRANVINEIMSTERHYIKHL 60 KDICEGYLKQCRKRRDMFSDEQLKVIFGNIEDIYRFQMGFVRDLEKQYNNDDPHLSEIGP 120 CFLEHQDGFWIYSEYCNNHLDACMELSKLMKDSRYQHFEEACRLLQQMIDIAIDGFLLTP 180 VQKICKYPLQLAELLKYTAQDHSDYRYVAAALAVMRNVTQQINERKRRLENIDKIAQWQA 240 SVLDWEGDDILDRSSELIYTGEMAWIYQPYGRNQQRVFFLFDHQMVLCKKDLIRRDILYY 300 KGRIDMDKYEVIDIEDGRDDDFNVSMKNAFKLHNKETEEVHLFFAKKLEEKIRWLRAFRE 360 ERKMVQEDEKIGFEISENQKRQAAMTVRKASKQKVTQRKWHY* 403

\section{$\underline{\mathrm{CB}} 2_{\mathrm{PH}}$}

MNIDKIAQWQASVLDWEGDDILDRSSELIYTGEMAWIYQPYGRNQQRVFFLFDHQMVLCK 60 KDLIRRDILYYKGRIDMDKYEVIDIEDGRDDDFNVSMKNAFKLHNKETEEVHLFFAKKLE 120 EKIRWLRAFREERKMVQEDEKIGEEISENQKRQAAMTVRKASKQKVTQRKWHY* 173 


\subsection{Chemikalien}

Acrylamid/Bisacrylamid (37.5:1) Carl Roth GmbH (Karlsruhe)

Agar

Merck (Darmstadt)

Agarose

Sigma Aldrich (Taufkirchen)

Ammoniak

Sigma Aldrich (Taufkirchen)

Ampicillin

Carl Roth GmbH (Karlsruhe)

Anti-Collybistin Antikörper

Synaptic Systems (Göttingen)

Anti-rabbit Antikörper

Santa Cruz Biotechnology (Dallas, USA)

APS

Sigma Aldrich (Taufkirchen)

Bromphenolblau

Carl Roth GmbH (Karlsruhe)

BSA, fettsäurefrei

Sigma Aldrich (Taufkirchen)

BSA, proteasefrei

Carl Roth GmbH (Karlsruhe)

Calciumchlorid $\left(\mathrm{CaCl}_{2}\right)$

Merck (Darmstadt)

Chloroform

VWR (Darmstadt)

Coomassie Brilliant Blau G-250

Fluka Chemie GmbH (Seelze)

p-Coumarinsäure

Sigma Aldrich (Taufkirchen)

Dikaliumhydrogenphosphat

Merck (Darmstadt)

DNase I

AppliChem (Darmstadt)

DTT

Sigma Aldrich (Taufkirchen)

EDTA

Merck (Darmstadt)

Essigsäure

VWR (Darmstadt)

Ethanol p. A.

Sigma Aldrich (Taufkirchen)

GelRed

Fluka Chemie GmbH (Seelze)

Glucose

VWR Prolabo (Darmstadt)

Glycerol, $87 \%$

Merck (Darmstadt)

Hefeextrakt

Carl Roth GmbH (Karlsruhe) 
Hellmanex

HEPES

IPTG

Isopropanol

Kaliumchlorid

Kaliumdihydrogenphosphat

Luminol

Magermilch

Magnesiumchlorid $\left(\mathrm{MgCl}_{2} \times 6 \mathrm{H}_{2} \mathrm{O}\right)$

$\beta$-Mercaptoethanol

Methanol

Mucasol

Natriumacetat

Natriumchlorid

Natriumhydroxid

PI (Soja)

$\mathrm{PI}(3) \mathrm{P}$

$\mathrm{PI}(4) \mathrm{P}$

$\mathrm{PI}(3,4) \mathrm{P}_{2}$

$\mathrm{PI}(3,5) \mathrm{P}_{2}$

$\mathrm{PI}(4,5) \mathrm{P}_{2}$

$\mathrm{PI}(3,4,5) \mathrm{P}_{3}$

PonceauS

POPC

POPG

POPS

Salzsäure
Hellma Analytics (Müllheim)

Carl Roth GmbH (Karlsruhe)

Sigma Aldrich (Taufkirchen)

VWR (Darmstadt)

Merck (Darmstadt)

Merck (Darmstadt)

Sigma Aldrich (Taufkirchen)

Merck (Darmstadt)

Merck (Darmstadt)

Sigma Aldrich (Taufkirchen)

Acros Organics (New Jersey, USA)

Merz Hygiene (Frankfurt am Main)

Merck (Darmstadt)

AppliChem (Darmstadt)

Merck (Darmstadt)

Avanti Polar Lipids (Alabaster, USA)

Echelon Bio. Inc. (Salt Lake City, USA)

Echelon Bio. Inc. (Salt Lake City, USA)

Echelon Bio. Inc. (Salt Lake City, USA)

Echelon Bio. Inc. (Salt Lake City, USA)

Echelon Bio. Inc. (Salt Lake City, USA)

Echelon Bio. Inc. (Salt Lake City, USA)

Sigma Aldrich (Taufkirchen)

Avanti Polar Lipids (Alabaster, USA)

Avanti Polar Lipids (Alabaster, USA)

Avanti Polar Lipids (Alabaster, USA)

VWR (Darmstadt) 
SYPRO Orange (5000x in DMSO) Life Technologies (Darmstadt)

TEMED

Tricin

TRIS

Trypton

Tween 20

Wasserstoffperoxid

\subsection{Materialien}

Aluminium (99.999\%)

Chitin-Resin

Econo-Column ${ }^{\circledR}$ Glassäule

Filterpapier/Whatman paper

Mikrotiterplatten

MonoQ 10/100 GL

Nitrocellulosemembran

Parafilm

Pipetten

Pipettenspitzen (unsteril)

Pumpenschläuche Tygon

Reaktionsgefäße

Schichtküvette $(0.01 \mathrm{~cm})$

Si-Wafer

Zentrifugalkonzentratoren (Vivaspin) Sartorius (Göttingen)
Sigma Aldrich (Taufkirchen)

Carl Roth GmbH (Karlsruhe)

Carl Roth GmbH (Karlsruhe)

Carl Roth GmbH (Karlsruhe)

Carl Roth GmbH (Karlsruhe)

Grüssing GmbH (Filsum)
Goodfellow (Bad Nauheim)

BioLabs Inc. (Ipswich, USA)

Bio-Rad Laboratories GmbH (München)

Sigma Aldrich (Taufkirchen)

4titude Ltd. (Berlin)

GE Healthcare Europe GmbH (Freiburg)

Bio-Rad Laboratories GmbH (München)

Pechiney Plastik Packaging (Chicago,USA)

Eppendorf (Hamburg)

Sarstedt (Nürnbrecht)

Ismatec (Wertheim-Mondfeld)

Sarstedt (Nürnbrecht)

Hellma Analytics (Müllheim)

Active Business Company (Brunnthal) 


\subsection{Geräte}

\section{Reflektometrische Interferenzspektroskopie}

ADC1000-USB, A/D Konverter Ocean Optics Germany GmbH (Ostfildern)

Gegabelte optische Faser, UV/Vis Ocean Optics Germany GmbH (Ostfildern)

LS-1 Wolfram Halogenlampe Ocean Optics Germany GmbH (Ostfildern)

SD2000, fiberoptisches Spektrometer Ocean Optics Germany GmbH (Ostfildern)

\section{CD-Spektroskopie}

CD-Spektrometer J-1500 JASCO (Groß-Umstadt)

\section{Thermofluor-Assay}

real-time PCR CFX 96

Bio-Rad Laboratories GmbH (München)

\section{Reinstwasseranlage}

Milli-Q Gradient A10

Millipore (Eschborn)

Milli-Q Elix 5

Millipore (Eschborn)

\section{Sonstige Geräte}

Feinwaage

Magnetrührer MR $3001 \mathrm{~K}$

pH-Meter Calimatic 766

Plasmacleaner ZEPTO

Sonopuls HD2070 Becherresonator

Tischzentrifuge Galaxy Mini

Ultraschallbad Sonorex RK 255 H

Vakuumtrockenschrank VD 23
Avestin (Ottawa, Kanada)

Heidolph (Schwabach)

Knick (Berlin)

Diener electronic GmbH (Ebhausen)

Bandelin (Berlin)

VWR (Darmstadt)

Bandelin (Berlin)

Binder (Tuttlingen) 
Varian Cary Scan 50

Zentrifuge Heraeus Fresco 17
Agilent Technologies (Santa Clara, USA)

Thermo Scientific (Waltham, USA)

\section{Zellkultivierung und Proteinaufreinigung}

ÄKTA Purifier 10 FPLC System

Kipp-/Rollenmischer SRT 6

Mikrofluidizer LM 10

Mini-PROTEAN ${ }^{\circledR}$ Tetra Cell

Orbital Schüttelschrank Innova 44

Schüttelschrank

Schwenker CAT ST5

Spannungsquelle PowerPac ${ }^{\mathrm{TM}}$

Thermomixer compact

Tischautoklav 2540 EL

Trans-Blot ${ }^{\circledR}$ SD

Ultrazentrifuge Centrikon T-1065

Zentrifuge Allegra $^{\mathrm{TM}} \mathrm{X}-22 \mathrm{R}$
GE Healthcare GmbH (Solingen)

Carl Roth GmbH (Karlsruhe)

Microfluidics (Westwood, USA)

Bio-Rad Laboratories GmbH (München)

New Brunswick Scientific (Enfield, USA)

Edmund Bühler GmbH (Hechingen)

Zipperer GmbH (Staufen)

Bio-Rad Laboratories GmbH (München)

Eppendorf (Hamburg)

Tuttnauer (Breda, Niederlande)

Bio-Rad Laboratories GmbH (München)

Kontron Instruments (Rossdorf)

Beckman Coulter (Krefeld) 


\subsection{Abkürzungsverzeichnis}

\begin{tabular}{|c|c|}
\hline APS & Ammoniumperoxodisulfat \\
\hline BSA & bovine serume albumin \\
\hline Btk & Bruton-Tyrosinkinase \\
\hline CB2 & Collybistin 2 \\
\hline CBD & Chitin-bindende Domäne \\
\hline $\mathrm{CD}$ & Circular Dichroismus \\
\hline $\mathrm{CV}$ & column volume \\
\hline Dbl & diffuse B-cell lymphoma \\
\hline $\mathrm{DH}$ & Dbl Homologie \\
\hline DNA & deoxyribonucleic acid \\
\hline DSPC & 1,2-Distearoyl-sn-glycero-3-phosphocholin \\
\hline $\mathrm{DTT}$ & Dithiothreithol \\
\hline E. coli & Escherichia coli \\
\hline EDTA & Ethylendiamintetraacetat \\
\hline Em. & Emission \\
\hline Ex. & Anregung (excitation) \\
\hline FYVE & Fab $1, \underline{Y O T B}, \underline{V a c} 1, \underline{E E A} 1$ \\
\hline GABA & $\gamma$-Aminobuttersäure ( $\gamma$-Aminobutyric acid) \\
\hline GEF & Guanine nucleotide exchange factor \\
\hline HEPES & 2-(4-(2-Hydroxyethyl)-1-piperazinyl)-ethansulfonsäure \\
\hline IPTG & Isopropyl- $\beta$-D-thiogalactopyranosid \\
\hline $\mathrm{kbp}$ & Kilo-Basenpaare \\
\hline $\mathrm{kD}$ & Kilodalton \\
\hline $\mathrm{L}$ & Liter \\
\hline LB & Lysogeny broth \\
\hline
\end{tabular}




$\begin{array}{ll}\text { ME } & \text { Mercaptoethanol } \\ \text { OD } & \text { optische Dichte } \\ \text { OT } & \text { optical thickness } \\ \text { p. A. } & \text { pro Analysi }\end{array}$

PAGE Polyacrylamidgelelektrophorese

PDPK1 3-Phosphoinositide dependent protein kinase-1

PH Pleckstrin Homologie

PI Phosphatidylinositol

PIP Phosphatidylinositolphosphat

PKB Proteinkinase B

POD Peroxidase

POPC 1-Palmitoyl-2-oleoyl-sn-glycero-3-phosphocholin

POPG 1-Palmitoyl-2-oleoyl-sn-glycero-3-phosphoglycerol

POPS 1-Palmitoyl-2-oleoyl-sn-glycero-3-phospho-L-serin

Pro Prolin

RIfS Reflektometrische Interferenzspektroskopie

RNase Ribonuklease

Rpm Umdrehungen pro Minute (revolutions per minute)

SDS Sodium codecyl sulfate

SH3 Src Homologie-3

SLB Supported lipid bilayer

SOC Super Optimal broth with Catabolite repression

SUV Kleine unilamellare Vesikel (small unilamellar vesicles)

TAE TRIS-Acetat-EDTA

TBS TRIS-buffered Saline

TEMED $\quad N, N, N^{6}, N^{6}$-Tetramethylethylendiamin

TRIS Tris(hydroxymethyl)-aminomethan 
UV

Vis
Ultraviolett

sichtbar (visible)

\subsection{Symbolverzeichnis}

\begin{tabular}{|c|c|}
\hline$A$ & Absorbanz, Fläche \\
\hline$c$ & Konzentration \\
\hline$\chi$ & Leitfähigkeit \\
\hline$d$ & physikalische Schichtdicke \\
\hline$\delta$ & Brechungswinkel \\
\hline$E$ & Amplitude \\
\hline$\varepsilon$ & molarer Extinktionskoeffizient \\
\hline$g$ & Erdbeschleunigung $\left(g=9.81 \mathrm{~m} / \mathrm{s}^{2}\right)$ \\
\hline$\Gamma$ & Flächenkonzentration \\
\hline$I$ & Intensität \\
\hline$i, j$ & Richtungsvektoren \\
\hline$\varphi$ & Phasenverschiebung \\
\hline$k$ & Wellenvektor, Geschwindigkeitskoeffizient \\
\hline$K_{\mathrm{D}}$ & Dissoziationskoeffizient \\
\hline$l$ & Schichtdicke \\
\hline$L$ & optische Weglänge \\
\hline$\lambda$ & Wellenlänge \\
\hline$n$ & Brechungsindex \\
\hline$O T$ & optische Schichtdicke \\
\hline$r$ & Fresnel-Koeffizient, Raumkoordinate \\
\hline$R$ & Reflektion \\
\hline
\end{tabular}


$s$

S

$\sigma$

$t$

$T$

$\vartheta$

$\Theta$

$v$

V

$\omega$
Strecke

Streuung

Oberflächenladungsdichte

Zeit

Transmission, Temperatur

Oberflächenbelegung

Elliptizität

Geschwindigkeit

Volumen

Kreisfrequenz 


\section{Lebenslauf}

Michaela Ludolphs, geb. Schatz

geboren am 19.01.1987 in Uelzen

deutsch

\section{Schulausbildung}

08/1993 - 07/1997 Grundschule Westerweyhe, Uelzen

08/1997 - 07/1999 Orientierungsstufe Sternschule, Uelzen

08/1999 - 06/2005 Lessing-Gymnasium, Uelzen

Allgemeine Hochschulreife

\section{Studium}

10/2005-09/2010 Studium der Chemie an der Georg-August-Universität Göttingen

12/2009 - 06/2010 Diplomarbeit im Arbeitskreis von Prof. Dr. C. Steinem am Institut für organische und biomolekulare Chemie, Georg-August-Universität Göttingen.

Thema: Quantifizierung der Wechselwirkung von cPolycystin-2 mit seinen spezifischen Interaktionspartnern unter Berücksichtigung von Massentransporteffekten

$09 / 2010$

Diplom Chemie (Gesamtnote: gut)

Seit $11 / 2010$

Promotion im Arbeitskreis von Prof. Dr. C. Steinem am Institut für organische und biomolekulare Chemie, Georg-August-Universität Göttingen.

Thema: Spezifität der Wechselwirkung von Collybistin 2 mit Phosphatidylinositolphosphaten: Einfluss der verschiedenen Proteindomänen 


\section{Publikationen}

Weiher, F., Schatz, M., Steinem, C., Geyer, A. (2013) Silica precipitation by synthetic minicollagens, Biomacromolecules, 14, 683-687.

Behn, D., Schatz, M., Hubrich, R., Hoffmeister, H., Krefft, A., Witzgall, R., Steinem, C. (2013) Phosphorylation of C-terminal polycystin-2 influences the interaction with PIGEA14: A QCM study based on solid supported membranes, Biochim. Biophys. Res. Comm. 437, 532-537.

Ludolphs, M., Schneeberger, D., Schindelin, H., Papadopoulos, T., Brose, N., Steinem, C., (in Bearbeitung) Specificity of collybistin interaction with phosphoinositides: Impact of the individual protein domains.

\section{Tagungsbeiträge}

08/2011 Poster: "Macromolecular transport across hyaluronic acid

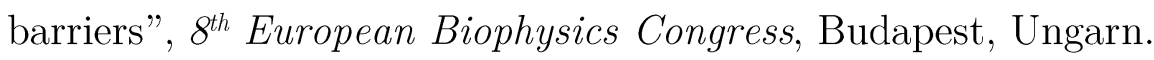

07/2013 Poster: "Lipid binding characteristics of collybistin", $9^{\text {th }}$ European Biophysics Congress, Lissabon, Portugal. 


\section{Danksagung}

Zunächst möchte ich Prof. Dr. Claudia Steinem für das entgegengebrachte Vertrauen und die wertvollen Anregungen, die zum Erfolg dieser Arbeit beigetragen haben, danken.

Frau Prof. Dr. Sarah Köster gilt mein Dank für die Übernahme des Korreferats.

Außerdem bedanke ich mich bei Dr. Theophilos Papadopoulos (MPI für experimentelle Medizin, Göttingen) und Dr. Daniela Schneeberger (Rudolf-VirchowZentrum, Würzburg) für die Bereitschaft mir jegliche Fragen rund um das Protein Collybistin zu beantworten. Daniela, du hast mich im Bereich Proteinisolierung ein großes Stück voran gebracht.

Unseren technischen Assistentinnen Michaela Klingebiel und besonders Jutta Gerber-Nolte danke ich für die Unterstützung bei der täglichen Laborarbeit. Bei Angela und Anja bedanke ich mich für sehr lehrreiche Tage in der Zellkultur.

Vielen Dank an unsere drei Damen Marianne Wagener, Melanie Sorhage und Dana Sachs für die Bereitschaft mir fast alle organisatorischen Aufgaben abzunehmen. Ein Kurzbesuch bei Euch hilft manchmal wirklich Wunder.

Weiterhin möchte ich mich bei Basti, Martin und Miri für das schnelle und sorgfältige Korrekturlesen dieser Arbeit bedanken.

Meinen Bachelorstudenten Jonas, Philipp und Hanna danke ich für die engagierte Arbeit. Auch wenn die Ergebnisse leider oft nicht das zeigten, was wir uns erwünscht hatten, habt ihr gut durchgehalten.

Ich möchte mich bei der gesamten Arbeitsgruppe für das gute Arbeitsklima, die Hilfsbereitschaft und den guten Zusammenhalt bedanken. Die „Fachdiskussionen“, die in den Pausen oft abgeschweift sind, werden mir in guter Erinnerung bleiben. 
Dank an Ole dafür, dass er mich mit manchen Bemerkungen über die Sinnhaftigkeit eines Experiments immer wieder auf den Boden der Tatsachen zurückgeholt hat. Besonders danken möchte ich Basti für die gemeinsamen Stunden im Zelllabor und die spontanen Tee- und Kaffeepausen mit wirklich fantastischen Törtchen!

Ich danke zudem meinen lieben Schwiegereltern. Ihr habt mich so toll in die Familie aufgenommen und sorgt immer dafür, dass ich mich wohlfühlen kann. Natürlich möchte ich mich auch bei Beate und Ralf für die tolle Freundschaft und die Unterstützung zu jeder Tages- und Nachtzeit bedanken.

Zwei große Schwestern $\mathrm{zu}$ haben ist manchmal anstrengend, aber immer unbezahlbar. Danke für den bedingungslosen Rückhalt, Jenny und Sonja! Wenn es schwierig wird, halten wir zusammen wie Pech und Schwefel! Euch ist diese Arbeit gewidmet :)

Schließlich danke ich von ganzem Herzen meinem Mann Florian dafür, dass er immer für mich da war und ist. Wir haben uns entschieden, dass wir zusammen viel stärker sind als einer allein. Du hast mir immer wieder Mut gemacht und mir die Kraft gegeben über mich heraus zu wachsen. Und egal wie gestresst und niedergeschlagen ich war, du hast es immer wieder geschafft mich zum Lachen zu bringen! Danke! 